\title{
Polycyclic aromatic hydrocarbon induced effects on gene expression in relation to carcinogenic potency
}

Citation for published version (APA):

Staal, Y. C. (2007). Polycyclic aromatic hydrocarbon induced effects on gene expression in relation to carcinogenic potency. [Doctoral Thesis, Maastricht University]. Universitaire Pers Maastricht. https://doi.org/10.26481/dis.20070412ys

Document status and date:

Published: 01/01/2007

DOI:

10.26481/dis.20070412ys

Document Version:

Publisher's PDF, also known as Version of record

\section{Please check the document version of this publication:}

- A submitted manuscript is the version of the article upon submission and before peer-review. There can be important differences between the submitted version and the official published version of record.

People interested in the research are advised to contact the author for the final version of the publication, or visit the DOI to the publisher's website.

- The final author version and the galley proof are versions of the publication after peer review.

- The final published version features the final layout of the paper including the volume, issue and page numbers.

Link to publication

\footnotetext{
General rights rights.

- You may freely distribute the URL identifying the publication in the public portal. please follow below link for the End User Agreement:

www.umlib.nl/taverne-license

Take down policy

If you believe that this document breaches copyright please contact us at:

repository@maastrichtuniversity.nl

providing details and we will investigate your claim.
}

Copyright and moral rights for the publications made accessible in the public portal are retained by the authors and/or other copyright owners and it is a condition of accessing publications that users recognise and abide by the legal requirements associated with these

- Users may download and print one copy of any publication from the public portal for the purpose of private study or research.

- You may not further distribute the material or use it for any profit-making activity or commercial gain

If the publication is distributed under the terms of Article $25 \mathrm{fa}$ of the Dutch Copyright Act, indicated by the "Taverne" license above, 
Polycyclic aromatic hydrocarbon induced effects on gene expression in relation to carcinogenic potency 
(C) copyright Y.C.M Staal, Maastricht 2007

ISBN 978-90-5278-612-4

Universitaire Pers Maastricht

Omslagontwerp

Yvonne Staal

Druk

Datawyse Boekproducties, Maastricht

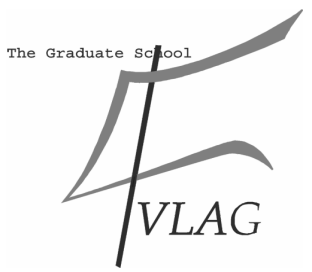

The studies presented in this thesis were performed at the Nutrition and Toxicology Reseach Institute Maastricht (NUTRIM), which participates in the Graduate School VLAG (Food Technology, Agrobiotechnology, Nutrition and Health Sciences), accredited by the Royal Netherlands Academy of Arts and Sciences. 


\title{
Polycyclic aromatic hydrocarbon induced effects on gene expression in relation to carcinogenic potency
}

\author{
PROEFSCHRIFT
}

ter verkrijging van de graad van doctor aan de Universiteit Maastricht, op gezag van de Rector Magnificus, Prof. mr. G.P.M.F. Mols volgens het besluit van het College van Decanen, in het openbaar te verdedigen op donderdag 12 april 2007 om 16.00 uur

door

Yvonne Catharina Maria Staal

geboren te Espel, Noordoostpolder op 9 april 1979

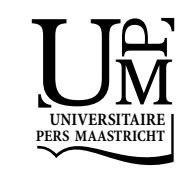




\section{Promotor}

Prof. dr. F.J. van Schooten

\section{Co-promotor}

Dr. J.H.M. van Delft

\section{Beoordelingscommissie}

Prof. dr. F.C.S. Ramaekers (voorzitter)

Prof. dr. A. Bast

Prof. dr. ir. J.P. Groten, Wageningen Universiteit / NV Organon

Prof. dr. J.C.S. Kleinjans

Prof. dr. S.A. Kyrtopoulos, National Hellenic Research Foundation, Greece

The research presented in this thesis was carried out in the context of the AMBIPAH project (mechanism-based approaches to improved cancer risk assessment of ambient air polycyclic aromatic hydrocarbons), funded by the European Union (No. QLRT2001-02402).

Financial support by the Dr. Ir. Van de Laar Stichting and Corning Life Sciences B.V. for the publication of this thesis is gratefully acknowledged. 


\section{Contents}

\section{Chapter 1}

General introduction

\section{Chapter 2}

Application of four dyes in gene expression analyses by microarrays

\section{Chapter 3}

Modulation of gene expression and DNA adduct formation in HepG2 cells

by polycyclic aromatic hydrocarbons with different carcinogenic potencies

\section{Chapter 4}

Modulation of gene expression and DNA-adduct formation in precisioncut liver slices exposed to polycyclic aromatic hydrocarbons of different carcinogenic potency

\section{Chapter 5}

Similarities in gene expression modulation in lung and liver of CD2F1 mice by polycyclic aromatic hydrocarbons at equally mutagenic doses

\section{Chapter 6}

Binary PAH-mixtures cause additive or antagonistic effects on gene expression but synergistic effects on DNA adduct formation

\section{Chapter 7}

Interactions between polycyclic aromatic hydrocarbons in binary mixtures:

Effects on gene expression and DNA adduct formation in precision-cut rat liver slices

\section{Chapter 8}

Summary and general discussion

\section{Chapter 9}

Samenvatting en algemene discussie

\section{Dankwoord}





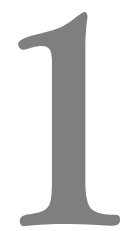

General introduction 


\section{POLYCYCLIC AROMATIC HYDROCARBONS}

\section{Occurrence in the environment}

Polycyclic aromatic hydrocarbons (PAHs) cover a wide range of structurally similar compounds, which are present in the air after incomplete combustion of organic compounds. Main sources are diesel engine exhaust, industry and the burning of wood (1).

Humans are daily exposed to PAHs because of their common occurrence in the environment, in the diet and in the air. Concentrations in the air vary according to the time of the year and the location. PAH concentrations are higher in winter than in summer (2) and are higher in urban areas than in the rural environment (1-3). Concentrations of individual PAHs vary between 1 and 30ng $/ \mathrm{m}^{3}(1,3)$. Not only the concentrations in the air vary, but also the composition of the PAH mixture. Some compounds are present in higher concentrations than others, depending on the source of $\mathrm{PAH}$ production. In the air, most PAHs are bound to dust particles and can enter the lung and the rest of the body by means of inhalation.

Apart from exposure through air, other sources of PAH-exposure are grilled meat, vegetables and tobacco smoke. The intake of the latter also occurs through the lung, while PAHs from grilled meat and vegetables enter the body through the gastrointestinal tract. Minor sources of exposure are drinking water and soil. Once entered the body, PAHs can be adsorbed and distributed via blood throughout the whole body, and thereby all organs are exposed to PAHs. The adverse effects of PAHs on humans are diverse; among others they can induce carcinogenesis.

\section{Structure of PAHs}

PAHs have a planar structure and consist of several fused benzene rings, to which for some PAHs a methyl group is added to one of the benzene rings. Mechanisms for the adverse effects of PAHs could be partly explained by their structural properties. Bayregions and Fjord-regions in their molecular structure (Figure 1.1) are important characteristics of PAHs for some of their properties, such as their ability to bind to the Aryl hydrocarbon receptor (Ah-receptor). Bay-regions are more potent in binding to the Ah-receptor, although Fjord-region PAHs appear to be more carcinogenic. A planar structure of PAHs is required for their binding as a substrate to the Cytochrome P450 enzyme, Cytochrome P450 1A1 (CYP1A1). Binding of PAHs to CYP1A1 is important for their metabolism. Affinity to bind to the Ah-receptor is one of the predictors of the carcinogenic potency of PAHs (4-6). See also Biotransformation. 

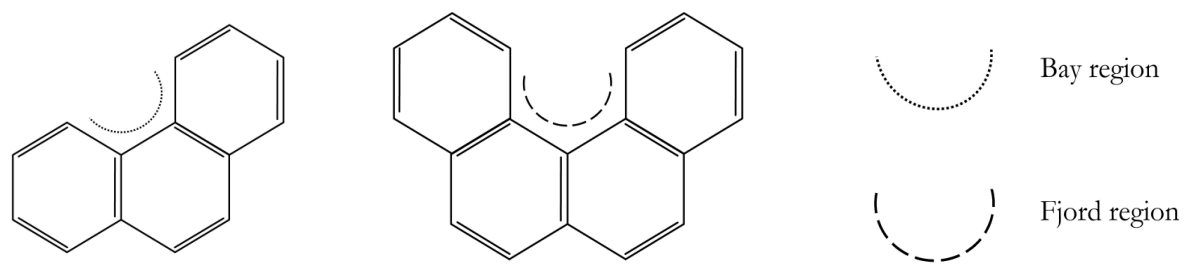

FIGURE 1.1. Bay and Fjord region within PAH structures.

\section{Biotransformation}

Biotransformation is the enzymatic modification of generally lipophilic chemicals to more water soluble compounds, which are more readily excreted. Biotransformation may be divided into phase I reactions, which introduce a polar group in the molecule, and phase II reactions, which conjugate an endogenous hydrophilic substance with a polar group in a molecule. The conjugated product is than water soluble. Sometimes, a phase III reaction is defined as the excretion of the compound out of the cell. Phase I reactions can either be reduction, hydrolysis or oxidation reactions, of which the latter is the most important. Cytochrome P450 enzymes, a major class of phase I enzymes, play an important role in the oxidation of xenobiotic lipophilic compounds. The introduction of a polar group into a molecule not only increases its suitability to undergo conjugation reactions in phase II, but may also increase its reactivity towards other substances. These phase I reactions leading to the formation of more reactive compounds than the mother compound, are called bioactivation reactions and play an important role in the adverse effects caused by PAHs (7). Due to structural similarities the metabolism of PAHs is generally similar. Metabolism for benzo[a]pyrene $(\mathrm{B}[\mathrm{a}] \mathrm{P})$ is shown in Figure 1.2. First B[a]P is metabolized into epoxides by Cytochrome P450 enzymes, which are metabolised by epoxide hydrolased into diols. These diols are again a substrate for Cytochrome P450 enzymes, which convert the diols into diolepoxides. Several conformations of these diolepoxides exist, of which the most dominant and the most reactive compound in producing tumours, is (+)-B[a]P-7,8-diol-9,10-oxide. Also $\mathrm{B}[\mathrm{a}] \mathrm{P}$ radicals may be formed, leading to the formation of quinones and semiquinones, which react with DNA and may also induce oxidative DNA damage.

Many PAHs can bind to the Ah-receptor, which thereafter translocates to the nucleus and induces the expression of several Ah-receptor controlled genes, among which those for enzymes of the Cytochrome P450 class. Several of these enzymes, like CYP1A1, CYP1A2 and CYP1B1, are important for the metabolic activation of PAHs $(8,9)$. 


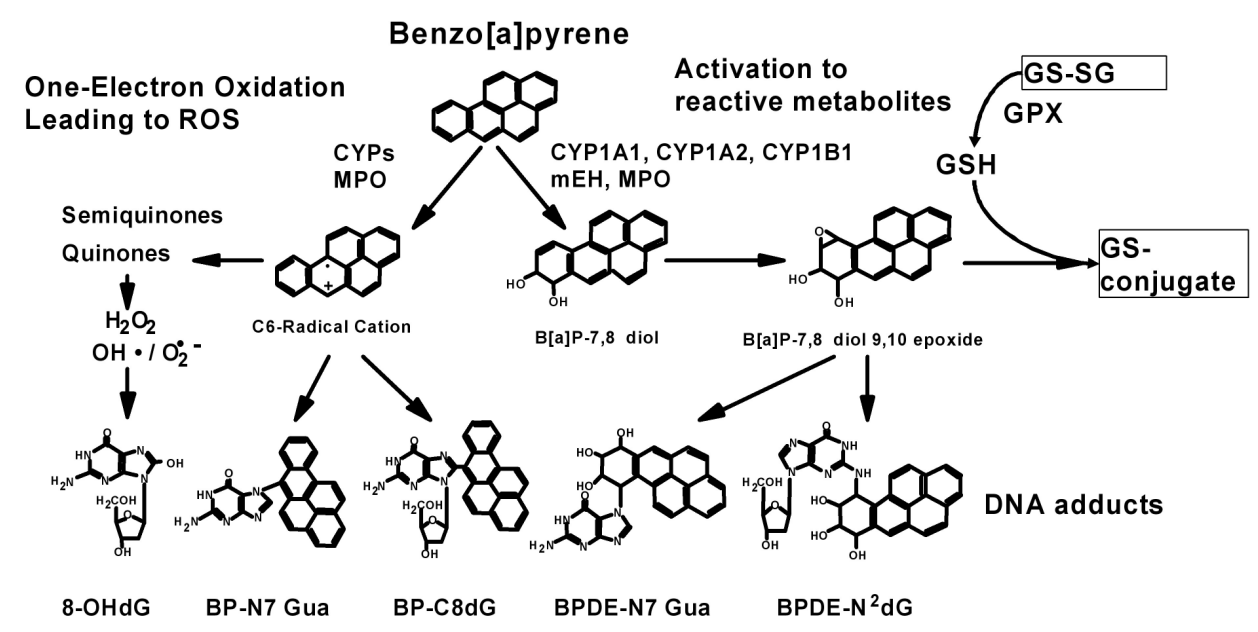

FIGURE 1.2. Metabolism of benzo[a]pyrene and the metabolites formed.

From: R.W.L.Godschalk (10).

It is generally believed that Cytochrome P450 activity is involved in the bioactivation of PAHs into reactive metabolites leading to DNA adduct formation and thereby induce the carcinogenic effect of PAHs (11). However, recent studies in knock-out mice showed a dual role of Cytochrome P450 enzymes in the biotransformation of PAHs, as the levels of DNA adducts found in mice lacking the CYP1A1 gene, was higher than in wild type mice (12,13). This was also found for dibenzo[a,l]pyrene (DB[a,l]P) in CYP1B1 knock-out mice (14). These results suggest that the balance between activation and deactivation as determined by Cytochrome P450 enzymes, is crucial in the bioactivation of PAHs. Knocking out a Cytochrome P450 gene also show that PAHs are efficiently bioactivated by other biotransformation enzymes. It has been suggested that CYP1B1 is more important in activating PAHs to toxic and carcinogenic metabolites than CYP1A1 (15).

\section{Carcinogenesis by PAHs}

\section{Development of cancer}

Carcinogenesis is a multistep process which is often divided into three stages, namely initiation, promotion and progression. In chemical carcinogenesis, initiation encompasses the binding of a compound to DNA resulting in genetic alterations like mutations and chromosomal defects. When a compound binds to DNA and thereby forms a DNA adduct, this DNA adduct may lead to the change of a nucleotide during DNA replication and thereby the adduct is fixed in the DNA as a mutation. Compounds inducing genetic damage (mutations) are called genotoxic compounds. However, DNA repair mechanisms can repair the damaged DNA and thereby prevent the mutation to be fixed in the DNA (16). Mutations in critical genes (like tumour suppressor genes, 
proto oncogenes, or genes involved in apoptosis or DNA repair) (17) are the key event in the initiation of carcinogenesis.

The next stage of carcinogenesis, the promotion stage, involves the development of an initiated cell into a more cancerous cell, by inducing its proliferation and reducing its differentiation. This means that initiated cells will start developing into tumours by increased growth and reduced cell communication with surrounding cells. These cells usually have an instable genome and mechanisms which would lead to apoptosis in these cells are repressed. Some carcinogenic compounds are able to induce these properties in initiated cells and are therefore called promoters or non-genotoxic carcinogens $(18,19)$. When a compound is both an initiator as well as a promoter, the compound is called a full carcinogen, which acts on different stages of the carcinogenic process. Many PAHs are considered full carcinogens, as they affect various biological processes leading to initiation and promotion of cancer development (Figure 1.3).

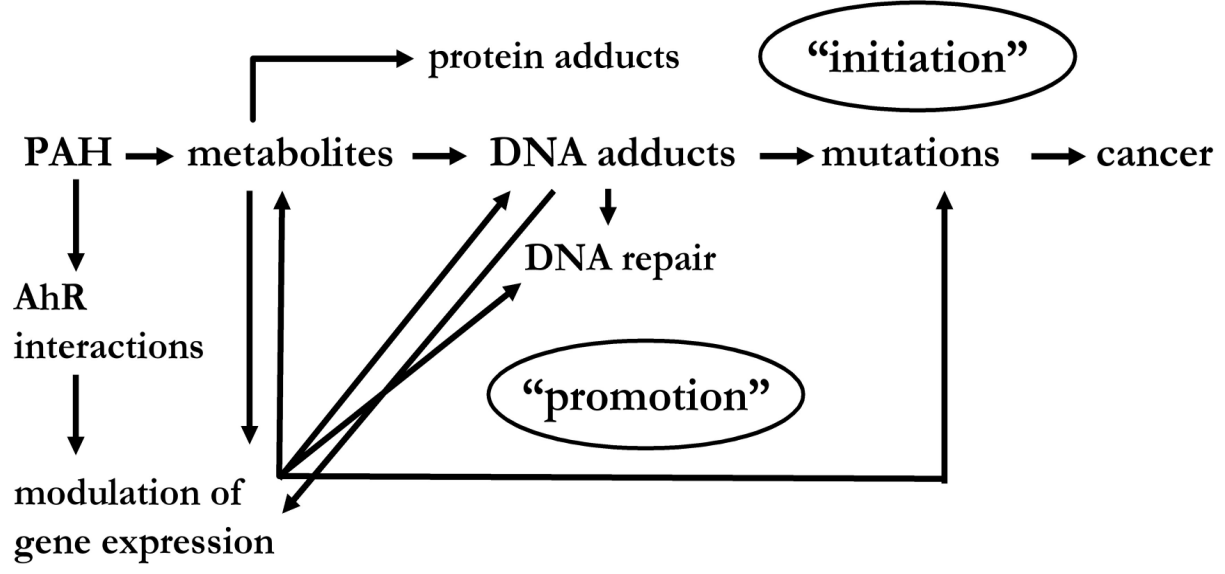

FIGURE 1.3. Effect of PAHs on biological processes leading to the development of cancer.

\section{Carcinogenesis related biological processes affected by $P A H s$}

As mentioned before, an important property of PAHs is their ability to bind to the Ahreceptor and thereby induce the expression of several genes for enzymes involved in metabolism of xenobiotic compounds, such as several members of the Cytochrome P450 family (20). These enzymes are among others involved in metabolism of PAHs to their DNA-reactive intermediates, and may also induce oxidative stress and DNA damage. This is summarized in Figure 1.2.

Induction of DNA damage can initiate the cell to develop into a tumour. However, protective mechanisms of the cell can prevent the damaged cell to develop into a tumour cell. Fixation of DNA damage induced by PAHs can be prevented by activation of ATM and ATR proteins which signal downstream to CHK1 and CHK2 pro- 
teins and p53. Activation of this pathway will lead to cell cycle arrest and thereby allowing the cell to repair DNA damage. If the PAH-induced DNA-damage is too high to be repaired, p53 triggers the induction of apoptosis, and at even higher doses necrosis will occur $(21,22)$. Thereby a fixation of the DNA-damage and a possible start of tumour initiation is prevented. Blocking these DNA-damage pathways may lead to tumour development.

As an initiated cell can only develop into a tumour if proliferation is induced and differentiation inhibited, effects on these processes may progress tumour development. Inhibition of intercellular communication for initiated cells, reduces the growth suppression by surrounding cells. By increased proliferation the initiated cell can develop into a tumour. PAHs have been shown to affect these processes (18,23,24). Also, PAHs may increase nutrient availability for pre-tumoric cells and thereby providing the cells with nutrients to grow and develop into a tumour $(25,26)$.

\section{$P A H$ air pollution and cancer}

The induction of cancer by PAHs has first been shown through occupational exposure (coke oven workers and chimney sweepers) (5). In 1915 was found that PAHs are responsible for these carcinogenic effects $(5,27)$, by the tumour induction at application sites in rabbits. The main target organ for $\mathrm{PAH}$ induced carcinogenesis seems to be the lung, but also cancer of the bladder, skin, larynx and kidney occurs, mainly after occupational exposure (28). In the 1980s, it has been estimated that in Sweden 4\% of all lung cancer cases could be contributed to air pollution, while recently air pollution was estimated to increase lung cancer risk by $8 \%$ (29). This can mainly be attributed to PAHs. However, due to restriction on burning of fossil fuels and on emission of air pollutants and due to changes in composition of car fuels, the PAH concentrations in the air are decreasing (1).

\section{Carcinogenic potency of PAHs}

Since PAHs cover such a wide range of different compounds, knowing the relative carcinogenic potency of each compound can be valuable for estimating the risk associated with PAH exposure. Of all PAHs, most research has been done on benzo[a]pyrene $(\mathrm{B}[\mathrm{a}] \mathrm{P}) . \mathrm{B}[\mathrm{a}] \mathrm{P}$ is often used as a reference compound in studies to which the effects of other PAHs are related to B[a]P. For instance, tumour induction by several PAHs has been assessed and expressed relative to $\mathrm{B}[\mathrm{a}] \mathrm{P}$. This is called a Toxic Equivalency Factor (TEF), and expresses the carcinogenic potency of a PAH relative to $\mathrm{B}[\mathrm{a}] \mathrm{P}$ (30). Another ranking for $\mathrm{PAHs}$ is substantiated by the Potency Equivalency Factor (PEF), which additionally includes data from carcinogenicity tests (31), and also expresses the carcinogenic potency of PAHs relative to $\mathrm{B}[\mathrm{a}] \mathrm{P}$. However, the suitability of $\mathrm{B}[\mathrm{a}] \mathrm{P}$ as a reference compound to estimate the risks of exposure to PAH mixtures has been questioned, since risk assessment of PAHs is mostly based on the exposure of coke-oven workers. The composition of emissions from other sources 
differs from coke-oven emissions. $\mathrm{B}[\mathrm{a}] \mathrm{P}$, for instance, is a major component in cokeoven emissions but only has a minor contribution in environmental air (5). Also, the use of $\mathrm{B}[\mathrm{a}] \mathrm{P}$ TEFs was found to be imperfect, since the carcinogenic risk of $\mathrm{PAH}$ mixtures is highly dependent on the exposure route (32).

Some PAHs are highly mutagenic, but were unable to induce carcinogenesis by their lack in promoting abilities. Other PAHs are good promoters but lack an initiation activity and are thereby not cancerous. It has been suggested that mutagenic potency reflects the cancer initiation potency, whereas binding to the Ah-receptor reflects the promotive effects of PAHs (4).

\section{Effects of PAH Mixtures}

As exposure to PAHs usually occurs in mixtures, it is important to study not only the effects of individual compounds, but also to assess the effects of mixtures. In theory many interactions between two or more compounds may exist. Mostly, the interaction is based on a biological endpoint, like tumorigenesis. Firstly, compounds may show additivity, which means that the effect of the mixture equals the sum of the compounds individually. Secondly, mixtures of compounds may show antagonism, in which one compound suppresses the effects of the other compound, resulting in a lower effect than additivity suggests. And finally, mixtures may show synergism, in which the effects of a mixture is enhanced compared to the summed effects of the individual compounds (33).

The TEF approach (see also Carcinogenic potency of PAHs) is often used for assessing the toxic potencies of PAH mixtures. However, this approach does not take into account the interactive effects PAHs may elicit, as it assumes additivity. For instance, when a mixture consists of a PAH which is able to bind to the Ah-receptor and induce the expression of biotransformation enzymes, together with a $\mathrm{PAH}$ that is not able to induce these enzymes, the result may be increased metabolism of the non-inducing PAH. This would imply an increased carcinogenic potency of non-Ah-receptor binding PAHs. Also, mixtures consisting of a PAH with initiating properties and a $\mathrm{PAH}$ with promoting properties might show synergistic effects on tumour formation. On the other hand, Cherng et al (34) have shown that mixtures of an Ah-receptor binding PAH with a non-Ah-receptor binding PAH show lower induction of CYP1A1 than expected based on additivity. This would imply a lower carcinogenic potency than expected (antagonism). However, only little is known about the interactive effects of PAHs and the molecular mechanisms occurring at PAH-mixture exposure. Most previous research suggest an additive or slightly antagonistic response of complex PAH mixtures. 


\section{TARGET ORGANS}

\section{Lung}

\section{$P A H$ exposure and lung}

As mentioned above, the first organ that is exposed to the PAHs in the air is the lung. Therefore the lung may be exposed to high concentrations of PAHs. Since lung tissue expresses high levels of several biotransformation enzymes which are important for PAH metabolism, PAHs can be metabolised in the lung and thereby cause their toxic effects. These biotransformation enzymes are inducible in lung tissue (35), which makes these cells more susceptible for adverse PAH effects. This makes the lung an interesting tissue to study PAH-induced effects, like carcinogenicity.

\section{Histology and function}

The lung is the essential respiration organ, whose principal function is to transport oxygen from the air into the bloodstream, and to excrete carbon dioxide from the bloodstream into the air. This exchange of gasses is accomplished in specialized cells that form millions of tiny, exceptionally thin-walled air sacs called alveoli. Figure 1.4 shows a schematic overview of the alveoli.

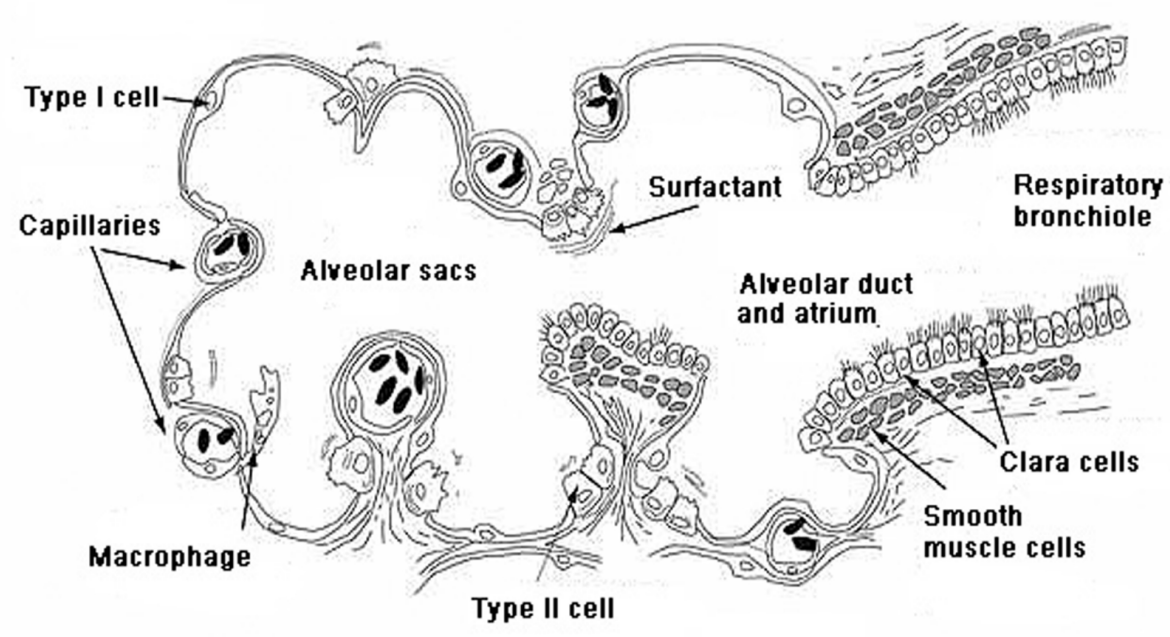

FIGURE 1.4. Schematic overview of the alveoli (based on

http://www.lab.toho-u.ac.jp/med/physi1/respi/respi4,5/respi4,5.html).

When breathing all air passes the bronchi and bronchioles before reaching the respiratory zone. Mucus is secreted by cells of the bronchi and bronchioles and serves to trap small particles in the inspired air and thereby performs a filtration function. As a result of this filtration function, particles larger than about $6 \mu \mathrm{m}$ do not normally enter the 
respiratory zone of the lungs. The cleansing action of cillia and macrophages (nonspecific immune cells) in the lungs is diminished by cigarette smoke (36).

Via the terminal bronchioles and respiratory bronchioles, the bronchiles transition into the alveoli. The joint surface area of the alveoli is enormous. The walls of the alveoli which separate air and blood are extremely thin, a property which contributes to the rapid and efficient exchange of gases. This of course implies that any gaseous pollutants in the inhaled air can also be absorbed quickly and efficiently (37). The alveoli are lined with type I and type II pneumocytes. Gaseous exchange takes place via type I pneumocytes. Type II pneumocytes produce pulmonary surfactant and contain a considerable amount of biotransformation enzymes. In case of damage to the alveolar epithelium, regeneration takes place by proliferation of type II pneumocytes. Another cell type present in the alveoli is the clara cell, which main function is to protect the bronchial epithelium. Clara cells and type II pneumocytes are responsible for detoxifying harmful substances inhaled into the lungs, by their expression of high levels of biotransformation enzymes (38).

\section{Liver}

\section{$P A H$ exposure and liver}

Another organ of interest is the liver, which is the most important organ in biotransformation of xenobiotic compounds. Not only compounds ingested through food are passing the liver and can be metabolized before they enter the rest of the body, but also compounds entering through other routes (through the lung) will pass the liver and can be metabolized (see Histology and function). By first passing the liver, the liver plays an important role in preventing the rest of the body to be exposed to xenobiotics and damaging agents.

Like for other xenobiotic compounds, the liver also participates in the metabolism of PAHs independently of the route of entry for PAH exposure (5). Also, DNA adducts have been found in liver as well as in other organs after exposure to B[a]P (39). As PAHs are bioactivated, it is believed that primarily formed metabolites, or the ultimate reactive intermediates, are formed in the liver and subsequently released into the extrahepatic tissues (40). This suggests an important role for the liver in PAH mediated carcinogenesis.

\section{Histology and function}

Liver is the largest intestinal organ, and lies immediately beneath the diaphragm in the abdominal cavity. It plays a major role in metabolism and has a number of functions in the body including glycogen storage, plasma protein synthesis, and biotransformation. All compounds that are absorbed in the intestine are transported to the liver through the portal vein, and thereby the liver is the first organ exposed to compounds from 


\section{CHAPTER 1}

food. The liver also produces bile, which is important in digestion of food in the small intestine. A schematic diagram of the liver is shown in Figure 1.5.

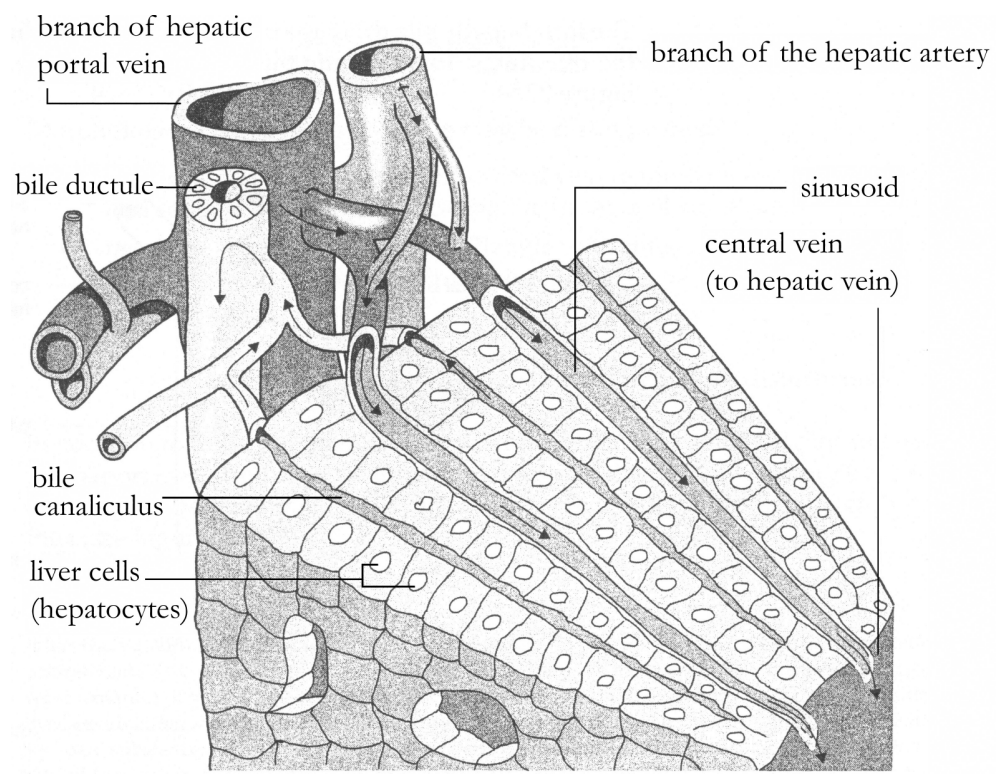

FIGURE 1.5. Schematic overview of the liver (41).

Liver cells, or hepatocytes, form hepatic plates that are one to two cells thick. The plates are separated from each other by large capillary spaces, called sinusoids. The sinusoids are highly permeable and lined with phagocytic Kupffer cells, which play a role in removing xenobiotics and debris from the blood by phagocytosis. The plate structure of the liver and the high permeability of the sinusoids allow each hepatocyte to have direct contact with the blood (42).

The hepatic plates are arranged into functional units called liver lobules. The middle of each lobule is a central vein, and at the periphery of each lobule are branches of the hepatic portal vein and of the hepatic artery, which opens into the sinusoids between the hepatic plates. The central veins of different liver lobules converge to form the hepatic vein, which carries blood from the liver to the inferior vena cava (42).

Liver lobules are surrounded by Kiernan's spaces, which is a triangular connective tissue space containing the portal triad, where a branch of the portal vein, a branch of the hepatic artery and a bile ductile meet. Such spaces of Kiernan also contain lymph vessels (41).

The hepatocytes can be divided into 3 zones, going from zone 1 at the portal vein to zone 3 at the central vein. Zone 3 receives blood which already contains exchange products from zones 1 and 2. Zone 2 is a transitional area between zones 1 and 3 . It is obvious that zone 3 is mostly affected by circulatory (ischemia, anoxemia, congestion) 
and nutritional disorders. The cells of zone 1 are active primarily in glycolysis and glycogen metabolism, the glucuronidation of xenobiotics, the pinocytosis of nutrients, the metabolism of proteins and the formation of plasma proteins. In addition, they are probably also active in the secretion of bile salts in the plasma. In comparison to zone 3 , this zone has wider bile canaliculi, and contains more mitochondria and less smooth endoplasmatic reticulum (SER).

Important functions of zone 3 are the storage of glycogen and the formation of fat and pigments. Chemical substances are metabolized in the liver via oxidation or reduction. The oxidative enzymes need oxygen and NADPH or NADH. The NADPH and $\mathrm{NADH}$ reductase reactions take place primarily in the cells of zone 3 . Zone 3 cells contain an ample amount of SER with mixed function oxidases (cytochrome P450 enzymes), and express higher levels of both Phase I and Phase II enzymes than the other zones (43). The liver can remove hormones, drugs, xenobiotics and other biologically active molecules from the blood by (1) excretion of these compounds in the bile, (2) phagocytosis by the Kupffer cells that line the sinusoids, and (3) biotransformation of these molecules within the hepatocytes (42).

\section{In vitro and in vivo liver models}

In order to study the effects of toxic compounds on different organs in humans, various models are used, which can be divided in in vitro (cell and organ cultures) and in vivo models (animal models). Most often in vivo animal models better resemble the in vivo human situation; however, in vitro models can be more easily studied and are valuable for gaining insight into the in vivo situation. Two commonly used in vitro models for liver will be discussed, namely a human hepatoma cell line (HepG2) and precision-cut rat liver slices (or liver slices).

The advantage of an in vitro cell system is that effects on the tissue of interest can be studied, without ethical considerations of an animal experiment and with higher throughput. Although the effect of compounds on the tissue is studied without the interactive effect of other organs or cells, in vitro models are valuable for gaining insight into mechanistic aspects.

As metabolism is important to study the effects of xenobiotic compounds, like PAHs, it is important that in vitro models express biotransformation enzymes (metabolically competent) and that the expression of these enzymes is under similar control as in vivo. Both HepG2 cells and liver slices are able to metabolize PAHs, indicating that biotransformation enzymes are active in these cells (44-46). Furthermore, B[a]P exposure also modulated gene expression in HepG2 cells, including genes involved in biotransformation (47). In addition it was shown that other mutagens are also activated by HepG2 cells (48). In other studies using rat liver slices metabolism of xenobiotics was 
proved (49), and induction of DNA adduct formation after B[a]P exposure was shown (50). Therefore, both models are suitable to study the effect of PAHs.

Many studies have been done on the comparison between in vitro cell models, and on the comparison with in vivo data. Wilkening et al (51) studied the differences between HepG2 cells and freshly isolated human hepatocytes. Although, they found that freshly isolated hepatocytes are more sensitive towards the mutagens tested and HepG2 cells expressed biotransformation enzymes at a lower rate, the effects upon xenobiotic exposure on gene expression and enzyme activities are generally similar. A comparison between liver in vivo, liver slices and freshly isolated hepatocytes on gene expression was done by Jessen et al (52), who found that both in vitro systems show in generally a higher than $80 \%$ concordance with in vivo liver, although the compound-induced changes were less in vitro than in vivo. Furthermore, both in vitro systems showed good similarity in response. Boess et al (53), found that in primary rat hepatocyte cultures, gene expression changes most rapidly soon after cell isolation and culture initiation and stabilizes with time, among others leading to lower levels of biotransformation enzymes. As in vitro cells systems generally show similar responses, both the HepG2 cell line and precision-cut rat liver slices are suitable for our studies on PAHs.

\section{MICROARRAY TECHNOLOGY IN TOXICOGENOMICS}

\section{Microarray technology}

Microarray technology provides the opportunity to assess the differential gene expression of large numbers of genes simultaneously by comparing levels of mRNA. Microarrays are glass slides onto which DNA probes (either cDNA probes or oligonucleotides) are printed, as shown in Figure 1.6. Each probe is specific for a single gene. Microarray slides may contain hundreds to thousands of different probes. To assess gene expression modulation by treatment of cells with a chemical compound, the level of expression after treatment should be compared to a control or reference. To do so, RNA is isolated from test and reference samples and reverse transcribed into cDNA. The cDNA may be labelled with a fluorescent dye during transcription, or labelling may done afterwards. In several microarray systems a two dye design is used $(54,55)$, though the application of a single dye or more than two dyes is also possible. In case of a two dye system, the test sample and reference sample are labelled with a different dye to distinguish between RNA from test and from reference sample. Equal amounts of both samples are applied on a microarray slide and hybridized with the probes. Each cDNA molecule hybridizes with the target probe for that gene. In order to determine the amount of labelled cDNA bound to the probes, the slides are scanned with lasers (each one corresponding to a specific dye). The intensity of the fluorescent signal of that spot is a measure for the number of RNA copies for that gene. By comparing intensities for each spot between dyes, a ratio for the RNA copies of a gene 
between control and experiment can be obtained. This ratio reflects the increase or decrease of gene expression in response to the treatment.
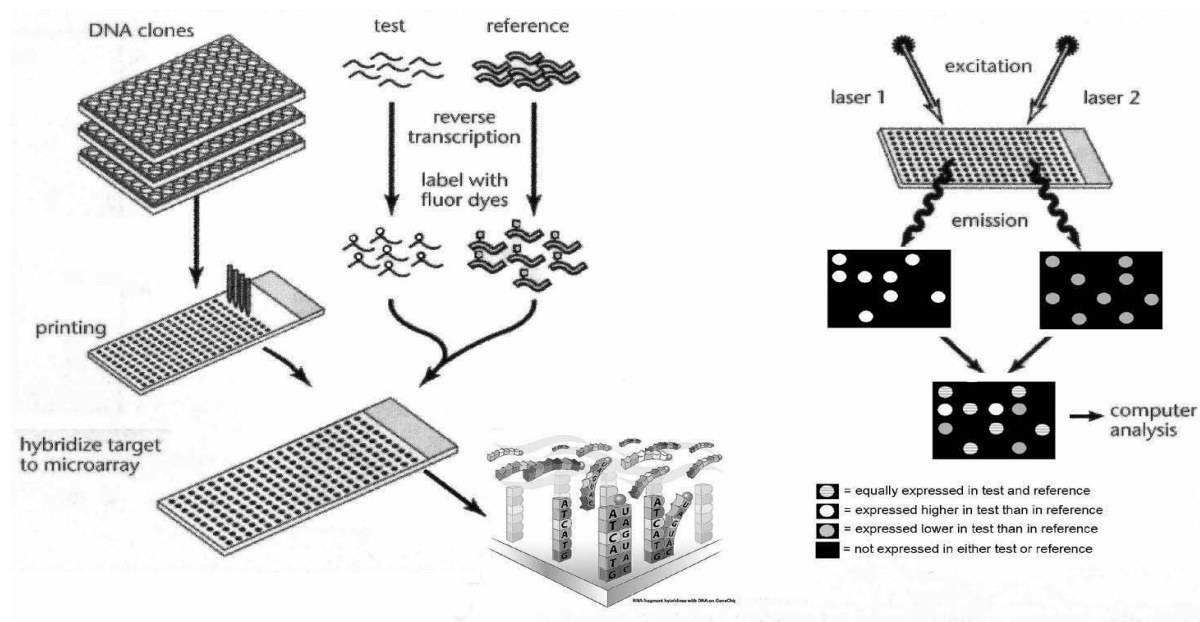

FIGURE 1.6. Schematic representation of gene expression analysis by DNA microarrays.

\section{Microarray applications in toxicogenomics}

Microarray technology in toxicological studies can result in insight on several levels. Altered transcription and translation of mRNA can result in altered protein levels and thereby altered biological processes. As many biological processes can be regulated on the level of gene expression, microarray technology creates the opportunity to assess many biological processes simultaneously. Thereby, microarray technology can be useful in studying the effects of compounds on a wide range of processes.

This technology may be useful in assessing differences in carcinogenic potency of PAHs. The general overview of changes in gene expression patterns, or "transcriptomic fingerprints", can be used to classify carcinogenic and non-carcinogenic compounds. It has been shown previously that gene expression analysis indeed can be used for classification of compounds on their genotoxic properties and insights could be obtained about mechanisms $(47,56)$. As the changes in gene expression upon exposure to a compound also gives information on altered biological processes, these could be related to carcinogenic potency of a compound (57,58). Thereby application of microarrays in toxicological studies may be useful for obtaining predictive as well as mechanistic information on PAH carcinogenic potency (59). 


\section{PROPERTIES OF SELECTED PAHS}

PAHs differ in their carcinogenic and mutagenic potencies and in their occurrence in the air. Here, this will be discussed for six PAHs, namely benzo[a]pyrene $(\mathrm{B}[\mathrm{a}] \mathrm{P})$, benzo[b]fluoanthene $(\mathrm{B}[\mathrm{a}] \mathrm{F})$, fluoranthene $(\mathrm{FA})$, dibenzo[a,h]anthracene $(\mathrm{DB}[\mathrm{a}, \mathrm{h}] \mathrm{A})$, dibenzo[a,l]pyrene (DB[a,l]P) and 1-methylphenanthrene (1-MPA). Table 1.1 shows data on carcinogenic and mutagenic potency and the occurrence in the air for these PAHs. Their chemical structures are shown in Figure 1.7. Some of these compounds are highly carcinogenic, like $\mathrm{DB}[\mathrm{a}, \mathrm{l}] \mathrm{P}$, though have a low occurrence in ambient air, whereas compounds like 1-MPA have a low carcinogenic potency and a high occurrence in the air. Furthermore, binding to the Ah-receptor does not necessarily correlate with carcinogenic potency. Whereas $\mathrm{DB}[\mathrm{a}, \mathrm{h}] \mathrm{A}$ has a high carcinogenic potency and relatively high affinity for the Ah-receptor, $\mathrm{DB}[\mathrm{a}, 1] \mathrm{P}$ also has a high carcinogenic potency but a relatively low affinity for the Ah-receptor. Diversity in properties of the selection of PAHs may help to relate the effects of these compounds, on for example gene expression, to the known properties, like carcinogenic potency.

TABLE 1.1. Data on carcinogenic potency, mutagenic potency, occurrence in the air and Ah-receptor binding for the six selected PAHs.

\begin{tabular}{lcccc}
\hline & $\begin{array}{c}\text { Occurrence } \\
\text { in air }\end{array}$ & $\begin{array}{c}\text { Mutagenic } \\
\text { potency }\end{array}$ & $\begin{array}{c}\text { Carcinogenic } \\
\text { potency }{ }^{1}\end{array}$ & $\begin{array}{c}\text { Ah-receptor } \\
\text { binding }^{2}\end{array}$ \\
\hline Benzo[a]pyrene & ++ & ++ & 1.0 & 1.0 \\
Benzo[b]fluoranthene & +++ & ++ & 0.1 & 0.24 \\
Fluoranthene & +++ & ++ & 0.001 & 0.0047 \\
Dibenzo[a,h]anthracene & + & ++ & 5.0 & 7.64 \\
Dibenzo[a,l]pyrene & $?$ & +++ & 10 & 0.0057 \\
1-methylphenanthrene & +++ & + & 0.001 & $\mathrm{~N} / \mathrm{A}$ \\
\hline
\end{tabular}

${ }^{1}=$ Toxic Equivalency Factor, TEF $(3,30,31,60) ;{ }^{2}=$ Induction Equivalency Factor, IEF (61)

The International Agency for Research on Cancer (3,60) classified PAHs and several other compounds according to their carcinogenic potential. $\mathrm{B}[\mathrm{a}] \mathrm{P}$ is classified as being probably carcinogenic to humans (group $2 \mathrm{~A}$ ), so is $\mathrm{DB}[\mathrm{a}, \mathrm{h}] \mathrm{A}$. DB[a,l]P and $\mathrm{B}[\mathrm{b}] \mathrm{F}$ are classified in group $2 \mathrm{~B}$, which are compounds possibly carcinogenic to humans. FA and 1-MPA are classified in group 3, which are the compounds being unclassifiable as to carcinogenicity in humans. However, many of these compounds have shown to induce tumours in rodents, and may have effects on different stages of carcinogenesis. FA was found to induce tumours in a mouse bioassay (62), but is thought to be inactive as a full carcinogen. 1-MPA was found to have a high mutagenic activity in bacteria, but did not induce tumour formation (63), indicating that this compound might be a good 
initiator of carcinogenesis, but a poor promoter. Both FA and 1-MPA are classified as being weakly carcinogenic. However, since $\mathrm{PAH}$ mixtures in the air also contain promoters of carcinogenesis, these compounds may contribute to the effects of airborne PAHs on carcinogenesis.

The carcinogenic potency of PAHs may vary according to the level of exposure. $\mathrm{DB}[\mathrm{a}, \mathrm{h}] \mathrm{A}$ was found to have a higher carcinogenic potency (TEF) at low concentrations than at high concentrations (30). Carcinogenic potency may also vary across mouse and rat strains and between organs, but in general, the tumour induction relative to $\mathrm{B}[\mathrm{a}] \mathrm{P}$ is similar (64). Therefore, the relative carcinogenic potency of PAHs (Toxic Equivalency Factor (TEF) and Potency Equivalency Factor (PEF)) might be a useful approach to classify PAHs.

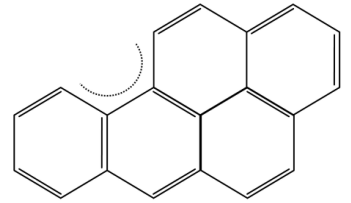

Benzo[a]pyrene

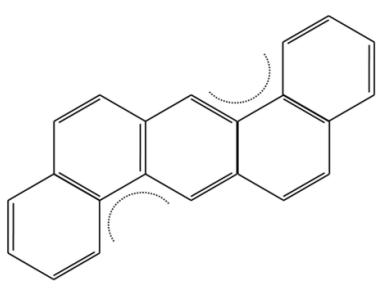

Dibenzo[a,h]anthracene

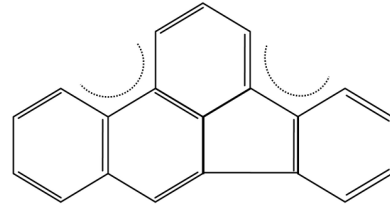

Benzo[b]fluoranthene

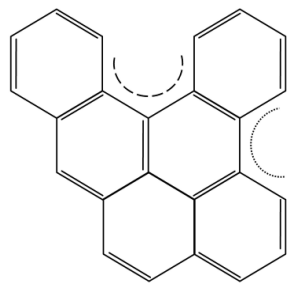

Dibenzo[a,l]pyrene

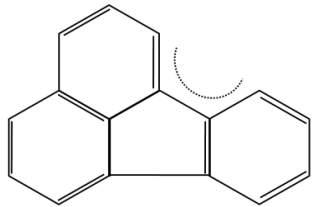

Fluoranthene

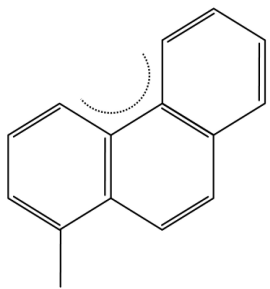

1-methylphenanthrene

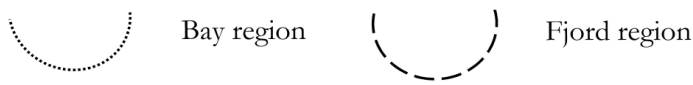

FIGURE 1.7 Chemical structures of six PAHs with their Bay and Fjord regions.

$\mathrm{B}[\mathrm{a}] \mathrm{P}$ is the most extensively studied $\mathrm{PAH}$ and is a full carcinogen causing local and systemic carcinogenic effects (3). $\mathrm{B}[\mathrm{a}] \mathrm{P}$ is also embryotoxic and teratogenic in mice (60). Human exposure to $\mathrm{B}[\mathrm{a}] \mathrm{P}$ occurs primarily through the smoking of tobacco, inhalation of polluted air and by ingestion of food and water contaminated with combustion effluents.

$\mathrm{B}[\mathrm{b}] \mathrm{F}$ is present as a major compound of the total PAHs in the air and induces DNA adduct formation and mutations in mouse lung $(3,60,65)$. B [b]F also induced lung 
adenoma formation in mice in a dose dependent manner but forms fewer tumours compared to B[a]P (64).

1-MPA is present in the air in relatively high concentrations. 1-MPA is inactive as an initiator of carcinogenesis, but was found to be mutagenic to Salmonella typhimurium $(60,63)$.

$\mathrm{DB}[\mathrm{a}, 1] \mathrm{P}$ is one of the most potent $\mathrm{PAHs}$ in inducing carcinogenesis and has been identified in several sources. It is present in the air is at relatively low concentrations. $\mathrm{DB}[\mathrm{a}, 1] \mathrm{P}$ is considered an in vivo mutagen on the basis of in vitro mutagenicity tests and DNA adduct formation in vivo. Its tumourigenicity has been demonstrated in a number of studies conducted in rodents (66). Main target of $\mathrm{DB}[\mathrm{a}, 1] \mathrm{P}$ carcinogenicity is the mammary gland (67).

$\mathrm{DB}[\mathrm{a}, \mathrm{h}] \mathrm{A}$ has been identified as a minor compound in many sources, like coal tar, soots, coke oven emissions and cigarette smoke and it is associated with human cancer. Noteworthy, the carcinogenic potency of DB[a,h]A varies with the route of administration and the dose, and has been reported to be up to 10 times more potent then $\mathrm{B}[\mathrm{a}] \mathrm{P}(64,66)$. $\mathrm{DB}[\mathrm{a}, \mathrm{h}] \mathrm{A}$ is considered to be equally carcinogenic to $\mathrm{B}[\mathrm{a}] \mathrm{P}$ at high concentrations, but to be on average 5 times more carcinogenic at low concentrations.

FA is found in relatively high concentrations in the air and increases lung and liver tumours in neonates after i.p. injection in a dose-dependent manner (62,68). However, FA did not show evidence of tumour initiating activity in experimental animals (60). FA down-regulates intracellular communication (69), which suggests that FA may be a tumour promoter and not an initiator (44).

\section{OBJECTIVES AND OUTLINE OF THE THESIS}

\section{Aim of the thesis}

As human exposure to PAHs occurs daily, it is important to be able to estimate the human cancer risks due to PAH exposure. Many different PAHs are present in the ambient air, and, although structurally alike, they can differ greatly in their carcinogenic potency. Although many data on the carcinogenic effects of PAHs are available for a selected number of PAHs, only limited information is present on many other PAHs. It is still unclear why some PAHs are carcinogenic whereas other PAHs are not. PAHs are known to directly and indirectly affect the expression of many genes, and gene expression profiling is nowadays considered an important tool for predictive and mechanistic toxicology. It can be hypothesized that PAHs with different carcinogenic potency will also differ in the gene expression profiles they induce in cells and organs. 
Therefore, this thesis aims to apply gene expression profiling in order to provide a rational for improving current risk assessment for ambient air PAHs.

As global gene expression profiles reveal the effects of compounds on many different processes simultaneously, gene expression analysis may be useful in revealing differences on several biological processes and may gain insight into the mechanisms of carcinogenicity of PAHs. So we first assessed gene expression profiles of PAHs induced in in vitro liver models, and related these profiles to the carcinogenic potency of PAHs. Also, the expression of one or more genes might be predictive for the carcinogenic potency of PAHs, which could be important in risk assessment of PAHs.

Secondly, in order to gain insight into the mechanisms and biological processes involved in PAH carcinogenicity in vivo, we assessed gene expression profiles of PAHs at doses inducing equal levels of mutations. Carcinogenic potency differs between PAHs, and as mutations are the initiating effect of carcinogenesis, we aim to find similarities and differences in gene expression modulation by PAHs at equally mutagenic doses.

Exposure to PAHs occurs mainly in mixtures (30,31), and it is mostly unclear whether different PAHs affect the effects of other PAHs. Our last aim was to gain insight into the interactive effects between PAHs that occur on gene expression. Gaining insight into the interactive effects occurring in PAH mixtures might help to improve cancer risk assessment of PAHs.

\section{Outline of the thesis}

First a method was developed for using four different dyes instead of the commonly used two dyes in microarray analyses (Chapter 2). By this new method we aimed to increase throughput and reduce costs, without limiting the data. This method is applied in Chapters 3, 4, 5 and 6. Chapters 3 and 4 describe the gene expression modulation and DNA adduct formation in respectively HepG2 cells and rat liver slices exposed to six PAHs described previously. We investigated whether gene expression profiling can be discriminative for their carcinogenic potencies. In $\underline{\text { Chapter } 5}$ the effects of the four most carcinogenic PAHs on gene expression modulation in lung and liver of mice was assessed, and related to the mutagenic potency of the compounds. Chapters 5 and 6 focus on the effects of binary PAH mixtures in HepG2 cells and rat liver slices respectively. The effects of mixtures on gene expression modulation and DNA adduct formation were compared to the effects of the individual compounds, in order to assess the interaction between PAHs in the mixture. 


\section{REFERENCES}

1. WHO, W.H.O. (1998) Environmental Health Criteria 202: Selected non-heterocyclic polycyclic aromatic hydrocarbons. IPCS, International Programme on Chemical Safety.

2. De Raat, W.K., Kooijman, S.A. and Gielen, J.W. (1987) Concentrations of polycyclic hydrocarbons in airborne particles in The Netherlands and their correlation with mutagenicity. Sci Total Environ, 66, 95-114.

3. IARC (1973) Certain polycyclic aromatic hydrocarbons and heterocyclic compounds. IARC Monogr Eval Carcinog Risk Chem Hum, 3, 1-271.

4. Sjogren, M., Ehrenberg, L. and Rannug, U. (1996) Relevance of different biological assays in assessing initiating and promoting properties of polycyclic aromatic hydrocarbons with respect to carcinogenic potency. Mutat Res, 358, 97-112.

5. Bostrom, C.E., Gerde, P., Hanberg, A., Jernstrom, B., Johansson, C., Kyrklund, T., Rannug, A., Tornqvist, M., Victorin, K. and Westerholm, R. (2002) Cancer risk assessment, indicators, and guidelines for polycyclic aromatic hydrocarbons in the ambient air. Environ Health Perspect, 110 Suppl 3, 451-88.

6. Ayrton, A.D., McFarlane, M., Walker, R., Neville, S., Coombs, M.M. and Ioannides, C. (1990) Induction of the P-450 I family of proteins by polycyclic aromatic hydrocarbons: possible relationship to their carcinogenicity. Toxicology, 60, 173-86.

7. Niesink R.J.M., d.V.J., Hollinger M.A. (1996) Chapter 3 Biotransformation: detoxication and bioactivation. In Toxicology, principles and applications. CRC Press LLC, USA.

8. Mollerup, S., Berge, G., Baera, R., Skaug, V., Hewer, A., Phillips, D.H., Stangeland, L. and Haugen, A. (2006) Sex differences in risk of lung cancer: Expression of genes in the PAH bioactivation pathway in relation to smoking and bulky DNA adducts. Int J Cancer, 119, 741-4.

9. Wolf, A., Kutz, A., Plottner, S., Behm, C., Bolt, H.M., Follmann, W. and Kuhlmann, J. (2005) The effect of benzo(a)pyrene on porcine urinary bladder epithelial cells analyzed for the expression of selected genes and cellular toxicological endpoints. Toxicology, 207, 255-69.

10. Godschalk, R.W.L. (1999) Biological markers for exposure to polycyclic aromatic hydrocarbons. Maastricht University, Maastricht, pp. 171.

11. Bartsch, H., Petruzzelli, S., De Flora, S., Hietanen, E., Camus, A.M., Castegnaro, M., Alexandrov, K., Rojas, M., Saracci, R. and Giuntini, C. (1992) Carcinogen metabolism in human lung tissues and the effect of tobacco smoking: results from a case--control multicenter study on lung cancer patients. Environ Health Perspect, 98, 119-24.

12. Uno, S., Dalton, T.P., Dragin, N., Curran, C.P., Derkenne, S., Miller, M.L., Shertzer, H.G., Gonzalez, F.J. and Nebert, D.W. (2006) Oral benzo[a]pyrene in Cyp1 knockout mouse lines: CYP1A1 important in detoxication, CYP1B1 metabolism required for immune damage independent of total-body burden and clearance rate. Mol Pharmacol, 69, 1103-14.

13. Kondraganti, S.R., Fernandez-Salguero, P., Gonzalez, F.J., Ramos, K.S., Jiang, W. and Moorthy, B. (2003) Polycyclic aromatic hydrocarbon-inducible DNA adducts: evidence by 32P-postlabeling and use of knockout mice for Ah receptor-independent mechanisms of metabolic activation in vivo. Int $\mathrm{J}$ Cancer, 103, 5-11.

14. Buters, J.T., Mahadevan, B., Quintanilla-Martinez, L., Gonzalez, F.J., Greim, H., Baird, W.M. and Luch, A. (2002) Cytochrome P450 1B1 determines susceptibility to dibenzo[a,l]pyrene-induced tumor formation. Chem Res Toxicol, 15, 1127-35.

15. Shimada, T. (2006) Xenobiotic-metabolizing enzymes involved in activation and detoxification of carcinogenic polycyclic aromatic hydrocarbons. Drug Metab Pharmacokinet, 21, 257-76.

16. Hartwig, A. (2002) Role of DNA repair in particle- and fiber-induced lung injury. Inhal Toxicol, 14, 91-100. 
17. Vogelstein, B. and Kinzler, K.W. (2004) Cancer genes and the pathways they control. Nat Med, 10, 789-99.

18. Blaha, L., Kapplova, P., Vondracek, J., Upham, B. and Machala, M. (2002) Inhibition of gap-junctional intercellular communication by environmentally occurring polycyclic aromatic hydrocarbons. Toxicol Sci, 65, 43-51.

19. Rosenkranz, H.S., Pollack, N. and Cunningham, A.R. (2000) Exploring the relationship between the inhibition of gap junctional intercellular communication and other biological phenomena. Carcinogenesis, 21, 1007-11.

20. Shimada, T. and Fujii-Kuriyama, Y. (2004) Metabolic activation of polycyclic aromatic hydrocarbons to carcinogens by cytochromes P450 1A1 and 1B1. Cancer Sci, 95, 1-6.

21. Roos, W.P. and Kaina, B. (2006) DNA damage-induced cell death by apoptosis. Trends Mol Med, 12, 440-50.

22. Niida, H. and Nakanishi, M. (2006) DNA damage checkpoints in mammals. Mutagenesis, 21, 3-9.

23. Chramostova, K., Vondracek, J., Sindlerova, L., Vojtesek, B., Kozubik, A. and Machala, M. (2004) Polycyclic aromatic hydrocarbons modulate cell proliferation in rat hepatic epithelial stem-like WBF344 cells. Toxicol Appl Pharmacol, 196, 136-48.

24. Pliskova, M., Vondracek, J., Vojtesek, B., Kozubik, A. and Machala, M. (2004) Deregulation of Cell Proliferation by Polycyclic Aromatic Hydrocarbons in Human Breast Carcinoma MCF-7 Cells Reflects Both Genotoxic and Nongenotoxic Events. Toxicol Sci.

25. Rao, K.N. (1995) The significance of the cholesterol biosynthetic pathway in cell growth and carcinogenesis (review). Anticancer Res, 15, 309-14.

26. Rao, K.N., Elm, M.S., Kelly, R.H., Chandar, N., Brady, E.P., Rao, B., Shinozuka, H. and Eagon, P.K. (1997) Hepatic hyperplasia and cancer in rats: metabolic alterations associated with cell growth. Gastroenterology, 113, 238-48.

27. Phillips, D.H. (1983) Fifty years of benzo(a)pyrene. Nature, 303, 468-72.

28. Boffetta, P., Jourenkova, N. and Gustavsson, P. (1997) Cancer risk from occupational and environmental exposure to polycyclic aromatic hydrocarbons. Cancer Causes Control, 8, 444-72.

29. Pope, C.A., 3rd, Burnett, R.T., Thun, M.J., Calle, E.E., Krewski, D., Ito, K. and Thurston, G.D. (2002) Lung cancer, cardiopulmonary mortality, and long-term exposure to fine particulate air pollution. Jama, 287, 1132-41.

30. Nisbet, I.C. and LaGoy, P.K. (1992) Toxic equivalency factors (TEFs) for polycyclic aromatic hydrocarbons (PAHs). Regul Toxicol Pharmacol, 16, 290-300.

31. Collins, J.F., Brown, J.P., Alexeeff, G.V. and Salmon, A.G. (1998) Potency equivalency factors for some polycyclic aromatic hydrocarbons and polycyclic aromatic hydrocarbon derivatives. Regul Toxicol Pharmacol, 28, 45-54.

32. Schneider, K., Roller, M., Kalberlah, F. and Schuhmacher-Wolz, U. (2002) Cancer risk assessment for oral exposure to PAH mixtures. J Appl Toxicol, 22, 73-83.

33. Niesink R.J.M., d.V.J., Hollinger M.A. (1996) Chapter 9 Toxicity of mixtures. In Toxicology, principles and applications. CRC Press LLC, USA.

34. Cherng, S.H., Hsu, S.L., Yang, J.L., Yu, C.T. and Lee, H. (2006) Suppressive effect of 1-nitropyrene on benzo[a]pyrene-induced CYP1A1 protein expression in HepG2 cells. Toxicol Lett, 161, 236-43.

35. Elovaara, E., Mikkola, J., Stockmann-Juvala, H., Luukkanen, L., Keski-Hynnila, H., Kostiainen, R., Pasanen, M., Pelkonen, O. and Vainio, H. (2006) Polycyclic aromatic hydrocarbon (PAH) metabolizing enzyme activities in human lung, and their inducibility by exposure to naphthalene, phenanthrene, pyrene, chrysene, and benzo(a)pyrene as shown in the rat lung and liver. Arch Toxicol.

36. Fox, S.I. (1996) Chapter 16 Respiratory physiology. In Human Physiology, fifth edition. Wim C. Brown publishers, USA.

37. Niesink R.J.M., d.V.J., Hollinger M.A. (1996) Chapter 18 Respiratory toxicology: pathophysiology, toxicological pathology and mechanisms of toxicity. In Toxicology, principles and applications. CRC Press LLC, USA. 


\section{CHAPTER 1}

38. Baron, J. and Voigt, J.M. (1990) Localization, distribution, and induction of xenobiotic-metabolizing enzymes and aryl hydrocarbon hydroxylase activity within lung. Pharmacol Ther, 47, 419-45.

39. Helleberg, H., Xu, H., Ehrenberg, L., Hemminki, K., Rannug, U. and Tornqvist, M. (2001) Studies of dose distribution, premutagenic events and mutation frequencies for benzo[a]pyrene aiming at low dose cancer risk estimation. Mutagenesis, 16, 333-7.

40. Wall, K.L., Gao, W.S., te Koppele, J.M., Kwei, G.Y., Kauffman, F.C. and Thurman, R.G. (1991) The liver plays a central role in the mechanism of chemical carcinogenesis due to polycyclic aromatic hydrocarbons. Carcinogenesis, 12, 783-6.

41. Niesink R.J.M., d.V.J., Hollinger M.A. (1996) Chapter 22 Hepatotoxicology: structure, function and toxicological pathology. In Toxicology, principles and applications. CRC Press LLC, USA.

42. Fox, S.I. (1996) Chapter 18 The digestive system. In Human Physiology, fifth edition. Wim C. Brown publishers, USA.

43. Braeuning, A., Ittrich, C., Kohle, C., Hailfinger, S., Bonin, M., Buchmann, A. and Schwarz, M. (2006) Differential gene expression in periportal and perivenous mouse hepatocytes. Febs J, 273, 5051-61.

44. Vaca, C., Tornqvist, M., Rannug, U., Lindahl-Kiessling, K., Ahnstrom, G. and Ehrenberg, L. (1992) On the bioactivation and genotoxic action of fluoranthene. Arch Toxicol, 66, 538-45.

45. Price, R.J., Renwick, A.B., Walters, D.G., Young, P.J. and Lake, B.G. (2004) Metabolism of nicotine and induction of CYP1A forms in precision-cut rat liver and lung slices. Toxicol In vitro, 18, 179-85.

46. Harrigan, J.A., McGarrigle, B.P., Sutter, T.R. and Olson, J.R. (2006) Tissue specific induction of cytochrome P450 (CYP) 1A1 and 1B1 in rat liver and lung following in vitro (tissue slice) and in vivo exposure to benzo(a)pyrene. Toxicol In vitro, 20, 426-38.

47. van Delft, J.H., van Agen, E., van Breda, S.G., Herwijnen, M.H., Staal, Y.C. and Kleinjans, J.C. (2004) Discrimination of genotoxic from non-genotoxic carcinogens by gene expression profiling. Carcinogenesis, 25, 1265-76.

48. Natarajan, A.T. and Darroudi, F. (1991) Use of human hepatoma cells for in vitro metabolic activation of chemical mutagens/carcinogens. Mutagenesis, 6, 399-403.

49. Hashemi, E., Dobrota, M., Till, C. and Ioannides, C. (1999) Structural and functional integrity of precision-cut liver slices in xenobiotic metabolism: a comparison of the dynamic organ and multiwell plate culture procedures. Xenobiotica, 29, 11-25.

50. Harrigan, J.A., Vezina, C.M., McGarrigle, B.P., Ersing, N., Box, H.C., Maccubbin, A.E. and Olson, J.R. (2003) DNA Adduct Formation in Precision-Cut Rat Liver and Lung Slices Exposed to Benzo(a)pyrene. Toxicol Sci.

51. Wilkening, S., Stahl, F. and Bader, A. (2003) Comparison of primary human hepatocytes and hepatoma cell line Hepg2 with regard to their biotransformation properties. Drug Metab Dispos, 31, 103542.

52. Jessen, B.A., Mullins, J.S., De Peyster, A. and Stevens, G.J. (2003) Assessment of hepatocytes and liver slices as in vitro test systems to predict in vivo gene expression. Toxicol Sci, 75, 208-22.

53. Boess, F., Kamber, M., Romer, S., Gasser, R., Muller, D., Albertini, S. and Suter, L. (2003) Gene expression in two hepatic cell lines, cultured primary hepatocytes, and liver slices compared to the in vivo liver gene expression in rats: possible implications for toxicogenomics use of in vitro systems. Toxicol Sci, 73, 386-402.

54. Quackenbush, J. (2001) Computational analysis of microarray data. Nat Rev Genet, 2, 418-27.

55. Schena, M., Shalon, D., Davis, R.W. and Brown, P.O. (1995) Quantitative monitoring of gene expression patterns with a complementary DNA microarray. Science, 270, 467-70.

56. Burczynski, M.E., McMillian, M., Ciervo, J., Li, L., Parker, J.B., Dunn, R.T., 2nd, Hicken, S., Farr, S. and Johnson, M.D. (2000) Toxicogenomics-based discrimination of toxic mechanism in HepG2 human hepatoma cells. Toxicol Sci, 58, 399-415.

57. Afshari, C.A., Nuwaysir, E.F. and Barrett, J.C. (1999) Application of complementary DNA microarray technology to carcinogen identification, toxicology, and drug safety evaluation. Cancer Res, 59, 475960. 
58. Nuwaysir, E.F., Bittner, M., Trent, J., Barrett, J.C. and Afshari, C.A. (1999) Microarrays and toxicology: the advent of toxicogenomics. Mol Carcinog, 24, 153-9.

59. Waring, J.F., Ciurlionis, R., Jolly, R.A., Heindel, M. and Ulrich, R.G. (2001) Microarray analysis of hepatotoxins in vitro reveals a correlation between gene expression profiles and mechanisms of toxicity. Toxicol Lett, 120, 359-68.

60. IARC (1983) Polynuclear aromatic compounds, Part 1, Chemical, environmental and experimental data. IARC Monogr Eval Carcinog Risk Chem Hum, 32, 1-453.

61. Machala, M., Vondracek, J., Blaha, L., Ciganek, M. and Neca, J.V. (2001) Aryl hydrocarbon receptormediated activity of mutagenic polycyclic aromatic hydrocarbons determined using in vitro reporter gene assay. Mutat Res, 497, 49-62.

62. Wang, J.S. and Busby, W.F., Jr. (1993) Induction of lung and liver tumors by fluoranthene in a preweanling CD-1 mouse bioassay. Carcinogenesis, 14, 1871-4.

63. LaVoie, E.J., Tulley-Freiler, L., Bedenko, V. and Hoffman, D. (1981) Mutagenicity, tumor-initiating activity, and metabolism of methylphenanthrenes. Cancer Res, 41, 3441-7.

64. Nesnow, S., Ross, J.A., Stoner, G.D. and Mass, M.J. (1995) Mechanistic linkage between DNA adducts, mutations in oncogenes and tumorigenesis of carcinogenic environmental polycyclic aromatic hydrocarbons in strain A/J mice. Toxicology, 105, 403-13.

65. Mass, M.J., Abu-Shakra, A., Roop, B.C., Nelson, G., Galati, A.J., Stoner, G.D., Nesnow, S. and Ross, J.A. (1996) Benzo[b]fluoranthene: tumorigenicity in strain A/J mouse lungs, DNA adducts and mutations in the Ki-ras oncogene. Carcinogenesis, 17, 1701-4.

66. Okona-Mensah, K.B., Battershill, J., Boobis, A. and Fielder, R. (2005) An approach to investigating the importance of high potency polycyclic aromatic hydrocarbons (PAHs) in the induction of lung cancer by air pollution. Food Chem Toxicol, 43, 1103-16.

67. Arif, J.M., Smith, W.A. and Gupta, R.C. (1999) DNA adduct formation and persistence in rat tissues following exposure to the mammary carcinogen dibenzo[a,l]pyrene. Carcinogenesis, 20, 1147-50.

68. Busby, W.F., Jr., Goldman, M.E., Newberne, P.M. and Wogan, G.N. (1984) Tumorigenicity of fluoranthene in a newborn mouse lung adenoma bioassay. Carcinogenesis, 5, 1311-6.

69. Upham, B.L., Masten, S.J., Lockwood, B.R. and Trosko, J.E. (1994) Nongenotoxic effects of polycyclic aromatic hydrocarbons and their oxygenation by-products on the intercellular communication of rat liver epithelial cells. Fundam Appl Toxicol, 23, 470-5. 



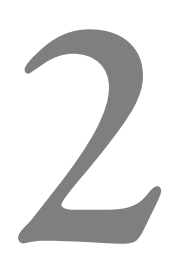

\section{Application of four dyes in gene expression analyses by microarrays}

Published in BMC Genomics, vol. 6, no 101, 2005

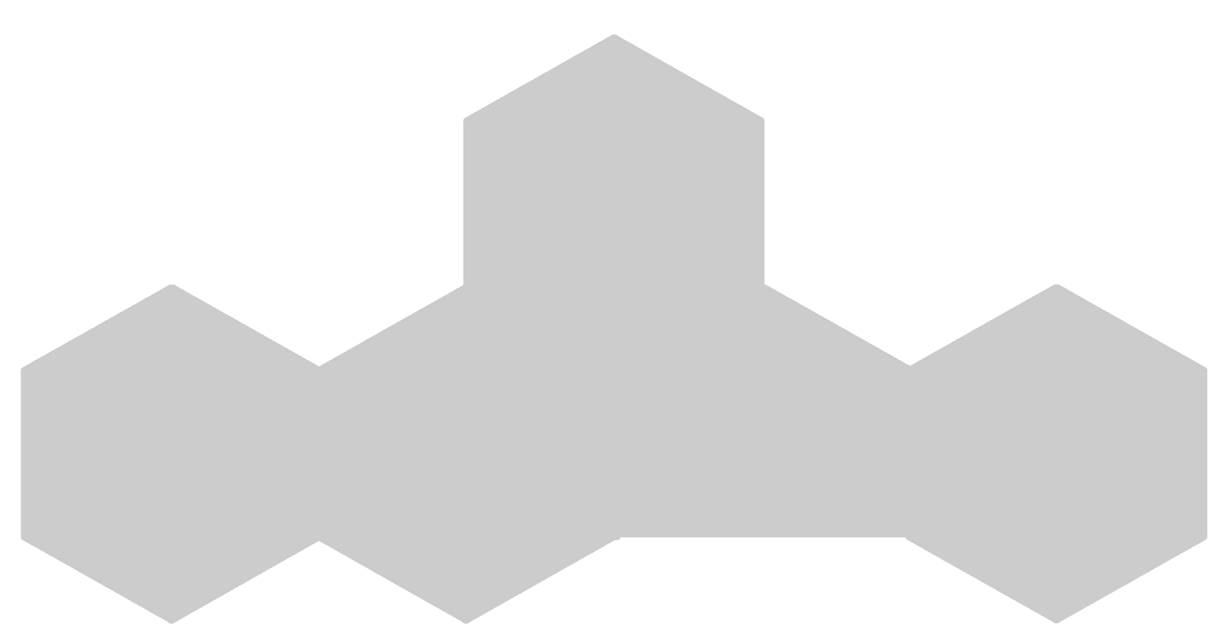

Yvonne C.M. Staal Marcel H.M. van Herwijnen

Frederik J. van Schooten Joost H.M. van Delft 


\begin{abstract}
DNA microarrays are widely used in gene expression analyses. To increase throughput and minimize costs without reducing gene expression data obtained, we investigated whether four mRNA samples can be analyzed simultaneously by applying four different fluorescent dyes. Following tests for cross-talk of fluorescence signals, Alexa 488, Alexa 594, Cyanine 3 and Cyanine 5 were selected for hybridizations. For selfhybridizations, a single RNA sample was labelled with all dyes and hybridized on commercial cDNA arrays or on in-house spotted oligonucleotide arrays. Correlation coefficients for all combinations of dyes were above 0.9 on the cDNA array. On the oligonucleotide array they were above 0.8 , except combinations with Alexa 488, which were approximately 0.5 . Standard deviation of expression differences for replicate spots were similar on the cDNA array for all dye combinations, but on the oligonucleotide array combinations with Alexa 488 showed a higher variation. In conclusion, the four dyes can be used simultaneously for gene expression experiments on the tested cDNA array, but only three dyes can be used on the tested oligonucleotide array. This was confirmed by hybridizations of control with test samples, as all combinations returned similar numbers of differentially expressed genes with comparable effects on gene expression.
\end{abstract}




\section{INTRODUCTION}

DNA microarray technology is widely used for gene expression analysis studies (1-5), as it is a high throughput technique by which the expression of all genes in a whole genome can be studied in a single assay. For many microarrays, the probe consists of cDNA or oligonucleotides spotted on a glass slide, and the target is fluorescent labelled cDNA (or cRNA). Both direct as well as indirect labelling protocols are applied: either, one target cDNA or cRNA is labelled with a single dye and hybridized on a microarray slide, or two targets are labelled with two different dyes, one for the reference and one for the test sample, and co-hybridized on a microarray slide. In dual label experiments, most often Cyanine 3 (Cy3) and Cyanine 5 (Cy5) are used as fluorescent dyes, although other dyes have been suggested (6). In this way differential expression for thousands of genes between two different RNA samples can be measured simultaneously. Usually these experiments are time consuming, and, because microarray slides and fluorescent labels are expensive, the experiments are also high in costs. Moreover, several replicates need to be performed to increase statistical significance and to detect small differences in gene expression $(7,8)$.

The application of four different dyes to label targets would be a major advantage as fewer microarrays will be required, leading to a reduction of costs and time without compromising gene expression data. A larger number of samples can be compared directly on a single microarray by labelling with more dyes, suggesting that fewer arrays will be required and that the hybridization design can be further optimized $(9,10)$. For instance, in the case that four samples need to be compared in all combinations, a dual-label common reference design requires four arrays for a single analysis of each sample, whereas a four-label design would require no common reference because all samples can be hybridized on a single array and only one array for a single analysis of each sample is needed. This will reduce variation, since variation between signal intensities for two dyes on a single spot is much smaller than variation between spots on different arrays (11). Furthermore, day to day variation is reduced since it is possible to achieve more hybridizations on the same day (12). In toxicogenomics assessments, as well as in other research areas, the approach to use multiple dyes can be of high value as it allows comparing several exposure conditions or time series simultaneously.

Forster et al (13) were the first to study the feasibility of using a third dye (Alexa 594) for labelling in microarray based gene expression analyses. Although they found that Alexa 594 gave a small signal in the Cy3 channel during scanning and Cy3 gave a small signal in the Alexa 594 channel, they concluded that Alexa 594 could be used besides $\mathrm{Cy} 3$ and $\mathrm{Cy} 5$ for direct comparison of two experimental samples and measuring these samples in relation to a reference sample. 
The goal of our study was to investigate whether more than three different fluorescent dyes can be applied in gene expression studies using DNA microarrays. This was studied using microarrays with cDNA and oligonucleotide probes by hybridizing with a single sample labelled with four dyes (a quadruple self-hybridization or further stated as self-hybridization). Self-hybridization experiments are useful for measuring microarray data variability since any deviation from the expected value of 0 (for log transformed data) is caused by systemic or technical variation $(13,14)$. We also studied the application of more than two dyes for gene expression changes caused by exposure of cells to benzo[a]pyrene, to verify that the new dyes can be applied simultaneously in microarray studies. In the present study, we demonstrate that on our cDNA arrays four dyes can be applied, but that hybridization on the oligonucleotide arrays should be restricted to three dyes.

\section{MATERIALS AND METHODS}

\section{Cross-talk analysis of fluorescent dyes}

Two ARES ${ }^{\text {TM }}$ Alexa fluor ${ }^{\circledR}$ dyes (Alexa 488 and 594) (Molecular Probes, Leiden, The Netherlands) and conventionally used Cyanine3 (Cy3) and Cyanine5 (Cy5) (Amersham Biosciences, Uppsala, Sweden) were tested for cross-talk of excitation / emission signals. All dyes were dissolved according to the producer's manual and applied on a glass slide. The slide was scanned with a ScanArrayExpress microarray scanner (Packard BioChip Technologies, Perkin Elmer life sciences, Boston, USA) with laser wavelengths for Alexa 488, Cy3, Alexa 594 and of 488, 543.8, 594 and $632.8 \mathrm{~nm}$ respectively, and emission filter of 522, 570, 614 and $670 \mathrm{~nm}$ respectively. The images were analyzed with ImaGene (BioDiscovery, USA). Fluorescence of each dye at the scanning settings of all tested dyes was measured and four dyes were selected for further use (see Results).

\section{Source of RNA samples}

RNA was isolated from cultured HepG2 cells or from rat liver or precision-cut liver slices and used for the microarray hybridizations. HepG2 cells were cultured in Minimal Essential Medium (MEM) supplemented with 1\% non-essential amino acids, 1\% sodium-pyruvate, $2 \%$ penicillin/streptomycin and 10\% Foetal Bovine Serum (all from Gibco/BRL, Breda, The Netherlands) in T25 culture flasks at $37^{\circ} \mathrm{C}$ and $5 \% \mathrm{CO}_{2}$. HepG2 cells were exposed to 3, 10 or $30 \mu \mathrm{M}$ of Benzo[a]pyrene (B[a]P, from SigmaAldrich, the Netherlands) and a vehicle control (DMSO) during 6 hours in two independent experiments. DMSO concentration in de cell culture media was $0.1 \%$. After exposure, media was removed and $1 \mathrm{ml}$ Trizol (Gibco/BRL, Breda, The Netherlands) was immediately added to the cells. 
A male Wistar albino rat (200 g) was killed by cervical dislocation, and the liver after removal, was snap frozen in liquid nitrogen and stored at $-80^{\circ} \mathrm{C}$. Liver tissue $(8.6 \mathrm{~g})$ was crushed using a mortar and pester. An amount of $0.05 \mathrm{~g}$ crushed liver tissue was dissolved in $1 \mathrm{ml}$ Trizol reagent. Additionally, precision-cut liver slices were obtained by using a Krumdieck tissue slicer (15). Cylindrical liver cores with a diameter of $8 \mathrm{~mm}$ were sliced into $250 \mu \mathrm{m}$ thick slices. In the two independent experiments, slices were exposed to 3, 10 or $30 \mu \mathrm{M} \mathrm{BaP}$ or a solvent control (DMSO 0.067\%) during 24 hours. After exposure, slices were snap frozen in liquid nitrogen and RNA was isolated in a manner similar to that of the whole liver tissue.

\section{RNA isolation and cDNA synthesis}

RNA was isolated from the Trizol solutions according to the producer's manual and purified with the RNeasy mini kit (Qiagen Westburg bv., Leusden, The Netherlands). RNA quantity was measured on a spectrophotometer and the quality was determined on a BioAnalyzer (Agilent Technologies, Breda, The Netherlands). Only RNA samples which showed clear $18 \mathrm{~S}$ and $28 \mathrm{~S}$ peaks were used for labelling and hybridization. In order to generate sufficient large uniform samples for the multiple self hybridizations, RNA samples from several isolations were pooled.

RNA was reverse transcribed into cDNA in quadruplicate with amino-allyl labelled dUTP (Sigma-Aldrich, St Louis, USA) and subsequently labelled with one of the dyes (based on Van Delft et al (16)). For each sample, a mixture of $10 \mu \mathrm{g}$ of RNA and $6 \mu \mathrm{g}$ of random hexamer primers were incubated in $18.5 \mu \mathrm{l}$ at $70^{\circ} \mathrm{C}$ for 10 minutes and snap frozen on dry ice / ethanol for 30 seconds. Thereafter DTT (final concentration 10 $\mathrm{mM}$ ), $0.5 \mathrm{mM}$ dATP, dCTP and dGTP, $0.3 \mathrm{mM}$ dTTP, $0.2 \mathrm{mM} \mathrm{5-(3-amino-allyl)-}$ 2'deoxyuridine-5'-triphosphate (aa-dUTP), and 400 U Superscript II reverse transcriptase (Invitrogen, Life Technologies, Breda, The Netherlands) were added to a final volume of $30.1 \mu \mathrm{l}$ and incubated overnight at $42^{\circ} \mathrm{C}$. RNA was hydrolyzed by adding 10 $\mu \mathrm{l}$ of $1 \mathrm{M} \mathrm{NaOH}$ and $10 \mu \mathrm{l}$ of $0.5 \mathrm{M}$ EDTA followed by an incubation of 15 minutes at $65^{\circ} \mathrm{C}$. To neutralize, $10 \mu \mathrm{l}$ of $1 \mathrm{M} \mathrm{HCl}$ was added. cDNA samples were purified to remove unincorporated amino-allyl dUTP and buffers using a QIAquick PCR Purification Kit (Qiagen Westburg bv., Leusden, The Netherlands) according to the producer's manual. However, in order to eliminate interference of amines during labelling, buffers were substituted by phosphate buffers (wash buffer: $5 \mathrm{mM} \mathrm{KPO}_{4} \mathrm{pH} 8.0$, 80\% ethanol; elution buffer: $4 \mathrm{mM} \mathrm{KPO}_{4} \mathrm{pH}$ 8.5). The sample was eluted in duplicate using 30 $\mu \mathrm{l}$ elution buffer and dried in vacuo. Following amino-allyl labelling, cDNA targets were resolved in $4.5 \mu \mathrm{l}$ of $0.1 \mathrm{M} \mathrm{Na}_{2} \mathrm{CO}_{3} \mathrm{pH} 9.0$ and $4.5 \mu \mathrm{l}$ of a $2.25 \mu \mathrm{M}$ of Cy TM 5 or Cy ${ }^{\mathrm{TM}} 3$ Monofunctional Reactive Dye esters (Amersham Biosciences, Uppsala, Sweden) was added. Samples were incubated in the dark at room temperature for 1 hour. Targets to be labelled with Alexa dyes were resolved in $5 \mu \mathrm{l}$ of MilliQ, $3 \mu \mathrm{l}$ of labelling buffer (Sodium bicarbonate, prepared according to the producers' manual) and $2 \mu$ l of a $6.3 \mu \mathrm{M}$ of ARES $^{\text {TM }}$ Alexa Fluor ${ }^{\circledR}$ (Molecular Probes, Leiden, The Netherlands) 
(dissolved in DMSO according to the producers' manual) was added. The sample was incubated for 1 hour in the dark at room temperature. After incubation $35 \mu$ l of 100 $\mathrm{mM} \mathrm{NaAc} \mathrm{pH} 5.2$ was added to the Cy-labelled targets and $90 \mu \mathrm{l}$ MilliQ was added to the Alexa labelled targets. The samples were purified using a QIAquick PCR Purification Kit (Qiagen Westburg bv, Leusden, The Netherlands) to remove unincorporated dyes. To the rat liver targets, additional $4 \mu \mathrm{l}$ of $100 \mathrm{U} / \mathrm{ml}$ Poly-dA (Amersham Biosciences, Uppsala, Sweden) and $3 \mu \mathrm{l}$ of $1 \mathrm{mg} / \mathrm{ml}$ mouse Cot1-DNA (Invitrogen, Breda, The Netherlands) were added to block an unspecific binding of the targets to the array. The targets were dried in vacuo.

\section{Microarray hybridizations}

HepG2 targets were hybridized to the PHASE-1 Microarray Human-600 (PHASE-1 Molecular Toxicology, Santa Fe, USA), containing 597 sequence verified cDNA clones from human genes, representing a number of toxicologically relevant, as well as control, genes, each printed in quadruplicate. Hybridization and washing was done according to the producer's manual as previously described [15]. The labelled cDNA target was dissolved in $30 \mu \mathrm{l}$ hybridization buffer (50\% formamide, 5x SSC, $0.1 \%$ SDS, 0.1 $\mathrm{mg} / \mathrm{ml}$ Salmon Sperm DNA) and incubated for 15 minutes in the dark at room temperature. The target was denatured by heating for 5 minutes at $95^{\circ} \mathrm{C}$, centrifuged for 3 minutes at maximum speed, and placed in a heat block at $70^{\circ} \mathrm{C}$ until further use. The target $(28 \mu \mathrm{l})$ was applied on the cover slip $(24 \times 32 \mathrm{~mm})$ and the microarray was placed on top of the cover slip. The slide was hybridized overnight in a humidified hybridization chamber (Corning, Life Sciences, The Netherlands) in a water bath at $42^{\circ} \mathrm{C}$. After incubation, the slide was placed in wash buffer $(2 \mathrm{x} \mathrm{SSC}, 30-34: \mathrm{C})$ to remove the cover slip, and washed 5 minutes in 2x SSC / 0.1\% SDS, 5 minutes in $0.1 x$ SSC / 0.1\% SDS, 2 times 5 minutes in $0.1 \times$ SSC at $32^{\circ} \mathrm{C}$, and 1 minute in MilliQ all at room temperature. The slide was centrifuged to dry.

Rat liver targets were hybridized on an Operon rat oligonucleotide array containing 5700 oligonucleotides (Operon, Qiagen, Venlo, The Netherlands) printed in triplicate on Corning UltraGAPS Coated Slides (Corning Life Sciences, New York, USA) by the Genome Centre Maastricht (Maastricht University, Maastricht, The Netherlands). Hybridization and washing was done according to Corning's protocol for oligonucleotide arrays. The labelled cDNA target was dissolved in $65 \mu$ l hybridization buffer $(30 \%$ formamide; $5 \mathrm{x}$ SSC; $0.1 \%$ SDS) and incubated for 15 minutes in the dark at room temperature. The target was denatured by heating for 5 minutes at $95^{\circ} \mathrm{C}$, centrifuged for 2 minutes at maximum speed, and kept at room temperature until further use. The microarray slide and cover slip $(24 \times 60 \mathrm{~mm})$ were prehybridized for 45 minutes in preheated prehybridization buffer ( $5 \mathrm{x}$ SSC; $0.1 \%$ SDS; $1 \% \mathrm{BSA}$ ) at $42^{\circ} \mathrm{C}$. Slides and cover slips were washed several times in MilliQ followed by dipping in isopropanol and centrifugation to dry. The target $(60 \mu \mathrm{l})$ was applied on the cover slip and the microarray was placed on top of the cover slip. The slide was hybridized overnight in a 
humidified hybridization chamber (Corning, Life Sciences, The Netherlands) in a water bath at $42^{\circ} \mathrm{C}$. After incubation, the slide was placed in wash buffer (2x SSC / $0.1 \%$ $\mathrm{SDS})$ at $42^{\circ} \mathrm{C}$ to remove the cover slip. The slide was washed for 2 times 5 minutes in $2 \mathrm{xSSC} / 0.1 \%$ SDS at $42^{\circ} \mathrm{C}, 2$ times 10 minutes in $0.1 \mathrm{x}$ SSC / $0.1 \%$ SDS at room temperature and 4 times 1 minute in $0.1 \mathrm{x}$ SSC at room temperature. The slide was centrifuged to dry.

\section{Microarray data analysis}

The microarray slides were scanned on a ScanArrayExpress (Packard Biochip Technologies, Perkin Elmer life sciences, Boston, USA). All four channels were scanned at several different settings for laser power and / or photo multiplier tube (PMT Gain). Settings were optimized such that the signal of the highest fluorescent spots is just below the maximum measurable level. Laser power settings were set at 100\% and PMT Gain was adjusted, unless otherwise stated. The images (10 micron resolution; 16 bit tiff) were processed with ImaGene 5.0 software (Biodiscovery Inc., Los Angeles, USA) to quantify spot signals. Irregular spots were manually or automatically flagged and not included in the data analysis.

For the self-hybridizations, data from ImaGene were exported to Microsoft Excel (Microsoft, USA) for transformations and analysis. For each spot, mean local background signal was subtracted from the mean spot signal, negative signals were excluded, and the resulting net spot signal data were log transformed. These log transformed background corrected expression signals for all combinations of dyes at all scanner settings were plotted and analyzed by linear regression and correlation coefficients $\left(\mathrm{R}^{2}\right)$ were calculated. Furthermore, standard deviations of ${ }^{10} \log$ transformed expression ratios for each gene (for 3 or 4 replicate spots, depending on the array used), were plotted against the mean ${ }^{10} \log$ transformed expression signals and analyzed by regression analysis.

For the $\mathrm{B}[\mathrm{a}] \mathrm{P}$ exposed samples, data from ImaGene were transported to GeneSight software version 4.1.5 (Biodiscovery Inc, Los Angeles, USA) for transformations and analyses. For each spot, background was subtracted; flagged spots and spots with a net expression level below 5 were omitted. Data were log base 2 transformed and expression difference between exposed and control were calculated. Data normalization was done by LOWESS and centring expression differences by subtracting mean values (the latter only for the oligonucleotide arrays). Data of replicate spots were combined while omitting outliers ( $>2$ standard deviations). In order to estimate the number of differentially expressed genes following a treatment, the confidence analysis tool from GeneSight was used. For confidence analyses, for each B[a]P concentration, data of the two replicate arrays with the same dye combination were combined. Up-regulated and down-regulated genes were identified at 99\% confidence intervals with up-regulation 
or down regulation levels set at 0.2 ( ${ }^{2} \log$-scale) for the cDNA arrays and respectively $99.5 \%$ and 0.5 for the oligonucleotide arrays.

\section{RESULTS}

\section{Selection of fluorescent dyes}

Four different dyes were tested for signal cross-talk at the emission / excitation settings of the ScanArrayExpress, namely Alexa 488, Alexa 594, Cyanine 3 and Cyanine 5. Therefore, the fluorescence of each dye at scanner settings of all tested dyes was measured. Results are summarized in Table 2.1. Since none of these dyes gives hardly any signal at settings for any other dye, it can be concluded that all dyes can be used simultaneously and were therefore considered suitable for use in microarray experiments. These dyes were further examined on two different microarray platforms.

TABLE 2.1. Cross-fluorescence of tested dyes. Fluorescence of dyes at scanner settings of all dyes expressed as a percentage of fluorescence at its own settings (the latter was set to $100 \%$ ).

\begin{tabular}{|c|c|c|c|c|c|}
\hline Settings & Dye & Alexa 488 & Alexa 594 & $\mathrm{Cy} 3$ & Су5 \\
\hline Alexa 488 & & 100.0 & 0.0 & 1.1 & 0.0 \\
\hline Alexa 594 & & 0.9 & 100.0 & 1.3 & 13.0 \\
\hline Cy3 & & 0.0 & 2.2 & 100.0 & 0.0 \\
\hline Cy5 & & 0.1 & 0.1 & 0.2 & 100.0 \\
\hline
\end{tabular}

\section{Optimizing laser power and PMT gain settings}

The cDNA microarray from PHASE-I Molecular Toxicology was hybridized with a single cDNA target labelled with four different dyes (Сy3, Сy5, Alexa 488 and Alexa 594). Initial laser power settings for Alexa 488, Alexa 594, Cyanine 3 and Cyanine 5 were respectively 93, 91, 89 and 80\%, and initial PMT gain settings were respectively $72,71,61,60 \%$. In order to obtain the optimal scan settings for each dye, the array is scanned at different laser power and PMT gain setting. Figure 2.1 shows, as an example, the data for varying laser power and PMT gain settings for Alexa 594. 


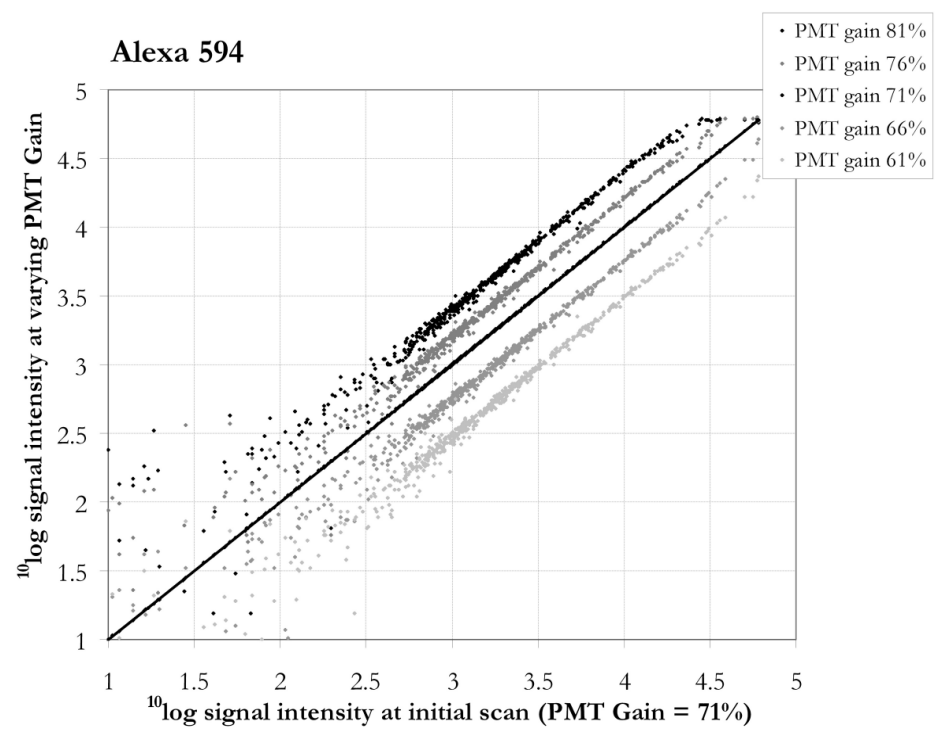

Figure 2.1a

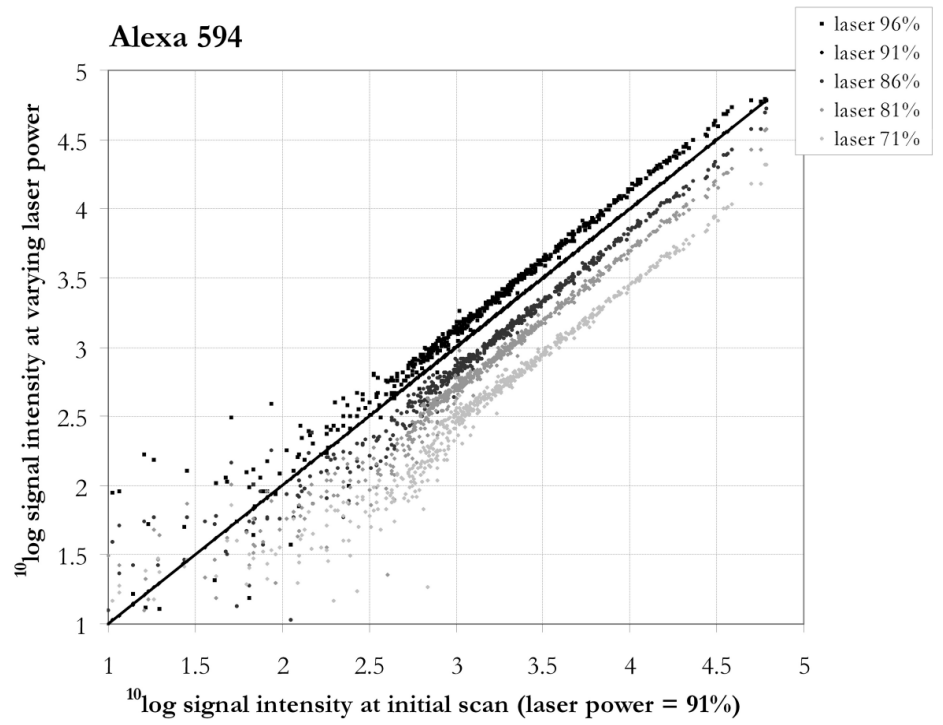

Figure 2.1b

FIGURE 2.1. Results for the PHASE-I cDNA microarray scanned with varying aser power(a) or varying PMT gain (b) on Alexa 594 fluorescence signals. Average ${ }^{10} \log$ transformed fluorescence data for each gene of the dyes at varying setting ( $\mathrm{y}$-axis) was plotted against the initial fluorescence data ( $\mathrm{x}$-axis). 
In the scatter plots of data of one scan versus another, in general the data points indicate parallel lines when the settings are varied between the scans, implying that the fluorescent signals are consistent for all levels of gene expression when targets are labelled with these dyes. The larger distribution of the data points at low signals is a normal effect, which is due to reduced accuracy to measure signals from low expressed genes. Compared to Alexa 594, varying laser settings gave similar results for Alexa 488. For $\mathrm{Cy} 3$ and $\mathrm{Cy} 5$, the data points in the scatter plots run parallel for each setting. Varying laser settings gave similar results for all tested dyes. The Alexa 488 and Alexa 594 graphs, however, show a minor disturbance in the lines of the data points when the laser is varied (shown for Alexa 594 in Figure 2.1a). This suggests that for these two dyes, a fixed laser power should always be applied, whereas the other dyes allow some variation. Furthermore, these data indicate that laser power and PMT gain can be varied to some extend without affecting relative gene expression levels, as long as there is no saturation of signal intensities.

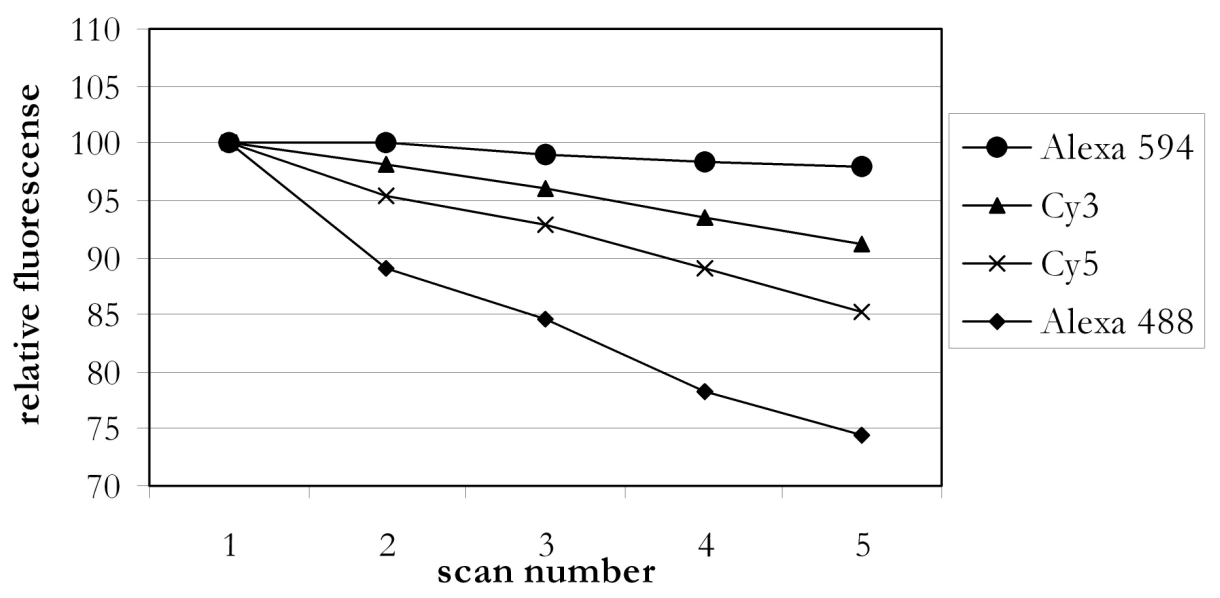

FIGURE 2.2. Photobleaching of Alexa 488, Alexa 594, Cy3 and Cy5 after repetitive scanning of the microarray. Mean signal intensity is presented after repetitive scanning, relative to the signal at the first scan.

We also tested photo bleaching of the 4 dyes by scanning the microarray slide up to 5 times with the same scanner settings for all 4 dyes, and plotted the mean signal intensities as percentage of the signal intensity at the first scan (Figure 2.2). As is evident, photo bleaching occurs for all dyes as for all the signals decreases. The reduction was highest for Alexa 488 and least for Alexa 594, but was always small $(<11 \%$ between the first and second round of scanning). Furthermore, the signal-to-noise ratio did not change for either of the dyes after repetitive scanning (data not shown). Therefore, we conclude that the photo bleaching is not expected to hamper gene expression analyses on microarrays. 


\section{Correlation coefficients between dyes at different laser power settings}

The influence of laser power and PMT gain settings on the correlations between the combinations of dyes to a trend line was examined. A cDNA microarray was scanned at the initial settings (mentioned above), and with a laser power of $70 \%$ or $100 \%$ and with adjusted PMT gain until none of the spots gave saturated signals. Results are shown in the Table 2.2. These correlation coefficients show that for all possible combinations of dyes, increasing the laser power, and thereby reducing the PMT gain, results in a higher correlation coefficient. This suggests that these cDNA microarrays with targets labelled with Alexa 488, Alexa 594, Cy3 and Cy5, and scanned with the ScanArrayExpress, could best be scanned at 100\% laser power setting and adjusted PMT gain settings, in order to obtain the smallest variation in gene expression values. Although the correlations are high and differences are marginal, the poorest correlation for the first array was found for Alexa 488 combined with Cy5 (0.935), and the highest correlation for Alexa 594 with Cy3 (0.988).

TABLE 2.2. Correlation coefficients for all genes on the PHASE- I cDNA array between combinations of dyes at different scanner settings for 1 array, and at laser power 100 settings for 5 arrays.

\begin{tabular}{lccc|ccc}
\hline \multicolumn{1}{c}{ Settings } & \multicolumn{3}{c|}{ array1 } & \multicolumn{2}{c}{ laser power $=\mathbf{1 0 0}(\mathbf{n}=\mathbf{5})$} \\
\cline { 2 - 6 } Dye combination & laser $=\mathbf{7 0}$ & original settings & laser=100 & mean & \pm & stdev \\
\hline Alexa 488 vs Alexa 594 & 0.953 & 0.967 & 0.965 & 0.953 & \pm & 0.020 \\
Alexa 488 vs Cy3 & 0.916 & 0.941 & 0.955 & 0.923 & \pm & 0.044 \\
Alexa 488 vs Cy5 & 0.890 & 0.935 & 0.935 & 0.942 & \pm & 0.014 \\
Alexa 594 vs Cy3 & 0.958 & 0.983 & 0.988 & 0.938 & \pm & 0.053 \\
Alexa 594 vs Cy5 & 0.946 & 0.978 & 0.979 & 0.986 & \pm & 0.005 \\
Cy3 vs Cy5 & 0.975 & 0.981 & 0.987 & 0.926 & \pm & 0.062 \\
\hline Mean & 0.940 & 0.964 & 0.968 & 0.945 & \pm & 0.025 \\
\hline
\end{tabular}

Original scanner settings for Alexa 488, Alexa 594, Cy3 and Cy5 are: laser power 93, 91, 89 and $80 \%$ respectively, and PMT Gain 72, 71, 91, 60\% respectively; * The correlation coefficient between Alexa 594 Cy5 is significantly higher than the correlation coefficient for any dye combination with Alexa 488, and the combination Alexa 594-Cy3 has a significantly higher correlation coefficient than Cy3-Cy5 (t-test, $\mathrm{p}<0.05)$.

The reproducibility was tested by several other self-hybridizations of different RNA samples. Table 2.2 shows the results for the correlation coefficients calculated for all combinations of dyes. Numerical data from the table indicate that correlation coefficients for the repeated experiments are similar with mean correlation coefficients varying between 0.923 (Alexa 488 and Cy3) and 0.986 (Alexa 594 and Cy5).

For the rat oligonucleotide microarray, also self-hybridizations with targets labelled with Cy3, Cy5, Alexa 488 and Alexa 594 were also conducted and the laser power was set to 70 or $100 \%$ with adjustment of the PMT gain until no saturation of fluorescence occurred. Table 2.3 represents the correlation coefficients for these settings, and similar on this array, the correlations for all combinations of dyes are higher at laser 
power settings of $100 \%$ compared to $70 \%$. However, in all cases the correlation coefficients were smaller (varying between 0.486 and 0.887 ) compared to the cDNA array. Furthermore, Table 2.3 shows that correlations between Alexa 488 and any other dye are much lower than the correlation for any of the other combinations. This is probably due to the high background fluorescence for Alexa 488 on these arrays compared to the spot signals. The ratio of mean spot signal to mean background variation (signal-to-noise ratio) was clearly lower for Alexa 488 then for the other dyes (namely, 1.25, 1.65, 2.88 and 1.88 for Alexa 488, Alexa 594, Cy3 and Cy5, respectively). The high background signal in the Alexa 488 channel can not be due to autofluorescence of the Corning slides alone as it was not observed when scanning an unhybridized microarray.

TABLE 2.3. Correlation coefficients for all genes on the oligonucleotide array between combinations of dyes at different scanner on 1 array, and at laser power 100 settings for 7 arrays. Alexa 488 labeled samples were only hybridized on the first array.

\begin{tabular}{lcc|rcc}
\hline \multirow{2}{*}{ Dye combination } & \multicolumn{5}{c}{ Settings } \\
\cline { 2 - 6 } & \multicolumn{2}{c}{ array1 } & \multicolumn{3}{c}{ laser power $=\mathbf{1 0 0}(\mathbf{n}=\mathbf{7})$} \\
\cline { 2 - 6 } & laser $=\mathbf{7 0}$ & laser=100 & mean & \pm & stdev \\
\hline Alexa 488 vs Alexa 594 & 0.118 & 0.561 & & & \\
Alexa 488 vs Cy3 & 0.080 & 0.512 & & & \\
Alexa 488 vs Cy5 & 0.127 & 0.486 & & & \\
Alexa 594 vs Cy3 & 0.334 & 0.857 & 0.855 & \pm & 0.034 \\
Alexa 594 vs Cy5 & 0.279 & 0.808 & $0.853^{*}$ & \pm & 0.029 \\
Cy3 vs Cy5 & 0.313 & 0.887 & 0.890 & \pm & 0.052 \\
\hline Mean & 0.208 & 0.685 & 0.843 & \pm & 0.077 \\
\hline
\end{tabular}

* The correlation coefficient between Cy3 - Cy5 is significantly higher than the correlation coefficient of Alexa $594-$ Cy3 (t-test, $\mathrm{p}<0.05)$.

To reduce the background binding on the oligonucleotide arrays, we applied several different hybridization and washing protocols. We varied BSA concentration in the hybridization buffer, added tRNA, Cot1 or PolyA and used a commercial hybridization buffer (DIG Easy Hyb granules, Roche, Germany). We also varied the concentrations SSC and SDS in the washing buffers. The best results for all dyes were obtained by using the hybridization protocol as described in "Microarray hybridizations" of the Methods section. The data from this most optimal protocol are presented here.

With the exclusion of Alexa 488, the other dyes were tested in several more selfhybridizations with for each array a different RNA sample in order to confirm the reproducibility. Table 2.3 shows the correlation coefficients for all combinations of the 3 dyes. The correlation coefficients are similar for all repetitive experiments with mean values varying between 0.854 and 0.891 . 


\section{Standard deviation in relation to spot intensity for all combinations of dyes}

The standard deviation for the ${ }^{10} \log$ transformed expression ratios of the 3 or 4 replicate spots per gene on the arrays was calculated and plotted against the mean signal intensity of the corresponding dyes (Figure 2.3). For both arrays, the standard deviation decreased with increasing gene expression level. For the cDNA array, the standard deviation was equal for all combinations of dyes at a ${ }^{10} \log$ signal intensity of 3 and higher. At lower signal intensities, however, the standard deviation for combinations of any dye with Alexa 488 were higher than for Cy3-Cy5 combinations, and standard deviations for combinations with Alexa 594 are intermediate. For the oligonucleotide array, the standard deviation for all combinations of dyes with Alexa 488 is higher at any signal intensity than for any other combination of dyes.

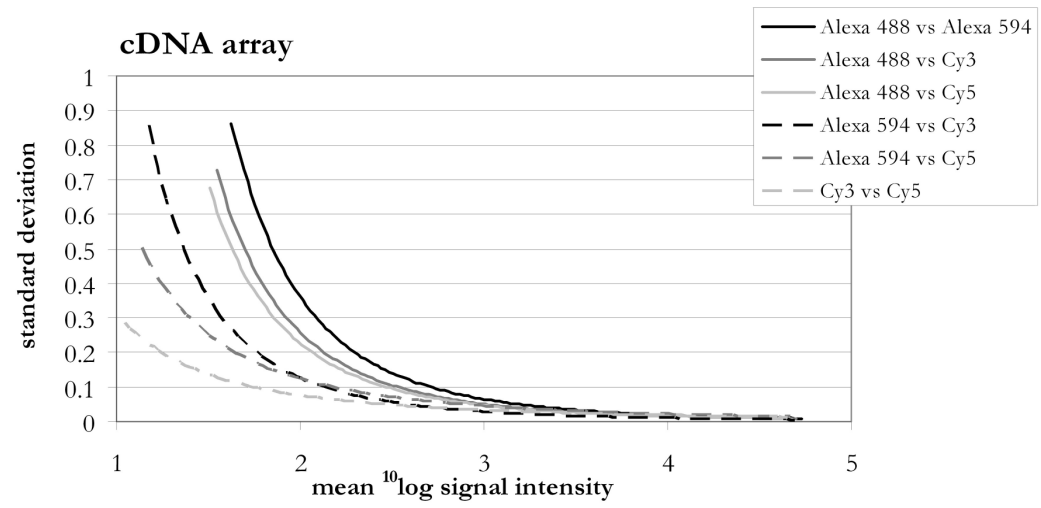

Figure 2.3a

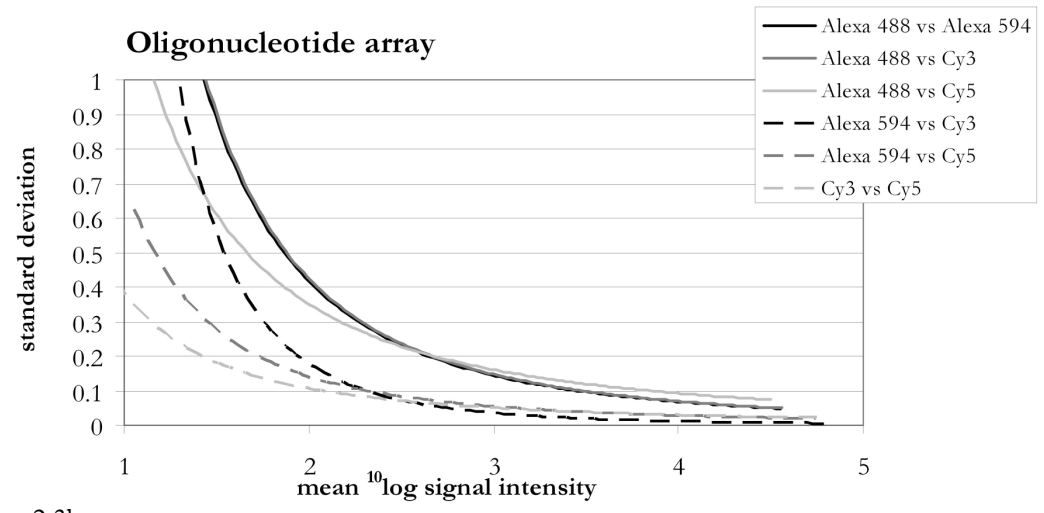

Figure 2.3b

FIGURE 2.3. Standard deviation of ${ }^{10} \log$ transformed expression ratios for the 3 replicate spots of each gene (y-axis) plotted against the mean ${ }^{10} \log$ transformed signal intensities ( $\mathrm{x}$-axis) for the corresponding dyes for all combinations of dyes for the cDNA array (a) and the oligonucleotide array(b). Regression lines are based on a power model. 


\section{Identification of modulated genes for various dye combinations}

As microarrays are intended to identify genes that are differentially expressed between different RNA samples, we tested the applicability of four dyes by analyzing RNA samples from cells exposed to 3 concentrations of $\mathrm{B}[\mathrm{a}] \mathrm{P}$ versus a vehicle control. Table 2.4 shows the labelling and hybridization schedule for the $\mathrm{B}[\mathrm{a}] \mathrm{P}$ exposed samples on the arrays (per array, four RNA samples were simultaneously hybridized), which was conducted to the two independent treatments (see Materials and Methods). Every dye was used for every RNA sample, but not each dye combination was applied for each combination of control and test sample. For every B[a]P concentration a confidence analysis was performed to select modulated genes for each dye combination separately. Also, for all dye combinations combined (paired data), a confidence analysis was conducted. For the cDNA array 20, 31 and 45 genes were found modulated for paired data of respectively 3,10 and $30 \mu \mathrm{M}$. For the oligonucleotide array 121, 97 and 195 genes were found modulated for paired data of respectively 3, 10 and 30 $\mu \mathrm{M}$. Modulated genes for each dye combination were compared to modulated genes found all dye combinations paired. Table 2.5 and 2.6 summarize the results for respectively the cDNA arrays and the oligonucleotide arrays; they present numbers of modulated genes for specific dye combinations as a percentage of numbers of modulated genes by all dye combinations combined (in bold). On average, this percentage is approximately $45 \%$, although in some cases it is clearly lower or higher. This deviation, however, is not consistent for a dye or a combination of dyes, so it can be concluded that all dyes perform equally well in identifying differentially expressed genes. Also in these Tables, the different dye-combinations are compared to each other, all as a percentage of modulated genes by all dye combinations (in italics). Once again differences are observed, which are not sufficient consistent to conclude that one combination of dyes performs worse or better than another to identify modulated genes.

TABLE 2.4. Labelling schedule for B[a]P exposed samples.

\begin{tabular}{ccccc}
\hline array no. & \multicolumn{4}{c}{ fluorescent label } \\
\cline { 2 - 5 } & Cy3 & Cy5 & Alexa 594 & Alexa 488 \\
\hline 1 & $0 \mu \mathrm{M}$ & $3 \mu \mathrm{M}$ & $10 \mu \mathrm{M}$ & $30 \mu \mathrm{M}$ \\
2 & $10 \mu \mathrm{M}$ & $0 \mu \mathrm{M}$ & $30 \mu \mathrm{M}$ & $3 \mu \mathrm{M}$ \\
3 & $3 \mu \mathrm{M}$ & $30 \mu \mathrm{M}$ & $0 \mu \mathrm{M}$ & $10 \mu \mathrm{M}$ \\
4 & $30 \mu \mathrm{M}$ & $10 \mu \mathrm{M}$ & $3 \mu \mathrm{M}$ & $0 \mu \mathrm{M}$ \\
\hline
\end{tabular}

Each HepG2 sample is labelled with each fluorescent dye. Rat liver samples were labelled as shown by array number 1-3, without the application of Alexa 488. 
TABLE 2.5. Performance of a dye combination in revealing modulated genes in HepG2 cells treated with $3(\mathrm{a}), 10(\mathrm{~b})$ or $30(\mathrm{c}) \mu \mathrm{M} \mathrm{B}[\mathrm{a}] \mathrm{P}$ using a cDNA array. For 3, 10 and $30 \mu \mathrm{M}, 20,31$ and 45 genes were modulated by analysis with all dyes combined.

Table $5 \mathrm{a}$

\begin{tabular}{lcccc}
\hline & Cy5-Cy3 & Cy3-A594 & A488-Cy5 & A594-A488 \\
\hline Cy5-Cy3 & $\mathbf{5 0 *}$ & & & \\
Cy3-A594 & 40 & $\mathbf{5 0}$ & & \\
A488-Cy5 & 25 & 35 & $\mathbf{5 0}$ & \\
A594-A488 & 40 & 40 & 25 & $\mathbf{4 0}$ \\
\hline
\end{tabular}

Table $5 b$

\begin{tabular}{lcccc}
\hline & Cy3-Cy5 & A594-Cy3 & Cy5-A488 & A488-A594 \\
\hline Cy3-Cy5 & $29 *$ & & & \\
A594-Cy3 & 23 & $\mathbf{5 8}$ & & \\
Cy5-A488 & 6 & 10 & 16 & \\
A488-A594 & 26 & 39 & 13 & $\mathbf{7 4}$ \\
\hline
\end{tabular}

Table $5 \mathrm{c}$

\begin{tabular}{lcccc}
\hline & Cy3-A488 & A488-Cy3 & Cy5-A594 & A594-Cy5 \\
\hline Cy3-A488 & $35 *$ & & & \\
A488-Cy3 & 24 & $\mathbf{5 3}$ & & \\
Cy5-A594 & 22 & 33 & 38 & 31 \\
A594-Cy5 & 16 & 20 & 16 & 3 \\
\hline
\end{tabular}

* In bold the intersection of two gene lists indicating the modulated genes for a dye combination as percentage of all modulated genes found by analysis of all dye combinations combined. In italics the intersection of three gene lists indicating the modulated genes for two dye combinations as percentage of all modulated genes found for all dye combinations combined. The first dye was used for $\mathrm{B}[\mathrm{a}] \mathrm{P}$ treatment, the second for the control. 
TABLE 2.6. Performance of a dye combination in revealing modulated genes in $\mathrm{B}[\mathrm{a}] \mathrm{P}$ treated liver slices using an oligonucleotide array.

\begin{tabular}{|c|c|c|c|c|c|c|c|c|}
\hline \multicolumn{3}{|c|}{ dye combination } & \multicolumn{6}{|c|}{$\mathrm{B}[\mathrm{a}] \mathrm{P}$ concentration } \\
\hline exposed & - & control & $3 \mu \mathrm{M}$ & & $10 \mu \mathrm{M}$ & & $30 \mu \mathrm{M}$ & \\
\hline Су5 & - & Су3 & $36^{*}$ & 11 & & & & \\
\hline Су3 & - & Alexa 594 & 64 & & & & & \\
\hline Су3 & - & Су5 & & & 47 & 13 & & \\
\hline Alexa 594 & - & Су3 & & & 48 & & & \\
\hline Сy5 & - & Alexa 594 & & & & & 51 & 8 \\
\hline Alexa 594 & - & Сy5 & & & & & 38 & \\
\hline
\end{tabular}

* In bold the intersection of two gene lists indicating the modulated genes for a dye combination as percentage of all modulated genes (for 3, 10 and $30 \mu \mathrm{M}$ : 121, 97 and 195 genes respectively) found by analysis of all dye combinations combined. In italics the intersection of three gene lists indicating the modulated genes for two dye combinations as percentage of all modulated genes found for all dye combinations combined. The first dye was used for B[a]P treatment, the second for the control.

Additionally, the performance of the dye combinations was evaluated by comparing the gene expression difference. Figure 2.4, which represents the results for the experiment with HepG2 cells on DNA microarrays with the application of four dyes simultaneously, can be used as an example. For each dye combination a similar effect on gene expression is observed and it can be summarized that all dye combinations result in similar gene expression changes. For the rat liver slices similar results were found. 


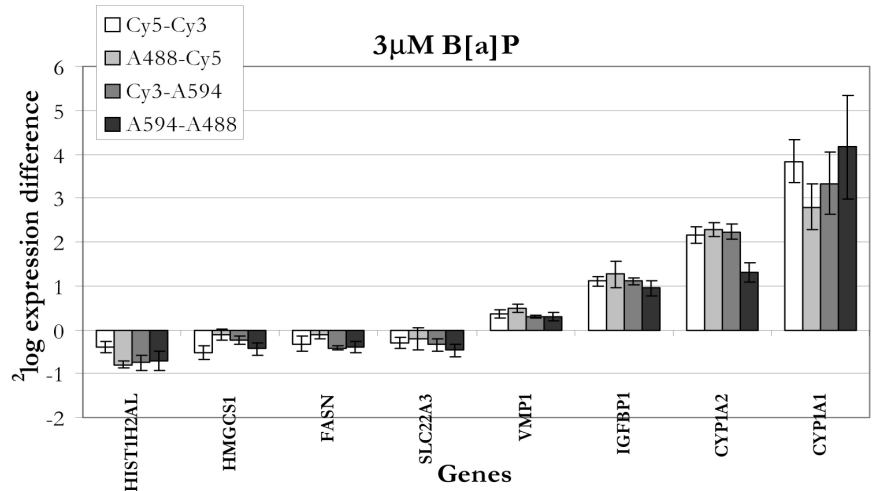

Figure 2.4a

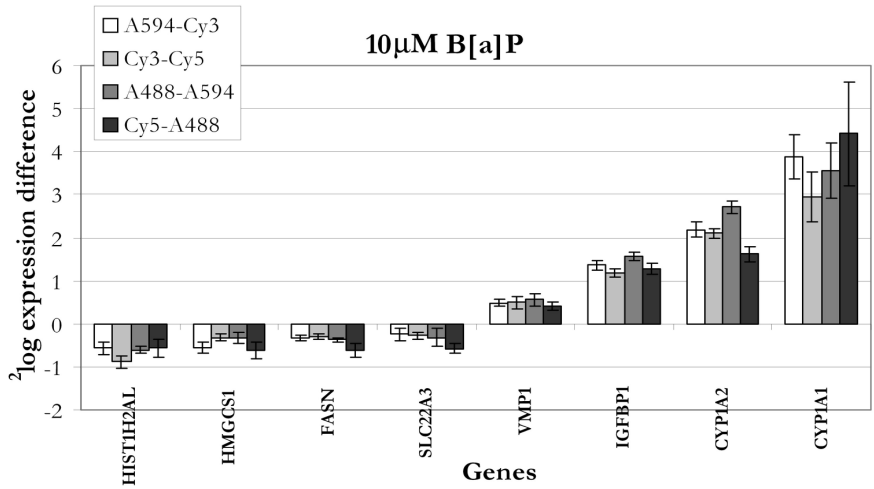

Figure $2.4 \mathrm{~b}$

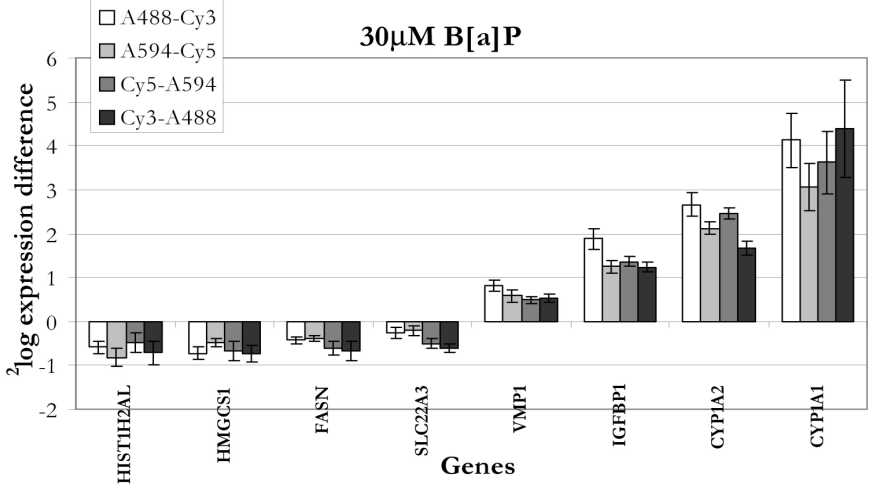

Figure 2.4c

FIGURE 2.4. Gene expression difference for several genes, in varying relative gene expression level of high (FASN and HIST1H2AL), middle (CYP1A2, HMGCS1, VMP1 and IGFBP1) and low (CYP1A1, SLC22A3), as measured by different dye combinations by using four dyes simultaneously on cDNA microarrays in RNA samples from HepG2 cells exposed to 3, 10 or $30 \mu \mathrm{M}$ B [a]P during 6 hours, in respectively Figure 4a, 4b and 4c. . Error bars indicate the standard deviation for the replicate spots. 


\section{DISCUSSION}

We have investigated the applicability of four fluorescent dyes in gene-expression analysis by microarrays. By using more than two dyes in microarray experiments, without lessening the data obtained, costs and time can be decreased as fewer microarrays are needed.

Initially, several dyes were tested for cross-talk on the ScanArrayExpress reader, and ultimately 4 dyes were tested for parallel use in microarray experiments. Today, Cy3 and $\mathrm{Cy} 5$ are the most widely used dyes in microarray experiments and much research has been done on these dyes $(4,8,11,17,18)$, although Alexa 555 and Alexa 647 have been suggested by Cox et al (6). It was our intention to select dyes that could complement Cy3 and Cy5 and we show that Alexa 488 and Alexa 594 are suited for this and can be used for parallel hybridization in microarray experiments. All dyes were applicable on the tested cDNA arrays. On the tested oligonucleotide arrays, however, only three dyes, namely Alexa 594, Cy3 and Cy5, could be used.

\section{Selection of fluorescent dyes}

Based on cross-talk signals, four dyes - Alexa 488, Alexa 594, Cy3 and Cy5 - were found suitable for hybridization on microarrays and some cross-talk did occur for this combination. The highest fluorescence for a dye at settings of another dye was observed for Cy5, namely 13\% cross-talk at the settings for Alexa 594. This cross-talk may influence differential gene expression analyses, especially if the signals for Cy5 and Alexa 594 differ drastically within a spot. Therefore, in order to minimize artificial gene expression differences, scan settings should be optimized such that emission intensities are gross similar (e.g. by assuring that the brightest spots are on the edge of saturation). Furthermore, dye swap design on replicate arrays will reduce the bias resulting from cross-talk, and algorithms can be developed to eliminate this bias.

\section{Dye bias}

Dye bias is the difference in labelling efficiency between different dyes as one dye can be better incorporated than another; this can affect the gene expression data (19-21). When using more than one dye, dye bias may occur and most likely, it is enhances with increasing number of dyes. Dye bias can be reduced by using the indirect amino-allyl labelling instead of direct labelling, but it is not clear whether dye bias is fully eliminated (11). However, dye bias can be eliminated by LOWESS normalization of the data, combined with a labelling and hybridization design in which each target is labelled with each different dye (22). Liang et al (7) showed that the correlation between predicted and observed gene expression ratios increased by adding a second microarray with dye switching. This confirms that accuracy can be improved by adding dye swap replicates and applying a balanced labelling design. A balanced labelling design with 
four dyes may increase the number of required arrays, but still saves the total number of arrays. For example, when 3 treatments and a control are to be compared using 4 data points per comparison, 16 microarrays are needed for a common reference design, 12 arrays for a block design (treatment vs control on an array), 8 when using a loop design, but only 4 with 4 dyes and the design shown in Table 2.4 .

\section{Applicability of selected dyes}

The applicability of the dyes was analyzed in four different ways. First by calculating the correlation coefficients between dyes in self-hybridizations, second by calculating the standard deviation of their log ratio per gene for replicate spots in the selfhybridizations, third by comparing numbers of modulated genes for all dye combinations in samples exposed to $\mathrm{B}[\mathrm{a}] \mathrm{P}$ and finally by comparing gene expression modulation for several genes from samples exposed to B[a]P.

When applied on the cDNA array, all combinations of dyes gave high correlation coefficients $(>0.9)$ and thus seem suitable for parallel hybridization in microarray experiments. On the oligonucleotide array, the correlation coefficients were high for all combinations $(>0.8)$, except for combinations with Alexa $488(\cong 0.5)$. The correlation coefficients for all combinations of dyes on both arrays are constant in multiple repeated hybridizations. These results are supported by the plots for the standard deviation of the replicate spots. For the cDNA array, the standard deviation is equal for all combinations of dyes at high gene expression level. However, for the oligonucleotide array the standard deviation of the signal intensity of high expressed genes for all combinations with Alexa 488 is higher than the standard deviation for all other combinations of dyes. Since the correlation coefficient of Alexa 488 with other dyes is low and the standard deviation for Alexa 488 is high, it is not advisable to use Alexa 488 for labelling and hybridization on the oligonucleotide array.

The correlation coefficients observed for all combinations of Alexa 488 with any other dye on the oligonucleotide array are lower than any of the other correlation coefficients. This was due to a high background signal and a lower signal-to-noise ratio in the Alexa 488 channel, which can not be attributed to autofluorescence. This background signal was much less pronounced on the cDNA array, which may be explained by a different coating of the microarray slides. Alexa dyes have a net negative charge, which may cause non-specific electrostatic interaction with positively charged molecules (23). This may be a reason for why the dye adhered differently to the two different microarray slides. However, this does not explain why the background binding for Alexa 594 is much less in comparison to that of Alexa 488.

For all dyes tested on the oligonucleotide array, many genes showed a low gene expression level compared to the cDNA array. In general, weak signals are detected with lower accuracy than strong ones (24). This is reflected by the higher standard devia- 
tions for lower signals in the plots for the cDNA and oligonucleotide array (Figure 2.3). Lyng et al (24) showed that reliable data for mean signal intensities were only achieved within a range of 200 to 50,000 (no background correction performed). This clarifies the lower correlation coefficients found for the oligonucleotide array compared to the cDNA array.

For all dye combinations, percentages of modulated genes relative to modulated genes for all dye combinations combined are generally equal (Tables 2.5 and 2.6). This indicates that any dye combination has approximately the same sensitivity to identify differentially expressed genes, and that the traditional combination of Cy3-Cy5 is not necessarily preferable above the others. Therefore, we consider all dyes suitable for usage in gene expression studies by microarrays. This was further substantiated by the observation for several differentially expressed genes that the level of modulation is in the same range for all dye combinations.

Although Forster et al (13) used a different approach to test the use of Alexa 594 besides Cy3 and Cy5 in microarray analysis, their conclusions are in agreement with that of this study. Forster et al (13) tested the use of different combinations of two dyes in hybridization, and found some cross-talk between Cy3 and Alexa 594 and between Cy5 and Alexa 594. Although, some cross-talk was observed between Cy5 and Alexa 594 (13\%), only small cross-talk was noticed (<3\%) for Cy3 and Alexa 594 in this study. Forster et al (13) also found a more linear relation between Cy3 and Alexa 594 than for Cy3 and Cy5. However, we noticed only a small difference in correlation coefficient for Cy3 / Cy5 and for Alexa 594 / Cy3 (Table 2.2 and 2.3). These differences could be due to the different testing methods and different arrays used.

\section{CONCLUSIONS}

All our experiments demonstrate that for gene expression analyses on microarrays Alexa 594 is best suited as a third dye in addition to Cy3 and Cy5, and that Alexa 488 can be applied as a fourth dye on some microarray platforms, but unfortunately not on all array platforms. The general applicability of four dyes on other microarray systems is therefore uncertain, and needs to be investigated on a case-by-case basis.

\section{Acknowledgements}

The authors thank Dr. C Ioannides and his colleagues for his help in making and the exposure of the rat liver slices and Ms D. Pushparajah for her help in correcting the English language. The research was carried out in the context of the AMBIPAH project (mechanism-based approaches to improved cancer risk assessment of ambient air polycyclic aromatic hydrocarbons), funded by the European Union (No. QLRT2001-02402). 


\section{REFERENCES}

1. Duggan, D.J., Bittner, M., Chen, Y., Meltzer, P. and Trent, J.M. (1999) Expression profiling using cDNA microarrays. Nat Genet, 21, 10-4.

2. Li, X., Gu, W., Mohan, S. and Baylink, D.J. (2002) DNA microarrays: their use and misuse. Microcirculation, 9, 13-22.

3. Nuwaysir, E.F., Bittner, M., Trent, J., Barrett, J.C. and Afshari, C.A. (1999) Microarrays and toxicology: the advent of toxicogenomics. Mol Carcinog, 24, 153-9.

4. van Hal, N.L.W., Vorst, O., van Houwelingen, A.M., Kok, E.J., Peijnenburg, A., Aharoni, A., van Tunen, A.J. and Keijer, J. (2000) The application of DNA microarrays in gene expression analysis. J Biotechnol, 78, 271-80.

5. Quackenbush, J. (2001) Computational analysis of microarray data. Nat Rev Genet, 2, 418-27.

6. Cox, W.G., Beaudet, M.P., Agnew, J.Y. and Ruth, J.L. (2004) Possible sources of dye-related signal correlation bias in two-color DNA microarray assays. Anal Biochem, 331, 243-54.

7. Liang, M., Briggs, A.G., Rute, E., Greene, A.S. and Cowley, A.W., Jr. (2003) Quantitative assessment of the importance of dye switching and biological replication in cDNA microarray studies. Physiol Genomics, 14, 199-207.

8. Rosenzweig, B.A., Pine, P.S., Domon, O.E., Morris, S.M., Chen, J.J. and Sistare, F.D. (2004) Dye bias correction in dual-labeled cDNA microarray gene expression measurements. Environ Health Perspect, 112, 480-7.

9. Lee, M.L., Kuo, F.C., Whitmore, G.A. and Sklar, J. (2000) Importance of replication in microarray gene expression studies: statistical methods and evidence from repetitive cDNA hybridizations. Proc Natl Acad Sci U S A, 97, 9834-9.

10. Rodi, C.P., Bunch, R.T., Curtiss, S.W., Kier, L.D., Cabonce, M.A., Davila, J.C., Mitchell, M.D., Alden, C.L. and Morris, D.L. (1999) Revolution through genomics in investigative and discovery toxicology. Toxicol Pathol, 27, 107-10.

11. Dobbin, K., Shih, J.H. and Simon, R. (2003) Questions and answers on design of dual-label microarrays for identifying differentially expressed genes. J Natl Cancer Inst, 95, 1362-9.

12. Chen, J.J., Delongchamp, R.R., Tsai, C.A., Hsueh, H.M., Sistare, F., Thompson, K.L., Desai, V.G. and Fuscoe, J.C. (2004) Analysis of variance components in gene expression data. Bioinformatics, 20, 1436-46.

13. Forster, T., Costa, Y., Roy, D., Cooke, H.J. and Maratou, K. (2004) Triple-target microarray experiments: a novel experimental strategy. BMC Genomics, 5, 13.

14. Hessner, M.J., Wang, X., Khan, S., Meyer, L., Schlicht, M., Tackes, J., Datta, M.W., Jacob, H.J. and Ghosh, S. (2003) Use of a three-color cDNA microarray platform to measure and control supportbound probe for improved data quality and reproducibility. Nucleic Acids Res, 31, e60.

15. Hashemi, E., Dobrota, M., Till, C. and Ioannides, C. (1999) Structural and functional integrity of precision-cut liver slices in xenobiotic metabolism: a comparison of the dynamic organ and multiwell plate culture procedures. Xenobiotica, 29, 11-25.

16. van Delft, J.H., van Agen, E., van Breda, S.G., Herwijnen, M.H., Staal, Y.C. and Kleinjans, J.C. (2004) Discrimination of genotoxic from non-genotoxic carcinogens by gene expression profiling. Carcinogenesis, 25, 1265-76.

17. Dobbin, K., Shih, J.H. and Simon, R. (2003) Statistical design of reverse dye microarrays. Bioinformatics, 19, 803-10.

18. Wang, Y., Wang, X., Guo, S.W. and Ghosh, S. (2002) Conditions to ensure competitive hybridization in two-color microarray: a theoretical and experimental analysis. Biotechniques, 32, 1342-6.

19. Dombkowski, A.A., Thibodeau, B.J., Starcevic, S.L. and Novak, R.F. (2004) Gene-specific dye bias in microarray reference designs. FEBS Lett, 560, 120-4. 


\section{CHAPTER 2}

20. Tseng, G.C., Oh, M.K., Rohlin, L., Liao, J.C. and Wong, W.H. (2001) Issues in cDNA microarray analysis: quality filtering, channel normalization, models of variations and assessment of gene effects. Nucleic Acids Res, 29, 2549-57.

21. Yang, Y.H., Dudoit, S., Luu, P., Lin, D.M., Peng, V., Ngai, J. and Speed, T.P. (2002) Normalization for cDNA microarray data: a robust composite method addressing single and multiple slide systematic variation. Nucleic Acids Res, 30, e15.

22. Churchill, G.A. (2002) Fundamentals of experimental design for cDNA microarrays. Nat Genet, 32 Suppl, 490-5.

23. Panchuk-Voloshina, N., Haugland, R.P., Bishop-Stewart, J., Bhalgat, M.K., Millard, P.J., Mao, F. and Leung, W.Y. (1999) Alexa dyes, a series of new fluorescent dyes that yield exceptionally bright, photostable conjugates. J Histochem Cytochem, 47, 1179-88.

24. Lyng, H., Badiee, A., Svendsrud, D.H., Hovig, E., Myklebost, O. and Stokke, T. (2004) Profound influence of microarray scanner characteristics on gene expression ratios: analysis and procedure for correction. BMC Genomics, 5, 10. 
Modulation of gene expression and DNA adduct formation in HepG2 cells by polycyclic aromatic hydrocarbons with different carcinogenic potencies

Published in Carcinogenesis, vol. 27, no. 3, p. 646-55, 2006

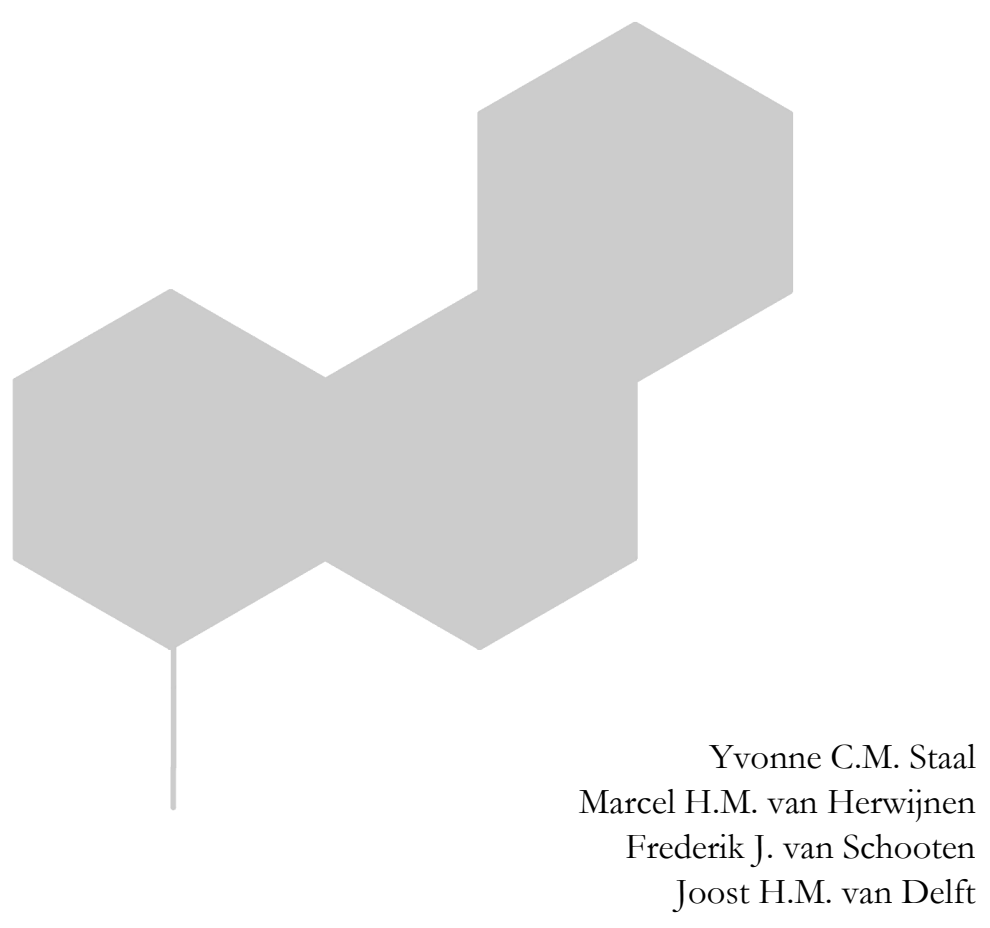




\begin{abstract}
Polycyclic aromatic hydrocarbons (PAHs) can occur in relatively high concentrations in the air, and many PAHs are known or suspected carcinogens. In order to better understand differences in carcinogenic potency between PAHs, we investigated modulation of gene expression in human HepG2 cells after $6 \mathrm{~h}$ incubation with varying doses of benzo[a]pyrene $(\mathrm{B}[\mathrm{a}] \mathrm{P})$, benzo[b]fluoranthene $(\mathrm{B}[\mathrm{b}] \mathrm{F})$, fluoranthene $(\mathrm{FA})$, dibenzo[a,h]anthracene (DB[a,h]A), 1-methylphenanthrene (1-MPA) or dibenzo[a,l]pyrene (DB[a,l]P), by using cDNA microarrays containing 600 toxicologically relevant genes. Furthermore, DNA adduct levels induced by the compounds were assessed with ${ }^{32} \mathrm{P}$ post-labeling, and carcinogenic potency was determined by literature study. All tested PAHs, except 1-MPA, induced gene expression changes in HepG2 cells, although generally no dose-response relationship could be detected. Clustering and principal component analysis showed that gene expression changes were compound specific, since for each compound all concentrations grouped together. Furthermore, it showed that the six PAHs can be divided into 3 groups, firstly FA and 1MPA, secondly $\mathrm{B}[\mathrm{a}] \mathrm{P}, \mathrm{B}[\mathrm{b}] \mathrm{F}$ and $\mathrm{DB}[\mathrm{a}, \mathrm{h}] \mathrm{A}$ and thirdly $\mathrm{DB}[\mathrm{a}, 1] \mathrm{P}$. This grouping corresponds with the carcinogenic potencies of the individual compounds. Many of the modulated genes are involved in biological pathways like apoptosis, cholesterol biosynthesis and fatty acid synthesis. The order of DNA-adduct levels induced by the PAHs was: $\mathrm{B}[\mathrm{a}] \mathrm{P}>>\mathrm{DB}[\mathrm{a}, \mathrm{l}] \mathrm{P}>\mathrm{B}[\mathrm{b}] \mathrm{F}>\mathrm{DB}[\mathrm{a}, \mathrm{h}] \mathrm{A}>1-\mathrm{MPA} \geq \mathrm{FA}$. When comparing the expression change of individual genes with DNA adduct levels, carcinogenic potency or Ah-receptor antagonicity (the last two were taken from literature), several highly correlated genes were found, of which CYP1A1, PRKCA, SLC22A3, NFKB1A, $C Y P 1 A 2$ and CYP2D6 correlated with all parameters. Our data indicate that discrimination of high and low carcinogenic PAHs by gene expression profiling is feasible. Also, the carcinogenic PAHs induce several pathways which were not affected by the least carcinogenic PAHs.
\end{abstract}




\section{INTRODUCTION}

Polycyclic Aromatic Hydrocarbons (PAHs) occur in the environment owing to incomplete combustion of organic fuels and cover a wide range of different compounds. Exposure to some of these compounds is known to cause cancer in mice and is also suspected to be carcinogenic in humans (1-5). Although PAHs have similar structural properties, their carcinogenic potency can differ greatly. Despite that some PAHs occur in low concentrations in the environment, they can substantially contribute to the carcinogenic risk of exposure to environmental PAH mixtures. At the same time, other PAHs that occur in high concentrations in the environment are regarded as noncarcinogenic $(1,2,6,7)$. PAHs can be carcinogenic because of their interaction with DNA and cause mutations in oncogenes or tumor suppressor genes and thereby initiate tumor formation (8).

PAHs are metabolically activated by Cytochrome P450 enzymes or by peroxidases to reactive intermediates that can damage DNA by covalently binding (9). The formation of DNA adducts by PAHs has been shown both in vitro (10) as well as in vivo $(4,11)$. The DNA adduct forming potency differs between the compounds (8) and has been shown to correlate with carcinogenic potency (12). Ross et al (11) suggested that timeintegrated DNA adduct levels are a better predictor for carcinogenicity of PAHs than DNA adduct levels at a certain time point.

Some PAHs are known to activate the Aromatic hydrocarbon receptor (Ah-receptor) (13-15) and thereby upregulate the expression and activity of several biotransformation enzymes, including CYP1A1 and CYP1A2 (16-18). The ability to bind to the Ahreceptor has been suggested to reflect tumor promoting activity of PAHs (19). Changes in the expression of genes regulated downstream of Ah receptor binding, could be considered representative for the tumor promoting potency of a PAH. The ability to bind to the Ah-receptor and induce CYP1A1 and CYP1A2 also affects the DNA binding potency of these compounds, and has been suggested to determine the genotoxicity of PAHs (20).

The Toxic Equivalency Factor (TEF) approach is mostly used to compare the carcinogenicity of PAHs. The TEF estimates the toxicity of a compound, relative to another compound, in case of PAHs mostly to benzo[a]pyrene $(\mathrm{B}[\mathrm{a}] \mathrm{P})$. Although based on limited information and multiple endpoints in cancer development (21,22), several authors have estimated a TEF for PAHs (23,24). Another ranking for carcinogenicity of PAHs is developed by Collins et al (25), who estimated a Potency Equivalency Factor (PEF) for PAHs relative to $\mathrm{B}[\mathrm{a}] \mathrm{P}$ and based these factors on bioassay data. According to the authors, $\mathrm{PEF}$ is an estimation of the carcinogenic activity rather than a true carcinogenic potency. 
For a better understanding of the differences in carcinogenic potency between PAHs and ultimately to improve carcinogenic risk assessment of PAHs, more knowledge is required about the biological and cellular effects induced by these compounds. To our opinion, information about alterations in gene expression following exposure of cells to a PAH, might be highly valuable for risk assessment. By gene expression profiling using DNA microarray technologies, early biological changes induced by a compound on a cellular system can be investigated. Indeed this technology has proven to yield mechanistic information about the mode-of-action of the compounds $(26,27)$. Furthermore, different classes of carcinogens can be discriminated from each other at gene expression level, as they induce different gene expression patterns $(28,29)$.

The aim of the current study was to investigate the changes in gene expression patterns in response to several PAHs which may help further understand the mechanism of carcinogenesis of these compounds. Therefore, we exposed human hepatoma cells (HepG2) to six PAHs selected on their diverge environmental occurrence and their range in carcinogenic potency. These were benzo[a]pyrene $(\mathrm{B}[\mathrm{a}] \mathrm{P})$, benzo[b]fluoranthene $(\mathrm{B}[\mathrm{b}] \mathrm{F})$, fluoranthene $(\mathrm{FA})$, dibenzo[a,h]anthracene $(\mathrm{DB}[\mathrm{a}, \mathrm{h}] \mathrm{A})$, dibenzo[a,l]pyrene $(\mathrm{DB}[\mathrm{a}, \mathrm{l}] \mathrm{P})$ and 1-methylphenanthrene (1-MPA). HepG2 cells are metabolic competent, which is important for the metabolic activation of PAHs $(30,31)$ and the cells express similar biotransformation enzymes as human liver (32,33). These cells are a suitable model for human liver and are useful to study regulation of drugmetabolizing enzymes on gene level (34). Cells were exposed to different concentrations of the PAHs and the effects at gene expression were studied in relation to their carcinogenic, DNA binding and Ah-receptor binding potencies.

\section{MATERIALS AND METHODS}

\section{Chemicals}

Benzo[a]pyrene (B[a]P, purity 97\%, CAS no. 50-32-8), benzo[b]fluoranthene $(\mathrm{B}[\mathrm{b}] \mathrm{F}$, purity 98\%, CAS no. 205-99-2), fluoranthene (FA, purity 99\%, CAS no. 206-44-0), dibenzo[a,h]anthracene(DB[a,h]A, purity 97\%, CAS no. 53-70-3) and dibenzo[a,l]pyrene (DB[a,l]P, purity 99.6\%, CAS no. 191-30-0) were obtained from Sigma-Aldich (Zwijndrecht, the Netherlands). 1-Methylphenanthrene (1-MPA, purity 99\%, CAS no. 832-69-9) was obtained from LGC Promchem (Teddington, United Kingdom). All chemicals were dissolved in DMSO.

\section{Cell culture and treatment}

HepG2 cells were cultured in Minimal Essential Medium (MEM) supplemented with $1 \%$ non-essential amino acids, 1\% sodium-pyruvate, 2\% penicillin/streptomycin and 10\% Foetal Bovine Serum (all from Gibco/BRL, Breda, The Netherlands) in T25 
culture flasks at $37^{\circ} \mathrm{C}$ and $5 \% \mathrm{CO}_{2}$. One day before treatment, cell cultures at $70-80 \%$ confluency were harvested and cells were undiluted divided among new culture flasks, in order to obtain a homogeneous cell population for each treatment. The next day, the medium was replaced with fresh medium containing 3,10 or $30 \mu \mathrm{M}$ of a PAH or a vehicle control (DMSO, 0.1\%). The cells were exposed during $6 \mathrm{~h}$, and two independent experiments were conducted. After exposure, media was removed and $1 \mathrm{ml}$ Trizol (Gibco/BRL, Breda, The Netherlands) was immediately added to the cells.

\section{RNA isolation and cDNA synthesis}

RNA was isolated from the Trizol solutions according to the producer's manual and purified with the RNeasy mini kit (Qiagen Westburg bv., Leusden, The Netherlands). RNA quantity was measured on a spectrophotometer and quality was determined on a BioAnalyzer (Agilent Technologies, Breda, The Netherlands). Only RNA samples which showed clear $18 \mathrm{~S}$ and $28 \mathrm{~S}$ peaks were used for labeling and hybridization.

Every RNA sample was reverse transcribed into cDNA in quadruplicate with aminoallyl labeled dUTP (Sigma-Aldrich, St Louis, USA) and subsequently labeled with one of the four dyes, namely Cy3, Cy5, Alexa 488 and Alexa 594. Four instead of two dyes were applied, in order to reduce the variation (four related samples are on one array instead of three) and the number of arrays (as described by Staal et al (35)).

\section{Microarray hybridizations}

Targets were hybridized on the Human-600 Microarray (PHASE-1 Molecular Toxicology, Santa Fe, USA), containing 597 sequence verified cDNA clones from human genes, representing a number of toxicologically relevant, as well as control, genes, each printed in quadruplicate. On every array, four samples were simultaneously hybridized, each with a different fluorophore. Hybridization and washing was done according to the producers' manual as previously described (35). The hybridization design is shown in Table 3.1.

TABLE 3.1. Labeling and hybridization of RNA from cells exposed to the shown PAH concentration.

\begin{tabular}{lcccc}
\hline & \multicolumn{3}{c}{ Dye } \\
\cline { 2 - 5 } Array no. & Cyanine 3 & Cyanine5 & Alexa 594 & Alexa 488 \\
\hline $\mathbf{1}$ & $10 \mu \mathrm{M}$ & $0 \mu \mathrm{M}$ & $30 \mu \mathrm{M}$ & $3 \mu \mathrm{M}$ \\
$\mathbf{2}$ & $3 \mu \mathrm{M}$ & $30 \mu \mathrm{M}$ & $0 \mu \mathrm{M}$ & $10 \mu \mathrm{M}$ \\
\hline
\end{tabular}




\section{Microarray data analysis and data mining}

The microarray slides were scanned on a ScanArrayExpress (Perkin Elmer life sciences, Boston, USA). All four channels were scanned at 100\% laser power and adjusted photo multiplier tube (PMT) gain, such that the signal of the highest fluorescent spots is just below the maximum measurable level. The images $(10$ micron resolution; 16 bit tiff) were processed with ImaGene 5.0 software (Biodiscovery Inc., Los Angeles, USA) to quantify spot signals. Abnormal spots were manually and automatically flagged and not included in the data analysis.

Data from ImaGene were transported to GeneSight software version 4.1.5 (Biodiscovery Inc, Los Angeles, USA) for transformations, normalizations and analyses. For each spot, background was subtracted; flagged spots and spots with a net expression level < 5 were omitted. Data were log (base 2) transformed and expression difference between exposed and control were calculated. Data normalization was done by LOWESS. Data of replicate spots were combined while omitting outliers ( $>2$ SD). Samples from each biological replicate were hybridized twice, thereby providing four hybridizations per PAH concentration (two biological replicates with for each replicate two technical replicates). Significantly modulated genes were found by a t-test between gene expression differences of each PAH concentration compared (four replicates) to selfhybridizations (four replicates) of the control samples labeled with the same dyes at $\mathrm{p}<0.05$. A Holm's correction of the $\mathrm{p}$-values was used to reduce false positives in these multiple tests.

Pathway analysis was done by the use of GenMAPP version 2.0 beta (Gladstone Institutes, University of California, San Fransisco, USA) and local maps from GenMAPP (human std 20040614). For each compound all modulated genes were included in the analysis. Pathways, with a Z-score $>2.0$ and $>1$ modulated gene, were assumed to be affected by the PAH.

\section{DNA adduct analysis}

After removal of the aqueous phase during RNA isolation using Trizol, the remaining phases were used for DNA isolation according to manufacturer's protocol. DNA adduct levels were determined according to the procedure originally described by Reddy and Randerath (36) with modifications described by Godschalk et al (37). By including samples with known DNA adduct levels (1 adduct per $10^{6}, 10^{7}$ or $10^{8} \mathrm{nt}$ ), DNA adduct levels were quantified (detection limit 1 adduct $10^{8} \mathrm{nt}$ ).

Adduct spots on the chromatograms were located and quantified using a phosphor imager (FLA-3000, Fuji, Paris, France) and AIDA/2D densometry software. 


\section{Correlation analysis}

For correlation with carcinogenic potency, we used TEF values proposed by Nisbet and LaGoy (23), for B[a]P, B[b]F, FA and DB[a,h]A. We complemented these with the PEF values proposed by Collins et al (25) for DB[a,1]P, and estimated a TEF for 1MPA based on IARC data $(1,2)$ according to the method proposed by Nisbet and LaGoy (23). The resulting TEF values were; 1.0 for $\mathrm{B}[\mathrm{a}] \mathrm{P}, 0.1$ for $\mathrm{B}[\mathrm{b}] \mathrm{F}, 0.001$ for $\mathrm{FA}$ and 1-MPA, 5.0 for DB[a,h]A and 10 for DB[a,l]P. For correlation with Ah-receptor antagonicity, IEF values determined by Machala et al (13) were used. We used the values after 6 hours exposure and calculated the values relative to $\mathrm{B}[\mathrm{a}] \mathrm{P}$. They were 1 for $\mathrm{B}[\mathrm{a}] \mathrm{P}, 0.37$ for $\mathrm{B}[\mathrm{b}] \mathrm{F}, 0$ for $\mathrm{FA}, 12.99$ for $\mathrm{DB}[\mathrm{a}, \mathrm{h}] \mathrm{A}$ and 0.05 for $\mathrm{DB}[\mathrm{a}, 1] \mathrm{P}$.

After $\log$ (base 2) transformation, DNA adduct levels, TEF and IEF were correlated with the expression changes of genes differentially expressed by at least one concentration of one compound. Since after log transformation, DNA adduct formation, TEF and IEF were normal distributed (according to the Kolmogorov-Smirnov test in SPSS, $\mathrm{p}<0.05)$, Pearson correlation coefficients of gene expression were calculated using SPSS for windows 11.5 (SPSS Inc., Chicago, USA).

\section{RESULTS}

\section{Gene expression modulation}

All PAHs, except 1-MPA, induced statistical significant gene expression changes. Figure 3.1 shows for each compound expression changes of the genes which were significantly modulated by that compound at least one concentration. Several genes were modulated by many compounds, for example CYP1A1, CYP1A2, VMP1, IGFBP1 and HIST1H2AL. B[a]P modulated the highest number of genes, namely 36, $\mathrm{B}[\mathrm{b}] \mathrm{F}, \mathrm{DB}[\mathrm{a}, \mathrm{h}] \mathrm{A}, \mathrm{DB}[\mathrm{a}, 1] \mathrm{P}$ and FA modulated 18, 31, 16 and 3 genes respectively. For most genes and compounds, no dose dependent effect on gene expression is observed. Only for DB[a,l]P a dose-response relation could be seen for most genes. Names, abbreviations, GenBank accession numbers and gene expression differences of the 62 modulated genes are listed in Table 3.2. Additional data files are available at http://fdgwgratsrv0401.unimaas.nl/data. 

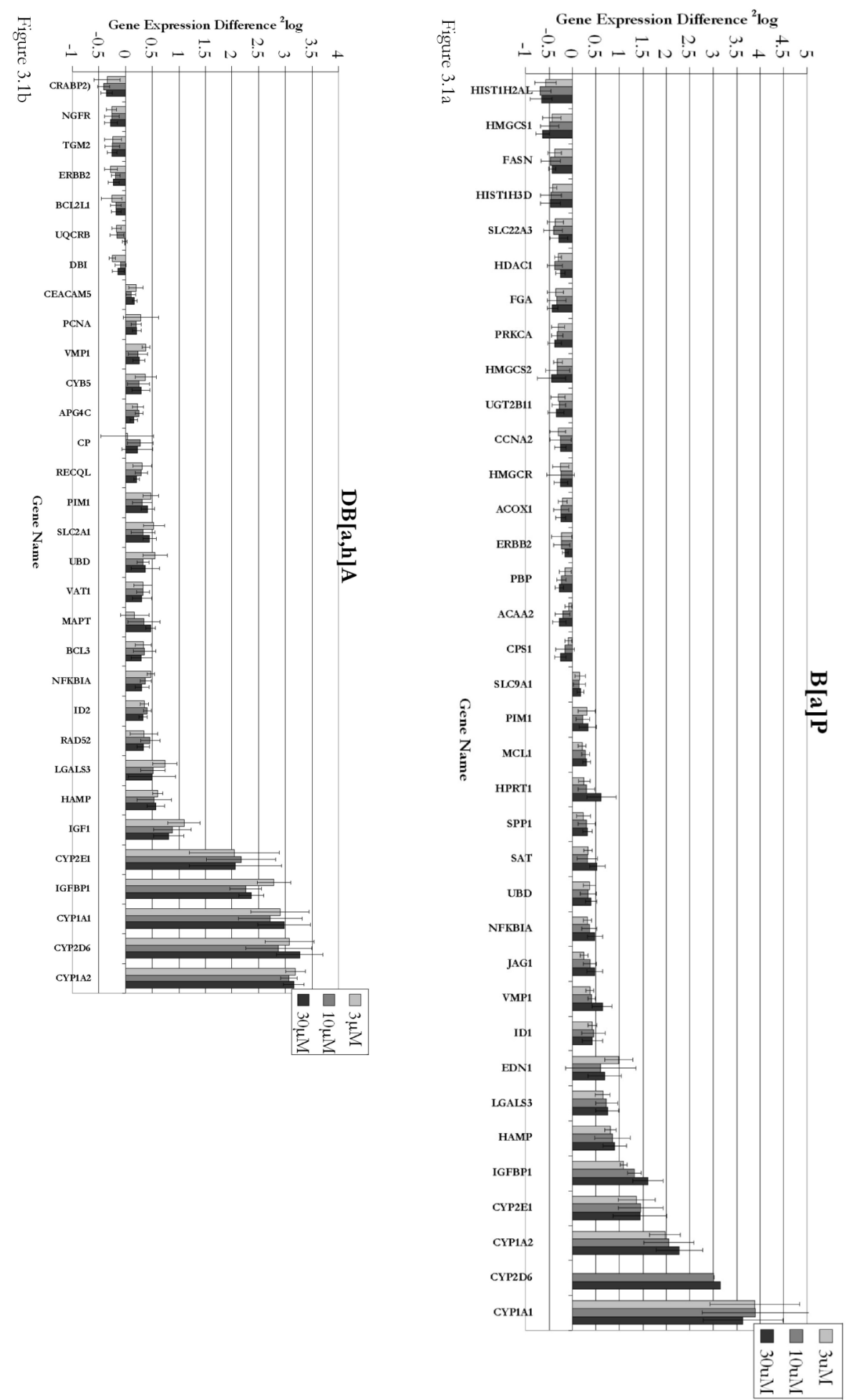


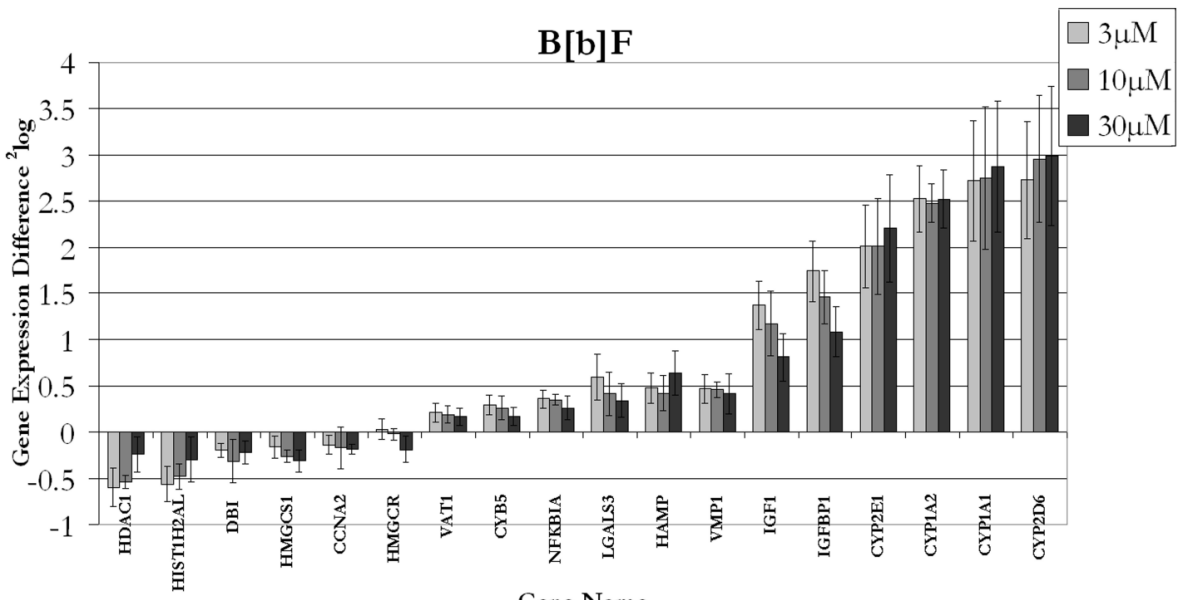

Figure 3.1c

Gene Name

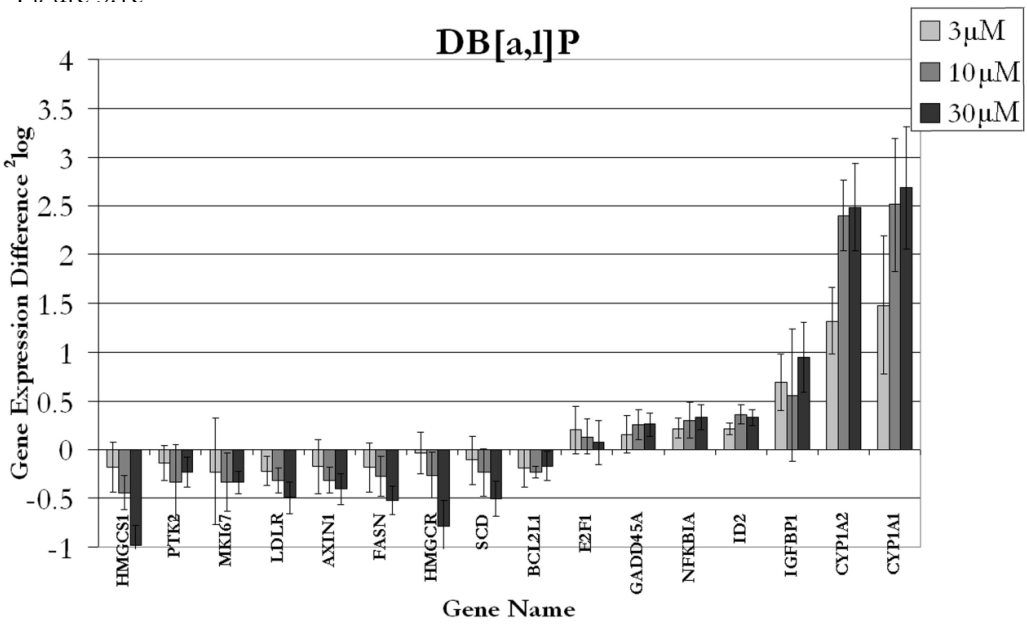

Figure 3.1d

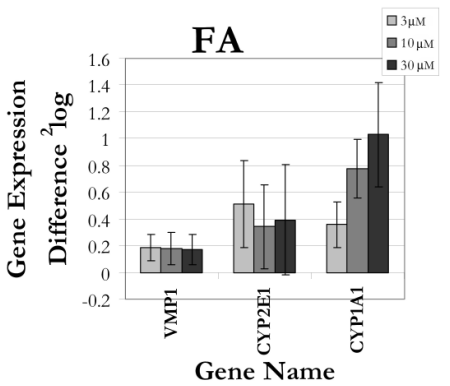

Figure 3.1e

FIGURE 3.1. Genes significantly modulated by a PAH for at least one of the concentrations of B[a]P (a), $\mathrm{DB}[\mathrm{a}, \mathrm{h}] \mathrm{A}$ (b), B[b]F (c), DB[a,l]P (d) and FA (e). Significant modulations (compared with selfhybridizations) are indicated with an asterix. Standard deviation is indicated as error bars. 


\section{CHAPTER 3}

TABLE 3.2. List of modulated genes, their abbreviations, full names and GenBank accession numbers Columns 3-7 show the significant gene expression changes and standard deviation for the corresponding compound, with its concentration in superscript.

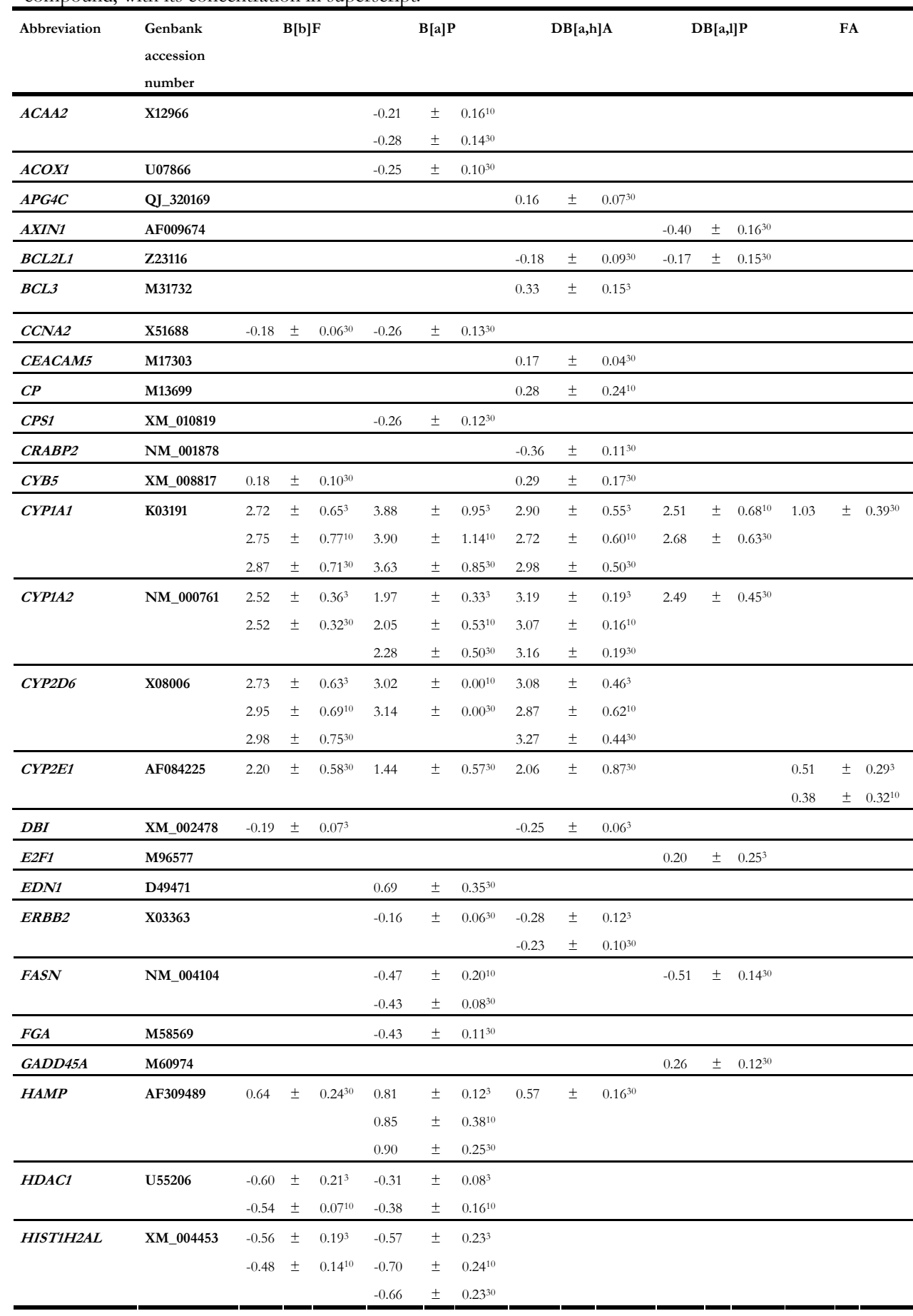




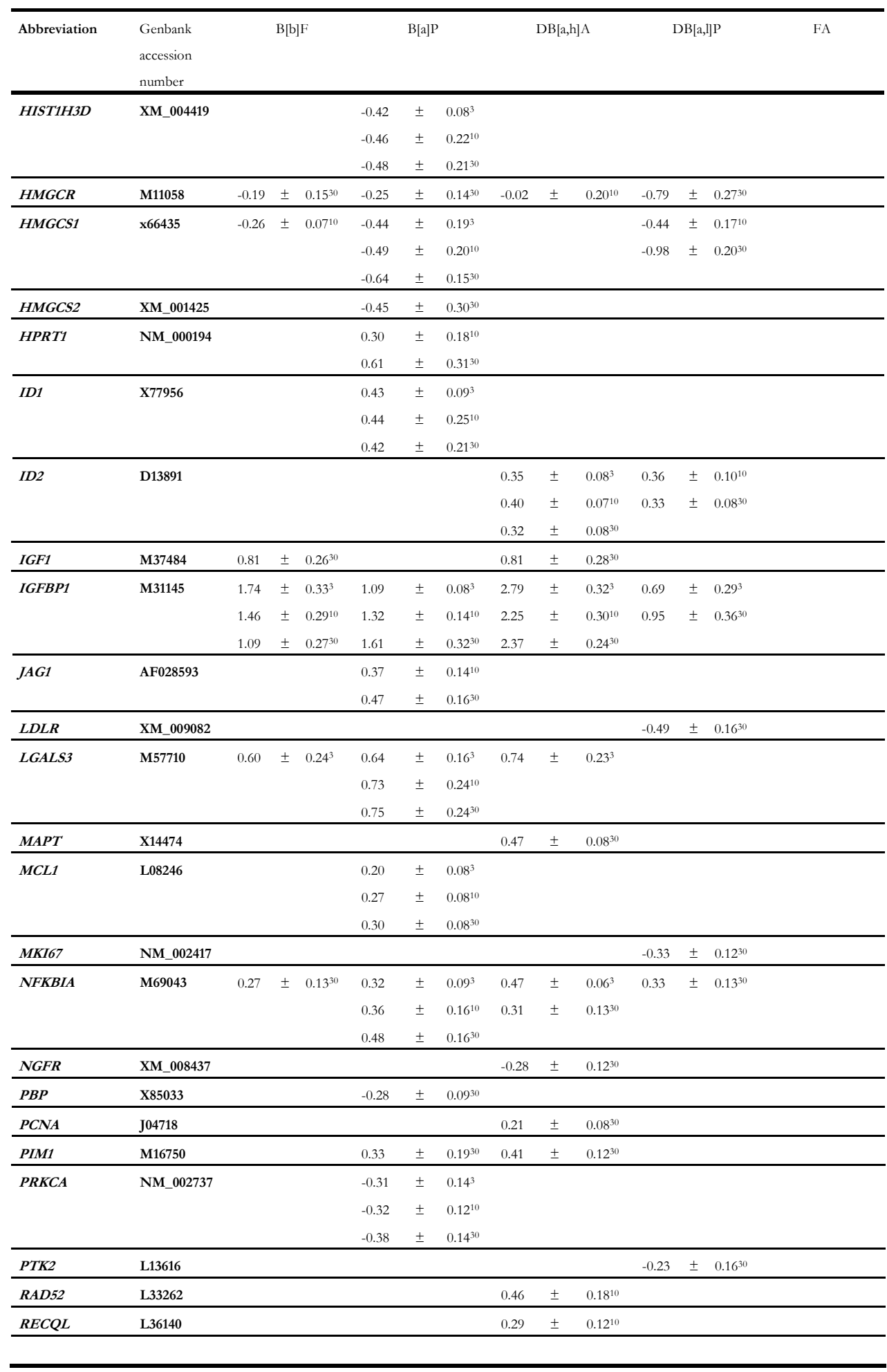




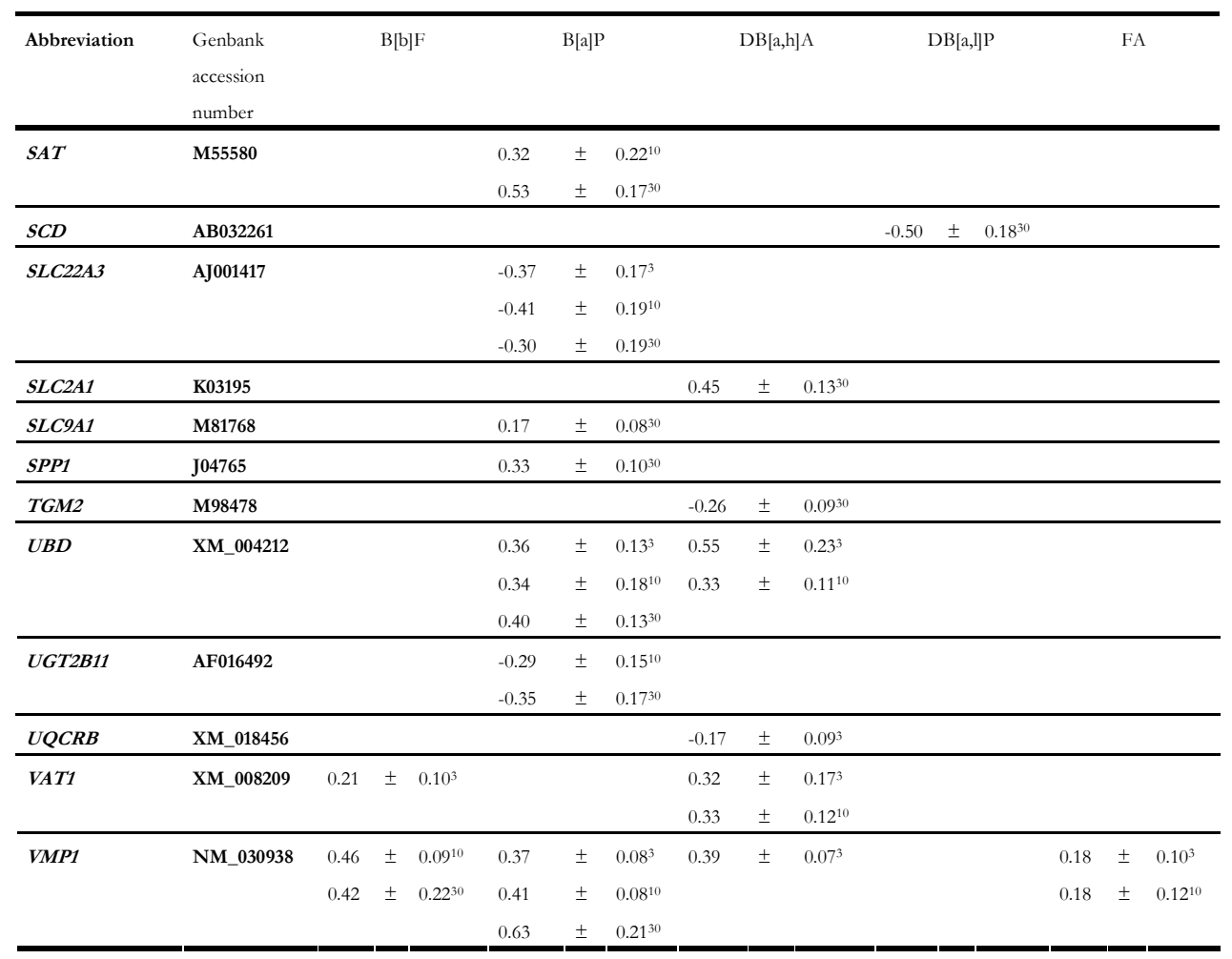

Hierarchical clustering of the PAH treatments, using the 62 genes that were modulated by at least one treatment is shown in Figure 3.2. The data shows that for each compound all concentrations induce similar responses, since for each compound the three concentrations are close together on the dendrogram. This indicates that compoundspecific gene expression profiles are induced. Also, differences and similarities between the compounds on gene expression patterns can be observed. FA and 1-MPA, which affect only a small number of genes, induce similar gene expression changes as they group closely together. Furthermore $\mathrm{B}[\mathrm{a}] \mathrm{P}, \mathrm{B}[\mathrm{b}] \mathrm{F}$ and $\mathrm{DB}[\mathrm{a}, \mathrm{h}] \mathrm{A}$ induce gross similar gene expression changes. $\mathrm{DB}[\mathrm{a}, 1] \mathrm{P}$ is found to have a different gene expression profile compared to the other compounds, but higher in the dendrogram, it groups with $\mathrm{B}[\mathrm{a}] \mathrm{P}, \mathrm{B}[\mathrm{b}] \mathrm{F}$ and $\mathrm{DB}[\mathrm{a}, \mathrm{h}] \mathrm{A}$ and not with FA and 1-MPA. This figure also shows the dendrograms for the genes. Most noteworthy is that all induced cytochrome P450 genes (CYP1A1, CYP1A2, CYP2D6 and CYP2E1) and IGFBP1 respond similar to all treatments and different from all other genes.

Differences in treatment related responses are also visualized by principal component analysis (Figure 3.3). Comparable to clustering data, this again shows that for each $\mathrm{PAH}$ the three dose levels are close together implying similar response on gene level. It also shows discrimination of the PAHs indicating the presence of PAH-specific gene expression profiles. 


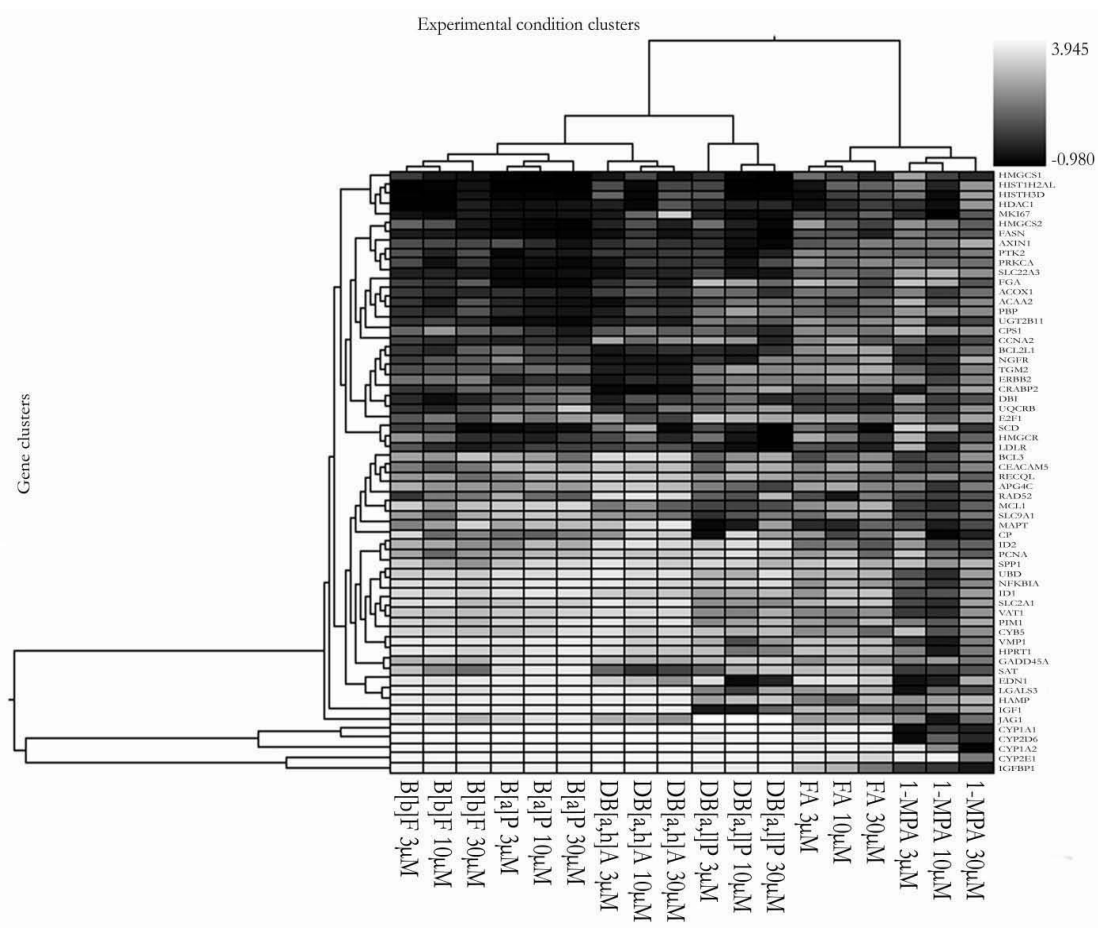

FIGURE 3.2. Hierarchical clustering of PAH treatments and genes, using the 62 that were significantly modulated by at least one of the treatments (see Table 3.2). Clustering with average cluster linkage and Euclidean distance metric was used.

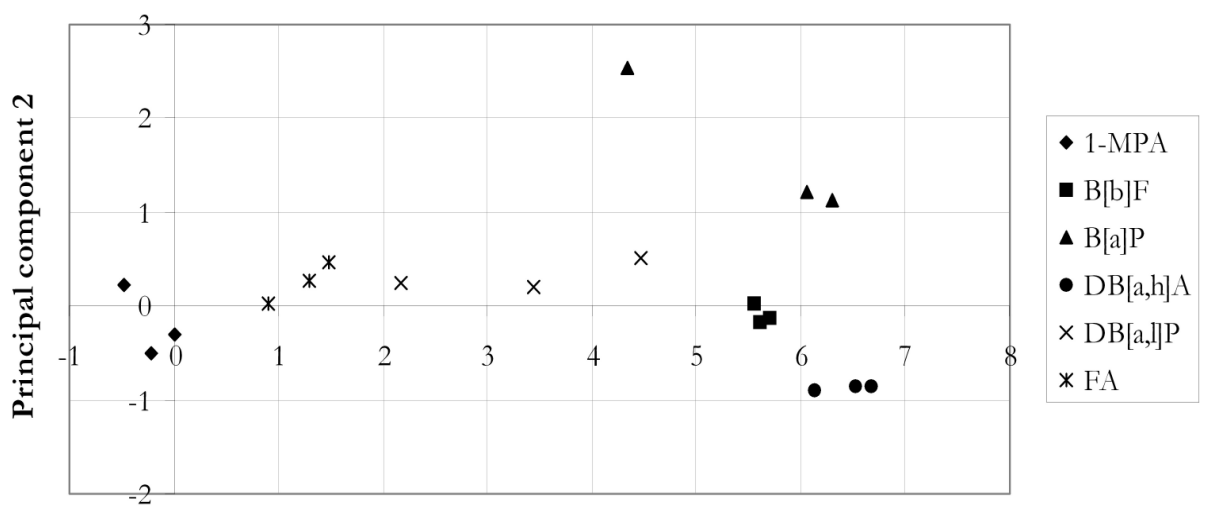

\section{Principal component 1}

FIGURE 3.3. Principal component analysis of all PAH treatments using the 62 genes that were significantly modulated by at least one of the treatments (see Table 3.2). 


\section{Pathway analysis}

Pathway analysis by GenMAPP of the significantly modulated genes per compound revealed several affected pathways for most compounds. An overview is shown in Table 3.3. Modulation of gene expressions suggest that apoptosis was induced by $\mathrm{DB}[\mathrm{a}, 1] \mathrm{P}$ and $\mathrm{DB}[\mathrm{a}, \mathrm{h}] \mathrm{A}$, cholesterol biosynthesis was inhibited by $\mathrm{B}[\mathrm{a}] \mathrm{P}$ and $\mathrm{B}[\mathrm{b}] \mathrm{F}$ and fatty acid synthesis was inhibited by B[a]P and DB[a,l]P. Furthermore some other pathways appear affected by one of the six compounds.

TABLE 3.3. Affected pathways in response to PAH treatment as revealed by analysis with GenMAPP.

\begin{tabular}{|c|c|c|c|c|c|c|}
\hline & $\mathbf{B}[\mathrm{a}] \mathbf{P}$ & $\mathrm{B}[\mathrm{b}] \mathrm{F}$ & $\mathrm{DB}[\mathrm{a}, \mathrm{h}] \mathrm{A}$ & $\mathrm{DB}[\mathrm{a}, 1] \mathrm{P}$ & FA & 1-MPA \\
\hline Apoptosis & & & $\uparrow$ & $\uparrow$ & & \\
\hline Cholesterol Biosynthesis & $\downarrow$ & $\downarrow$ & & & & \\
\hline Fatty acid biosynthesis path 2 & $\downarrow$ & & & & & \\
\hline Fatty Acid Synthesis & $\downarrow$ & & & $\downarrow$ & & \\
\hline G Protein Signaling & ? & & & & & \\
\hline Nucleotide Metabolism & $\uparrow$ & & & & & \\
\hline Wnt signaling & & & & $\downarrow$ & & \\
\hline
\end{tabular}

Induction of the pathway is indicated with an arrow pointing upwards $(\uparrow)$, inhibition with an arrow pointing downwards $(\downarrow)$ and unknown with an question mark (?). Blank cells mean that for that PAH the pathway was not significantly affected.

\section{DNA adduct formation}

DNA adduct levels were measured by ${ }^{32} \mathrm{P}$-postlabeling in the same samples as used for gene expression profiling. Results are summarized in Table 3.4. B[a]P exposure results in the highest number of DNA adducts (up to 1.9 adducts per $10^{5}$ nucleotides), and that FA and 1-MPA DNA adduct levels were not detected (detection limit 1 adduct per $10^{8}$ nucleotides). No dose-response relations could be detected.

TABLE 3.4. DNA adduct levels in HepG2 cells exposed to PAHs.

\begin{tabular}{llllllll}
\hline & $\mathbf{B}[\mathbf{a}] \mathbf{P}$ & $\mathbf{B}[\mathbf{b}] \mathbf{F}$ & $\mathbf{D B}[\mathbf{a}, \mathbf{h}] \mathbf{A}$ & $\mathbf{D B}[\mathbf{a}, \mathbf{l}] \mathbf{P}$ & $\mathbf{F A}$ & 1-MPA & blank \\
\hline $\mathbf{3} \boldsymbol{\mu} \mathbf{M}$ & $1857 \pm 780^{*}$ & $131 \pm 28$ & $30 \pm 19$ & $203 \pm 184$ & $0 \pm 0$ & $2 \pm 1$ & \\
$\mathbf{1 0} \boldsymbol{\mu M}$ & $839 \pm 280$ & $100 \pm 50$ & $36 \pm 31$ & $576 \pm 181$ & $0 \pm 0$ & $3 \pm 3$ & $3 \pm 0$ \\
$\mathbf{3 0} \boldsymbol{\mu M}$ & $1238 \pm 112$ & $85 \pm 38$ & $34 \pm 27$ & $336 \pm 209$ & $1 \pm 1$ & $4 \pm 0$ & \\
\hline
\end{tabular}

* Number of DNA adducts per $10^{8}$ nt $($ Mean \pm SD) 


\section{Correlation studies}

DNA adduct levels for all compounds and all concentrations were correlated with the expression changes of all 62 modulated genes. Significant correlations coefficients with an $\mathrm{R}^{2}>0.4$ are shown in Table 3.5. The expression of several genes showed significant correlation with DNA adduct levels, for instance, that of CYP1A1 $(\mathrm{R}=0.818$, $\mathrm{p}<0.001)$.

TABLE 3.5. Pearson correlation analysis of gene expression changes and DNA adduct levels for all tested PAHs and doses.

\begin{tabular}{lcc}
\hline Gene & Pearson Correlation & p-value \\
\hline CYP1A1 & 0.818 & $<0.001$ \\
$\boldsymbol{P R K C A}$ & -0.762 & $<0.001$ \\
SLC22A3 & -0.761 & $<0.001$ \\
$\boldsymbol{P}$ TK2 & -0.746 & $<0.001$ \\
GADD45A & 0.719 & $<0.001$ \\
NFKBIA & 0.690 & $<0.001$ \\
$\boldsymbol{C Y P 1 A 2}$ & 0.655 & $<0.001$ \\
HAMP & 0.653 & $<0.001$ \\
HIST1H2A & -0.650 & $<0.001$ \\
$\boldsymbol{C Y P 2 D 6}$ & 0.670 & $<0.001$ \\
JAG1 & 0.658 & $<0.001$ \\
\hline
\end{tabular}

All $\log$ (base 2) transformed data. Only significantly correlating genes are shown with an $\mathrm{R}^{2}>0.4$.

Expression changes of significantly modulated genes were also correlated with a parameter for carcinogenic potency, TEF, and for Ah-receptor binding potency, IEF. Both parameters are based on literature data (see materials and methods). Since for every compound we hardly observed dose-response relations in gene expression changes, the same TEF and IEF value was used for all concentrations. Significant correlation coefficients with $\mathrm{R}^{2}$ above 0.4 are shown in Tables 3.6 and 3.7. CYP1A1, PRKCA, SLC22A3, NFKB1A, CYP1A2 and CYP2D6 appeared to correlate with all parameters, and several other genes correlated with one or two parameters. 


\section{CHAPTER 3}

TABLE 3.6. Pearson correlation analysis of gene expression changes and TEF for all tested PAHs and doses.

\begin{tabular}{|c|c|c|}
\hline Gene & Pearson Correlation & p-value \\
\hline CYP1A2 & 0.846 & $<0.001$ \\
\hline ID2 & 0.844 & $<0.001$ \\
\hline NFKBIA & 0.821 & $<0.001$ \\
\hline$A X I N 1$ & -0.802 & $<0.001$ \\
\hline CYP1A1 & 0.790 & $<0.001$ \\
\hline$S L C 22 A 3$ & -0.783 & $<0.001$ \\
\hline PTK2 & -0.752 & $<0.001$ \\
\hline CYP2E1 & 0.744 & $<0.001$ \\
\hline$I G F 1$ & 0.734 & 0.001 \\
\hline$B C L 2 L 1$ & -0.727 & 0.001 \\
\hline PRKCA & -0.718 & 0.001 \\
\hline FASN & -0.699 & 0.001 \\
\hline$U B D$ & 0.694 & 0.001 \\
\hline CYB5 & 0.677 & 0.002 \\
\hline CPS1 & -0.669 & 0.002 \\
\hline$G A D D 45 A$ & 0.657 & 0.003 \\
\hline CYP2DG & 0.670 & 0.003 \\
\hline PCNA & 0.646 & 0.004 \\
\hline$V A T 1$ & 0.634 & 0.005 \\
\hline
\end{tabular}

All $\log$ (base 2) transformed data. Only significantly correlating genes are shown with an $\mathrm{R}^{2}>0.4$ 
TABLE 3.7. Pearson correlation analysis of gene expression changes and IEF for all tested PAHs and doses.

\begin{tabular}{|c|c|c|}
\hline Gene & Pearson Correlation & p-value \\
\hline CYP1A2 & 0.925 & $<0.001$ \\
\hline IGF1 & 0.921 & $<0.001$ \\
\hline CYP2E1 & 0.886 & $<0.001$ \\
\hline$C Y B 5$ & 0.877 & $<0.001$ \\
\hline NFKBIA & 0.871 & $<0.001$ \\
\hline$V A T 1$ & 0.865 & $<0.001$ \\
\hline CYP2D6 & 0.869 & $<0.001$ \\
\hline$T G M 2$ & -0.836 & $<0.001$ \\
\hline CYP1A1 & 0.836 & $<0.001$ \\
\hline$E R B B 2$ & -0.822 & $<0.001$ \\
\hline PIM1 & 0.810 & $<0.001$ \\
\hline$U Q C R B$ & -0.806 & $<0.001$ \\
\hline HAMP & 0.785 & 0.001 \\
\hline$B C L 2 L 1$ & -0.784 & 0.001 \\
\hline$U B D$ & 0.776 & 0.001 \\
\hline$B C L 3$ & 0.774 & 0.001 \\
\hline MAPT & 0.742 & 0.002 \\
\hline$S L C 22 A 3$ & -0.739 & 0.002 \\
\hline$L G A L S 3$ & 0.724 & 0.002 \\
\hline PRKCA & -0.705 & 0.003 \\
\hline$N G F R$ & -0.701 & 0.004 \\
\hline ACAA2 & -0.698 & 0.004 \\
\hline$I G F B P 1$ & 0.673 & 0.006 \\
\hline RAD52 & 0.668 & 0.006 \\
\hline
\end{tabular}

All $\log$ (base 2) transformed data. Only significantly correlating genes are shown with an $\mathrm{R}^{2}>0.4$.

\section{DISCUSSION}

\section{Differential gene expression}

As modulation of gene expression in human liver cells, i.e. HepG2 cells, and might reveal a toxic outcome (38), we studied this after exposure of the cells to several PAHs, and related gene expression differences to parameters for genotoxicity, carcinogenic potency and Ah-receptor binding potency. Based on a diverse carcinogenicity and abundance in the air, we used B[a]P, B[b]F, FA, DB[a,l]P, DB[a,h]P and 1-MPA to study the effects on gene expression in HepG2 cells.

All tested PAHs, except 1-MPA, were able to modulate gene expression at concentrations up to $30 \mu \mathrm{M}$. However, a clear dose-response was not observed. Only DB[a,l]P 
showed a dose-response relation in gene expression difference for many genes. This indicates that in general a maximum induction was already achieved at the lowest concentration. The fact that also DNA adducts show no clear dose-response relations, suggests that saturation of metabolism of the PAH compounds is responsible for the absence of dose-response effects on gene expression. However, Bláha et al (39) did not find a maximum induction level in the CALUX assay at similar concentrations we tested. Also, in liver and lung slices a dose response was seen up to $80 \mu \mathrm{M}$ (40). The difference with our results could be due to a different cell system.

Of all 600 genes on the microarray, 62 genes were found modulated by one or more compounds. Principal component and hierarchical clustering analysis using these 62 genes, show that for each compound the response on gene expression profiles is grossly independent of the concentration, as all concentrations of a single compound are grouped closely together. This indicates that each compound induces a unique gene expression profile in HepG2 cells. Moreover, in the hierarchical clustering at the next higher level, the compounds are grouped into carcinogenic $(\mathrm{B}[\mathrm{a}] \mathrm{P}, \mathrm{B}[\mathrm{b}] \mathrm{F}, \mathrm{DB}[\mathrm{a}, \mathrm{h}] \mathrm{A}$ and $\mathrm{DB}[\mathrm{a}, 1] \mathrm{P})$ and non-carcinogenic (FA and 1-MPA). Furthermore, the most carcinogenic $\mathrm{PAH}(\mathrm{DB}[\mathrm{a}, 1] \mathrm{P})$ is separated from the less carcinogenic compounds $(\mathrm{B}[\mathrm{a}] \mathrm{P}$, $\mathrm{B}[\mathrm{b}] \mathrm{F}$ and $\mathrm{DB}[\mathrm{a}, \mathrm{h}] \mathrm{A})$. Taken into account that we examined only 6 PAHs, our results suggest the possibility to discriminate carcinogenic from non-carcinogenic PAHs, based on gene expression profiles.

\section{Pathway analysis}

Pathway analysis by GenMAPP revealed that several pathways appeared to be affected by the PAHs (Table 3.3). According to the modulated gene expression, apoptosis was induced by $\mathrm{DB}[\mathrm{a}, \mathrm{h}] \mathrm{A}$ and $\mathrm{DB}[\mathrm{a}, 1] \mathrm{P}$. We did not find induction of the apoptotic pathway in our experiments by $\mathrm{B}[\mathrm{a}] \mathrm{P}$, although $\mathrm{B}[\mathrm{a}] \mathrm{P}$, and several other $\mathrm{PAHs}$, have been shown to induce apoptosis in in vitro cell systems $(20,41,42)$. This could be due to the relative short exposure time of 6 hours.

Modulated gene expression suggests an inhibition of cholesterol synthesis by B[a]P and $\mathrm{B}[\mathrm{b}] \mathrm{F}$. It has been shown that the cholesterol content and the cholesterol biosynthesis are elevated in proliferating normal tissue and in tumors (43), and are suggested to be an indicator for neoplasmatic growth (44). Since decreased cholesterol synthesis has been shown to inhibit cell growth (43), our results suggest a cell growth reduction by $\mathrm{B}[\mathrm{a}] \mathrm{P}$ and $\mathrm{B}[\mathrm{b}] \mathrm{F}$ in HepG2 cells which may allow the cell to recover from damage by PAHs. However, it is unclear whether PAHs indeed affect cholesterol synthesis.

Exposure to $\mathrm{B}[\mathrm{a}] \mathrm{P}$ or $\mathrm{DB}[\mathrm{a}, 1] \mathrm{P}$ leads to an inhibition of genes involved in fatty acid synthesis. It has been reported that tumorigenic tissue expresses a higher level of Fatty Acid Synthase (FAS) than normal tissue $(45,46)$. Also, it has been shown that inhibition of FAS will result in apoptosis in human cancer cells $(46,47)$. This would suggest that 
$\mathrm{B}[\mathrm{a}] \mathrm{P}$ and $\mathrm{DB}[\mathrm{a}, 1] \mathrm{P}$ induce a protective response by inhibition of fatty acid synthesis. In literature we did not find a relation between PAH exposure and fatty acid synthesis pathway. However, Iwano et al (48), previously studied the effect of 3methylcholanthrene on the expression of several genes in HepG2 cells, and found a down-regulation of FASN and SCD. These enzymes are involved in fatty acid synthesis and are also downregulated in our study.

Furthermore, the Wnt signaling pathway was down regulated in response to DB[a,l]P. Genes involved in Wnt signaling (APC, $\beta$-catenin and $A X I N)$ are often mutated in human cancers $(49,50)$. As down-regulation of $A X I N$ by $\mathrm{DB}[\mathrm{a}, 1] \mathrm{P}$ is involved in this pathway, and as $A X I N$ is a tumor suppressor gene (49), this would suggest a tumorigenic potency of DB[a,l]P. However, no data on the influence of PAHs on the Wnt signaling pathway is known from literature.

The two pathways affected by B[a]P, G protein signaling and nucleotide metabolism, could not be related to carcinogenicity based on literature data.

Taken together, the affected pathways are generally involved in defense mechanisms which protect against cancer. An up-regulation of apoptosis would eliminate damaged cells, and by inhibiting the cell cycle and cholesterol biosynthesis, the damage due to the PAHs could be repaired. Other pathways, like fatty acid synthesis would suggest a less neoplastic phenotype of the cells after exposure to PAHs, which could be a defense mechanism of the cell against carcinogenic compounds.

$\mathrm{DB}[\mathrm{a}, \mathrm{h}] \mathrm{A}$ and $\mathrm{DB}[\mathrm{a}, \mathrm{l}] \mathrm{P}$ are the most carcinogenic of all tested compounds, and both are also the only two which induce apoptosis. This suggests that induction of apoptosis is related to high carcinogenic potency. Other affected pathways do not seem to relate with carcinogenicity of the PAHs. As FA and 1-MPA modulate only a few or no gene significantly, they affect no biological pathways.

\section{DNA adduct formation}

PAHs have been shown to form DNA adduct adducts in several tissues, including skin, lung and liver $(10,40,51,52)$. The order of DNA adduct levels induced by the PAHs in HepG2 cells is $\mathrm{B}[\mathrm{a}] \mathrm{P}>>\mathrm{DB}[\mathrm{a}, 1] \mathrm{P}>\mathrm{B}[\mathrm{b}] \mathrm{F}>\mathrm{DB}[\mathrm{a}, \mathrm{h}] \mathrm{A}>1-\mathrm{MPA} \geq \mathrm{FA}$. This differs from the order found in several other studies, namely $\mathrm{DB}[\mathrm{a}, \mathrm{h}] \mathrm{P}>\mathrm{DB}[\mathrm{a}, \mathrm{h}] \mathrm{A}>$ $\mathrm{B}[\mathrm{a}] \mathrm{P}>\mathrm{B}[\mathrm{b}] \mathrm{F}(10,40,51,52)$. This difference could be due to the difference in tissue (lung versus liver), in model system (in vivo versus in vitro), in species (rat or mouse versus human), or exposure time. However, Topinka et al (10) also found that in rat hepatocytes $\mathrm{B}[\mathrm{a}] \mathrm{P}$ induced higher DNA adduct levels than $\mathrm{B}[\mathrm{b}] \mathrm{F}$, and Segerback and Vodicka (52) found the same order of DNA adduct levels as we did, for B[a]P, B[b]F, $\mathrm{DB}[\mathrm{a}, \mathrm{h}] \mathrm{A}$ and FA in DNA directly exposed to the PAHs in the presence of rat S9-mix. 


\section{Correlation studies}

We correlated the 62 genes that were modulated by at least one concentration of one compound with DNA adduct formation, TEF and IEF and found that several genes gave a high correlation coefficient. Some genes correlated with all three parameters tested, namely CYP1A1, PRKCA, SLC22A3, NFKB1A, CYP1A2 and CYP2D6. Although these genes might be used for qualitative carcinogenic risk assessment of PAHs, they are not specific for either one of the parameters. The other correlating genes might be important for a single biological function or effect, like DNA adduct levels or Ah-receptor antagonicity. Sjorgen et al (19) related several parameters, for example Ah-receptor binding, EROD assay data, Ames test data and carcinogenicity of PAHs and found that the affinity of PAHs to bind to the Ah-receptor correlates with carcinogenic potency of the compounds.

As expected, we found significant correlation between IEF and the gene expression of the modulated cytochome P450 enzymes. These enzymes are also involved in the metabolism of PAHs and they are known to be induced via the Ah-receptor following exposure to PAHs $(14,18)$. Also, we found a correlation between DNA adduct formation and expression of GADD45, which can be explained by the DNA damage induced by the PAHs. Pathway analysis of the significantly correlating genes revealed only pathways involved in metabolism, which is probably due to the highly correlating cytochrome P450 enzymes.

\section{CONCLUSION}

Our data indicate that qualitative cancer risk prediction of $\mathrm{PAH}$ by gene expression profiling is feasible, i.e. the discrimination of carcinogenic PAH from non-carcinogenic PAH. This may help in the characterization of risks of other PAHs for which carcinogenic potency is unknown. Additionally, some genes appeared to correlate with all three carcinogenic parameters, indicating a relationship between the expression of these genes and carcinogenicity of PAHs.

\section{Acknowledgements}

The research was carried out as part of the AMBIPAH project (mechanism-based approaches to improved cancer risk assessment of ambient air polycyclic aromatic hydrocarbons), funded by the European Union (No. QLRT-2001-02402). 


\section{REFERENCES}

1. IARC (1983) Polynuclear aromatic compounds, Part 1, Chemical, environmental and experimental data. IARC Monogr Eval Carcinog Risk Chem Hum, 32, 1-453.

2. IARC (1973) Certain polycyclic aromatic hydrocarbons and heterocyclic compounds. IARC Monogr Eval Carcinog Risk Chem Hum, 3, 1-271.

3. Wang, J.S. and Busby, W.F., Jr. (1993) Induction of lung and liver tumors by fluoranthene in a preweanling CD-1 mouse bioassay. Carcinogenesis, 14, 1871-4.

4. Nesnow, S., Mass, M.J., Ross, J.A., Galati, A.J., Lambert, G.R., Gennings, C., Carter, W.H., Jr. and Stoner, G.D. (1998) Lung tumorigenic interactions in strain A/J mice of five environmental polycyclic aromatic hydrocarbons. Environ Health Perspect, 106 Suppl 6, 1337-46.

5. Boffetta, P., Jourenkova, N. and Gustavsson, P. (1997) Cancer risk from occupational and environmental exposure to polycyclic aromatic hydrocarbons. Cancer Causes Control, 8, 444-72.

6. Ciganek, M., Neca, J., Adamec, V., Janosek, J. and Machala, M. (2004) A combined chemical and bioassay analysis of traffic-emitted polycyclic aromatic hydrocarbons. Sci Total Environ, 334-335, 141 8 .

7. Kuo, C.Y., Cheng, Y.W., Chen, C.Y. and Lee, H. (1998) Correlation between the amounts of polycyclic aromatic hydrocarbons and mutagenicity of airborne particulate samples from Taichung City, Taiwan. Environ Res, 78, 43-9.

8. Cavalieri, E.L. and Rogan, E.G. (1995) Central role of radical cations in metabolic activation of polycyclic aromatic hydrocarbons. Xenobiotica, 25, 677-88.

9. Melendez-Colon, V.J., Luch, A., Seidel, A. and Baird, W.M. (1999) Cancer initiation by polycyclic aromatic hydrocarbons results from formation of stable DNA adducts rather than apurinic sites. Carcinogenesis, 20, 1885-91.

10. Topinka, J., Schwarz, L.R., Kiefer, F., Wiebel, F.J., Gajdos, O., Vidova, P., Dobias, L., Fried, M., Sram, R.J. and Wolff, T. (1998) DNA adduct formation in mammalian cell cultures by polycyclic aromatic hydrocarbons $(\mathrm{PAH})$ and nitro-PAH in coke oven emission extract. Mutat Res, 419, 91-105.

11. Ross, J.A., Nelson, G.B., Wilson, K.H., Rabinowitz, J.R., Galati, A., Stoner, G.D., Nesnow, S. and Mass, M.J. (1995) Adenomas induced by polycyclic aromatic hydrocarbons in strain A/J mouse lung correlate with time-integrated DNA adduct levels. Cancer Res, 55, 1039-44.

12. Brookes, P. and Lawley, P.D. (1964) Evidence for the Binding of Polynuclear Aromatic Hydrocarbons to the Nucleic Acids of Mouse Skin: Relation between Carcinogenic Power of Hydrocarbons and Their Binding to Deoxyribonucleic Acid. Nature, 202, 781-4.

13. Machala, M., Vondracek, J., Blaha, L., Ciganek, M. and Neca, J.V. (2001) Aryl hydrocarbon receptormediated activity of mutagenic polycyclic aromatic hydrocarbons determined using in vitro reporter gene assay. Mutat Res, 497, 49-62.

14. Jones, J.M. and Anderson, J.W. (1999) Relative potencies of PAHs and PCBs based on the response of human cells. Environ Toxicol Pharmacol, 7, 19-26.

15. Tsuchiya, Y., Nakajima, M., Itoh, S., Iwanari, M. and Yokoi, T. (2003) Expression of aryl hydrocarbon receptor repressor in normal human tissues and inducibility by polycyclic aromatic hydrocarbons in human tumor-derived cell lines. Toxicol Sci, 72, 253-9.

16. Chaloupka, K., Steinberg, M., Santostefano, M., Rodriguez, L.V., Goldstein, L. and Safe, S. (1995) Induction of Cyp1a-1 and Cyp1a-2 gene expression by a reconstituted mixture of polynuclear aromatic hydrocarbons in B6C3F1 mice. Chem Biol Interact, 96, 207-21.

17. Shimada, T. and Fujii-Kuriyama, Y. (2004) Metabolic activation of polycyclic aromatic hydrocarbons to carcinogens by cytochromes P450 1A1 and 1B1. Cancer Sci, 95, 1-6.

18. Shimada, T., Inoue, K., Suzuki, Y., Kawai, T., Azuma, E., Nakajima, T., Shindo, M., Kurose, K., Sugie, A., Yamagishi, Y., Fujii-Kuriyama, Y. and Hashimoto, M. (2002) Arylhydrocarbon receptor-dependent 
induction of liver and lung cytochromes P450 1A1, 1A2, and 1B1 by polycyclic aromatic hydrocarbons and polychlorinated biphenyls in genetically engineered C57BL/6J mice. Carcinogenesis, 23, 1199-207.

19. Sjogren, M., Ehrenberg, L. and Rannug, U. (1996) Relevance of different biological assays in assessing initiating and promoting properties of polycyclic aromatic hydrocarbons with respect to carcinogenic potency. Mutat Res, 358, 97-112.

20. Solhaug, A., Refsnes, M., Lag, M., Schwarze, P.E., Husoy, T. and Holme, J.A. (2004) Polycyclic aromatic hydrocarbons induce both apoptotic and anti-apoptotic signals in Hepa1c1c7 cells. Carcinogenesis, 25, 809-19.

21. Delistraty, D. (1997) Toxic equivalency factor approach for risk assessment of polycyclic aromatic hydrocarbons. Toxicol Environ Chem, 64, 81-108.

22. Reeves, W.R., Barhoumi, R., Burghardt, R.C., Lemke, S.L., Mayura, K., McDonald, T.J., Phillips, T.D. and Donnelly, K.C. (2001) Evaluation of methods for predicting the toxicity of polycyclic aromatic hydrocarbon mixtures. Environ Sci Technol, 35, 1630-6.

23. Nisbet, I.C. and LaGoy, P.K. (1992) Toxic equivalency factors (TEFs) for polycyclic aromatic hydrocarbons (PAHs). Regul Toxicol Pharmacol, 16, 290-300.

24. Bostrom, C.E., Gerde, P., Hanberg, A., Jernstrom, B., Johansson, C., Kyrklund, T., Rannug, A., Tornqvist, M., Victorin, K. and Westerholm, R. (2002) Cancer risk assessment, indicators, and guidelines for polycyclic aromatic hydrocarbons in the ambient air. Environ Health Perspect, 110 Suppl 3, 451-88.

25. Collins, J.F., Brown, J.P., Alexeeff, G.V. and Salmon, A.G. (1998) Potency equivalency factors for some polycyclic aromatic hydrocarbons and polycyclic aromatic hydrocarbon derivatives. Regul Toxicol Pharmacol, 28, 45-54.

26. de Longueville, F., Atienzar, F.A., Marcq, L., Dufrane, S., Evrard, S., Wouters, L., Leroux, F., Bertholet, V., Gerin, B., Whomsley, R., Arnould, T., Remacle, J. and Canning, M. (2003) Use of a lowdensity microarray for studying gene expression patterns induced by hepatotoxicants on primary cultures of rat hepatocytes. Toxicol Sci, 75, 378-92.

27. Guerreiro, N., Staedtler, F., Grenet, O., Kehren, J. and Chibout, S.D. (2003) Toxicogenomics in drug development. Toxicol Pathol, 31, 471-9.

28. Hu, T., Gibson, D.P., Carr, G.J., Torontali, S.M., Tiesman, J.P., Chaney, J.G. and Aardema, M.J. (2004) Identification of a gene expression profile that discriminates indirect-acting genotoxins from direct-acting genotoxins. Mutat Res, 549, 5-27.

29. van Delft, J.H.M.., van Agen, E., van Breda, S.G.J., Herwijnen, M..H..M., Staal, Y.C.M. and Kleinjans, J.C. (2004) Discrimination of genotoxic from non-genotoxic carcinogens by gene expression profiling. Carcinogenesis, 25, 1265-76.

30. Lehr, R.E. and Jerina, D.M. (1977) Metabolic activations of polycyclic hydrocarbons. Structure-activity relationships. Arch Toxicol, 39, 1-6.

31. Vaca, C., Tornqvist, M., Rannug, U., Lindahl-Kiessling, K., Ahnstrom, G. and Ehrenberg, L. (1992) On the bioactivation and genotoxic action of fluoranthene. Arch Toxicol, 66, 538-45.

32. Knasmuller, S., Parzefall, W., Sanyal, R., Ecker, S., Schwab, C., Uhl, M., Mersch-Sundermann, V., Williamson, G., Hietsch, G., Langer, T., Darroudi, F. and Natarajan, A.T. (1998) Use of metabolically competent human hepatoma cells for the detection of mutagens and antimutagens. Mutat Res, 402, 185-202.

33. Natarajan, A.T. and Darroudi, F. (1991) Use of human hepatoma cells for in vitro metabolic activation of chemical mutagens/carcinogens. Mutagenesis, 6, 399-403.

34. Wilkening, S., Stahl, F. and Bader, A. (2003) Comparison of primary human hepatocytes and hepatoma cell line Hepg2 with regard to their biotransformation properties. Drug Metab Dispos, 31, 103542.

35. Staal, Y.C.M., van Herwijnen, M.H.M., van Schooten, F.J. and van Delft, J.H.M. (2005) Application of four dyes in gene expression analyses by microarrays. BMC Genomics, 6 . 
36. Reddy, M.V. and Randerath, K. (1986) Nuclease P1-mediated enhancement of sensitivity of 32Ppostlabeling test for structurally diverse DNA adducts. Carcinogenesis, 7, 1543-51.

37. Godschalk, R.W., Maas, L.M., Van Zandwijk, N., van 't Veer, L.J., Breedijk, A., Borm, P.J., Verhaert, J., Kleinjans, J.C. and van Schooten, F.J. (1998) Differences in aromatic-DNA adduct levels between alveolar macrophages and subpopulations of white blood cells from smokers. Carcinogenesis, 19, 81925.

38. Burczynski, M.E., McMillian, M., Ciervo, J., Li, L., Parker, J.B., Dunn, R.T., 2nd, Hicken, S., Farr, S. and Johnson, M.D. (2000) Toxicogenomics-based discrimination of toxic mechanism in HepG2 human hepatoma cells. Toxicol Sci, 58, 399-415.

39. Blaha, L., Kapplova, P., Vondracek, J., Upham, B. and Machala, M. (2002) Inhibition of gap-junctional intercellular communication by environmentally occurring polycyclic aromatic hydrocarbons. Toxicol Sci, 65, 43-51.

40. Harrigan, J.A., Vezina, C.M., McGarrigle, B.P., Ersing, N., Box, H.C., Maccubbin, A.E. and Olson, J.R. (2003) DNA Adduct Formation in Precision-Cut Rat Liver and Lung Slices Exposed to Benzo(a)pyrene. Toxicol Sci.

41. Chen, S., Nguyen, N., Tamura, K., Karin, M. and Tukey, R.H. (2003) The role of the Ah receptor and p38 in benzo[a]pyrene-7,8-dihydrodiol and benzo[a]pyrene-7,8-dihydrodiol-9,10-epoxide-induced apoptosis. J Biol Chem, 278, 19526-33.

42. Pliskova, M., Vondracek, J., Vojtesek, B., Kozubik, A. and Machala, M. (2004) Deregulation of Cell Proliferation by Polycyclic Aromatic Hydrocarbons in Human Breast Carcinoma MCF-7 Cells Reflects Both Genotoxic and Nongenotoxic Events. Toxicol Sci.

43. Rao, K.N. (1995) The significance of the cholesterol biosynthetic pathway in cell growth and carcinogenesis (review). Anticancer Res, 15, 309-14.

44. Venturini, I., Amedei, R., Modonesi, G., Cosenza, R., Miglioli, L., Cioni, G. and Zeneroli, M.L. (1999) May plasma cholesterol level be considered a neoplastic marker in liver disease from cirrhosis to hepatocellular carcinoma? Ital J Gastroenterol Hepatol, 31, 61-5.

45. Pizer, E.S., Jackisch, C., Wood, F.D., Pasternack, G.R., Davidson, N.E. and Kuhajda, F.P. (1996) Inhibition of fatty acid synthesis induces programmed cell death in human breast cancer cells. Cancer Res, 56, 2745-7.

46. Kuhajda, F.P. (2000) Fatty-acid synthase and human cancer: new perspectives on its role in tumor biology. Nutrition, 16, 202-8.

47. Zhou, W., Simpson, P.J., McFadden, J.M., Townsend, C.A., Medghalchi, S.M., Vadlamudi, A., Pinn, M.L., Ronnett, G.V. and Kuhajda, F.P. (2003) Fatty acid synthase inhibition triggers apoptosis during $\mathrm{S}$ phase in human cancer cells. Cancer Res, 63, 7330-7.

48. Iwano, S., Nukaya, M., Saito, T., Asanuma, F. and Kamataki, T. (2005) A possible mechanism for atherosclerosis induced by polycyclic aromatic hydrocarbons. Biochem Biophys Res Commun, 335, $220-6$.

49. Kikuchi, A. (2003) Tumor formation by genetic mutations in the components of the Wnt signaling pathway. Cancer Sci, 94, 225-9.

50. Giles, R.H., van Es, J.H. and Clevers, H. (2003) Caught up in a Wnt storm: Wnt signaling in cancer. Biochim Biophys Acta, 1653, 1-24.

51. Arif, J.M., Smith, W.A. and Gupta, R.C. (1999) DNA adduct formation and persistence in rat tissues following exposure to the mammary carcinogen dibenzo[a,l]pyrene. Carcinogenesis, 20, 1147-50.

52. Segerback, D. and Vodicka, P. (1993) Recoveries of DNA adducts of polycyclic aromatic hydrocarbons in the 32P-postlabelling assay. Carcinogenesis, 14, 2463-9. 



\section{4}

Modulation of gene expression and DNA-adduct formation in precision-cut liver slices exposed to polycyclic aromatic hydrocarbons of different carcinogenic potency

Published in Mutagenesis, vol. 22 ,p55-62, 2007

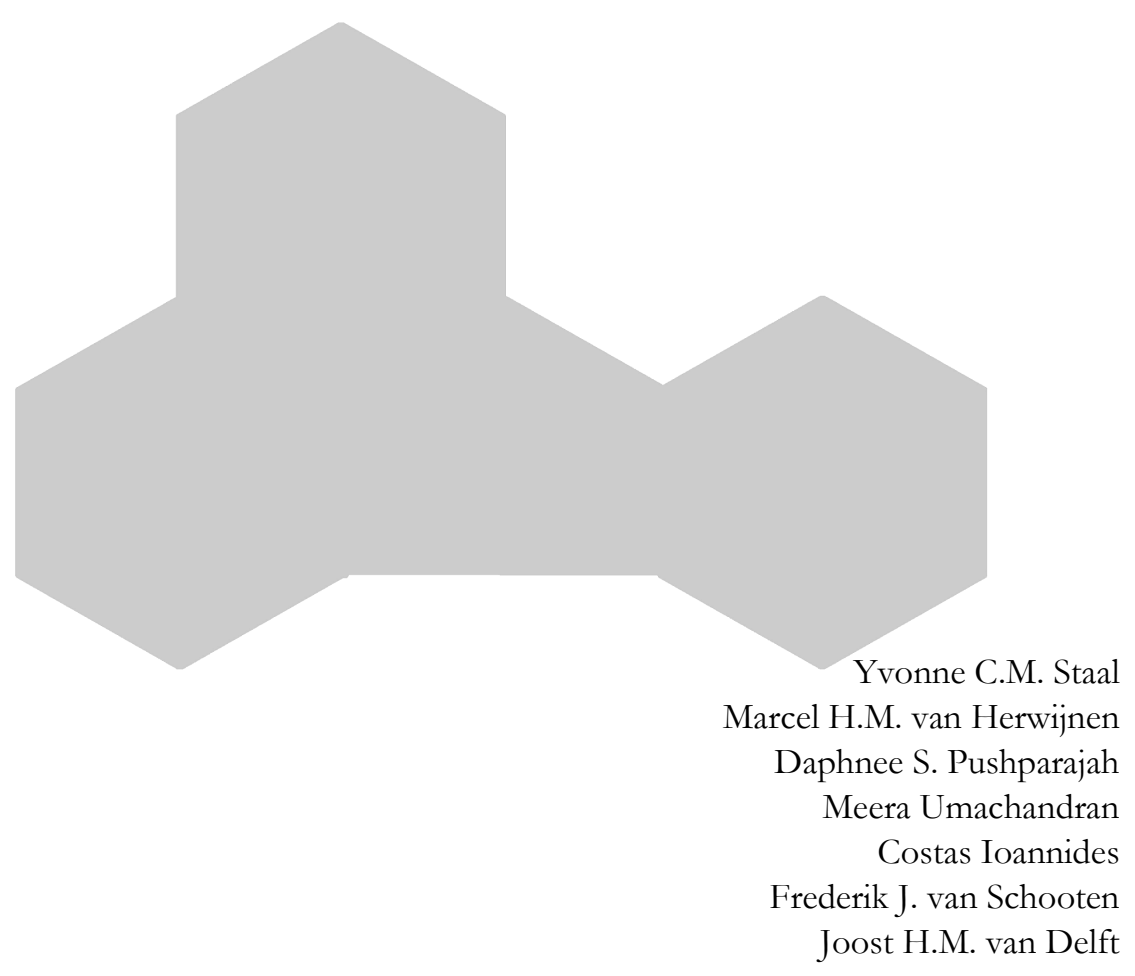




\begin{abstract}
Polycyclic aromatic hydrocarbons (PAHs) differ markedly in their carcinogenic potencies. Differences in transcriptomic responses upon PAH exposures might improve our current understanding of the differences in carcinogenicity, and therefore gene expression modulation by six PAHs in precision-cut rat liver slices was investigated. Gene expression modulation of benzo[a]pyrene $(\mathrm{B}[\mathrm{a}] \mathrm{P})$, dibenzo[a,1]pyrene (DB[a,1]P), benzo[b]fluoranthene $(\mathrm{B}[\mathrm{b}] \mathrm{F})$, fluoranthene $(\mathrm{FA})$, dibenzo[a,h]anthracene $(\mathrm{DB}[\mathrm{a}, \mathrm{h}] \mathrm{A})$ and 1-methylphenanthrene (1-MPA) was assessed after $6 \mathrm{~h}(\mathrm{~B}[\mathrm{a}] \mathrm{P}, \mathrm{DB}[\mathrm{a}, 1] \mathrm{P})$ and $24 \mathrm{~h}$ (all compounds) exposure, using oligonucleotide arrays. DNA-adduct formation was determined using ${ }^{32} \mathrm{P}$ post-labelling. The effects of PAHs on gene expression and on DNA-adduct formation were much more pronounced after $24 \mathrm{~h}$ exposure than after a $6 \mathrm{~h}$ exposure. Each compound induced gene expression changes dose-dependently and gene expression profiles were generally compound-specific. B[a]P, B $[\mathrm{b}] \mathrm{F}$ and $\mathrm{DB}[\mathrm{a}, \mathrm{h}] \mathrm{A}$ displayed comparable gene expression profiles, and so did DB[a,1]P, FA and 1-MPA. Only the carcinogenic PAHs (B[a]P, B b]F, DB[a,l]P and DB[a,h]A) induced the oxidative stress pathway. DNA-adduct levels were: $\mathrm{DB}[\mathrm{a}, 1] \mathrm{P}>>\mathrm{B}[\mathrm{a}] \mathrm{P}>\mathrm{B}[\mathrm{b}] \mathrm{F} \geq$ $\mathrm{DB}[\mathrm{a}, \mathrm{h}] \mathrm{A}>\mathrm{FA} \geq 1$-MPA. The expression of only a few genes was found to correlate significantly with DNA-adduct formation, carcinogenic potency or Ah-receptor binding capacity (the last two taken from literature). These genes differed between the parameters. Our results indicate that PAHs generally induce a compound-specific response on gene expression and that discrimination of carcinogenic from noncarcinogenic compounds is partly feasible using this approach. Only at a specific pathway level, namely oxidative stress response, PAHs with high and low carcinogenic potency could be discriminated.
\end{abstract}




\section{INTRODUCTION}

Polycyclic aromatic hydrocarbons comprise a large and ubiquitous class of structurally related environmental chemicals that differ greatly in their carcinogenic potency $(1,2)$. An indication of their carcinogenic potential may be derived from a consideration of their structural properties, such as the presence of fjord and bay regions, in relation to their metabolism $(3,4)$. Several other properties may help define the carcinogenic potency of PAHs, such as their ability to interact covalently with DNA following metabolic activation (5-9). Although DNA-adduct formation has been shown to correlate with the mutagenic potency in the case of PAHs (6), the various PAH-DNAadducts may be differently repaired by the cellular DNA-repair mechanisms, and thereby induction of mutations (5), and additional events are required to transform a normal cell into a malignant one.

In the liver, PAHs are metabolically activated by the CYP1 family of cytochromes P450, whose genes are under transcriptional control of the Aromatic hydrocarbonreceptor (Ah-receptor) (10). The principal catalysts of the activation of PAHs are CYP1A1 and CYP1B1 which, although poorly expressed in the liver, are highly inducible by these compounds (11). After metabolic activation, PAHs form adducts with DNA, induce mutations, and thereby initiate carcinogenesis (5,12). Many PAHs are ligands for the Ah-receptor, leading to transactivation of Ah-receptor mediated gene expression, including CYP1. Consequently, PAHs can increase their own metabolism including the activation pathways (13). The ability to bind to the Ah-receptor is considered to be a critical factor in determining the genotoxicity of PAHs (14). For comparison of PAHs in their ability to bind to the Ah-receptor, we used the data of Machala et al (13), who expressed Ah-receptor binding of a $\mathrm{PAH}$ as an Induction Equivalency Factor (IEF).

Ranking of PAHs according to their carcinogenic potencies is currently based on several parameters, such as the ability to generate DNA-adducts, mutagenicity and tumour forming potency. In order to compare the different PAHs, the Toxic Equivalency Factor (TEF) has been introduced $(15,16)$, based on the formation of carcinomas, full carcinogenesis and DNA-adduct formation. Another ranking for carcinogenicity of PAHs is developed by Collins et al (17), who estimated a Potency Equivalency Factor (PEF) for PAHs relative to B[a]P, based on bioassay data. However, for many PAHs these data are not currently available. Since none of the short term endpoints, e.g. DNA-adduct formation, mutagenicity, Ah-receptor binding, is solely indicative of PAH carcinogenicity, the development of additional methods that can improve their ranking would be advantageous. 
Gene expression profiling by DNA microarray technology has proved to be a useful tool in revealing mechanisms of toxicity and in toxicity classification of compounds $(18,19)$. Thus this technology can improve our appreciation of the carcinogenic potency of chemicals. By studying the effects of a PAH on the expression of a large set of genes, a compound-specific "transcriptomic fingerprint" may be obtained that reveals mechanistic information related to its carcinogenicity. Data derived from studies with a large number of PAHs may eventually improve our understanding of the differences in carcinogenic potency between PAHs, and might enable us to discriminate better between carcinogenic from less or non-carcinogenic compounds.

To better understand the difference in carcinogenic potency among PAHs, we investigated the transcriptomic fingerprints induced by PAHs with a wide range of carcinogenic activity in precision-cut rat liver slices. Precision-cut liver slices is a frequently used in vitro model with an increasing number of applications, including transcriptome profiling studies (20). In this model, cells are refrained in an environment with normal cell-cell and cell-matrix contacts, and remain to express high levels of metabolic enzymes that are important in PAH-mediated effects. The effects of PAHs on gene expression were examined for a total of 5700 genes simultaneously and compared with DNA-adduct formation, carcinogenic potency and Ah-receptor binding.

\section{MATERIALS AND METHODS}

\section{Chemicals}

Benzo[a]pyrene (B[a]P, purity 97\%, CAS no. 50-32-8), benzo[b]fluoranthene (B[b]F, purity 98\%, CAS no. 205-99-2), fluoranthene (FA, purity 99\%, CAS no. 206-44-0), dibenzo[a,h]anthracene (DB[a,h]A, purity 97\%, CAS no. 53-70-3) and dibenzo[a,1]pyrene (DB[a,1]P, purity 99.6\%, CAS no. 191-30-0) were obtained from Sigma-Aldich (Zwijndrecht, the Netherlands). 1-Methylphenanthrene (1-MPA, purity 99\%, CAS no. 832-69-9) was obtained from LGC Promochem (Teddington, United Kingdom). All chemicals were dissolved in DMSO.

\section{Preparing and exposure of precision-cut liver slices}

Rat livers were obtained from male Wistar rats (175-250g) killed by cervical dislocation. Livers were immediately excised and slices $(250 \mu \mathrm{m})$ were prepared using a Krumdieck tissue slicer (Alabama Research and Development Corp., Munsford, AL, USA) as previously described (21). Slices were pre-incubated for 30 minutes at $37^{\circ} \mathrm{C}$ in RPMI supplemented with $5 \%$ foetal calf serum, $0.5 \mathrm{mM}$ L-methionine, $1 \mu \mathrm{M}$ insulin, $0.1 \mathrm{mM}$ hydrocothsone-21-hemisuccinate and $50 \mu \mathrm{g} / \mathrm{ml}$ gesntomycin in 12 well plates on a shaking incubator $\left(5 \% \mathrm{CO}_{2}\right.$ and $95 \%$ air). After pre-incubation, the slices were transferred to 12 well plates containing fresh media and to which was added 3,10 or $30 \mu \mathrm{M}$ 
of the PAHs or a solvent control (DMSO, $0.067 \% \mathrm{v} / \mathrm{v}$ ). In each of two independent experiments, three slices were used for each treatment. After 6- or 24-h exposure, the slices were removed from the medium and immediately frozen in liquid nitrogen.

\section{RNA isolation, cDNA synthesis and dye labelling}

After crushing the liver slices under liquid nitrogen, RNA was stabilized by dissolving the crushed powder in Trizol (Gibco/BRL, Breda, the Netherlands) and isolated according to the manufacturer's manual. RNA was purified using the RNeasy mini kit (Qiagen Westburg bv., Leusden, The Netherlands) with DNase treatment, quantity was measured spectrophotometrically in $50 \mathrm{mM} \mathrm{NaOH}$ and quality was determined using a BioAnalyzer (Agilent Technologies, Breda, The Netherlands). OD 260nm/280nm were $1.79 \pm 0.13$. Only RNA samples which were not degraded (clear $18 \mathrm{~S}$ and $28 \mathrm{~S}$ peaks) were used for labelling and hybridization. To obtain sufficient RNA for microarray analysis, for each treatment two or three liver slices were pooled.

RNA samples were reverse transcribed into cDNA in triplicate with amino-allyl labelled dUTP (Sigma-Aldrich, St Louis, USA) and subsequently labelled with one of the three dyes, namely Cyanine 3 (Cy3), Cyanine 5 (Cy5) or Alexa 594 (A594), as was described previously (22). The labelling schedule is shown in Table 4.1.

TABLE 4.1. Labelling and hybridization design of RNA samples from each experiment with a PAH.

\begin{tabular}{cccc}
\hline Array no. & Cyanine 3 & Cyanine 5 & Alexa 594 \\
\hline $\mathbf{1}$ & $0 \mu \mathrm{M}$ & $3 \mu \mathrm{M}$ & $10 \mu \mathrm{M}$ \\
$\mathbf{2}$ & $10 \mu \mathrm{M}$ & $0 \mu \mathrm{M}$ & $30 \mu \mathrm{M}$ \\
$\mathbf{3}$ & $3 \mu \mathrm{M}$ & $30 \mu \mathrm{M}$ & $0 \mu \mathrm{M}$ \\
\hline
\end{tabular}

\section{Microarray hybridization and data analysis}

Dye-labelled samples were hybridized on an Operon rat oligonucleotide array containing 5700 oligonucleotides (v1.2.1, Operon, Qiagen, Venlo, The Netherlands) printed in triplicate on Corning UltraGAPS Coated Slides (Corning Life Sciences, New York, USA) by the Genome Centre Maastricht (Maastricht University, Maastricht, The Netherlands). Hybridization and washing were performed according to Corning's protocol for oligonucleotide arrays and as described previously (22).

The microarray slides were scanned on a ScanArrayExpress (Packard Biochip Technologies, Perkin Elmer life sciences, Boston, USA). All three channels were scanned at 100\% laser power and PMT Gain was adjusted, such that the signal of the highest fluorescent spots was just below the maximum measurable level. The images (10 micron resolution; 16 bit tiff) were processed with ImaGene 5.0 software (BioDiscov- 
ery Inc., Los Angeles, USA) to quantify spot signals. Irregular spots were manually or automatically flagged and excluded from the data analysis.

Data from ImaGene were transported into GeneSight software version 4.1.5 (BioDiscovery Inc. Los Angeles, USA) for further analysis. For each spot, local background was subtracted and flagged spots as well as spots with a net expression level $<20$ were omitted. Data were log base 2 transformed and expression differences between exposed and control calculated. Data normalization was carried out using LOWESS and centring expression differences by subtracting mean values. Data of replicate spots were combined while omitting outliers ( $>2 \mathrm{SD}$ ). To detect significantly modulated genes, first genes were selected using the confidence analysis tool from GeneSight (up or down regulation of 0.1 and $99 \%$ confidence limit) using the averaged data per treatment. This was followed by a Student's t-test analysis $(\mathrm{p}<0.01)$ between the gene expression differences at each PAH concentration compared to self-hybridizations of RNA labelled with the same dyes. Genes were assumed significantly modulated if they were found in both the confidence analysis and the Student's t-test.

Unsupervised clustering was performed by hierarchical clustering analysis and principal component analysis using GeneSight tools. Classification analysis by supervised clustering was achieved using the nearest-shrunken-centroid method using the PAM software tool (http://www-stat.stanford.edu/ tibs/PAM/, 27-09-2005 (23)). Genes used for classification were selected by multiple cross-validations based on the leaveone-out procedure. At the lowest misclassification rate, the smallest number of genes for that rate was selected for classification analysis into carcinogenic or noncarcinogenic.

\section{Pathway analysis}

Pathway analysis was carried out using GenMAPP version 2.0 software (Gladstone Institutes, University of California, San Fransisco, USA) and local maps from GenMAPP (Gene database Rn_contributed_20041216 and maps Rn_std_20041102 from www.GenMAPP.org) (24,25). For each treatment, all modulated genes were included in the analysis, with the exclusion of flagged genes. Pathways with a Z-score $>2$ and at least two genes affected, were assumed to be significantly affected by the treatment.

\section{DNA-adduct analysis}

After removal of the aqueous phase during RNA isolation using Trizol, the remaining phases were used for DNA isolation according to the manufacturer's protocol. DNAadduct levels were determined according to the procedure originally described by Reddy and Randerath (26) with the modifications introduced by Godschalk et al (27). By including samples with known DNA-adduct levels ( 1 adduct per $10^{6}, 10^{7}$ or $10^{8} \mathrm{nt}$ ), it was possible to quantify DNA-adduct levels (detection limit 1 adduct per $10^{8} \mathrm{nt}$ ). 
Adduct spots on the chromatograms were located and quantified using a phosphor imager (FLA-3000, Fuji, Paris, France) and AIDA/2D densitometry software.

\section{Correlation analysis}

For correlation of gene expression changes with carcinogenic potency, TEF values from Nisbet and LaGoy (16) were used for B[a]P, B[b]F, FA and DB[a,h]A. These were complemented with the PEF values proposed by Collins et al (17) for DB[a,1]P, and we estimated a TEF for 1-MPA based on IARC data $(1,2)$ according to the method proposed by Nisbet and LaGoy (16). The resulting TEF values were; 1.0 for $\mathrm{B}[\mathrm{a}] \mathrm{P}, 0.1$ for $\mathrm{B}[\mathrm{b}] \mathrm{F}, 0.001$ for FA and 1-MPA, 5.0 for DB[a,h]A and 10 for DB[a,l]P. For correlation with Ah-receptor binding, IEF values determined by Machala et al (13) were used. The values after 24 hours exposure were used and expressed relative to $\mathrm{B}[\mathrm{a}] \mathrm{P}$. They were 1 for $\mathrm{B}[\mathrm{a}] \mathrm{P}, 0.24$ for $\mathrm{B}[\mathrm{b}] \mathrm{F}, 0$ for $\mathrm{FA}, 7.64$ for $\mathrm{DB}[\mathrm{a}, \mathrm{h}] \mathrm{A}$ and 0.01 for $\mathrm{DB}[\mathrm{a}, 1] \mathrm{P}$.

After log (base 2) transformation, DNA-adduct levels, TEF and IEF were correlated with the expression changes of modulated genes by at least one concentration of the compound. Since after log transformation, DNA-adduct formation, TEF and IEF were normally distributed (according to the Kolmogorov-Smirnov test in SPSS, P < 0.05), Pearson correlation coefficients of gene expression with TEF, IEF (both for each concentration separately) and DNA-adduct formation (for all concentrations) were calculated using SPSS for windows 11.5 (SPSS Inc., Chicago, USA).

\section{RESULTS}

After $6 \mathrm{~h}$ exposure, B[a]P modulated 30 genes and DB[a,l]P 41 modulated genes. When exposure was extended to $24 \mathrm{~h}$, the number of modulated genes rose to 56 for $\mathrm{B}[\mathrm{a}] \mathrm{P}$ and 111 for $\mathrm{DB}[\mathrm{a}, 1] \mathrm{P}$. Only three genes were found to overlap between both time points for $\mathrm{B}[\mathrm{a}] \mathrm{P}$ and for $\mathrm{DB}[\mathrm{a}, 1] \mathrm{P}$ this was one gene. Hierarchical clustering as well as principal component analysis of the 83 genes modulated by $\mathrm{B}[\mathrm{a}] \mathrm{P}$ at either 6 or $24 \mathrm{~h}$ together with self-hybridizations showed that the $6 \mathrm{~h}$ exposure resembles the selfhybridizations more closely than the longer exposure (Figure 4.1); similar results were obtained for DB[a,l]P. Furthermore, at $6 \mathrm{~h}$, DNA-adduct levels in $\mathrm{B}[\mathrm{a}] \mathrm{P}$ - or DB[a,l]Ptreated liver slices were approximately $6 \%$ of those following a $24 \mathrm{~h}$ exposure (data not shown). Collectively, these data led us to conclude that the PAHs have only limited effects on gene expression and DNA-adduct formation after $6 \mathrm{~h}$ exposure compared with $24 \mathrm{~h}$, and therefore we focused on the $24 \mathrm{~h}$ time point only for the remaining four compounds. 


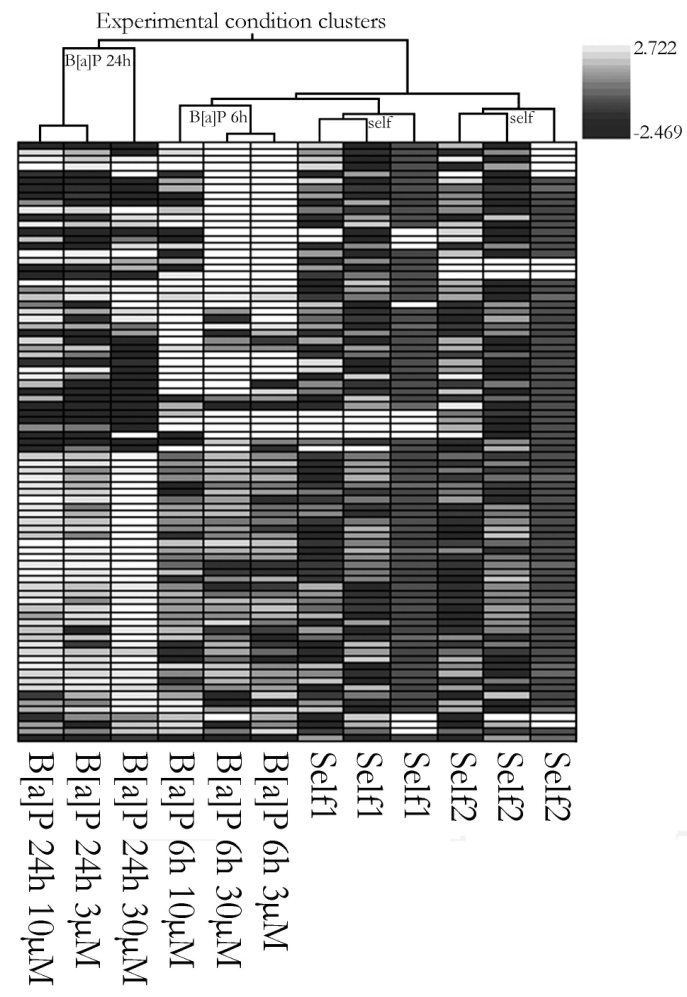

FIGURE 4.1. Hierarchical clustering of B[a]P treatments for 6 or $24 \mathrm{~h}$ and self-hybridizations, using the 83 genes that were significantly modulated by at least one of the treatments. Clustering with average linkage and Pearson distance metric was used.

All six compounds modulated gene expression in liver slices after 24 h exposure. B[b]F modulated the highest number of genes, namely 165 genes for all concentrations combined, followed by DB[a,h]A (115 genes), DB[a,l]P (111 genes), FA (77 genes), B [a]P (56 genes), and finally 1-MPA (27 genes). Overall, 425 genes were modulated by at least one treatment after $24 \mathrm{~h}$ exposure, and in general a dose-dependent effect on gene expression modulation was observed (see supplemented data file at http://fdgwgratsrv0401.unimaas.nl/data, including information on probe ID, gene names, abbreviations, GenBank accession numbers and gene expression differences).

Hierarchical clustering of the PAH treatments and the 425 modulated genes shows that for each compound, except for $\mathrm{DB}[\mathrm{a}, 1] \mathrm{P}$, all doses cluster together, indicating a compound-specific response on gene expression (Figure 4.2). Higher in the dendrogram, it can be seen that $\mathrm{B}[\mathrm{a}] \mathrm{P}, \mathrm{DB}[\mathrm{a}, \mathrm{h}] \mathrm{A}$ and $\mathrm{B}[\mathrm{b}] \mathrm{F}$ elicit, to some extent similar responses on gene expression. Similar observations were made for DB[a, $]$ P, FA and 1MPA. This finding is supported by the principal component analysis (PCA) using the 
425 modulated genes (Figure 4.3). Moreover, using PCA the compounds are split in the same two groups, indicating a distinction between the gene expression profiles of both groups. However, PCA also shows a similarity on gene expression response after $\mathrm{DB}[\mathrm{a}, 1] \mathrm{P}$ and $\mathrm{DB}[\mathrm{a}, \mathrm{h}] \mathrm{A}$ treatment, which are both in the lower part of the plot. Thus using both of these unsupervised clustering methods, the most carcinogenic PAH $(\mathrm{DB}[\mathrm{a}, 1] \mathrm{P})$, is grouped together with the two least carcinogenic (FA and 1-MPA).

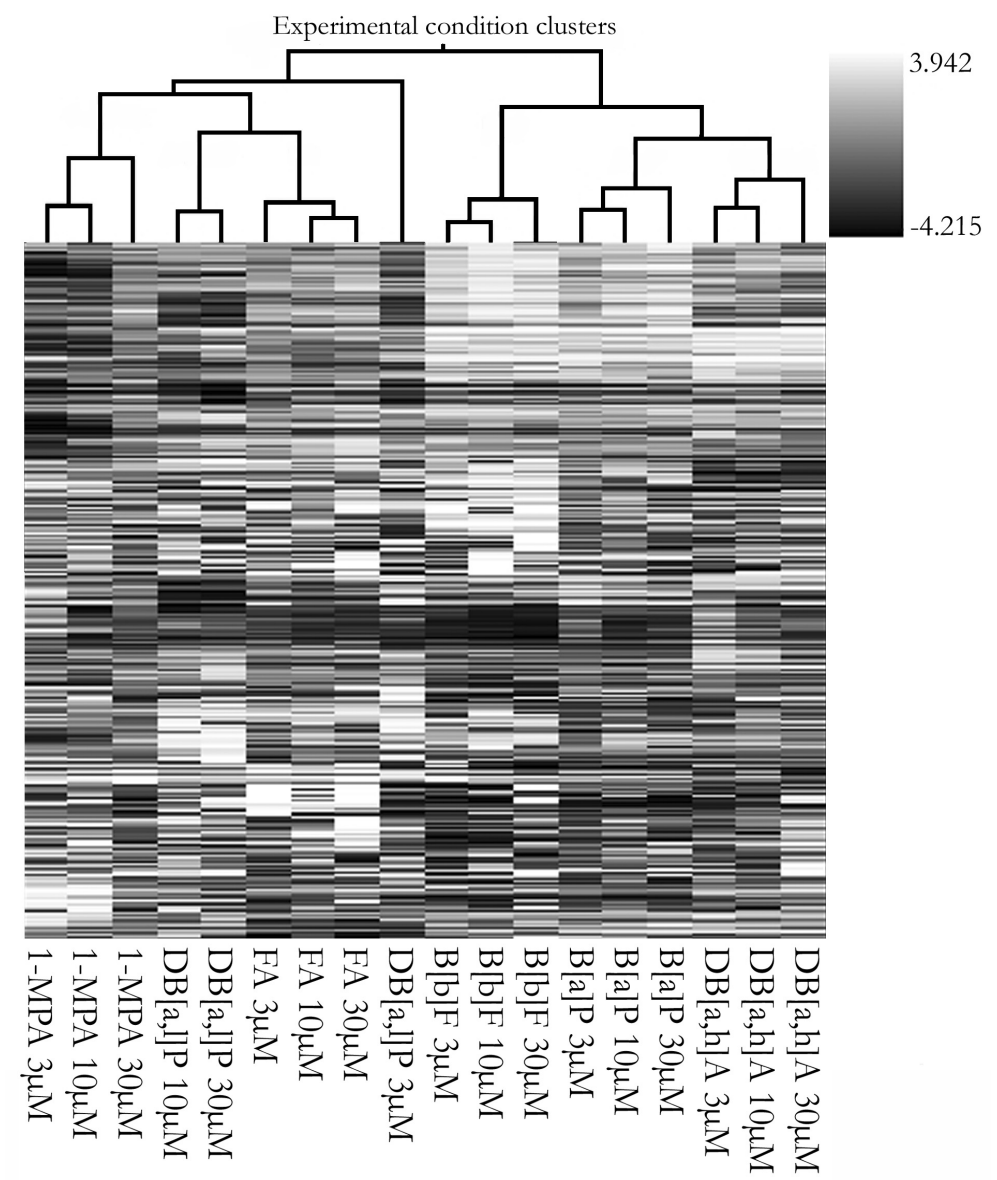

Figure 4.2. Hierarchical clustering of $\mathrm{PAH}$ treatments and genes using the 425 genes that were significantly modulated by at least one of the treatments. Clustering with average linkage and Pearson distance metric was used. 


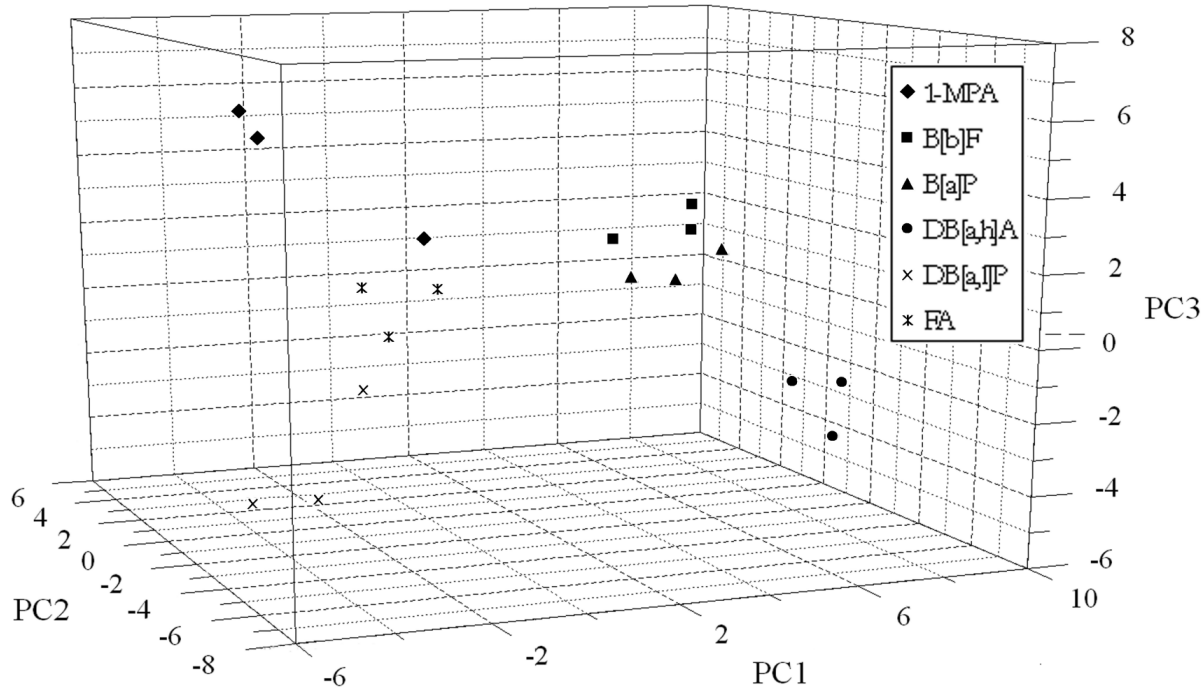

Figure 4.3. Principal component analysis of all PAH treatments using the 425 genes that were significantly modulated by at least one of the treatments. PC1 explains $23.4 \%$ of the variance between treatments, PC2 $13.3 \%$ and PC3 9.8\%.

Furthermore, we investigated whether a sub-group of the 425 genes would be better classifiers for discrimination of the highly carcinogenic PAHs (B[a]P, DB[a,1]P, $\mathrm{DB}[\mathrm{a}, \mathrm{h}] \mathrm{A}$ and $\mathrm{B}[\mathrm{b}] \mathrm{F}$ ) from the weakly carcinogenic PAHs (FA and 1-MPA). In this approach the supervised clustering method, the nearest-shrunken-centroid method was employed. When all treatments for all PAHs are used, 16 classifier genes were selected to best discriminate carcinogenic from non-carcinogenic PAHs, namely CYP1A1, CYP1A2, NQO1, PGRMC1, SPP1, EPHX1, CYP1B1, MPL3, GSTM1, TTR, RT1-N1, GBP2, DIG1, AOX1, GRAG16 and CTSK. Using these genes, it was noted that all treatments, except the two lowest doses of $\mathrm{DB}[\mathrm{a}, 1] \mathrm{P}$, were correctly classified as being non-carcinogenic or carcinogenic (Figure 4.4). In addition, this method was applied to predict the carcinogenic potency of a PAH based on data derived from the 5 other PAHs. This was done at all concentrations studied, and the results are shown in Table 4.2. $\mathrm{B}[\mathrm{a}] \mathrm{P}, \mathrm{B}[\mathrm{b}] \mathrm{F}$ and $\mathrm{DB}[\mathrm{a}, \mathrm{h}] \mathrm{A}$ were always correctly classified, whereas $\mathrm{DB}[\mathrm{a}, 1] \mathrm{P}$ was always misclassified. Classification of 1-MPA and FA based on data of the remaining 5 compounds was not possible since at least two compounds are required in each class for classification. 


\section{Test Probabilities}

- predicted strong carcinogen

predicted weak carcinogen

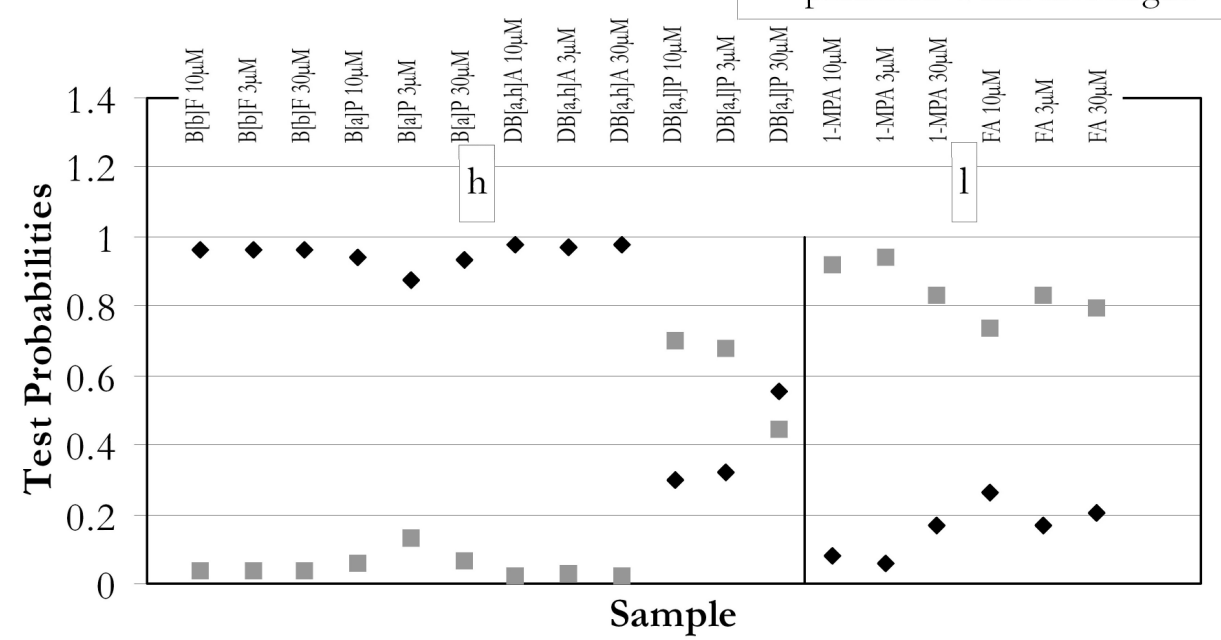

FIGURE 4.4. Classification by the nearest-shrunken-centroid method of PAH treatments $(24 \mathrm{~h})$ in high (h) or low (1) carcinogenic potency based on the expression of CYP1A1, CYP1A2, NQO1, PGRMC1, SPP1, EPHX1, CYP1B1, MPL3, GSTM1, TTR, RT1-N1, GBP2, DIG1, AOX1, GRAG16 and CTSK.

TABLE 4.2. Prediction by the Nearest-shrunken-centroid method of carcinogenic potency of a PAH based on gene expression data of the five other PAHs per concentration. Classification of FA and 1-MPA was not possible since at least two compounds are needed in each class.

\begin{tabular}{lllllll}
\hline PAH concentration & DB $[\mathrm{a}, \mathbf{l}] \mathbf{P}$ & $\mathbf{B}[\mathrm{a}] \mathbf{P}$ & $\mathbf{B}[\mathrm{b}] \mathbf{F}$ & DB[a,h]A & FA & 1-MPA \\
\hline $\mathbf{3 \mu \mathbf { M }}$ & Wrong & Correct & Correct & Correct & Not done & Not done \\
$\mathbf{1 0} \boldsymbol{\mu M}$ & Wrong & Correct & Correct & Correct & Not done & Not done \\
$\mathbf{3 0} \boldsymbol{\mu} \mathbf{M}$ & Wrong & Correct & Correct & Correct & Not done & Not done \\
\hline
\end{tabular}

Pathway analysis by GenMAPP based on the modulated genes for each PAH and exposure concentration, revealed several affected pathways, which are listed in Table 4.3. Only oxidative stress was affected by more than one compound, namely by $\mathrm{DB}[\mathrm{a}, \mathrm{l}] \mathrm{P}, \mathrm{DB}[\mathrm{a}, \mathrm{h}] \mathrm{A}, \mathrm{B}[\mathrm{a}] \mathrm{P}$ and $\mathrm{B}[\mathrm{b}] \mathrm{F}$. It is noteworthy that these are all PAHs with a medium or high carcinogenic activity. 
TABLE 4.3 Affected pathways (or groups of related genes) in response to PAH treatment as revealed by analysis with GenMAPP.

\begin{tabular}{|c|c|c|c|c|c|c|c|}
\hline & $\mathrm{DB}[\mathrm{a}$, & & $\mathrm{DB}[\mathrm{a}, \mathrm{h}] \mathrm{A}$ & $\mathrm{B}[\mathrm{a}] \mathbf{P}$ & $\mathrm{B}[\mathrm{b}] \mathrm{F}$ & FA & 1-MPA \\
\hline $\begin{array}{l}\text { ACE-Inhibitor } \\
\text { pathway }\end{array}$ & & & & & $\begin{array}{ll}? & \text { AGTR2 } \\
& \text { KNG } \\
\end{array}$ & & \\
\hline Apoptosis & $?$ & $\begin{array}{l}\text { CASP3 } \\
\text { CASP8 } \\
\text { NFKB1 }\end{array}$ & & & & & \\
\hline $\begin{array}{l}\text { Cholesterol } \\
\text { Biosynthesis }\end{array}$ & & & $\begin{array}{ll}\uparrow & \text { HMGCR } \\
& \text { IDI1 } \\
\end{array}$ & & & & \\
\hline $\begin{array}{l}\text { Electron } \\
\text { Transport } \\
\text { Chain }\end{array}$ & & & $\begin{array}{ll}\text { COX6A1 } \\
\text { ATP5E }\end{array}$ & & & & \\
\hline $\begin{array}{l}\text { Glycolysis and } \\
\text { Gluconeogene- } \\
\text { sis }\end{array}$ & & & & & $\begin{array}{ll}\downarrow & \text { GCK } \\
& \text { PKM2 }\end{array}$ & & \\
\hline $\begin{array}{l}\text { GPCRDB Class } \\
\text { A Rhodopsin- } \\
\text { like }\end{array}$ & & & & & & $\begin{array}{ll}\uparrow & \text { OPN1SW } \\
& \text { TRHR2 }\end{array}$ & \\
\hline $\begin{array}{l}\text { HSP70 and } \\
\text { Apoptosis }\end{array}$ & $\uparrow$ & $\begin{array}{l}\text { CASP3 } \\
\text { CASP8 }\end{array}$ & & & & & \\
\hline $\begin{array}{l}\text { Irinotecan } \\
\text { pathway }\end{array}$ & & & & & $\begin{array}{ll}\downarrow & \text { BCHE } \\
& \text { UGT1A6 } \\
\end{array}$ & & \\
\hline $\begin{array}{l}\text { Mitochondrial } \\
\text { fatty acid } \\
\text { betaoxidation }\end{array}$ & & & & & & $\begin{array}{ll}\uparrow & \text { DCI } \\
& \text { SLC25A20 }\end{array}$ & \\
\hline $\begin{array}{l}\text { Nuclear } \\
\text { Receptors }\end{array}$ & $\bar{\uparrow}$ & $\begin{array}{l}\text { NR1H3 } \\
\text { RXRG }\end{array}$ & & & & & \\
\hline $\begin{array}{l}\text { Oxidative } \\
\text { Stress }^{1}\end{array}$ & $\downarrow / ?$ & $\begin{array}{l}\text { GPX1 } \\
\text { NFKB1 }\end{array}$ & $\begin{array}{ll}\downarrow & \text { CYP1A1 } \\
& \text { GSTA2 } \\
& \text { NQO1 } \\
& \text { UGT1A6 }\end{array}$ & $\begin{array}{ll}\downarrow & \text { CYP1A1 } \\
& \text { NQO1 } \\
& \text { UGT1A6 } \\
& \text { TXNRD1 }\end{array}$ & $\begin{array}{ll}\downarrow & \text { CYP1A1 } \\
& \text { GSTA2 } \\
& \text { GSTT2 } \\
& \text { NQO1 } \\
& \text { UGT1A6 } \\
& \text { TXNRD1 }\end{array}$ & & \\
\hline $\begin{array}{l}\text { Regulation of } \\
\text { Actin Cytoske- } \\
\text { leton }\end{array}$ & $\downarrow$ & $\begin{array}{l}\mathrm{F} 2 \\
\mathrm{FN} 1\end{array}$ & & & & & \\
\hline $\begin{array}{l}\text { TGF Beta } \\
\text { Signalling } \\
\text { Pathway }\end{array}$ & $\downarrow$ & $\begin{array}{l}\text { LTBP1 } \\
\text { NFKB1 }\end{array}$ & & & & & \\
\hline
\end{tabular}

Induction of the pathway is indicated with an arrow pointing upwards $(\uparrow)$, inhibition with an arrow pointing downwards $(\downarrow)$ and unsure with a question mark (?). The modulated genes in the pathway are listed at the corresponding pathway. 1 Down-regulation of oxidative stress implies increased antioxidant production and decreased ROS formation. 
DNA-adducts were measured by ${ }^{32} \mathrm{P}$-postlabelling in the same samples used for gene expression profiling (Table 4.4). DB[a,l]P exposure resulted in the highest number of DNA-adducts (up to 912 adducts per $108 \mathrm{nt}$ ), followed by B[a]P (up to 35 per $10^{8} \mathrm{nt}$ ), $\mathrm{B}[\mathrm{b}] \mathrm{F}$ (up to 15 per $10^{8} \mathrm{nt}$ ) and $\mathrm{DB}[\mathrm{a}, \mathrm{h}] \mathrm{A}$ (up to 12 per $10^{8} \mathrm{nt}$ ). In most cases dosedependent DNA-adduct formation was observed. No or virtually no DNA-adducts above background were detected after exposure of the liver slices to FA or 1-MPA.

TABLE 4.4. DNA-adduct levels (adducts per $10^{8} \mathrm{nt}$; mean $\pm \mathrm{SD}$ ) in precision-cut rat liver slices after exposure to PAHs.

\begin{tabular}{lcccccc}
\hline PAH concentration & $\mathbf{D B}[\mathbf{a}, \mathbf{l}] \mathbf{P}$ & $\mathbf{B}[\mathbf{a}] \mathbf{P}$ & $\mathbf{B}[\mathbf{b}] \mathbf{F}$ & $\mathbf{D B}[\mathbf{a}, \mathbf{h}] \mathbf{A}$ & FA & 1-MPA \\
\hline vehicle control & $4.3 \pm 1.4$ & $0.64 \pm 0.55$ & 2.2 & $2.6 \pm 0.4$ & $1.2 \pm 0.6$ & $4.9 \pm 0.9$ \\
$\mathbf{3} \boldsymbol{\mu M}$ & $130 \pm 80.3$ & $2.4 \pm 0.3$ & $17 \pm 6.0$ & $8.7 \pm 0.8$ & $0.72 \pm 0.29$ & $2.4 \pm 1.2$ \\
$\mathbf{1 0} \boldsymbol{\mu M}$ & $455 \pm 111$ & $14 \pm 7.4$ & 12.2 & $15 \pm 3.2$ & 0.71 & $4.4 \pm 0.8$ \\
$\mathbf{3 0} \boldsymbol{\mu M}$ & $912 \pm 197$ & 35 & $15 \pm 0.9$ & $12 . \pm 4.1$ & $9.2 \pm 5.6$ & $2.7 \pm 0.1$ \\
\hline
\end{tabular}

DNA-adduct levels (after log transformation) were correlated with the expression changes for each of the 425 modulated genes. Significantly correlating genes $(p<0.05)$ with an $\mathrm{R}^{2}>0.4$ are shown in Table 4.4. Only six genes satisfied these criteria.

The expression changes for the 425 significantly modulated genes were also correlated with carcinogenic potency (TEF) and Ah-receptor binding capacity (IEF). Significantly correlating genes $(\mathrm{p}<0.05)$ with a $\mathrm{R}^{2}>0.4$ are shown in Table 4.5 . Two genes correlated with carcinogenic potency and 24 genes with Ah-receptor binding. No genes were found to correlate with more than one parameter. More detailed information on correlation coefficients and fold changes of the genes can be found in the supplemented data file (http://fdgwgratsrv0401.unimaas.nl/data). 
TABLE 4.5. Genes with significant correlation $(\mathrm{p}<0.05$ and $\mathrm{R} 2>0.4)$ between expression and DNA-adduct levels, TEF or IEF (all log base 2 transformed data).

\begin{tabular}{ccc}
\hline DNA-adduct formation & TEF & IEF \\
\hline SERPINB10 & $A O X 1$ & $A D A R$ \\
$S N A P 25$ & NOS2 & $A H C Y$ \\
$G T F 2 A 1$ & & $C A S P 12$ \\
RPB1 & $C L D N 3$ \\
$A M E L$ & $C R O T$ \\
$M M P 9$ & $C T S K$ \\
& & $C X C L 2$ \\
& $C Y P 1 A 1$ \\
& $C Y P 1 A 2$ \\
& & $C Y P 2 A 1$ \\
& DEFB1 \\
& FABP1 \\
& GSTA2 \\
& HSD17B2 \\
& IFITM3L \\
\hline
\end{tabular}

\section{DISCUSSION}

To better understand the difference in carcinogenic potency among PAHs, we examined the effect of six PAHs on gene expression in precision-cut rat liver slices in relation to carcinogenic potency, DNA binding capacity and Ah-receptor binding.

After $24 \mathrm{~h}$ exposure, all tested PAHs modulated gene expression in a dose dependent manner. Although no genes were found to be modulated by every PAH, CYP1A1 and BEST5 were both up-regulated by five of six compounds (not by 1-MPA or DB[a,h]A respectively). Further, $A F A R, D I G 1, E P H X 1$ and GSTM1 were all up-regulated by the carcinogenic PAHs but not by the non-carcinogenic PAHs (FA and 1-MPA). Interestingly, these four genes are all involved in mechanisms to prevent carcinogenic damaging events and thereby protecting the cell, which may explain their modulation solely by carcinogenic PAHs (28-30).

Hierarchical clustering and principal component analyses using all 425 modulated genes both indicate that, in general, each compound has a specific gene expression pattern. Only the $3 \mu \mathrm{M}$ treatment with $\mathrm{DB}[\mathrm{a}, 1] \mathrm{P}$ had a different gene expression pattern than the higher concentration treatments, which is probably due to a marginal effect on gene expression at this low dose. Although the response on gene expression of $\mathrm{DB}[\mathrm{a}, 1] \mathrm{P}$ seems to show some similarity with the response of $\mathrm{DB}[\mathrm{a}, \mathrm{h}] \mathrm{A}$ treatment 
(Figure 4.3), all compounds can be divided into two groups, one consisting of $\mathrm{B}[\mathrm{a}] \mathrm{P}$, $\mathrm{DB}[\mathrm{a}, \mathrm{h}] \mathrm{A}$ and $\mathrm{B}[\mathrm{b}] \mathrm{F}$ and the other of 1-MPA, FA and $\mathrm{DB}[\mathrm{a}, 1] \mathrm{P}$. The first group comprises only carcinogenic PAHs, whereas the other group contains a highly carcinogenic compound, $\mathrm{DB}[\mathrm{a}, 1] \mathrm{P}$ in addition to two relatively non-carcinogenic compounds. Thus, the two groups do not perfectly correspond with carcinogenicity based on studies carried out in precision-cut rat liver slices. The separation in these two groups might be explained by the poor induction of Ah-receptor dependent gene expression (CYP1A1, CYP1A2 and CYP1B1) by DB[a,l]P and the two relatively non-carcinogenic compounds, whereas $\mathrm{B}[\mathrm{a}] \mathrm{P}, \mathrm{B}[\mathrm{b}] \mathrm{F}$ and $\mathrm{DB}[\mathrm{a}, \mathrm{h}] \mathrm{A}$ are all strong inducers of $\mathrm{Ah}$-receptor dependent gene expression. In contrast, in HepG2 cells, a human hepatoma cell line, exposed to identical PAHs at similar concentrations carcinogenic and non-carcinogenic PAHs could be discriminated in hierarchical clustering (31). This discrepancy most probably reflects differences in the in vitro system employed and the species differences.

In order to investigate whether within the total of 425 genes a sub-group of genes exists that can be used to discriminate PAHs regarding carcinogenicity, classification analyses by the nearest-shrunken-centroid method was performed. Though the gene numbers could be reduced, still $\mathrm{B}[\mathrm{a}] \mathrm{P}, \mathrm{B}[\mathrm{b}] \mathrm{F}$ and $\mathrm{DB}[\mathrm{a}, \mathrm{h}] \mathrm{A}$ were constantly and correctly classified as being carcinogenic, whereas $\mathrm{DB}[\mathrm{a}, 1] \mathrm{P}$ was wrongly classified as having a low carcinogenic potency. This incorrect classification of $\mathrm{DB}[\mathrm{a}, 1] \mathrm{P}$ may be caused by the minor induction of the CYP1A1 gene by $\mathrm{DB}[\mathrm{a}, 1] \mathrm{P}$ only at the highest concentration, whereas the other carcinogenic PAHs induce CYP1A1 to a higher extent and at all concentrations. Noteworthy, DB[a,l]P was found to induce CYP1A1 in HepG2 cells, which probably contributed to the more accurate classification of PAHs in these cells.

These results suggest that HepG2 cells are a more suitable model for PAH classification of their carcinogenic potency based on gene expression profiling. However, we tested only six compounds and used arrays with only a limited part of all genes. A larger number of compounds and arrays covering the whole transcriptome, may improve the classification of PAHs in liver slices.

Pathway analysis can be useful in revealing the processes in which the modulated genes are involved and, thereby, may elucidate PAH induced carcinogenic mechanisms. All carcinogenic PAHs modified genes involved in oxidative stress (which implies an increased antioxidant production and decreased ROS formation), whereas the least carcinogenic PAHs, FA and 1-MPA, failed to do so. This observation would imply that affecting oxidative stress might be an important characteristic or classifier for carcinogenic PAHs. PAHs are known to induce oxidative stress following metabolism to yield compounds such as quinones (reviewed in (4)). Our observation might be a protective mechanism of the liver cells to oxidative damage induced by PAHs. Nuclear receptors were affected by $\mathrm{DB}[\mathrm{a}, 1] \mathrm{P}$ as for instance the $\mathrm{RXR}$ receptor was down-regulated and 
the LXR (or oxysterol) receptor was up-regulated. Over-expression of the RXR receptor has been shown to inhibit growth of carcinoma cells (32), which means that our observed down regulation may be seen as a tumour promoting activity of $\mathrm{DB}[\mathrm{a}, 1] \mathrm{P}$. Furthermore, DB[a,l]P seems to influence apoptosis and HSP70 suggesting a stress response of the liver slices. Accordingly, the regulation of actin cytoskeleton is downregulated in response to $\mathrm{DB}[\mathrm{a}, 1] \mathrm{P}$ which also indicate induction of apoptosis. Additionally, DB[a,1]P decreased the TGF beta protein signalling pathway. TGF-beta serves as a tumour suppressor pathway in normal tissue and is known to be over-expressed in advanced stages of carcinogenesis (33). DB[a,h]A influenced the electron transport chain pathway which may be related to its carcinogenic mode of action. There is evidence that defects in electron transport activities is linked to carcinogenic outcome, as for instance was shown for brain tumours (34). Further, DB[a,h]A showed elevation of cholesterol biosynthesis pathway, which could be interpreted as cell growth promotion by $\mathrm{DB}[\mathrm{a}, \mathrm{h}] \mathrm{A}$, since in proliferating normal tissue and tumours cholesterol biosynthesis is enhanced (35). Treatment with $\mathrm{B}[\mathrm{b}] \mathrm{F}$ was found to down-regulate glycolysis and gluconeogenesis. Although the energy requirement of hepatic cancer cells increases, gluconeogenesis decreases in poorly differentiated cells (36). This seems to indicate a preliminary carcinogenic response to $\mathrm{B}[\mathrm{b}] \mathrm{F}$ treatment. Overall, some of the perturbed pathways point to either a protective mechanism of the cell against carcinogenic insult or promotion of the carcinogenic process. Thus, with the exception of effects on oxidative stress, all PAHs appear to have a different effect on liver slices.

At pathway level, some similarities between the current study on liver slices and the data from our previous study in HepG2 cells were found. In both cell systems, the apoptosis pathway, cholesterol biosynthesis and effects on fatty acid synthesis or degradation were observed. Only the HMGCR gene in the cholesterol biosynthesis pathway and the NFKB gene in the apoptosis pathway were modulated in liver slices and HepG2 cells. Other genes (caspases in the apoptosis pathway) were not affected in HepG2 cells or genes (others) were not present on the arrays used in the HepG2 experiment. Thus, modulation of these pathways appear important responses to PAH exposure

The order of DNA binding capacity in liver slices was: $\mathrm{DB}[\mathrm{a}, 1] \mathrm{P}>>\mathrm{B}[\mathrm{a}] \mathrm{P}>\mathrm{B}[\mathrm{b}] \mathrm{F} \geq$ $\mathrm{DB}[\mathrm{a}, \mathrm{h}] \mathrm{A}>\mathrm{FA} \geq 1-\mathrm{MPA}$. This order differs slightly from literature data (7-9), where it is in general: $\mathrm{DB}[\mathrm{a}, 1] \mathrm{P}>\mathrm{DB}[\mathrm{a}, \mathrm{h}] \mathrm{A}>\mathrm{B}[\mathrm{a}] \mathrm{P}>\mathrm{B}[\mathrm{b}] \mathrm{F}$. Most of these data, however, were obtained in in vivo studies conducted in the lung, whereas the current studies were carried out in vitro in the liver. DNA-adduct formation in rat hepatocytes in vitro, in the presence of rat S9-mix, resulted in the same order of DNA binding capacity for $\mathrm{B}[\mathrm{a}] \mathrm{P}$, $\mathrm{B}[\mathrm{b}] \mathrm{F}, \mathrm{DB}[\mathrm{a}, \mathrm{h}] \mathrm{A}$ and $\mathrm{FA}$ as observed in the present studies (9). In HepG2 cells the order of DNA binding capacity was $\mathrm{B}[\mathrm{a}] \mathrm{P}>>\mathrm{DB}[\mathrm{a}, \mathrm{l}] \mathrm{P}>\mathrm{B}[\mathrm{b}] \mathrm{F}>\mathrm{DB}[\mathrm{a}, \mathrm{h}] \mathrm{A}>1-\mathrm{MPA}$ $\geq$ FA showing that $\mathrm{DB}[\mathrm{a}, \mathrm{l}] \mathrm{P}$ induces far more DNA-adducts in liver slices than in HepG2 cells. DNA-adduct formation has been shown to be higher in CYP1A1 knockout mice after $\mathrm{B}[\mathrm{a}] \mathrm{P}$ exposure compared to wild types (37), and therefore 
CYP1A1 activation results in lower DNA-adduct levels. DB[a,l]P only marginally induced the expression of CYP1A1 in liver slices, but it caused a more markedly induction of CYP1A1 in HepG2 cells, and may therefore induce higher levels of DNA-adducts in liver slices than in HepG2 cells.

Correlation of gene expression changes with DNA-adduct formation, carcinogenic potency and Ah-receptor binding revealed several highly correlating genes. As expected, many genes known to be regulated via the Ah-receptor were seen to correlate with IEF. These were genes from the cytochrome family (e.g. CYP1A1 and CYP1A2), from the UDP glucuronyltransferase 1 family (UGT1A1, UGT1A6 and UGT1A7), SLC21 A5, NQO1 and GSTA2. These genes are also modulated in rats following exposure to 2,3,7,8-tetrachlorodibenzo-p-dioxin, the highest affinity ligand known for this receptor (38). In comparison with HepG2 cells only the Ah-receptor controlled genes CYP1A1 and CYP1A2 correlated in both cell systems with IEF. Other genes were either not significantly modulated in HepG2 cells, or were not present on the arrays used for these experiments. The functions of some significantly correlating genes could be related to carcinogenicity. For example, IEF correlated with CASP12 (involved with the terminal stage of apoptosis), FABP1 (may play a role in hepatocyte cell proliferation and may transport activated chemical carcinogens), SLCO1A4 (SLC21A4, mediates transport of organic anions) and the UDP glucuronyltransferase 1 family (involved in metabolism of, for example, PAHs). TEF correlated with $A O X 1$ and NOS2, which are both enzymes involved in inflammation response, and thereby possibly indirectly with carcinogenesis (reviewed in (39)). Furthermore, NOS2 plays an important role in the carcinogenesis of the PAH 3-methylcholanthrene (40). Finally, in relation to carcinogenesis, DNA-adduct formation correlated significantly with MMP9. The transcription and expression of $M M P 9$ is increased throughout the process of hepatocarcinogenesis (41). Although genes involved in DNA repair might be expected to correlate with DNA-adduct formation, those that were present on the array (for example XRCC1, XRCC5, OGG1, MPG and BRCA1) were not significantly modulated by either of the treatments and therefore not included in the correlation studies. From this study, but also from other studies with HepG2 cells, it appears that modulation of DNA repair genes by genotoxic carcinogens is not a pronounced effect $(19,31)$. No gene was found to correlate with all parameters, indicating that either not all parameters used for correlation are highly relevant to carcinogenicity or no gene can be used as an indicator of carcinogenic potency of PAHs.

When analyzing the correlating genes for each parameter with GenMAPP, no pathways were significantly affected by genes correlating with DNA-adduct formation or TEF. Genes correlating with IEF, however, appear to affect the oxidative stress pathway. The relationship between oxidative stress and IEF might be explained by the ability of PAHs to interact with the Ah-receptor, which leads to induction of cytochrome P450 enzymes. PAHs are metabolized by these enzymes and can form reactive intermediates which can give rise to oxidative stress (reviewed in (4)). 


\section{CONCLUSION}

It may be inferred that PAHs generally induce a compound-specific response on gene expression. This is reflected in both the clustering analyses as well as in the pathway analyses.Using all modulated genes, discrimination of carcinogenic from noncarcinogenic compounds is, to some extent, feasible (only $\mathrm{DB}[\mathrm{a}, 1] \mathrm{P}$ is incorrectly grouped). But reduction of the discriminating genes using a classification tool, does not improve this discrimination. Only at a specific pathway level, namely that for oxidative stress response, PAHs with high and low carcinogenic potency could be discriminated.

\section{Supplementary data}

Supplementary data can be found on the website of Mutagenesis. "Differences and standard deviations modulated genes" contains information on probe ID, gene names, abbreviations, GenBank accession numbers and gene expression differences. "Correlations" contains more detailed information on correlation coefficients and fold changes of the genes significantly correlating genes. All microarray data are stored in ArrayExpress (http://www.ebi.ac.uk/arrayexpress/). Accession numbers are E-TOXM-24 and E-TOXM25 for the experiments and A-MEXP-350, 351 and 352 for the array designs.

\section{Acknowledgements}

The research was carried out as part of the AMBIPAH project (mechanism-based approaches to improved cancer risk assessment of ambient air polycyclic aromatic hydrocarbons), funded by the European Union (No. QRLT-2001-024202) 


\section{REFERENCES}

1. IARC (1973) Certain polycyclic aromatic hydrocarbons and heterocyclic compounds. IARC Monogr Eval Carcinog Risk Chem Hum, 3, 1-271.

2. IARC (1983) Polynuclear aromatic compounds, Part 1, Chemical, environmental and experimental data. IARC Monogr Eval Carcinog Risk Chem Hum, 32, 1-453.

3. Melendez-Colon, V.J., Luch, A., Seidel, A. and Baird, W.M. (2000) Formation of stable DNA adducts and apurinic sites upon metabolic activation of bay and fjord region polycyclic aromatic hydrocarbons in human cell cultures. Chem Res Toxicol, 13, 10-7.

4. Xue, W. and Warshawsky, D. (2005) Metabolic activation of polycyclic and heterocyclic aromatic hydrocarbons and DNA damage: a review. Toxicol Appl Pharmacol, 206, 73-93.

5. Ross, J.A., Nelson, G.B., Wilson, K.H., Rabinowitz, J.R., Galati, A., Stoner, G.D., Nesnow, S. and Mass, M.J. (1995) Adenomas induced by polycyclic aromatic hydrocarbons in strain A/J mouse lung correlate with time-integrated DNA adduct levels. Cancer Res, 55, 1039-44.

6. Kriek, E., Rojas, M., Alexandrov, K. and Bartsch, H. (1998) Polycyclic aromatic hydrocarbon-DNA adducts in humans: relevance as biomarkers for exposure and cancer risk. Mutat Res, 400, 215-31.

7. Harrigan, J.A., Vezina, C.M., McGarrigle, B.P., Ersing, N., Box, H.C., Maccubbin, A.E. and Olson, J.R. (2003) DNA Adduct Formation in Precision-Cut Rat Liver and Lung Slices Exposed to Benzo(a)pyrene. Toxicol Sci.

8. Arif, J.M., Smith, W.A. and Gupta, R.C. (1999) DNA adduct formation and persistence in rat tissues following exposure to the mammary carcinogen dibenzo[a,l]pyrene. Carcinogenesis, 20, 1147-50.

9. Segerback, D. and Vodicka, P. (1993) Recoveries of DNA adducts of polycyclic aromatic hydrocarbons in the 32P-postlabelling assay. Carcinogenesis, 14, 2463-9.

10. Shimada, T. and Fujii-Kuriyama, Y. (2004) Metabolic activation of polycyclic aromatic hydrocarbons to carcinogens by cytochromes P450 1A1 and 1B1. Cancer Sci, 95, 1-6.

11. Shimada, T., Sugie, A., Shindo, M., Nakajima, T., Azuma, E., Hashimoto, M. and Inoue, K. (2003) Tissue-specific induction of cytochromes P450 1A1 and 1B1 by polycyclic aromatic hydrocarbons and polychlorinated biphenyls in engineered C57BL/6J mice of arylhydrocarbon receptor gene. Toxicol Appl Pharmacol, 187, 1-10.

12. Melendez-Colon, V.J., Luch, A., Seidel, A. and Baird, W.M. (1999) Cancer initiation by polycyclic aromatic hydrocarbons results from formation of stable DNA adducts rather than apurinic sites. Carcinogenesis, 20, 1885-91.

13. Machala, M., Vondracek, J., Blaha, L., Ciganek, M. and Neca, J.V. (2001) Aryl hydrocarbon receptormediated activity of mutagenic polycyclic aromatic hydrocarbons determined using in vitro reporter gene assay. Mutat Res, 497, 49-62.

14. Solhaug, A., Refsnes, M., Lag, M., Schwarze, P.E., Husoy, T. and Holme, J.A. (2004) Polycyclic aromatic hydrocarbons induce both apoptotic and anti-apoptotic signals in Hepa1c1c7 cells. Carcinogenesis, 25, 809-19.

15. Bostrom, C.E., Gerde, P., Hanberg, A., Jernstrom, B., Johansson, C., Kyrklund, T., Rannug, A., Tornqvist, M., Victorin, K. and Westerholm, R. (2002) Cancer risk assessment, indicators, and guidelines for polycyclic aromatic hydrocarbons in the ambient air. Environ Health Perspect, 110 Suppl 3, 451-88.

16. Nisbet, I.C. and LaGoy, P.K. (1992) Toxic equivalency factors (TEFs) for polycyclic aromatic hydrocarbons (PAHs). Regul Toxicol Pharmacol, 16, 290-300.

17. Collins, J.F., Brown, J.P., Alexeeff, G.V. and Salmon, A.G. (1998) Potency equivalency factors for some polycyclic aromatic hydrocarbons and polycyclic aromatic hydrocarbon derivatives. Regul Toxicol Pharmacol, 28, 45-54. 
18. Hu, T., Gibson, D.P., Carr, G.J., Torontali, S.M., Tiesman, J.P., Chaney, J.G. and Aardema, M.J. (2004) Identification of a gene expression profile that discriminates indirect-acting genotoxins from direct-acting genotoxins. Mutat Res, 549, 5-27.

19. van Delft, J.H.M., van Agen, E., van Breda, S.G.J., Herwijnen, M.H.M., Staal, Y.C.M.. and Kleinjans, J.C. (2004) Discrimination of genotoxic from non-genotoxic carcinogens by gene expression profiling. Carcinogenesis, 25, 1265-76.

20. Parrish, A.R., Fisher, R., Bral, C.M., Burghardt, R.C., Gandolfi, A.J., Brendel, K. and Ramos, K.S. (1998) Benzo(a)pyrene-induced alterations in growth-related gene expression and signaling in precision-cut adult rat liver and kidney slices. Toxicol Appl Pharmacol, 152, 302-8.

21. Hashemi, E., Dobrota, M., Till, C. and Ioannides, C. (1999) Structural and functional integrity of precision-cut liver slices in xenobiotic metabolism: a comparison of the dynamic organ and multiwell plate culture procedures. Xenobiotica, 29, 11-25.

22. Staal, Y.C.M., van Herwijnen, M.H.M., van Schooten, F.J. and van Delft, J.H.M. (2005) Application of four dyes in gene expression analyses by microarrays. BMC Genomics, 6, 101.

23. Tibshirani, R., Hastie, T., Narasimhan, B. and Chu, G. (2002) Diagnosis of multiple cancer types by shrunken centroids of gene expression. Proc Natl Acad Sci U S A, 99, 6567-72.

24. Doniger, S.W., Salomonis, N., Dahlquist, K.D., Vranizan, K., Lawlor, S.C. and Conklin, B.R. (2003) MAPPFinder: using Gene Ontology and GenMAPP to create a global gene-expression profile from microarray data. Genome Biol, 4, R7.

25. Dahlquist, K.D., Salomonis, N., Vranizan, K., Lawlor, S.C. and Conklin, B.R. (2002) GenMAPP, a new tool for viewing and analyzing microarray data on biological pathways. Nat Genet, 31, 19-20.

26. Reddy, M.V. and Randerath, K. (1986) Nuclease P1-mediated enhancement of sensitivity of 32Ppostlabeling test for structurally diverse DNA adducts. Carcinogenesis, 7, 1543-51.

27. Godschalk, R.W., Maas, L.M., Van Zandwijk, N., van 't Veer, L.J., Breedijk, A., Borm, P.J., Verhaert, J., Kleinjans, J.C. and van Schooten, F.J. (1998) Differences in aromatic-DNA adduct levels between alveolar macrophages and subpopulations of white blood cells from smokers. Carcinogenesis, 19, 81925.

28. Bardwell, L., Cook, J.G., Zhu-Shimoni, J.X., Voora, D. and Thorner, J. (1998) Differential regulation of transcription: repression by unactivated mitogen-activated protein kinase Kss1 requires the Dig1 and Dig2 proteins. Proc Natl Acad Sci U S A, 95, 15400-5.

29. Knight, L.P., Primiano, T., Groopman, J.D., Kensler, T.W. and Sutter, T.R. (1999) cDNA cloning, expression and activity of a second human aflatoxin B1-metabolizing member of the aldo-keto reductase superfamily, AKR7A3. Carcinogenesis, 20, 1215-23.

30. Spivack, S.D., Hurteau, G.J., Fasco, M.J. and Kaminsky, L.S. (2003) Phase I and II carcinogen metabolism gene expression in human lung tissue and tumors. Clin Cancer Res, 9, 6002-11.

31. Staal, Y.C.M., van Herwijnen, M.H.M., van Schooten, F.J. and van Delft, J.H.M. (2006) Modulation of gene expression and DNA adduct formation in HepG2 cells by polycyclic aromatic hydrocarbons with different carcinogenic potencies. Carcinogenesis, 27, 646-55.

32. Wu, S., Zhang, D., Zhang, Z.P., Soprano, D.R. and Soprano, K.J. (1998) Critical role of both retinoid nuclear receptors and retinoid-X-receptors in mediating growth inhibition of ovarian cancer cells by all-trans retinoic acid. Oncogene, 17, 2839-49.

33. Letterio, J.J. (2005) Disruption of the TGF-beta pathway and modeling human cancer in mice. Mutat Res, 576, 120-31.

34. Lichtor, T. and Dohrmann, G.J. (1986) Respiratory patterns in human brain tumors. Neurosurgery, 19, 896-9.

35. Rao, K.N. (1995) The significance of the cholesterol biosynthetic pathway in cell growth and carcinogenesis (review). Anticancer Res, 15, 309-14.

36. Bannasch, P., Klimek, F. and Mayer, D. (1997) Early bioenergetic changes in hepatocarcinogenesis: preneoplastic phenotypes mimic responses to insulin and thyroid hormone. J Bioenerg Biomembr, 29, 303-13. 
37. Uno, S., Dalton, T.P., Dragin, N., Curran, C.P., Derkenne, S., Miller, M.L., Shertzer, H.G., Gonzalez, F.J. and Nebert, D.W. (2006) Oral benzo[a]pyrene in Cyp1 knockout mouse lines: CYP1A1 important in detoxication, CYP1B1 metabolism required for immune damage independent of total-body burden and clearance rate. Mol Pharmacol, 69, 1103-14.

38. Fletcher, N., Wahlstrom, D., Lundberg, R., Nilsson, C.B., Nilsson, K.C., Stockling, K., Hellmold, H. and Hakansson, H. (2005) 2,3,7,8-Tetrachlorodibenzo-p-dioxin (TCDD) alters the mRNA expression of critical genes associated with cholesterol metabolism, bile acid biosynthesis, and bile transport in rat liver: a microarray study. Toxicol Appl Pharmacol, 207, 1-24.

39. Moss, S.F. and Blaser, M.J. (2005) Mechanisms of disease: Inflammation and the origins of cancer. Nat Clin Pract Oncol, 2, 90-7; quiz 1 p following 113.

40. Li, H., Chen, F., Yu, L., Liu, M., Chen, H., Zhang, Y. and Liu, X. (2002) Expression of inflammation related enzymes during experimental rat lung carcinogenesis. Zhonghua Zhong Liu Za Zhi, 24, 316-9.

41. Gao, Y., Zhang, Z., Jiang, Z.S., Fang, S.G., Sun, E.W., Wang, Y. and Chen, B.H. (2002) Dynamic changes of matrix metalloproteinases in rat liver during the development of diethylnitrosamineinduced hepatocarcinoma. Di Yi Jun Yi Da Xue Xue Bao, 22, 865-8. 



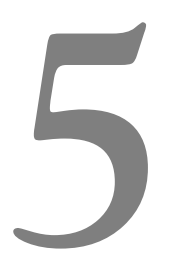

Similarities in gene expression modulation in lung and liver of $\mathrm{CD} 2 \mathrm{~F} 1$ mice by polycyclic aromatic hydrocarbons at equally mutagenic doses

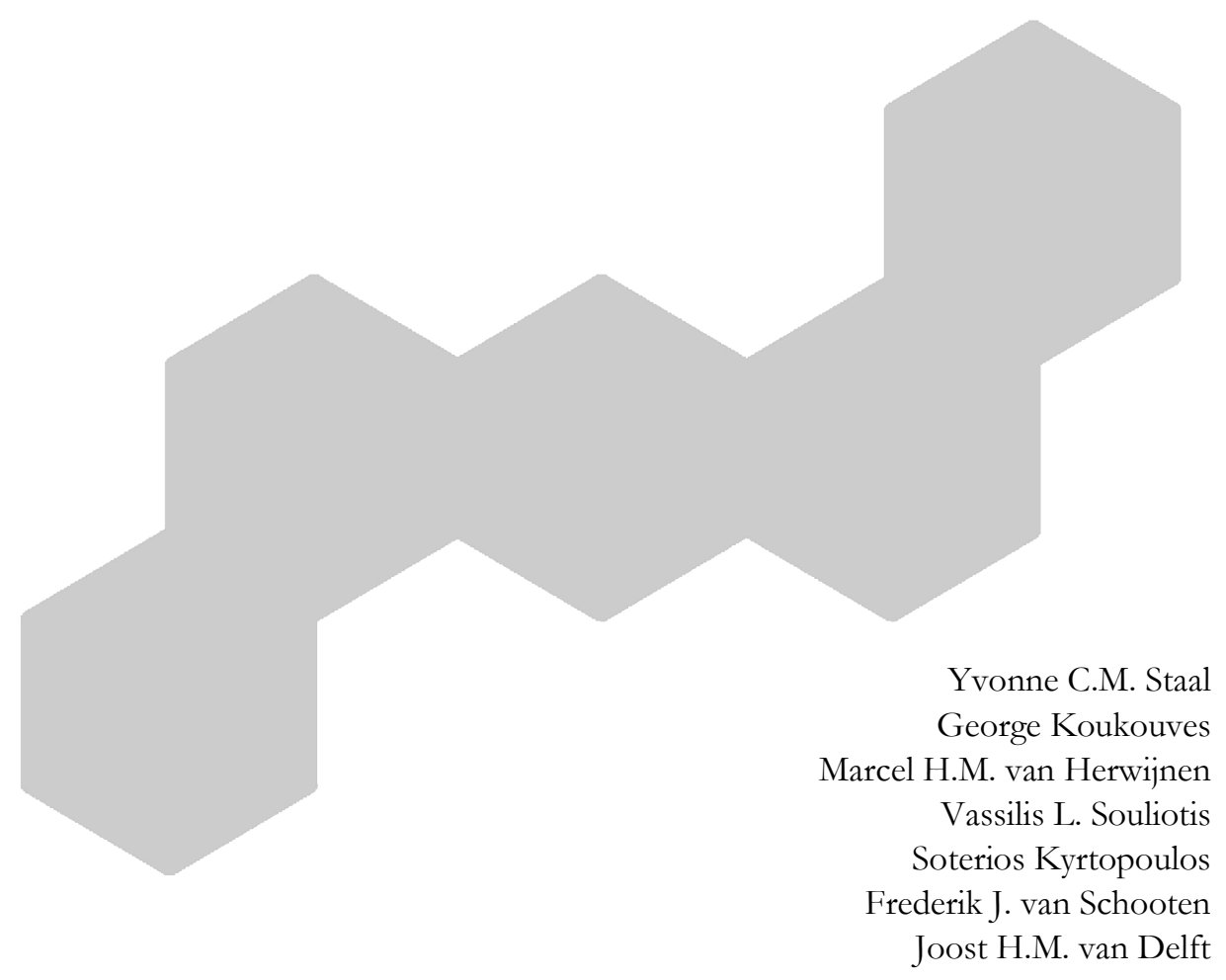




\section{ABSTRACT}

Polycyclic aromatic hydrocarbons (PAHs) are ubiquitous in ambient air and comprise a large class of structurally related compounds with varying mutagenic and carcinogenic potencies. As mutagenic potency of a PAH is important for its carcinogenic potency, we aimed to find similarities in gene expression modulation between PAHs dosed at equal mutagenic doses, which can help us to gain insight into the biological processes involved in PAH carcinogenesis. Therefore, we assessed gene expression modulation in liver and lung of $\mathrm{CD} 2 \mathrm{~F} 1$ mice by PAHs administered at equal mutagenic doses. These doses were based on a previous dose finding study inMutaMice. The PAHs were administered by i.p. injection to $\mathrm{CD} 2 \mathrm{~F} 1$ mice. Doses were for benzo[a]pyrene $(\mathrm{B}[\mathrm{a}] \mathrm{P})$ $50 \mathrm{mg} / \mathrm{kg}$ and $100 \mathrm{mg} / \mathrm{kg}$, for benzo[b]fluoranthene (B[b]F) 400 and $600 \mathrm{mg} / \mathrm{kg}$, for dibenzo[a,h]anthracene $(\mathrm{DB}[\mathrm{a}, \mathrm{h}] \mathrm{A}) 2.5$ and $5 \mathrm{mg} / \mathrm{kg}$ and for dibenzo[a,l]pyrene $(\mathrm{DB}[\mathrm{a}, \mathrm{l}] \mathrm{P}) 4$ and $9 \mathrm{mg} / \mathrm{kg}$. Gene expression modulation was assessed 24h posttreatment in lung and liver with Agilent arrays containing $22 \mathrm{k}$ probes. Generally, the gene expression differences were higher in the liver than in the lung. Gene expression profiles tended to be compound-specific, and differing more between organs than between compounds. Nine genes were similarly regulated by all compounds in both tissues. Some of these genes are involved in metabolism and some in DNA damage response and stress response. Generally, we found that for all compounds the induced gene expression profiles were similar in the lung and in the liver. Genes affected similarly by all treatments in either lung ( 89 genes) or liver ( 71 genes) are involved in processes related to carcinogenesis. The gene expression profiles indicate that several pathways were affected, but none by all compounds. No pathways involved in DNA damage response were significantly affected. However, the finding that pathways involved in oxidative stress and cell cycle were affected, could be indicative for PAH toxicity and mutagenicity. This study shows that several genes were similarly modulated in lung or liver by different PAHs at equally mutagenic doses. Some of these genes were involved in DNA damage response and might play a role in PAH induced mutagenicity. As the overlap between genes similarly modulated in liver and in lung was small, this might indicate that differences in gene expression may lay behind the difference in susceptibility of these organs to the effects of PAH exposure. Furthermore, pathway analysis showed that several pathways were affected, including pathways related to oxidative stress response and cell cycle control, which might be related to PAH toxicity and mutagenicity. 


\section{INTRODUCTION}

Polycyclic aromatic hydrocarbons (PAHs) comprise a large class of structurally related chemicals which are present in the air due to incomplete combustion of organic compounds. Although structurally alike, PAHs have a diverse range in mutagenic and carcinogenic potency. Many PAHs induce tumour formation in mice, whereas other PAHs are not tumorigenic. Of importance for mutagenic and carcinogenic potency of PAHs, is the ability of cells to convert them into reactive metabolites.

PAHs bind to the Ah receptor, which subsequently translocates to the nucleus and induces the expression of several Ah-receptor controlled genes, among which are those for several Cytochrome P450 enzymes (e.g. CYP1A1, CYP1A2 and CYP1B1) (1), which can metabolize PAHs to reactive intermediates (2,3). Many PAHs are able to bind to DNA after metabolic activation and thereby form DNA adducts. When such DNA adducts are not properly removed or repaired, mutations can occur during cell division, which may induce cancer development (4). Although different PAH-adducts are repaired with different accuracy and at different rate, DNA adduct formation has been shown to correlate with mutagenic and carcinogenic potency of PAHs (5,6). In addition to genotoxicity, PAHs can also induce epigenetic effects, which may lead to changes in biological processes, like cellular communication $(7,8)$ and cell proliferation (9), and ultimately may promote cancer development. PAHs can also induce changes in biological processes by the effect on the transcription of genes (10), which may be related to their mutagenic and carcinogenic potency.

Lung is the primary target for environmental PAH exposure by inhalation. Because of its capacity to metabolise PAHs (11), the lung forms a potential target for the adverse effects of PAHs, such as carcinogenesis (12,13). The liver is also known to metabolise many xenobiotic compounds, including PAHs, owing to its high levels of biotransformation enzymes, and is therefore also susceptible to adverse effects of PAHs, such as mutagenesis (14).

In the present study, our aim was to gain insight into the biological processes involved in PAH carcinogenesis by assessing similarities in gene expression modulation by various PAHs at equally mutagenic doses. Therefore, we studied the effects on the expression of several genes in lung and liver after exposure of CD2F1 mice to PAHs, and compared the overall gene expression profiles as well as the expression of selected genes. This may help us to better understand the biological processes involved in PAH induced carcinogenesis.

For this study, we selected four PAHs, namely benzo[a]pyrene $(\mathrm{B}[\mathrm{a}] \mathrm{P})$, benzo[b]fluoranthene $(\mathrm{B}[\mathrm{b}] \mathrm{F}), \quad$ dibenzo[a,l]pyrene $\quad(\mathrm{DB}[\mathrm{a}, 1] \mathrm{P}) \quad$ and 
dibenzo[a,h]anthracene (DB[a,h]A), based on their environmental occurrence and their carcinogenic potency. Previous studies have shown that these PAHs are all mutagenic (15-17). Doses were based on previous mutagenicity studies in MutaMice (Koukouves et al, in preparation). CD2F1 mice were injected intra peritoneally (i.p.) at two dose levels with each of the four PAHs and gene expression in lung and liver was studied $24 \mathrm{~h}$ post-treatment, using $22 \mathrm{~K}$ mouse oligonucleotide arrays from Agilent Technologies.

\section{MATERIALS AND METHODS}

\section{Chemicals}

Benzo[a]pyrene (B[a]P, purity 97\%, CAS no. 50-32-8), benzo[b]fluoranthene (B[b]F, purity 98\%, CAS no. 205-99-2), dibenzo[a,h]anthracene (DB[a,h]A, purity 97\%, CAS no. 53-70-3) and dibenzo[a,l]pyrene (DB[a,l]P, purity 99,6\%, CAS no. 191-30-0) were obtained from Sigma-Aldich (Zwijndrecht, The Netherlands). All chemicals were dissolved in tricaprillin.

\section{Animals}

Male CD2F1 mice (Charles River Laboratories - Italia) were housed in plastic cages $\left(1264 \mathrm{C}\right.$ - Techniplast SA), temperature $22^{\circ} \mathrm{C}, 12 \mathrm{~h}$ light/dark cycle, 5 animals per cage according to the EU requirements, and were supplied food (RF 18 - Mucedola SRL / Italia) and water ad libitum.

\section{Treatment}

Eight week old CD2F1 mice were i.p. injected with 50 or $100 \mathrm{mg} / \mathrm{kg}$ B[a]P, 400 or 600 $\mathrm{mg} / \mathrm{kg} \mathrm{B}[\mathrm{b}] \mathrm{F}, 2.5$ or $5 \mathrm{mg} / \mathrm{kg} \mathrm{DB}[\mathrm{a}, \mathrm{h}] \mathrm{A}$, 4 or $9 \mathrm{mg} / \mathrm{kg} \mathrm{DB}[\mathrm{a}, \mathrm{l}] \mathrm{P}$, or solvent control (tricaprillin $10 \mathrm{ml} / \mathrm{kg}$ ). Each treatment group consisted of 3 animals. $24 \mathrm{~h}$ after injection, animals were sacrificed by ether anaesthetization and lung and liver tissue was removed and frozen in liquid nitrogen.

\section{RNA isolation}

After crushing the lung and liver tissue under liquid nitrogen, RNA was stabilized by dissolving the crushed powder in Trizol (Gibco/BRL, Breda, the Netherlands) and isolated according to the manufacturer's manual. RNA was purified using the RNeasy mini kit (Qiagen Westburg bv., Leusden, The Netherlands) with DNase treatment, quantity was measured spectrophotometrically in $50 \mathrm{mM} \mathrm{NaOH}$ and quality was determined using a BioAnalyzer (Agilent Technologies, Breda, The Netherlands). Only 
RNA samples which were not degraded (clear 18S and 28S peaks and RIN>6) were used for labelling and hybridization.

\section{Labelling and hybridization}

Labelling and hybridization was done according to Agilent's manual for microarrays with minor modifications. RNA $(0.5 \mu \mathrm{g})$ from PAH or vehicle treated lung or liver was transcribed into cDNA of which half was labelled with Cyanine 5 (Cy5). Parallel $1 \mu \mathrm{g}$ RNA from lung or liver of untreated mice, the common reference sample, was transcribed into cDNA, and labelled with Cyanine 3 (Cy3). cDNA synthesis and dyelabelling was performed in the same run for each hybridization. When dyeincorporation was above $7 \mathrm{pmol} / \mu \mathrm{g}$ RNA, $2 \mu \mathrm{g}$ of cRNA of the treated samples and $2 \mu \mathrm{g}$ cRNA of the common reference sample was applied on the G4121A Agilent 22K Mouse Oligo Microarray. Hybridization and washing was done according to Agilent's manual and slides were scanned on a ScanArrayExpress (Packard Biochip Technologies, Perkin Elmer life sciences, Boston, USA) with fixed laser power (100\%) and PMT gain (55\% for Cy5 and 60\% for Cy3).

\section{Microarray data analysis}

The images (10 micron resolution; 16 bit tiff) were processed with ImaGene 6.0 software (BioDiscovery Inc., Los Angeles, USA) to quantify spot signals. Irregular spots were automatically flagged and excluded from data analysis.

Data from ImaGene were transported into GeneSight software version 4.1.6 (BioDiscovery Inc., Los Angeles, USA) for further analysis. For each spot, background was subtracted and flagged spots as well as spots with a net expression level below 20 in both channels were omitted. Data were log base 2 transformed and LOWESS normalization was applied. Expression difference with the common reference was calculated and if more than one probe of a gene was present on the array, the replicates were combined while omitting outliers ( $>2$ standard deviations). Genes were significantly modulated by a PAH if $\mathrm{p}<0.001$ in the Student's t-test versus the vehicle treated control, and if the folds ratio compared to the corresponding control was at least 1.5 up-regulated or down-regulated (on non-log transformed data). Hierarchical clustering and principal component analysis was done using GeneSight tools.

\section{Pathway analysis}

Pathway analysis was carried out using GenMAPP version 2.0 software (Gladstone institutes, University of California, San Francisco, USA) and local maps from GenMAPP (gene database Mm-Std_20051114 and maps Mm_Contributed_20051212 from www.GenMAPP.org). For each treatment, all modulated genes were included in the 
analysis. Pathways with a z-score higher than 2 and at least 2 affected genes, were significantly modulated by the treatment.

\section{RESULTS}

CD2F1 mice were i.p. treated with each of the four PAHs and sacrificed $24 \mathrm{~h}$ posttreatment. Gene expression modulation in lung and liver tissue was examined. All treatments affected gene expression in both tissues. Results are described for lung and liver separately, followed by a comparison between lung and liver gene expression modulation.

\section{Lung}

After treatment with the PAHs, a total of 165 genes were significantly modulated in the lung. Modulated genes with their standard deviation, names and genbank accession numbers are shown in the supplemented data file (http://fdgwgratsrv0401.unimaas.nl/data). Table 5.1 shows the number of modulated genes for each treatment and the overlap between doses. Although the overlap between the different doses of a PAH seemed small, hierarchical clustering analysis showed that the gene expression responses were compound-specific (Figure 5.1). At a higher level, the four compounds segregated into two groups, one consisting of $\mathrm{B}[\mathrm{a}] \mathrm{P}$ and $\mathrm{B}[\mathrm{b}] \mathrm{F}$ and the other consisting of $\mathrm{DB}[\mathrm{a}, \mathrm{h}] \mathrm{A}$ and $\mathrm{DB}[\mathrm{a}, 1] \mathrm{P}$. The same conclusions could be drawn using principal component analysis (data not shown).

TABLE 5.1. Numbers of significantly modulated genes in mouse lung and liver after treatment with PAHs.

\begin{tabular}{|c|c|c|c|c|}
\hline Treatment & $\begin{array}{c}\text { Number of } \\
\text { modulated } \\
\text { genes in lung }\end{array}$ & $\begin{array}{c}\text { Number of genes } \\
\text { overlapping between } \\
\text { doses in lung }\end{array}$ & $\begin{array}{c}\text { Number of } \\
\text { modulated } \\
\text { genes in liver }\end{array}$ & $\begin{array}{c}\text { Number of genes } \\
\text { overlapping between } \\
\text { doses in liver }\end{array}$ \\
\hline $\begin{array}{l}\mathrm{B}[\mathrm{a}] \mathrm{P} \\
50 \mathrm{mg} / \mathrm{kg} \\
\mathrm{B}[\mathrm{a}] \mathrm{P} \\
100 \mathrm{mg} / \mathrm{kg}\end{array}$ & 20 & 3 & $\begin{array}{l}66 \\
110\end{array}$ & 14 \\
\hline $\begin{array}{l}\mathrm{B}[\mathrm{b}] \mathrm{F} \\
400 \mathrm{mg} / \mathrm{kg} \\
\mathrm{B}[\mathrm{b}] \mathrm{F} \\
600 \mathrm{mg} / \mathrm{kg}\end{array}$ & 61 & 22 & $\begin{array}{l}336 \\
224\end{array}$ & 114 \\
\hline $\begin{array}{c}\mathrm{DB}[\mathrm{a}, \mathrm{h}] \mathrm{A} \\
2.5 \mathrm{mg} / \mathrm{kg} \\
\mathrm{DB}[\mathrm{a}, \mathrm{h}] \mathrm{A} \\
5 \mathrm{mg} / \mathrm{kg} \\
\end{array}$ & 3 & 0 & $\begin{array}{l}55 \\
43\end{array}$ & 10 \\
\hline $\begin{array}{c}\mathrm{DB}[\mathrm{a}, 1] \mathrm{P} \\
4 \mathrm{mg} / \mathrm{kg} \\
\mathrm{DB}[\mathrm{a}, 1] \mathrm{P} \\
9 \mathrm{mg} / \mathrm{kg}\end{array}$ & 9 & 0 & $\begin{array}{l}89 \\
34\end{array}$ & 7 \\
\hline
\end{tabular}


Of all genes modulated in the lung, 89 were modulated in the same direction by all treatments. These genes are related to the oxidative stress response (induction of antioxidant production) and GPCRDB class proteins.
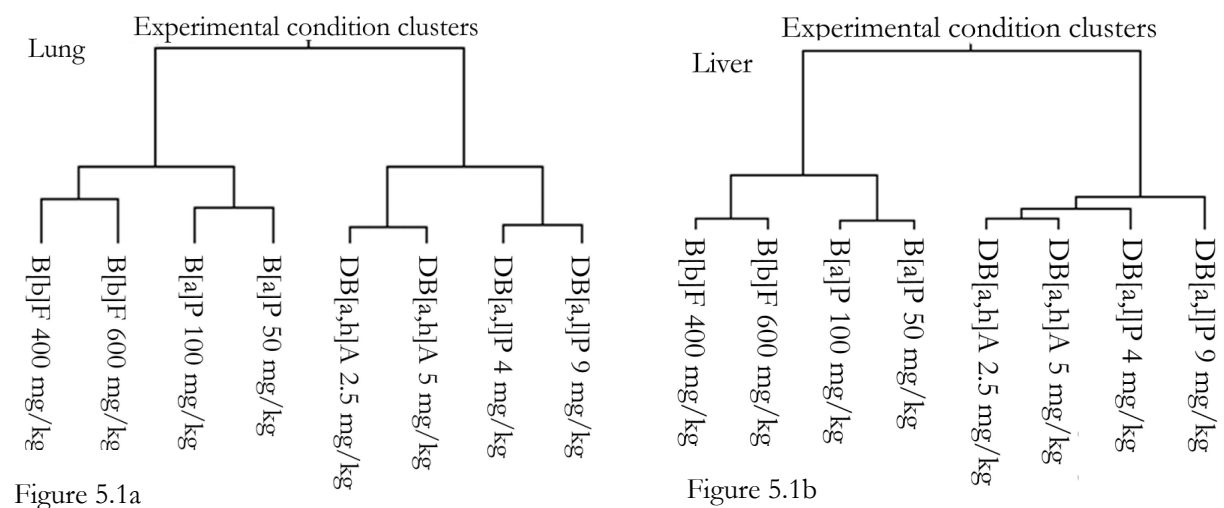

Experimental condition clusters

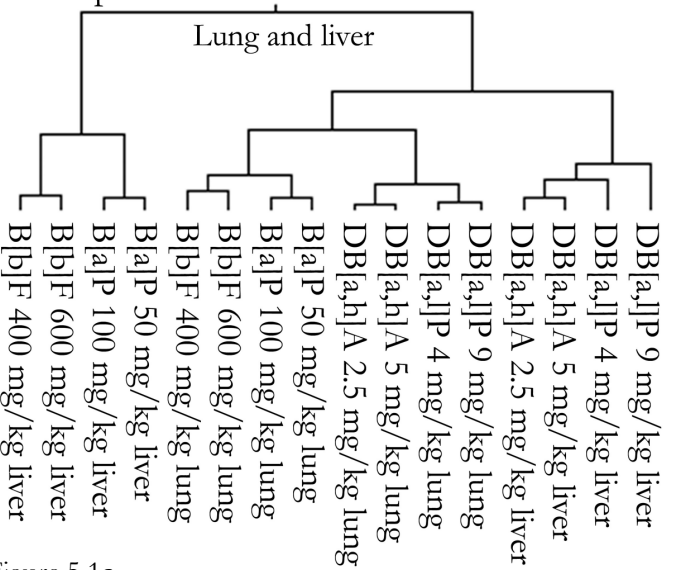

Figure 5.1c 吉

FIGURE 5.1. Hierarchical clustering analysis for lung (a), liver (b), or both lung and liver (c) with genes modulated in either mouse in the corresponding tissue(s) $24 \mathrm{~h}$ after $\mathrm{PAH}$ administration. Euclidean cluster linkage was used with average distance metrics.

Pathway analysis revealed only one pathway being affected in the lung, e.g. the oxidative stress response pathway. This analysis suggested that antioxidants producing systems were up-regulated, while reactive oxygen species-producing systems were down-regulated after $24 \mathrm{~h}$ application of $\mathrm{B}[\mathrm{a}] \mathrm{P}(100 \mathrm{mg} / \mathrm{kg})$ or $\mathrm{B}[\mathrm{b}] \mathrm{F}(400$ and $600 \mathrm{mg} / \mathrm{kg})$. 


\section{Liver}

After treatment with the PAHs, a total of 707 genes were significantly modulated in the liver. Modulated genes with their standard deviation, names and genbank accession numbers are shown in the supplemented data file (http://fdgwgratsrv0401.unimaas.nl/data). Table 5.1 shows the number of modulated genes for each treatment and the overlap between doses. As observed in the lung, the overlap between the effects of the two doses of a PAH seemed small, however, hierarchical clustering analysis again showed compound-specific effects on gene expression (Figure 5.1). Again, this was confirmed by principal component analysis (data not shown).

Of all genes modulated in the liver, 71 were modulated in the same direction by all treatments in liver. These genes are related to nuclear receptors (ROR and vitamin D3) and nuclear receptors involved in lipid metabolism and toxicity.

Pathway analysis revealed several affected pathways in the liver (Table 5.2). As seen in the lung, in the liver the oxidative stress pathway was one of those affected. However, this pathway analysis suggested that $100 \mathrm{mg} / \mathrm{kg} \mathrm{B}[\mathrm{a}] \mathrm{P}$ resulted in inhibition of antioxidant production in the liver, whereas it appeared to stimulate antioxidant production in the lung. The effects of $\mathrm{B}[\mathrm{b}] \mathrm{F}$ on the oxidative stress response pathway in the liver were similar to those in the lung, namely up-regulation of antioxidant producing systems and down-regulation of reactive oxygen species-producing systems. Other pathways affected in the liver included pathways related to DNA replication, G1 to S cell cycle and some pathways involved in metabolism. 
TABLE 5.2. Pathways affected $24 \mathrm{~h}$ after PAH treatment in mouse liver as revealed by analysis with GenMAPP.

\begin{tabular}{|c|c|c|c|c|c|c|c|c|}
\hline & \multicolumn{2}{|c|}{$\mathbf{B}[\mathrm{a}] \mathbf{P}$} & \multicolumn{2}{|c|}{$\mathrm{B}[\mathrm{b}] \mathrm{F}$} & \multicolumn{2}{|c|}{$\mathrm{DB}[\mathrm{a}, \mathrm{h}] \mathrm{A}$} & \multicolumn{2}{|c|}{$\mathrm{DB}[\mathrm{a}, 1] P$} \\
\hline & 50 & 100 & 400 & 600 & 2.5 & 5 & 4 & 9 \\
\hline $\begin{array}{l}\text { Biogenic Amine } \\
\text { Synthesis }\end{array}$ & & & $\downarrow$ & $?$ & & & & \\
\hline Circadian Exercise & & & $?$ & & & & $\downarrow$ & \\
\hline $\begin{array}{l}\text { DNA replication } \\
\text { Reactome }\end{array}$ & & & & $\downarrow$ & & & & \\
\hline $\begin{array}{l}\text { Fatty Acid Beta } \\
\text { Oxidation }\end{array}$ & $\downarrow$ & & $?$ & & & & & \\
\hline $\begin{array}{l}\text { G1 to } S \text { cell cycle } \\
\text { Reactome }\end{array}$ & & & & $\downarrow$ & & & & \\
\hline $\begin{array}{l}\text { Glucocorticoid } \\
\text { Mineralocorticoid } \\
\text { Metabolism }\end{array}$ & & & $\downarrow$ & $\downarrow$ & & & & \\
\hline $\begin{array}{l}\text { Glycogen Metabo- } \\
\text { lism }\end{array}$ & & & $\downarrow$ & & & & & \\
\hline $\begin{array}{l}\text { Inflammatory } \\
\text { Response Pathway }\end{array}$ & $\downarrow$ & & & & & & & \\
\hline $\begin{array}{l}\text { Integrin-mediated } \\
\text { cell adhesion }\end{array}$ & $?$ & & & & & & & \\
\hline Krebs-TCA Cycle & & $\downarrow$ & $\downarrow$ & & & & & \\
\hline $\begin{array}{l}\text { MAPK signaling } \\
\text { pathway }\end{array}$ & & & & & & $?$ & & \\
\hline $\begin{array}{l}\text { Nuclear receptors in } \\
\text { lipid metabolism } \\
\text { and toxicity }\end{array}$ & $?$ & $?$ & $?$ & $\uparrow$ & & & & \\
\hline Oxidative Stress & & $\begin{array}{l}\text { ROS prod } \downarrow \\
\text { antiox } \downarrow\end{array}$ & $\begin{array}{l}\text { ROS prod } \downarrow \\
\text { antiox } \uparrow\end{array}$ & $\begin{array}{l}\text { ROS prod } \downarrow \\
\text { antiox } \uparrow\end{array}$ & & & & \\
\hline $\begin{array}{l}\text { Smooth muscle } \\
\text { contraction }\end{array}$ & & & & & & & $?$ & $\uparrow$ \\
\hline Steroid Biosynthesis & & & $\downarrow$ & $\downarrow$ & & & & \\
\hline $\begin{array}{l}\text { Striated muscle } \\
\text { contraction }\end{array}$ & & & & & & & $\uparrow$ & \\
\hline $\begin{array}{l}\text { Synthesis and } \\
\text { Degradation of } \\
\text { Ketone Bodies } \\
\end{array}$ & & & $\downarrow$ & & & & & \\
\hline $\begin{array}{l}\text { Triacylglyceride } \\
\text { Synthesis }\end{array}$ & & & & $\downarrow$ & & & & \\
\hline
\end{tabular}

Induction of the pathway is indicated with $\uparrow$, inhibition with $\downarrow$, and unsure with ?. 


\section{Comparison of effects in lung and liver}

Few genes were modulated in both lung and liver (Table 5.3), suggesting that the response of these two tissues to a treatment were different. This is also supported by the results of hierarchical clustering analysis with all 851 genes modulated in either the liver or the lung (Figure 5.1), as well as principal component analysis (Figure 5.2), which shows that the effects of different PAHs within a tissue are more similar than the effects of a PAH in different tissues. Noteworthy, two pairs of PAHs, namely $\mathrm{B}[\mathrm{a}] \mathrm{P}$ and $\mathrm{B}[\mathrm{b}] \mathrm{F}$ versus $\mathrm{DB}[\mathrm{a}, \mathrm{h}] \mathrm{A}$ and $\mathrm{DB}[\mathrm{a}, 1] \mathrm{P}$, cause relatively similar effects in the lung and the liver.

TABLE 5.3. Numbers of significantly modulated genes in mouse lung and liver after treatment with PAHs in two doses and the overlap between both tissues.

\begin{tabular}{lccc}
\hline Treatment & $\begin{array}{c}\text { No. of modulated } \\
\text { genes in lung }\end{array}$ & $\begin{array}{c}\text { No. of modulated } \\
\text { genes in liver }\end{array}$ & $\begin{array}{c}\text { No. of genes overlapping } \\
\text { between lung and liver }\end{array}$ \\
\hline B[a]P 50mg/kg & 20 & 66 & 0 \\
B[a]P 100 $\mathbf{m g} / \mathbf{k g}$ & 48 & 110 & 3 \\
B[b]F 400 $\mathbf{m g} / \mathbf{k g}$ & 61 & 336 & 7 \\
B[b]F 600 $\mathbf{m g} / \mathbf{k g}$ & 55 & 224 & 12 \\
DB[a,h]A 2.5mg/kg & 3 & 55 & 0 \\
DB[a,h]A 5mg/kg & 9 & 43 & 0 \\
DB[a,1]P 4mg/kg & 9 & 89 & 0 \\
DB[a,1]P 9mg/kg & 6 & 34 & 0 \\
\hline
\end{tabular}

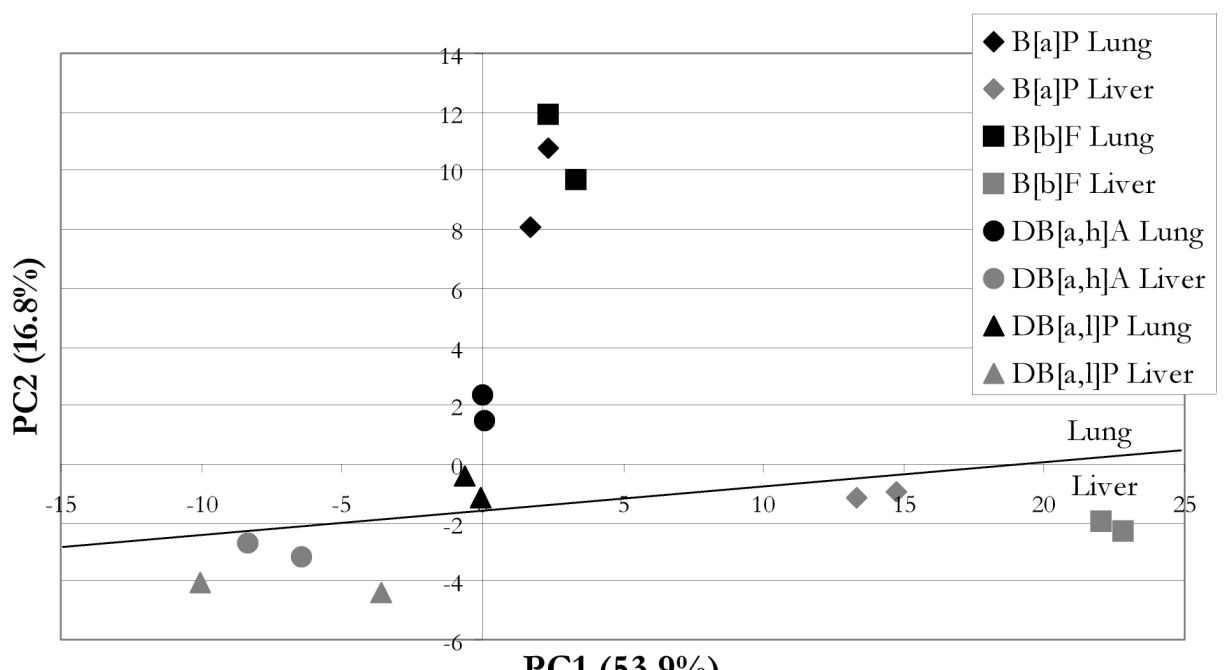

PC1 (53.9\%)

FIGURE 5.2. Principal component analysis with the 851 genes modulated in either mouse lung or liver $24 \mathrm{~h}$ after $\mathrm{PAH}$ administration. 


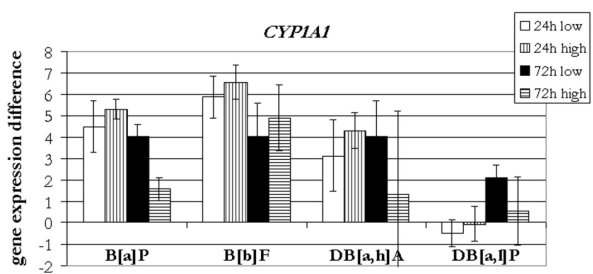

Figure 5.3a

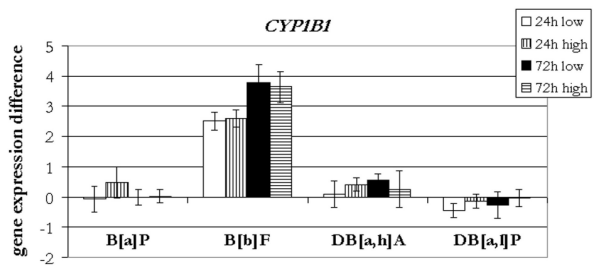

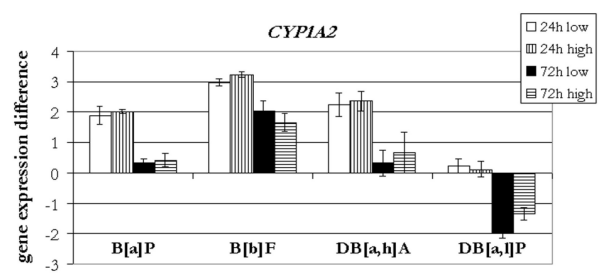

Figure 5.3b

Figure 5.3c

FIGURE 5.3. Gene expression difference for CYP1A1(a), CYP1A2(b) and CYP1B1(c) in mouse liver and lung $24 \mathrm{~h}$ after PAH treatment.

Of the 851 genes modulated in either the lung or the liver, 9 were modulated in the same direction in both tissues by all PAHs and at all concentrations. Thus, NEDD4, PLA2G1BR and CYP3A16 were down-regulated and FMO3, GSTM2, MOG, NQO1, ATG16L and an unknown EST were up-regulated by all treatments. On the other hand, four genes showed different modulation in the liver versus the lung. Examination of genes that were modulated in the same direction by at least one of the doses employed, shows that 43 genes were down-regulated and 39 genes were up-regulated. Furthermore, CYP1A1, CYP1 $A 2$ and CYP1B1, which are important for biotransformation of PAHs, generally showed up-regulation in both the liver and the lung. Figure 5.3 shows the modulation of the expression of these genes. Genes modulated in the same direction, their names and genbank accession numbers are shown in the supplemented data file (http://fdgwgratsrv0401.unimaas.nl/data).

\section{DISCUSSION}

The effects on gene expression in mouse lung and liver of equally mutagenic doses of four PAHs were assessed using microarrays. As mutagenic potency seems an important determinant of the carcinogenic potency of PAHs, we attempted to find similarities in gene expression modulation induced by the PAHs, which could help us to gain insight into the biological processes involved in PAH carcinogenesis. Therefore gene expression modulation in lung and liver after PAH exposure was assessed by looking for genes modulated by the different PAHs in the same direction in either tissue, the differences between tissues, and finally by pathway analysis of the genes modulated after PAH treatment in lung or liver. 
Gene expression was assessed $24 \mathrm{~h}$ post-treatment with a PAH. Each compound showed a compound specific effect on gene expression at the two doses tested in the liver and the lung (Figure 5.1). On the other hand, the effects of each PAH on gene expression tended to be different in lung and in liver, as indicated by the hierarchical clustering analysis and the principal component analysis (Figure 5.1 and 5.2). The gene expression differences are larger in the liver than in the lung. However, there was a greater similarity between the effects of the different PAHs within the same tissue than between the effects of a PAH on different tissues. Given that these results were obtained at equally mutagenic doses of the PAHs, this observation may reflect a link between mutagenic potency and gene expression modulation.

Generally, PAHs induce DNA adducts in liver and lung to similar levels and no prediction can be made between target organs (lung) and non-target (liver) organs on basis of DNA adduct levels. As already stated, the overlap between genes similarly modulated in liver and in lung, was small (13 genes), which indicates that differences in gene expression modulation between liver and lung do occur and this might be related to the difference in susceptibility of these organs to the mutagenic effects of PAHs.

The genes found to be similarly regulated by both doses in either lung ( 89 genes) or liver (71 genes) were related to oxidative stress and the GPCRDB class proteins (lung), or were involved in nuclear receptor pathways (liver). The oxidative stress response in the lung could be caused by the oxidative stress, which is known to be induced upon PAH exposure (18), and which might play an important role in PAH induced carcinogenicity (19). The role of the nuclear receptor pathways in carcinogenesis, which were affected by the genes similarly modulated in the liver, is unclear, but might be related to the estrogenic responses PAHs have been shown to induce $(20,21)$.

Many genes showed consistent up-regulation or down-regulation by all compounds in both tissues at at least one dose (39 up and 43 down). Some of these genes are involved in xenobiotic metabolism (Glutathione S-transferases, Cytochrome P450 enzymes). However, genes involved in DNA damage response were not among these. Focusing on genes similarly affected in either liver or lung for one dose of each PAH, however, does reveal genes involved in cell cycle, DNA damage response or carcinogenesis (NDRG1, DCLRE1C, DDIT4, CCNJ, CDC2A, CDK2AP2, CEACAM18 and CXCL12), some genes involved in stress response (heat shock proteins), and tumour necrosis factors, a TCDD inducible protein (TIPARP) and several solute carrier proteins. This suggests that these genes might be related to the mutagenic potency of PAHs.

Nine genes were similarly regulated by both doses of a PAH in both tissues. Namely ATG16L, FMO3, GSTM2, MOG, NQO1 and an unknown EST were up-regulated, and CYP3A16, NEDD4 and PLA2G1BR were down-regulated. ATG16L is involved in autophagosome formation (22). FMO3 is an enzyme that converts nucleophilic 
heteroatom-containing chemicals, drugs and xenobiotics to more polar compounds that are more efficiently excreted in the urine (23) and may be involved in PAH metabolism. Furthermore, GSTM2 is a phase II enzyme, also involved in detoxification of xenobiotics, including PAHs (24). MOG is involved as an autoantigen in multiple sclerosis. NQO1 is an enzyme involved in metabolic reduction of quinones and derivates (25) and is, like several cytochrome P450 enzymes, controlled by the Ahreceptor. CYP3A16 was expressed at higher levels in cytochrome P450 reductaselacking mice (26), and may also be involved in metabolism of PAHs. NEDD4 is a family of different enzymes with related function which is largely unknown (27). PLA2G1BR is involved in cell proliferation, cell migration, lipid mediator production and may also have a role in the production of pro-inflammatory cytokines (28). Its consistent down-regulation indicates a pro-carcinogenic effect of PAHs. Generally, many up-regulated genes are involved in metabolism, which can be related to elimination of PAHs after exposure.

Among the various biotransformation enzymes whose expression was affected (Figure 5.3), CYP1 A1 was up-regulated in both liver and lung, whereas the expression of CYP1A2 was preferentially up-regulated in the liver and that of CYP1B1 was preferentially up-regulated in the lung. These effects reflect the known tissue differences in biotransformation enzymes for PAHs, and is in agreement with previous reports (29). Of the four PAHs tested, DB[a,l]P is the only compound which did not cause significant induction of the expression of CYP1A1. Indeed, it is known that DB[a,l]P is a weak activator of the Ah-receptor (30).

Pathway analysis for each PAH treatment showed that several pathways were affected by the different treatments in the liver, whereas in the lung only the oxidative stress response pathway was affected. This pathway was affected by $\mathrm{B}[\mathrm{a}] \mathrm{P}$ and $\mathrm{B}[\mathrm{b}] \mathrm{F}$ treatment in both tissues, implying altered gene expression leading to decreased $(\mathrm{B}[\mathrm{a}] \mathrm{P})$ or increased $(\mathrm{B}[\mathrm{b}] \mathrm{F})$ levels of antioxidants and suppression of reactive oxygen species (ROS) (both B[a]P and B[b]F). Such induction of enzymes involved in repression of oxidative stress, might be related to the reactive intermediates formed during $\mathrm{PAH}$ metabolism (31).

Furthermore, DNA replication and G1 to $\mathrm{S}$ transition was inhibited after B[b]F treatment. It is known that PAHs induce induce DNA adduct formation $(12,32,33)$ and cell cycle arrest (34). This may be due to the need of the cell to repair the DNA damage by inhibiting DNA replication and arresting the cell cycle. Only B[b]F induced these pathways, which might be due to the higher doses of the compound, or other mechanisms of carcinogenicity involved in $\mathrm{B}[\mathrm{b}] \mathrm{F}$ exposure.

The modulation of some of the other affected pathways, like fatty acid beta oxidation, Krebs TCA cycle, glycogen metabolism and synthesis and degradation of ketone bodies, might be related to the increased energy requirement of the cells in the first 
stages of tumorigenesis. Tumour cells have been found to have no or impaired ketone body metabolism (35). Also, dysfunction of mitochondria, which are important in energy metabolism of the cell, is related to apoptosis and tumorigenesis (reviewed in (36)). Furthermore, DB[a,l]P affects muscle contraction. Non-carcinogenic PAHs have been suggested to pose a possible risk for the vascular system resulting in cardiovascular disorders (37), which might relate to muscle contraction.

Overall it seems that several pathways were affected by the four PAHs, but no pathway was affected by all compounds. It is notable that, contrary to the expectations, pathways involved in DNA damage response were not among those affected. On the other hand, the modulation of pathways involved in oxidative stress response and cell cycle control might reflect a link with PAH toxicity and mutagenicity. Possibly DNA damage response is activated later, or may be modulated at the protein level.

\section{CONCLUSION}

This study shows that several genes were similarly modulated in lung or liver by different PAHs at equally mutagenic doses. Some of these genes were involved in DNA damage response and might play a role in $\mathrm{PAH}$ induced mutagenicity. As the overlap between genes similarly modulated in liver and in lung was small, this might indicate that differences in gene expression may lay behind the difference in susceptibility of these organs to the effects of PAH exposure. Furthermore, pathway analysis showed that several pathways were affected, including pathways related to oxidative stress response and cell cycle control, which might be related to $\mathrm{PAH}$ toxicity and mutagenicity.

\section{Acknowledgements}

The research was carried out as part of the AMBIPAH project (Mechanism-based approaches to improved cancer risk assessment of ambient air polycyclic aromatic hydrocarbons), funded by the European Union (No. QRLT-2001-024202). 


\section{REFERENCES}

1. Shimada, T., Sugie, A., Shindo, M., Nakajima, T., Azuma, E., Hashimoto, M. and Inoue, K. (2003) Tissue-specific induction of cytochromes P450 1A1 and 1B1 by polycyclic aromatic hydrocarbons and polychlorinated biphenyls in engineered C57BL/6J mice of arylhydrocarbon receptor gene. Toxicol Appl Pharmacol, 187, 1-10.

2. Mollerup, S., Berge, G., Baera, R., Skaug, V., Hewer, A., Phillips, D.H., Stangeland, L. and Haugen, A. (2006) Sex differences in risk of lung cancer: Expression of genes in the PAH bioactivation pathway in relation to smoking and bulky DNA adducts. Int J Cancer, 119, 741-4.

3. Uno, S., Dalton, T.P., Dragin, N., Curran, C.P., Derkenne, S., Miller, M.L., Shertzer, H.G., Gonzalez, F.J. and Nebert, D.W. (2006) Oral benzo[a]pyrene in Cyp1 knockout mouse lines: CYP1A1 important in detoxication, CYP1B1 metabolism required for immune damage independent of total-body burden and clearance rate. Mol Pharmacol, 69, 1103-14.

4. Hartwig, A. (2002) Role of DNA repair in particle- and fiber-induced lung injury. Inhal Toxicol, 14, 91-100.

5. Ross, J.A., Nelson, G.B., Wilson, K.H., Rabinowitz, J.R., Galati, A., Stoner, G.D., Nesnow, S. and Mass, M.J. (1995) Adenomas induced by polycyclic aromatic hydrocarbons in strain A/J mouse lung correlate with time-integrated DNA adduct levels. Cancer Res, 55, 1039-44.

6. Ayrton, A.D., McFarlane, M., Walker, R., Neville, S., Coombs, M.M. and Ioannides, C. (1990) Induction of the P-450 I family of proteins by polycyclic aromatic hydrocarbons: possible relationship to their carcinogenicity. Toxicology, 60, 173-86.

7. Blaha, L., Kapplova, P., Vondracek, J., Upham, B. and Machala, M. (2002) Inhibition of gap-junctional intercellular communication by environmentally occurring polycyclic aromatic hydrocarbons. Toxicol Sci, 65, 43-51.

8. Rosenkranz, H.S., Pollack, N. and Cunningham, A.R. (2000) Exploring the relationship between the inhibition of gap junctional intercellular communication and other biological phenomena. Carcinogenesis, 21, 1007-11.

9. Pliskova, M., Vondracek, J., Vojtesek, B., Kozubik, A. and Machala, M. (2004) Deregulation of Cell Proliferation by Polycyclic Aromatic Hydrocarbons in Human Breast Carcinoma MCF-7 Cells Reflects Both Genotoxic and Nongenotoxic Events. Toxicol Sci.

10. Solhaug, A., Refsnes, M., Lag, M., Schwarze, P.E., Husoy, T. and Holme, J.A. (2004) Polycyclic aromatic hydrocarbons induce both apoptotic and anti-apoptotic signals in Hepa1c1c7 cells. Carcinogenesis, 25, 809-19.

11. Elovaara, E., Mikkola, J., Stockmann-Juvala, H., Luukkanen, L., Keski-Hynnila, H., Kostiainen, R., Pasanen, M., Pelkonen, O. and Vainio, H. (2006) Polycyclic aromatic hydrocarbon (PAH) metabolizing enzyme activities in human lung, and their inducibility by exposure to naphthalene, phenanthrene, pyrene, chrysene, and benzo(a)pyrene as shown in the rat lung and liver. Arch Toxicol.

12. Nesnow, S., Ross, J.A., Mass, M.J. and Stoner, G.D. (1998) Mechanistic relationships between DNA adducts, oncogene mutations, and lung tumorigenesis in strain A mice. Exp Lung Res, 24, 395-405.

13. Nesnow, S., Ross, J.A., Stoner, G.D. and Mass, M.J. (1995) Mechanistic linkage between DNA adducts, mutations in oncogenes and tumorigenesis of carcinogenic environmental polycyclic aromatic hydrocarbons in strain A/J mice. Toxicology, 105, 403-13.

14. Wall, K.L., Gao, W.S., te Koppele, J.M., Kwei, G.Y., Kauffman, F.C. and Thurman, R.G. (1991) The liver plays a central role in the mechanism of chemical carcinogenesis due to polycyclic aromatic hydrocarbons. Carcinogenesis, 12, 783-6.

15. McCann, J., Choi, E., Yamasaki, E. and Ames, B.N. (1975) Detection of carcinogens as mutagens in the Salmonella/microsome test: assay of 300 chemicals. Proc Natl Acad Sci U S A, 72, 5135-9. 
16. IARC (1973) Certain polycyclic aromatic hydrocarbons and heterocyclic compounds. IARC Monogr Eval Carcinog Risk Chem Hum, 3, 1-271.

17. IARC (1983) Polynuclear aromatic compounds, Part 1, Chemical, environmental and experimental data. IARC Monogr Eval Carcinog Risk Chem Hum, 32, 1-453.

18. Xue, W. and Warshawsky, D. (2005) Metabolic activation of polycyclic and heterocyclic aromatic hydrocarbons and DNA damage: a review. Toxicol Appl Pharmacol, 206, 73-93.

19. Shen, Y.M., Troxel, A.B., Vedantam, S., Penning, T.M. and Field, J. (2006) Comparison of p53 Mutations Induced by PAH o-Quinones with Those Caused by anti-Benzo[a]pyrene Diol Epoxide in vitro: Role of Reactive Oxygen and Biological Selection. Chem Res Toxicol, 19, 1441-1450.

20. Charles, G.D., Bartels, M.J., Zacharewski, T.R., Gollapudi, B.B., Freshour, N.L. and Carney, E.W. (2000) Activity of benzo[a]pyrene and its hydroxylated metabolites in an estrogen receptor-alpha reporter gene assay. Toxicol Sci, 55, 320-6.

21. Villeneuve, D.L., Khim, J.S., Kannan, K. and Giesy, J.P. (2002) Relative potencies of individual polycyclic aromatic hydrocarbons to induce dioxinlike and estrogenic responses in three cell lines. Environ Toxicol, 17, 128-37.

22. Mizushima, N., Kuma, A., Kobayashi, Y., Yamamoto, A., Matsubae, M., Takao, T., Natsume, T., Ohsumi, Y. and Yoshimori, T. (2003) Mouse Apg16L, a novel WD-repeat protein, targets to the autophagic isolation membrane with the Apg12-Apg5 conjugate. J Cell Sci, 116, 1679-88.

23. Cashman, J.R. (2000) Human flavin-containing monooxygenase: substrate specificity and role in drug metabolism. Curr Drug Metab, 1, 181-91.

24. Sheehan, D., Meade, G., Foley, V.M. and Dowd, C.A. (2001) Structure, function and evolution of glutathione transferases: implications for classification of non-mammalian members of an ancient enzyme superfamily. Biochem J, 360, 1-16.

25. Iskander, K., Li, J., Han, S., Zheng, B. and Jaiswal, A.K. (2006) NQO1 and NQO2 Regulation of Humoral Immunity and Autoimmunity. J Biol Chem, 281, 30917-24.

26. Wang, X.J., Chamberlain, M., Vassieva, O., Henderson, C.J. and Wolf, C.R. (2005) Relationship between hepatic phenotype and changes in gene expression in cytochrome P450 reductase (POR) null mice. Biochem J, 388, 857-67.

27. Ingham, R.J., Gish, G. and Pawson, T. (2004) The Nedd4 family of E3 ubiquitin ligases: functional diversity within a common modular architecture. Oncogene, 23, 1972-84.

28. Hanasaki, K. and Arita, H. (2002) Phospholipase A2 receptor: a regulator of biological functions of secretory phospholipase A2. Prostaglandins Other Lipid Mediat, 68-69, 71-82.

29. Harrigan, J.A., McGarrigle, B.P., Sutter, T.R. and Olson, J.R. (2006) Tissue specific induction of cytochrome P450 (CYP) 1A1 and 1B1 in rat liver and lung following in vitro (tissue slice) and in vivo exposure to benzo(a)pyrene. Toxicol In vitro, 20, 426-38.

30. Staal, Y.C.M., van Herwijnen, M.H.M., Pushparajah, D.S., Umachandran, M., Ioannides, C., van Schooten, F.J. and van Delft, J.H.M. (2007) Modulation of gene expression and DNA-adduct formation in precision-cut liver slices exposed to polycyclic aromatic hydrocarbons of different carcinogenic potency. Mutagenesis, 22, 55-62.

31. Park, J.H., Gopishetty, S., Szewczuk, L.M., Troxel, A.B., Harvey, R.G. and Penning, T.M. (2005) Formation of 8-oxo-7,8-dihydro-2'-deoxyguanosine (8-oxo-dGuo) by PAH o-quinones: involvement of reactive oxygen species and copper(II)/copper(I) redox cycling. Chem Res Toxicol, 18, 1026-37.

32. Keshava, C., Divi, R.L., Whipkey, D.L., Frye, B.L., McCanlies, E., Kuo, M., Poirier, M.C. and Weston, A. (2005) Induction of CYP1A1 and CYP1B1 and formation of carcinogen-DNA adducts in normal human mammary epithelial cells treated with benzo[a]pyrene. Cancer Lett, 221, 213-24.

33. Perera, F.P., Hemminki, K., Gryzbowska, E., Motykiewicz, G., Michalska, J., Santella, R.M., Young, T.L., Dickey, C., Brandt-Rauf, P., De Vivo, I. and et al. (1992) Molecular and genetic damage in humans from environmental pollution in Poland. Nature, 360, 256-8.

34. Binkova, B., Giguere, Y., Rossner, P., Jr., Dostal, M. and Sram, R.J. (2000) The effect of dibenzo[a,l]pyrene and benzo[a]pyrene on human diploid lung fibroblasts: the induction of DNA adducts, expression of p53 and p21(WAF1) proteins and cell cycle distribution. Mutat Res, 471, 57-70. 
35. Seyfried, T.N., Sanderson, T.M., El-Abbadi, M.M., McGowan, R. and Mukherjee, P. (2003) Role of glucose and ketone bodies in the metabolic control of experimental brain cancer. Br J Cancer, 89, 1375-82.

36. Eng, C., Kiuru, M., Fernandez, M.J. and Aaltonen, L.A. (2003) A role for mitochondrial enzymes in inherited neoplasia and beyond. Nat Rev Cancer, 3, 193-202.

37. Kang, J.J. and Cheng, Y.W. (1997) Polycyclic aromatic hydrocarbons-induced vasorelaxation through activation of nitric oxide synthase in endothelium of rat aorta. Toxicol Lett, 93, 39-45. 



\section{Binary PAH-mixtures cause additive or antagonistic effects on gene expression but synergistic effects on DNA adduct formation}

Submitted for publication

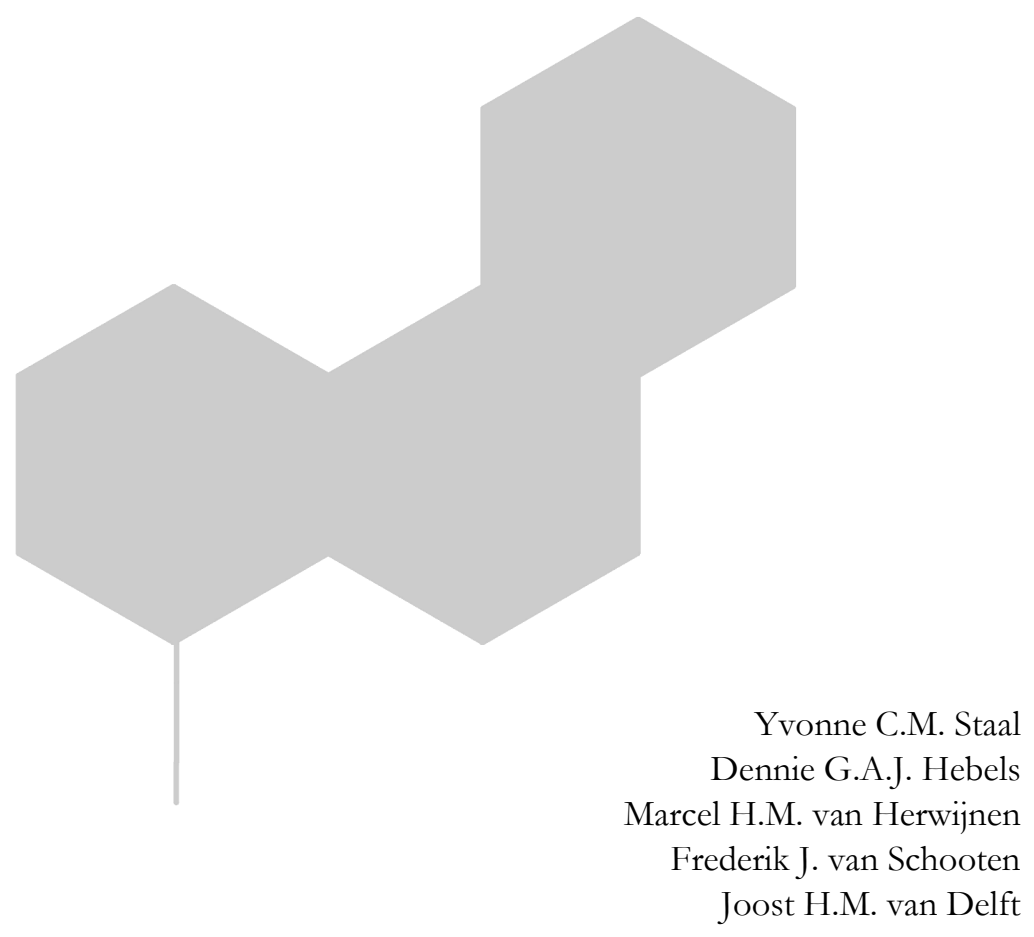




\begin{abstract}
Polycyclic aromatic hydrocarbons (PAHs) cover a wide range of structurally related compounds which differ greatly in their carcinogenic potency. PAH exposure usually occurs through mixtures rather than individual compounds. Therefore, we assessed whether the effects of binary PAH mixtures on gene expression, DNA adduct formation, apoptosis and cell cycle are additive compared to the effects of the individual compounds in human hepatoma cells (HepG2). Equimolar and equitoxic mixtures of benzo[a]pyrene $(\mathrm{B}[\mathrm{a}] \mathrm{P})$ with either dibenzo[a,l]pyrene (DB[a,1]P), dibenzo[a,h]anthracene $(\mathrm{DB}[\mathrm{a}, \mathrm{h}] \mathrm{A})$, benzo[b]fluoranthene $(\mathrm{B}[\mathrm{b}] \mathrm{F})$, fluoranthene $(\mathrm{FA})$, or 1-methylphenanthrene (1-MPA) were studied. DB[a,l]P, B[a]P, DB[a,h]A and B[b]F dose-dependently increased apoptosis and blocked cells cycle in S-phase. PAH mixtures showed an additive effect on apoptosis and on cell cycle blockage. DNA adduct formation in mixtures was higher than expected based on the individual compounds, indicating a synergistic effect of PAH mixtures. Equimolar mixtures of $\mathrm{B}[\mathrm{a}] \mathrm{P}$ and $\mathrm{DB}[\mathrm{a}, 1] \mathrm{P}(0.1,0.3$ and $1.0 \mu \mathrm{M})$ were assessed for their effects on gene expression. Only at $1.0 \mu \mathrm{M}$, the mixture showed antagonism. All five compounds were also tested as a binary mixture with $\mathrm{B}[\mathrm{a}] \mathrm{P}$ in equitoxic concentrations. The combinations of $\mathrm{B}[\mathrm{a}] \mathrm{P}$ with $\mathrm{B}[\mathrm{b}] \mathrm{F}, \mathrm{DB}[\mathrm{a}, \mathrm{h}] \mathrm{A}$ or $\mathrm{FA}$ showed additivity, whereas $\mathrm{B}[\mathrm{a}] \mathrm{P}$ with $\mathrm{DB}[\mathrm{a}, 1] \mathrm{P}$ or $1-\mathrm{MPA}$ showed antagonism. Many individual genes showed additivity in mixtures, but some genes showed mostly antagonism or synergism. Our results show that the effects of binary mixtures of PAHs on gene expression are generally additive or slightly antagonistic, whereas the effects on DNA adduct formation show synergism.
\end{abstract}




\section{INTRODUCTION}

Polycyclic aromatic hydrocarbons (PAHs) are organic compounds present in the air after incomplete combustion of organic fuels. PAHs cover a wide range of structurally related compounds with a diverse range in carcinogenic and mutagenic potency.

Many PAHs bind to the Ah receptor, which trans locates to the nucleus and induces the expression of several genes, among which several genes for Cytochrome P450 enzymes (e.g. CYP1A1, CYP1A2 and CYP1B1) (1). These enzymes are capable of metabolizing PAHs to their reactive intermediates (2). PAHs vary in their affinity for the Ah-receptor and thereby the induction of Cytochrome P450 enzymes will vary accordingly (3). Many PAHs are able to bind to DNA after metabolic activation and thereby form DNA adducts. When these DNA adducts are not properly removed or repaired, mutations can occur and thereby induction of cancer development (4). Although different PAH-adducts are repaired with different accuracy and at different rate, DNA adduct formation has been shown to correlate with mutagenic potency of PAHs (4,5). DNA adducts can also affect the p53 pathway, which may lead to changes in biological processes (such as cell cycle arrest or apoptosis) (6). We have previously shown that PAHs can induce compound specific gene expression profiles in HepG2 cells and that these profiles can be related to the carcinogenic potency of the PAH (7).

PAH exposure usually occurs through mixtures, and the various compounds may modulate the effect of other compounds. PAH interactions can lead to an addition of the effect of both PAHs (additivity), or to an higher effect than expected based on additivity (synergism), or PAHs may repress the effects of the other PAH (antagonism) $(8,9)$. Either synergism or antagonism can be expected in PAH mixtures, which is further explained by two hypotheses.

The first hypothesis suggests synergism, which occurs when the metabolism of a compound is influenced by another (10). For example, when cells are exposed to B[a]P - an inducer of the CYP1A1 gene expression - in combination with a PAH which is not able to induce $C Y P 1 A 1$. The non-CYP1 $A 1$ inducing compound might be metabolized by the increased levels of CYP1A1 in a mixture and thereby induce its DNA adduct formation and its toxic and carcinogenic potency.

The second hypothesis suggests antagonism. It has been shown, that the expression of the CYP1 $A 1$ gene and protein is decreased in HepG2 cells after exposure to B[a]P and 1-nitropyrene compared to $\mathrm{B}[\mathrm{a}] \mathrm{P}$ alone (11). This was also found for mixtures of $\mathrm{B}[\mathrm{a}] \mathrm{P}$ with FA in the EROD assay (12). Theoretically, this would lead to decreased metabolism of $\mathrm{B}[\mathrm{a}] \mathrm{P}$ and thereby less DNA adduct formation and reduced toxic and carcinogenic potency of $\mathrm{B}[\mathrm{a}] \mathrm{P}$. 
This study aims to gain knowledge on interactive effects in binary PAH mixtures on gene expression profiles in human cells. To our knowledge, we are the first to study the effects of binary PAH mixtures on gene expression profiles obtained by microarray technology, combined with apoptosis, cell cycle and DNA adduct formation.

Since liver is an important organ in metabolism of xenobiotic compounds, and the human hepatoma cell line HepG2 is competent in PAH metabolism and was shown to give PAH-specific gene expression profiles, we used this cell line to study interaction between PAHs. Six PAHs were selected, namely benzo[a]pyrene (B[a]P), benzo[b]fluoranthene $(\mathrm{B}[\mathrm{b}] \mathrm{F})$, dibenzo[a,h]anthracene $(\mathrm{DB}[\mathrm{a}, \mathrm{h}] \mathrm{A})$, dibenzo[a,l]pyrene $(\mathrm{DB}[\mathrm{a}, 1] \mathrm{P})$, fluoranthene $(\mathrm{FA})$ and 1-methylphenanthrene (1-MPA). B[a]P, B[b]F and $\mathrm{DB}[\mathrm{a}, \mathrm{h}] \mathrm{A}$ induced the CYP1A1 expression, whereas $\mathrm{DB}[\mathrm{a}, 1] \mathrm{P}$ mildly induced CYP1A1 and FA and 1-MPA did not affect the expression of CYP1A1 (7). We assessed the effects of equimolar mixtures of $\mathrm{B}[\mathrm{a}] \mathrm{P}$ and $\mathrm{DB}[\mathrm{a}, 1] \mathrm{P}$ in the low toxic range as well as the effects of equitoxic mixtures of each PAH with $\mathrm{B}[\mathrm{a}] \mathrm{P}$. We measured cell cycle distribution and apoptosis by FACS analysis, DNA adduct formation by ${ }^{32} \mathrm{P}-$ postlabelling and gene expression changes by microarray analysis using a PHASE-I array containing 600 toxicologically relevant genes. All data were used to study the effects of a mixture of PAH in relation to the effects of the individual compounds using an additive model to estimate the mixture effect.

\section{MATERIALS AND METHODS}

\section{Chemicals}

Benzo[a]pyrene (B[a]P, purity 97\%, CAS no. 50-32-8), benzo[b]fluoranthene (B[b]F, purity 98\%, CAS no. 205-99-2), fluoranthene (FA, purity 99\%, CAS no. 206-44-0), dibenzo[a,h]anthracene (DB[a,h]A, purity 97\%, CAS no. 53-70-3) and dibenzo[a,l]pyrene (DB[a,1]P, purity 99.6\%, CAS no. 191-30-0) were obtained from Sigma-Aldich (Zwijndrecht, the Netherlands). 1-Methylphenanthrene (1-MPA, purity 99\%, CAS no. 832-69-9) was obtained from LGC Promchem (Teddington, United Kingdom). All chemicals were dissolved in DMSO.

\section{Cell culture and treatment}

HepG2 cells were cultured in Minimal Essential Medium (MEM) supplemented with 1\% non-essential amino acids, 1\% sodium-pyruvate, 2\% penicillin/streptomycin and $10 \%$ Foetal Bovine Serum (all from Gibco/BRL, Breda, The Netherlands) in T25 culture flasks at $37^{\circ} \mathrm{C}$ and $5 \% \mathrm{CO}_{2}$. One day before treatment, cell cultures at 70 $80 \%$ confluency were harvested and cells were undilutedly divided among 6 well plates (for flow cytometry) or new culture flasks (for gene expression and DNA adduct analysis), in order to obtain a homogeneous cell population for each treatment. The 
next day, the medium was replaced with fresh medium containing $1 \mathrm{nM}$ to $30 \mu \mathrm{M}$ of a $\mathrm{PAH}$, an equimolar or equitoxic mixture of two PAHs or a vehicle control (DMSO, $0.1 \%$ ). The cells were exposed for 24 hours, and thereafter either cells were fixed with $2 \mathrm{ml}$ cold methanol and stored at $-20^{\circ} \mathrm{C}$ ( 6 well plates, for FACS analysis) or media was removed from the culture flasks and $1 \mathrm{ml}$ Trizol (Gibco/BRL, Breda, The Netherlands) was immediately added to the cells (for RNA and DNA isolation). Two independent experiments were conducted.

\section{Flow cytometric analysis for cell cycle and apoptosis}

For flow cytometry we used the primary antibody M30 CytoDeath (Roche, Penzberg, Germany), and the producers' manual. Wash buffer was replaced with PBS containing $1 \mathrm{mg} / \mathrm{ml} \mathrm{BSA}$. The secondary antibody, FITC conjugated anti-mouse Ig, was obtained from DakoCytomation (Glostrup, Denmark), which was incubated in the dark overnight at $4^{\circ} \mathrm{C}$. After washing, the cells were resuspended in $0.5 \mathrm{ml}$ PBS containing 20 $\mu \mathrm{g} / \mathrm{ml}$ propidium iodide (PI) and incubated 15 minutes at room temperature prior to flow cytometric analysis.

A FACSort (Becton Dickinson, Sunnyvale, USA) equipped with an Argon ion laser and a diode laser was used for flow cytometric analysis. An excitation wavelength of $488 \mathrm{~nm}$ and emission filters of $515-545 \mathrm{~nm}$ band pass and $600 \mathrm{~nm}$ low pass were used. For each sample 10,000 cells were analyzed. FITC signals were recorded as logarithmic amplified data and the PI signals as linear amplified data. Electronic compensation was used to eliminate any bleed-trough of fluorescence. Data analysis was done using CellQuest software (version 3.1, Becton Dickinson, San Jose, USA). Data were gated on pulse-processed PI signals to exclude doublets and larger aggregates from the analysis.

M30 CytoDeath positive (apoptotic) and negative (non-apoptotic) signals were sorted in the gated population and displayed as percentage of total cells with WinMDI 2.8 (http://facs.scripps.edu/software.html, 15-05-2006). Cell cycle was analyzed on the gated population of single using ModFit LT for Mac (version 2.0). Cells in the G0-1, S or G2-M phase were expressed as a percentage of the total number of cells.

Expected apoptosis levels were calculated by adding the total percentage of apoptosis of both constituents and subtracting the basal percentage of apoptosis found for the control sample.

\section{DNA adduct formation}

As DNA recoveries from cells exposed to equimolar concentrations of PAHs were limited, we only measured DNA adduct formation in cells exposed to equitoxic concentrations of PAHs. 
After removal of the aqueous phase during RNA isolation using Trizol (see RNA isolation and Quality control), the remaining phases were used for DNA isolation according to manufacturer's protocol. DNA adduct levels were determined according to the procedure originally described by Reddy and Randerath (13) with modifications described by Godschalk et al (14). By including samples with known DNA adduct levels ( 1 adduct per $10^{6}, 10^{7}$ or $10^{8}$ nucleotides), DNA adduct levels were quantified (detection limit 1 adduct $10^{8}$ nucleotides).

Adduct spots on the chromatograms were located and quantified using a phosphor imager (FLA-3000, Fuji, Paris, France) and AIDA/2D densometry software.

Expected DNA adduct levels were calculated by adding the total DNA adduct levels of both constituents and subtracting the background DNA adduct level found for the control sample. The limited number of analysis did not allow statistical analysis.

\section{Gene expression analysis}

\section{$\mathrm{RN} A$ isolation and quality control}

RNA was isolated from the Trizol solutions according to the producer's manual and purified with the RNeasy mini kit (Qiagen Westburg bv., Leusden, The Netherlands). RNA quantity was measured on a spectrophotometer and quality was determined on a BioAnalyzer (Agilent Technologies, Breda, The Netherlands). Only RNA samples which showed clear $18 \mathrm{~S}$ and $28 \mathrm{~S}$ peaks and with a RIN level higher than 8 were used for labeling and hybridization.

\section{cDNA synthesis}

RNA was reverse transcribed into cDNA with amino-allyl labeled dUTP (SigmaAldrich, St Louis, USA) and subsequently labeled with one of the four dyes, namely Cy3, Cy5, Alexa 488 and Alexa 594. Four instead of two dyes were applied, in order to reduce the variation (four related samples are on one array instead of two) and the number of arrays (as described by Staal et al (15)).

\section{Microarray bybridizations}

Targets were hybridized on the Human-600 Microarray (PHASE-1 Molecular Toxicology, Santa Fe, USA), containing 597 sequence verified cDNA clones from human genes, representing a number of toxicologically relevant, as well as control, genes, each printed in quadruplicate. Hybridization and washing was done according to the producers' manual as previously described (15). Hybridization of the equimolar experiment was designed such that all treatments of the same concentration were hybridized on a single array and the dyes were swapped for the technical duplicate. The hybridization design for the equitoxic experiment is shown in Table 6.1. 
TABLE 6.1. Labelling and hybridization design of RNA samples from cells exposed to PAHs in the first equitoxic experiment. In the second experiment $\mathrm{FA}$ and $\mathrm{B}[\mathrm{b}] \mathrm{F}$ were swapped and so were 1-MPA and $\mathrm{DB}[\mathrm{a}, \mathrm{h}] \mathrm{A}$.

\begin{tabular}{ccccc}
\hline array & Cyanine 3 & Cyanine 5 & Alexa 594 & Alexa 488 \\
\hline $\mathbf{1}$ & $\mathrm{B}[\mathrm{a}] \mathrm{P}$ & Solvent control & $\mathrm{B}[\mathrm{a}] \mathrm{P} / \mathrm{B}[\mathrm{b}] \mathrm{F}$ & $\mathrm{B}[\mathrm{b}] \mathrm{F}$ \\
$\mathbf{2}$ & $\mathrm{B}[\mathrm{a}] \mathrm{P} /$ 1-MPA & 1-MPA & Solvent control & $\mathrm{B}[\mathrm{a}] \mathrm{P} / \mathrm{FA}$ \\
$\mathbf{3}$ & $\mathrm{FA}$ & Solvent control & $\mathrm{B}[\mathrm{a}] \mathrm{P} / \mathrm{DB}[\mathrm{a}, \mathrm{h}] \mathrm{A}$ & $\mathrm{DB}[\mathrm{a}, \mathrm{h}] \mathrm{A}$ \\
$\mathbf{4}$ & $\mathrm{B}[\mathrm{a}] \mathrm{P} / \mathrm{DB}[\mathrm{a}, \mathrm{l}] \mathrm{P}$ & $\mathrm{DB}[\mathrm{a}, \mathrm{l}] \mathrm{P}$ & Solvent control & $\mathrm{B}[\mathrm{a}] \mathrm{P}$ \\
$\mathbf{5}$ & $\mathrm{B}[\mathrm{a}] \mathrm{P} / \mathrm{FA}$ & Solvent control & FA & $\mathrm{B}[\mathrm{a}] \mathrm{P}$ \\
$\mathbf{6}$ & $\mathrm{B}[\mathrm{a}] \mathrm{P} / \mathrm{B}[\mathrm{b}] \mathrm{F}$ & $\mathrm{B}[\mathrm{b}] \mathrm{F}$ & Solvent control & $\mathrm{B}[\mathrm{a}] \mathrm{P} / \mathrm{1}-\mathrm{MPA}$ \\
$\mathbf{7}$ & 1-MPA & Solvent control & $\mathrm{B}[\mathrm{a}] \mathrm{P} / \mathrm{DB}[\mathrm{a}, \mathrm{l}] \mathrm{P}$ & $\mathrm{DB}[\mathrm{a}, \mathrm{P}] \mathrm{P}$ \\
$\mathbf{8}$ & $\mathrm{B}[\mathrm{a}] \mathrm{P}$ & $\mathrm{DB}[\mathrm{a}, \mathrm{h}] \mathrm{A}$ & Solvent control & $\mathrm{B}[\mathrm{a}] \mathrm{P} / \mathrm{DB}[\mathrm{a}, \mathrm{h}] \mathrm{A}$ \\
\hline
\end{tabular}

\section{Microarray data analysis and data mining}

The microarray slides were scanned on a ScanArrayExpress (Perkin Elmer life sciences, Boston, USA). All four channels were scanned at 100\% laser power and adjusted photo multiplier tube (PMT) gain, such that the signal of the highest fluorescent spots is just below the maximum measurable level. The images $(10$ micron resolution; 16 bit tiff) were processed with ImaGene 5.5 software (Biodiscovery Inc., Los Angeles, USA) to quantify spot signals. Abnormal spots were manually or automatically flagged and not included in the data analysis.

Data from ImaGene were transported to GeneSight software version 4.1.6 (Biodiscovery Inc, Los Angeles, USA) for transformations, normalizations and analyses. For each spot, background mean was subtracted from signal means; flagged spots and spots with a net expression level below 20 were omitted. Data were log base 2 transformed and expression difference between exposed and control were calculated. Data normalization was done by LOWESS. Data of replicate spots were combined while omitting outliers ( $>2$ standard deviations). Samples from each biological replicate were hybridized twice, thereby providing four hybridizations per PAH concentration (two technical replicates for each biological replicate). Only for $\mathrm{B}[\mathrm{a}] \mathrm{P}$ exposed cells from the equitoxic experiment, eight hybridizations were available (4 technical and 2 biological). Significantly modulated genes were found by the confidence analysis tool in GeneSight, with a minimal up-regulation or down-regulation of 0.5 (after ${ }^{2} \log$ transformation) and a confidence limit of $99 \%$. To obtain equal statistical power for B [a]P exposed cells from the equitoxic experiment, the samples were split in 2 groups (each 
containing 2 biological and 2 technical replicates) for the analysis. The union of the modulated genes was assumed to be affected by the treatment.

\section{Assessing additivity for gene expression modulation}

Assuming additivity of both compounds in a mixture, the expected effects for a mixture can be calculated. Comparing the observed modulations with the expected, may provide information on whether the effects caused by mixtures are additive, synergistic or antagonistic.

To calculate the expected gene expression modulation by a mixture of two compounds based on the modulations of the individual compounds, only genes were included which were significantly modulated by either of the individual compounds or the mixture and which had the same direction of modulation (up or down). Genes of which the expression difference (log transformed) was between -0.1 and 0.1 were assumed to be similarly regulated as the other compound of the mixture.

For up-regulated genes, starting with ${ }^{2} \log$ transformed expression ratios of the individual PAHs, the next formulae were used to calculate the expected ${ }^{2} \log$ transformed expression ratio for a gene in the mixture:

1. $2^{2 \log (\mathrm{PAH} / \mathrm{C})}=(\mathrm{PAH} / \mathrm{C})$

In which $\mathrm{PAH}$ is the expression of a gene following treatment with a $\mathrm{PAH}$ and $\mathrm{C}$ is the expression of a gene following control treatment (DMSO). In this step the ${ }^{2} \log$ transformed expression ratios are transformed back into non-logarithmic values.

2.

$$
\frac{\text { Mixture }}{\mathrm{C}}=(\mathrm{B}[\mathrm{a}] \mathrm{P} / \mathrm{C})+(\mathrm{PAH} / \mathrm{C})-1
$$

The expected effect of the mixture $\mathrm{B}[\mathrm{a}] \mathrm{P}$ and a $\mathrm{PAH}$ equals the sum of the effect of $\mathrm{B}[\mathrm{a}] \mathrm{P}$ and of the other PAH minus the basal gene expression level of 1 .

3.

The expected ${ }^{2} \log$ transformed expression ratio for a gene in a mixture:

$={ }^{2} \log ((\mathrm{B}[\mathrm{a}] \mathrm{P} / \mathrm{C})+(\mathrm{PAH} / \mathrm{C})-1)$

For down-regulated genes, starting with ${ }^{2} \log$ transformed expression ratios of the individual PAHs, the following formulae were used to calculate the expected ${ }^{2} \log$ transformed expression ratio for a gene in a mixture: 
4.

$1 / 2^{2 \log (\mathrm{PAH} / \mathrm{C})}=(\mathrm{C} / \mathrm{PAH})$

In which $\mathrm{PAH}$ is the expression of a gene following treatment with a $\mathrm{PAH}$ and $\mathrm{C}$ is the expression of a gene following control treatment (DMSO). In this step the ${ }^{2} \log$ transformed expression ratios are transformed back into non-logarithmic values, followed by a calculation of its inverse (hereby the effects are transformed into upregulations). Then the same procedure is followed as above (from step 2 onwards), finalized with inversing back the value before log transformation.

Finally, the observed gene expression values (y-axis) were plotted versus the expected values (x-axis). Linear regression analysis and Pearson correlation coefficients were calculated using SPSS 12.0.1 for windows (SPSS Inc., Chicago, USA). Additivity was assumed when regression analysis for the observed and expected data did not show a deviation from $y=x$ (confidence interval of 2 SD). If it did deviate from $y=x$, synergism is shown by a slope $>1$ and antagonism by a slope $<1$.

To assess whether the expression of single genes showed additivity, the formulae as described above were used. Expected gene expression levels showed additive response if they fell within the confidence interval (1 SD) of the observed gene expression modulation. If not, the gene was classified as being higher or lower expressed than expected for that mixture.

\section{RESULTS}

\section{Equimolar concentrations}

\section{Apoptosis and cell cycle changes}

Flow cytometric analysis of cells exposed to $\mathrm{B}[\mathrm{a}] \mathrm{P}, \mathrm{DB}[\mathrm{a}, 1] \mathrm{P}$ or an equimolar mixture of both compounds showed dose dependent induction of apoptosis (Figure 6.1). $\mathrm{DB}[\mathrm{a}, 1] \mathrm{P}$ and the mixture increased apoptosis levels from $0.1 \mu \mathrm{M}$ and higher, while for $\mathrm{B}[\mathrm{a}] \mathrm{P}$ this was at $3 \mu \mathrm{M}$ and higher. 


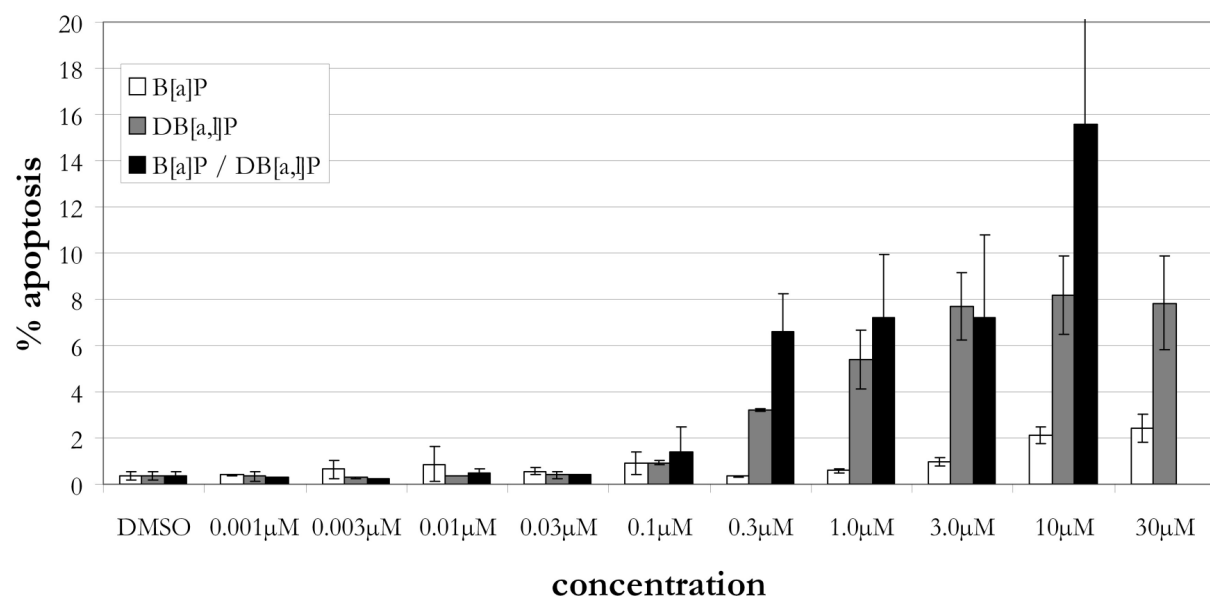

FIGURE 6.1. Apoptosis in HepG2 cells exposed to B[a]P, DB[a,l]P or their equimolar mixture for $24 \mathrm{~h}$ expressed as a percentage of total cells. Means of duplicate experiments and their standard deviation are indicated.

An increase of cells in S-phase was seen after $0.01 \mu \mathrm{M}$ with a subsequent decrease from $0.1 \mu \mathrm{M}$ for all treatments (Figure 6.2). For B[a]P an increased percentage of cells in S-phase was observed from $0.3 \mu \mathrm{M}$ and higher, $\mathrm{DB}[\mathrm{a}, 1] \mathrm{P}$ and the mixture showed increased S-phase from $0.01 \mu \mathrm{M}$ and $0.003 \mu \mathrm{M}$ and higher respectively.

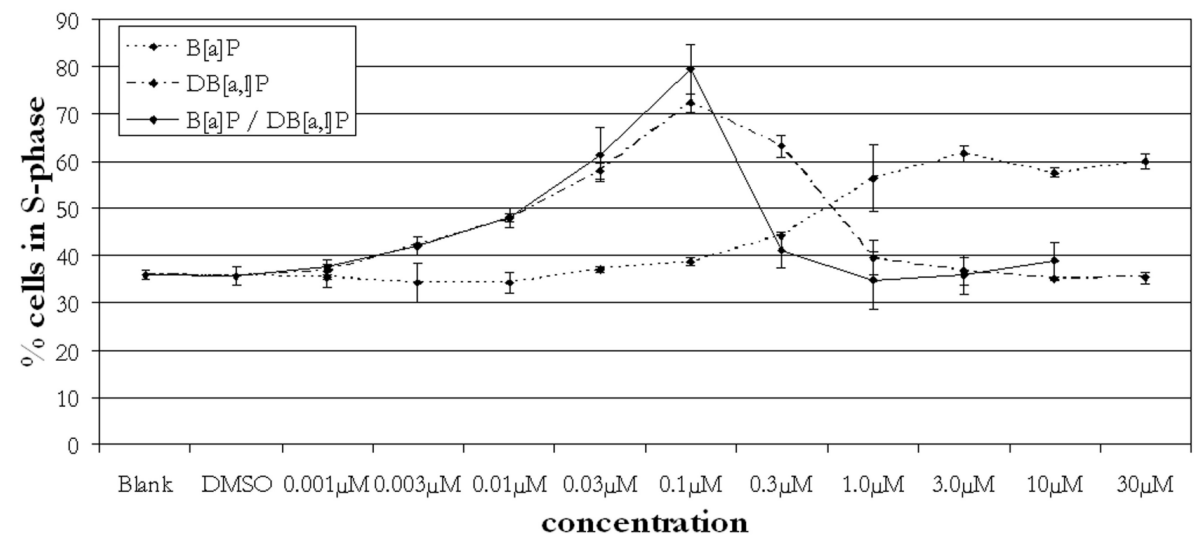

FIGURE 6.2. Percentage of HepG2 cells in the S-phase of cell cycle after exposure to B[a]P, DB[a, $] \mathrm{P}$ or their equimolar mixture for $24 \mathrm{~h}$. Means of duplicate experiments and their standard deviation are indicated.

Based on these data concentrations of $0.1,0.3$ and $1.0 \mu \mathrm{M}$ were used for gene expression analysis. 


\section{Gene expression modulation}

Microarray analysis showed that a total number of 127 genes were affected by one or more treatments. For B[a]P 2, 5 and 6 genes were modulated by respectively $0.1,0.3$ and $1.0 \mu \mathrm{M}$ exposure, for DB[a,l]P 7, 29 and 72 genes were affected and for the mixture 6, 49 and 77 genes. Many, but not all, genes affected by B[a]P or DB[a,1]P were also affected by the mixture, although the mixture also affected genes which were not modulated by one of the constituents. Names, abbreviations, GenBank accession numbers and gene expression differences of the modulated genes can be found in the supplemented data file (http://fdgwgratsrv0401.unimaas.nl/data).

Principal component analysis, Figure 6.3, showed that gene expression profiles induced by $\mathrm{B}[\mathrm{a}] \mathrm{P}$ are similar for all concentrations and different from either the mixture or $\mathrm{DB}[\mathrm{a}, 1] \mathrm{P}$. The gene expression profiles of $\mathrm{DB}[\mathrm{a}, 1] \mathrm{P}$ and the mixture treatments were closely related between each concentration of treatment, but the resemblance between gene expression profiles induced by $\mathrm{DB}[\mathrm{a}, \mathrm{l}] \mathrm{P}$ and the mixture decreased with increasing concentration of treatment. This suggests a contribution of $\mathrm{B}[\mathrm{a}] \mathrm{P}$ to the mixture at the higher concentrations.

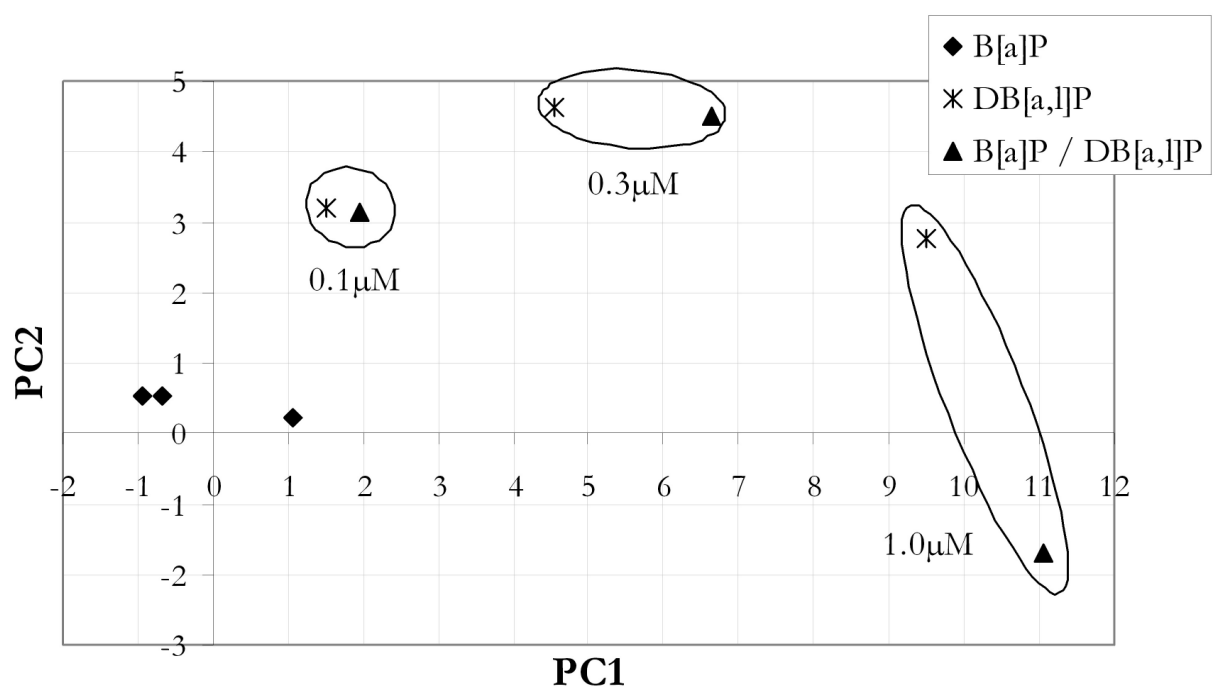

FIGURE 6.3. Principal component analysis of gene expression differences in HepG2 cells after exposure for $24 \mathrm{~h}$ to $\mathrm{B}[\mathrm{a}] \mathrm{P}, \mathrm{DB}[\mathrm{a}, \mathrm{l}] \mathrm{P}$ or their equimolar mixture with the 127 genes differentially expressed by either of the treatments. Each circle contains the same concentration of treatment with $\mathrm{DB}[\mathrm{a}, \mathrm{l}] \mathrm{P}$ and the mixture of $\mathrm{B}[\mathrm{a}] \mathrm{P}$ and $\mathrm{DB}[\mathrm{a}, \mathrm{l}] \mathrm{P}$. 
Assessing the additivity of effects induced by the mixture

By using the gene expression profiles of $\mathrm{B}[\mathrm{a}] \mathrm{P}$ and $\mathrm{DB}[\mathrm{a}, \mathrm{l}] \mathrm{P}$ it was possible to calculate the expected effect of the mixture for the significantly modulated genes. Expected gene expression levels were plotted against observed expression levels for all concentrations, (Figure 6.4). For the 0.3 and $1.0 \mu \mathrm{M}$ treatments the correlation coefficient was significant $(\mathrm{p}<0.05)$. At $1.0 \mu \mathrm{M}$ we found a significant deviation from the line $\mathrm{y}=\mathrm{x}$ in these regression models, where antagonism is shown (slope $<1$ ). The mixture effects at 0.1 and $0.3 \mu \mathrm{M}$ are unclear due to the small contribution of $\mathrm{B}[\mathrm{a}] \mathrm{P}$ to the mixture.

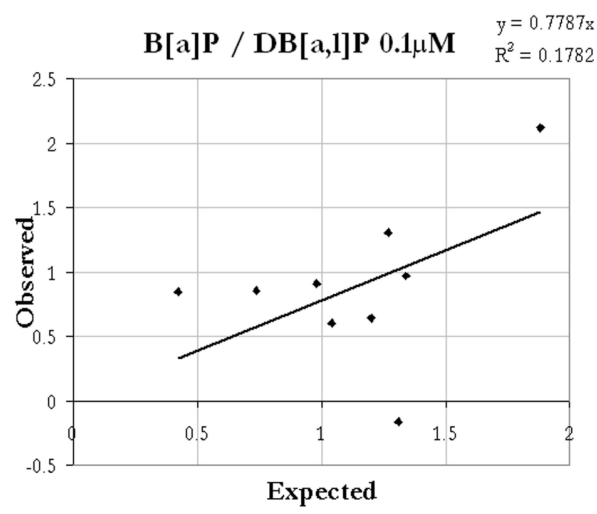

Figure $6.4 \mathrm{a}$

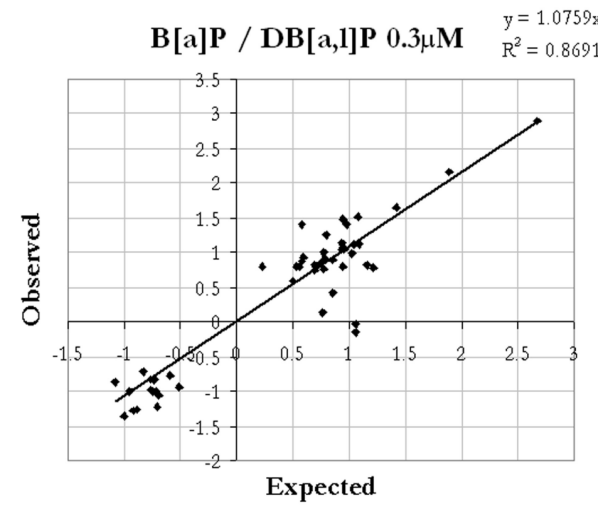

Figure 6.4b

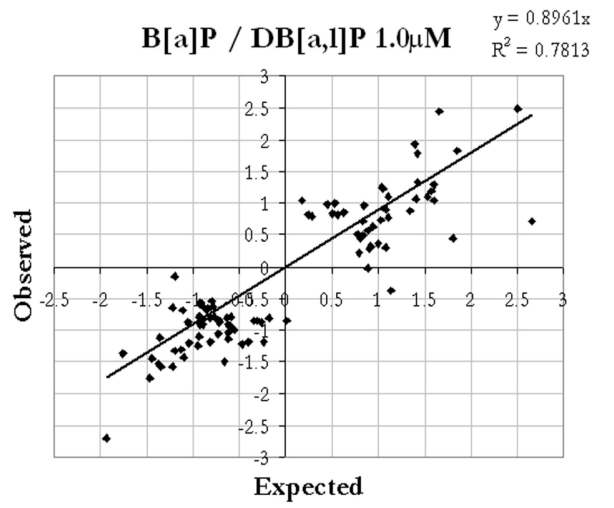

Figure 6.4c

FIGURE 6.4. Expected (based on additivity) versus observed gene expression of the equimolar mixture of $\mathrm{B}[\mathrm{a}] \mathrm{P}$ and $\mathrm{DB}[\mathrm{a}, 1] \mathrm{P}$ for the concentrations $0.1,0.3$ and $1.0 \mu \mathrm{M}$ in respectively $6.4 \mathrm{a}, 6.4 \mathrm{~b}$ and $6.4 \mathrm{c}$. Correlation coefficients $\left(\mathrm{R}^{2}\right)$ and the line equation are indicated in the graph.

Also, individual genes show interactive effect after exposure to the mixture. The expression of 12 genes consistently showed additivity of the gene expression of the mixture. These genes were ACTGP3, ATF3, CDH2, CDKN1A, CHK, CYP2C19, 
GADD45A, HAMP, MMP3, MT2A, SLC6A9 and an unknown gene with GenBank accession number XM_010682. No genes showed consistent antagonistic or synergistic responses.

\section{Equitoxic concentrations}

\section{Apoptosis and cell cycle changes}

Apoptosis and cell cycle disturbances were measured for each of the 6 PAHs in concentrations ranging from 0.01 to $30 \mu \mathrm{M}$. All PAHs increased apoptosis levels in HepG2 cells, except FA and 1-MPA (Figure 6.5a). B[a]P, DB[a,l]P, B[b]F and $\mathrm{DB}[\mathrm{a}, \mathrm{h}] \mathrm{A}$ increased apoptosis levels from 3.0, $0.1,10.0$ and $1.0 \mu \mathrm{M}$ and higher respectively.
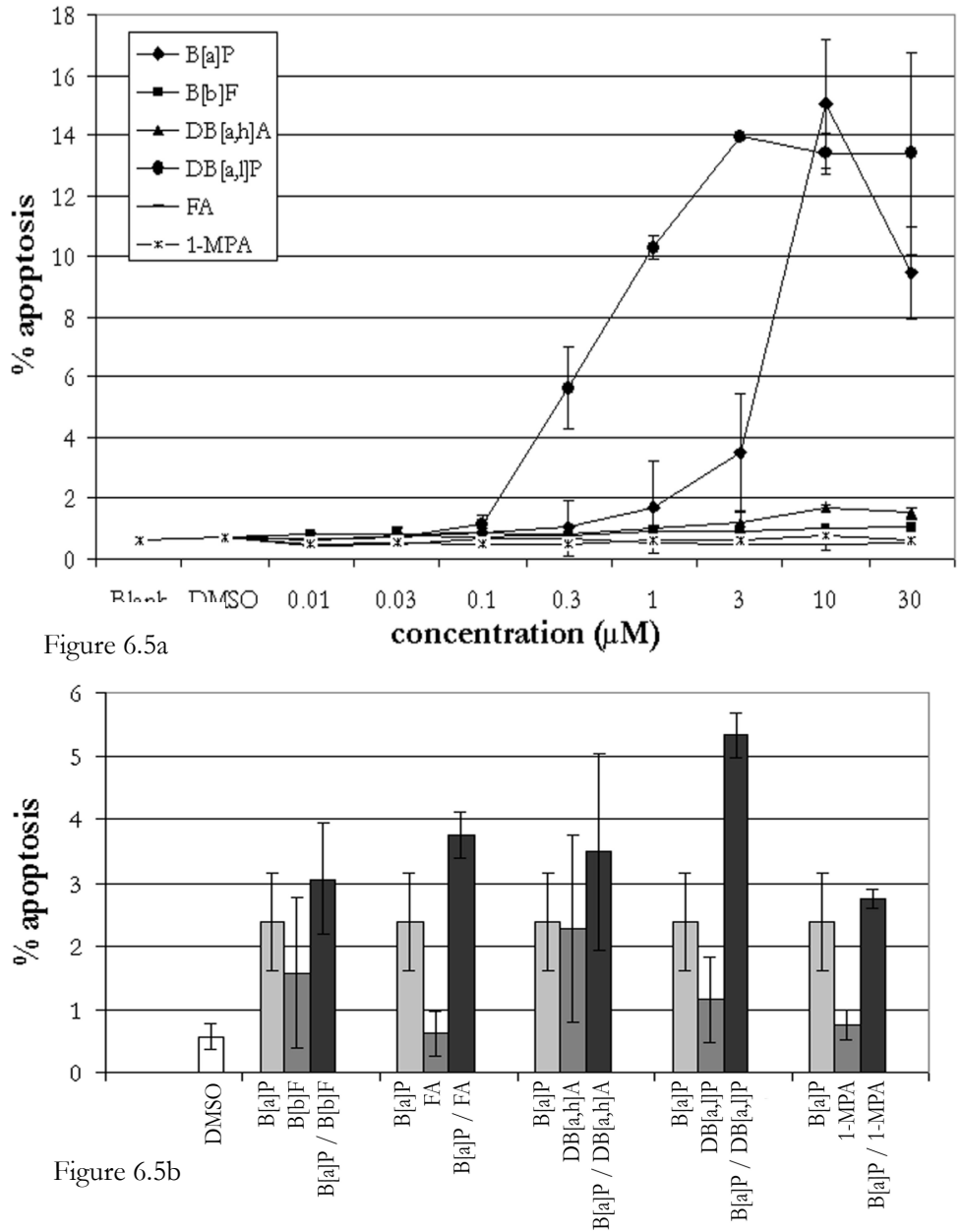

FIGURE 6.5. Apoptosis in HepG2 cells exposed to B[a]P, DB[a, ]P, DB[a,h]A, B[b]F, FA or 1-MPA (5a) or a mixture of each $\mathrm{PAH}$ with $\mathrm{B}[\mathrm{a}] \mathrm{P}$ (5b) for $24 \mathrm{~h}$ expressed as a percentage of total cells. Means of duplicate experiments and their standard deviation are indicated. 
Many PAHs also increased the number of cells in S-phase; only FA and 1-MPA did not affect cell cycle (Figure 6.6a). B[a]P, DB[a,l]P, B[b]F and DB[a,h]A disturbed cell cycle from $0.3,0.01,0.1$ and $0.03 \mu \mathrm{M}$ and higher respectively.

Concentrations to study the effects of equitoxic concentrations were selected based on these apoptosis and cell cycle data. Each PAH affected both parameters at similar concentrations, only $\mathrm{B}[\mathrm{b}] \mathrm{F}$ disturbed cell cycle at much lower concentrations than apoptosis induction. As FA and 1-MPA did not change either apoptosis or in cell cycle, the highest concentration $(30 \mu \mathrm{M})$ was used to study the effects of mixtures with $\mathrm{B}[\mathrm{a}] \mathrm{P}$. The concentrations selected for $\mathrm{B}[\mathrm{a}] \mathrm{P}, \mathrm{DB}[\mathrm{a}, \mathrm{l}] \mathrm{P}, \mathrm{B}[\mathrm{b}] \mathrm{F}$ and $\mathrm{DB}[\mathrm{a}, \mathrm{h}] \mathrm{A}$ were respectively $3.0,0.1,3.0$ and $1.0 \mu \mathrm{M}$.

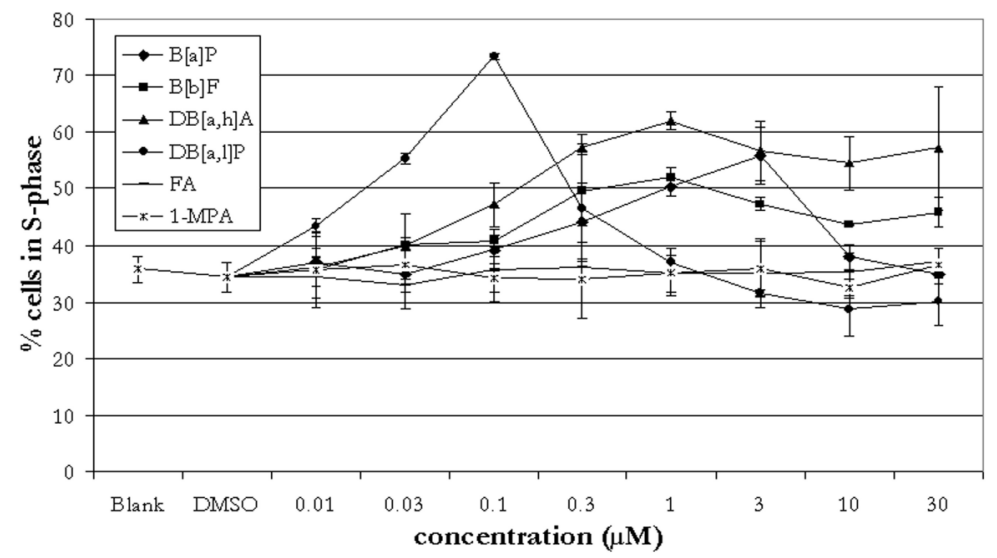

Figure 6.6a

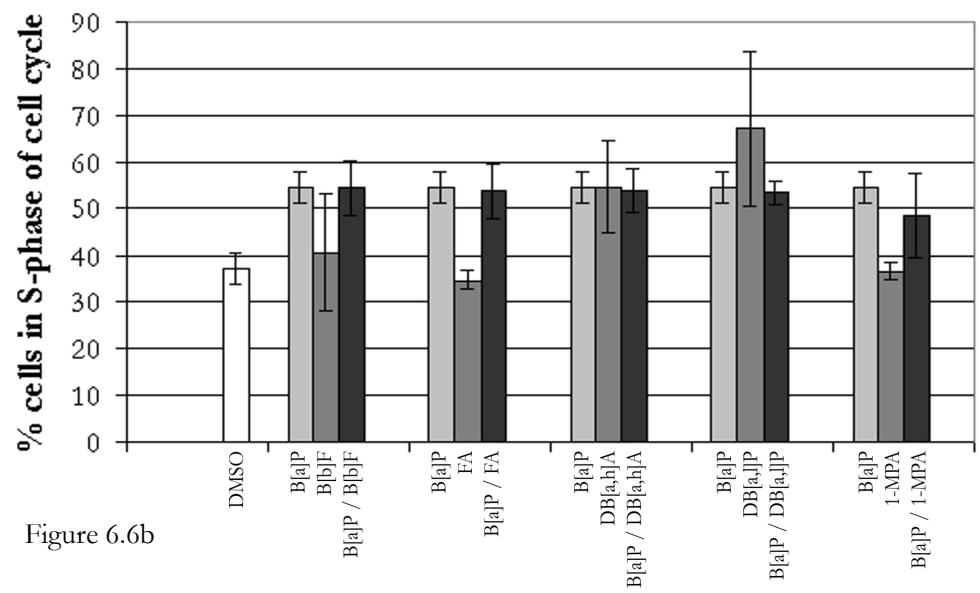

FIGURE 6.6. Percentage of HepG2 cells in the S-phase of cell cycle after exposure to B[a]P, DB[a,l]P, $\mathrm{DB}[\mathrm{a}, \mathrm{h}] \mathrm{A}, \mathrm{B}[\mathrm{b}] \mathrm{F}, \mathrm{FA}$ or $1-\mathrm{MPA}(6.6 \mathrm{a})$ or a mixture of each $\mathrm{PAH}$ with $\mathrm{B}[\mathrm{a}] \mathrm{P}(6.6 \mathrm{~b})$ for $24 \mathrm{~h}$. Means of duplicate experiments and their standard deviation are indicated. 
None of the apoptosis levels induced by the mixture of a $\mathrm{PAH}$ with $\mathrm{B}[\mathrm{a}] \mathrm{P}$ differed significantly from the expected effect (Figure 6.5b). The percentage of cells in S-phase of cell cycle after treatment with a mixture resembled mostly that after $\mathrm{B}[\mathrm{a}] \mathrm{P}$ treatment (no significant deviation; Figure 6.6b).

\section{$D N A$ adduct formation}

DNA adduct formation as measured by ${ }^{32} \mathrm{P}$-postlabelling in the HepG2 cells exposed to the equitoxic concentrations of PAHs is shown in Figure 6.7. DNA adduct formation for equitoxic concentrations was $\mathrm{B}[\mathrm{a}] \mathrm{P}>\mathrm{B}[\mathrm{b}] \mathrm{F}>\mathrm{DB}[\mathrm{a}, \mathrm{l}] \mathrm{P} \geq \mathrm{DB}[\mathrm{a}, \mathrm{h}] \mathrm{A}>\mathrm{FA} \geq 1$ MPA. Interestingly, the mixtures of $\mathrm{B}[\mathrm{a}] \mathrm{P}$ with $\mathrm{FA}$ or 1-MPA induced the highest DNA adduct levels, whereas FA and 1-MPA itself did not induce DNA adducts. For these treatments the $\mathrm{B}[\mathrm{a}] \mathrm{P}$ adduct spots were increased and no other adducts were found. All mixtures showed higher DNA adduct levels than expected, which indicates a synergistic effect on DNA adduct formation.

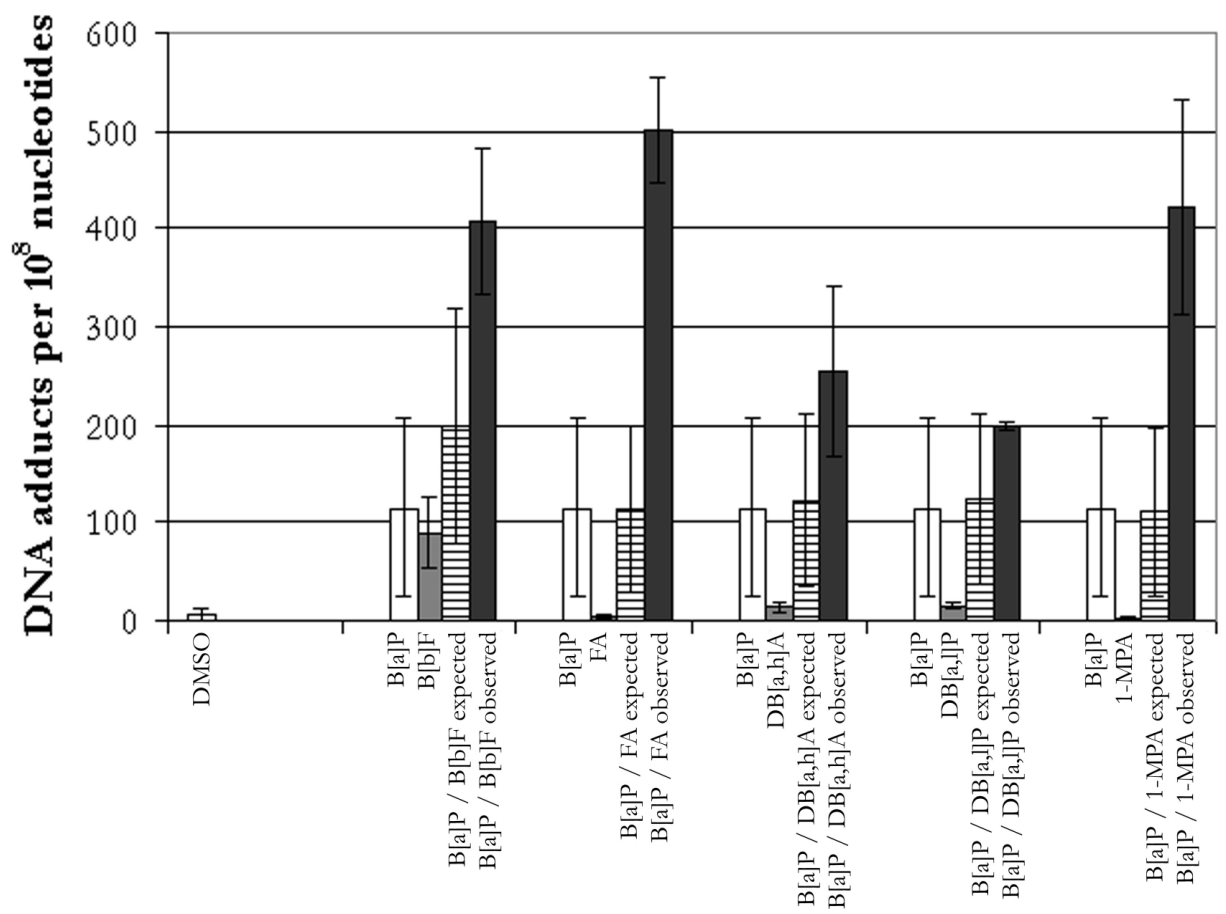

FIGURE 6.7. DNA adduct formation in HepG2 cells exposed to equitoxic concentrations of PAHs for $24 \mathrm{~h}$ as measured by ${ }^{32} \mathrm{P}$-postlabelling. The mean number of DNA adducts per $10^{8}$ nucleotides and their SDs are shown. Expected is based on additivity of the constituents of the mixture. 


\section{Gene expression modulation}

In total 54 genes were modulated by one or more treatments, varying from 1 gene for the 1-MPA and FA treatments to 37 genes by the treatment with a mixture of $\mathrm{B}[\mathrm{a}] \mathrm{P} /$ $\mathrm{B}[\mathrm{b}] \mathrm{F}$. The numbers of modulated genes for each treatment and the overlap between treatments shows that most genes modulated by a single compound were also modulated by their mixture with B[a]P (Figure 6.8). Names, abbreviations, GenBank accession numbers and gene expression differences of the modulated genes can be found in the supplementary data (Table 2).

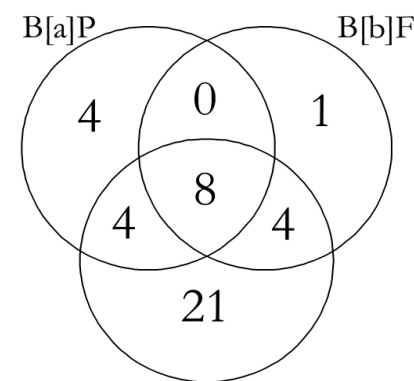

Figure 6.8a

$$
\mathrm{B}[\mathrm{a}] \mathrm{P} / \mathrm{B}[\mathrm{b}] \mathrm{F}
$$

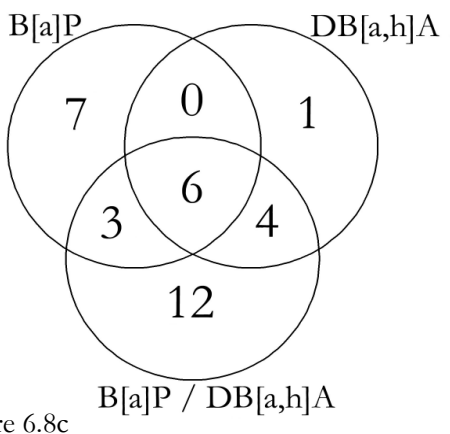

Figure 6.8c

Figure $6.8 \mathrm{~b}$

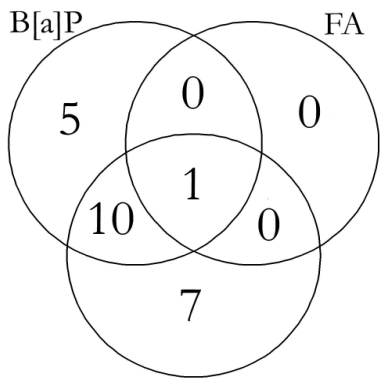

$\mathrm{B}[\mathrm{a}] \mathrm{P} / \mathrm{FA}$

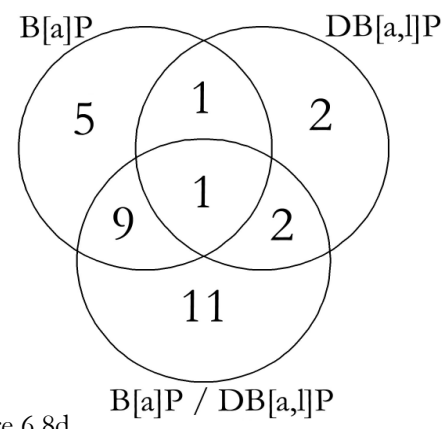

Figure 6.8d

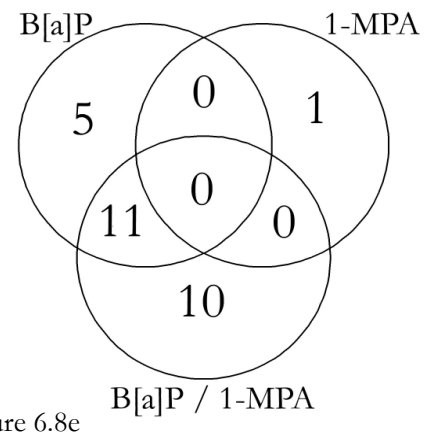

Figure 6.8e

FIGURE 6.8. Venn diagrams showing the numbers of modulated genes and their overlap between treatments in HepG2 cells exposed for $24 \mathrm{~h}$ to B $[\mathrm{a}] \mathrm{P}, \mathrm{B}[\mathrm{b}] \mathrm{F}(8 \mathrm{a}), \mathrm{FA}(8 \mathrm{~b}), \mathrm{DB}[\mathrm{a}, \mathrm{h}] \mathrm{A}(8 \mathrm{c}), \mathrm{DB}[\mathrm{a}, \mathrm{l}] \mathrm{P}(8 \mathrm{~d})$ or 1-MPA (8e) or a mixture of each with B[a]P. 


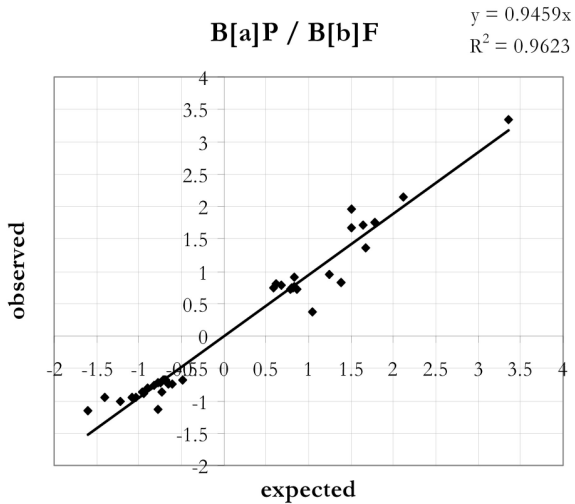

Figure 6.9a

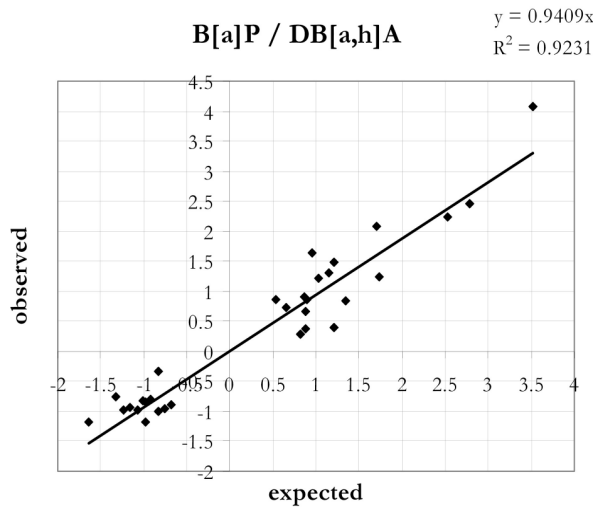

Figure 6.9c

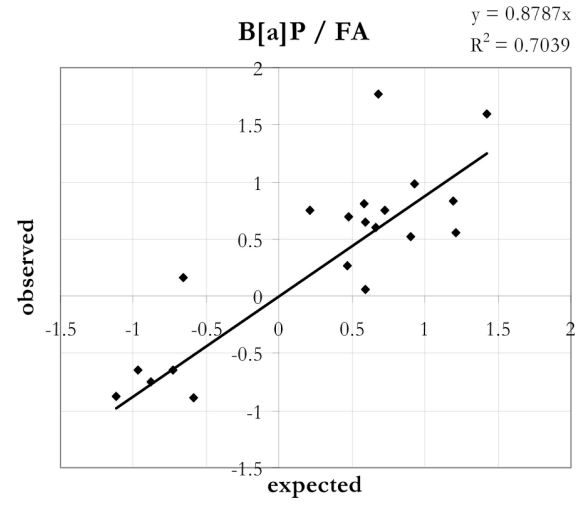

Figure 6.9b

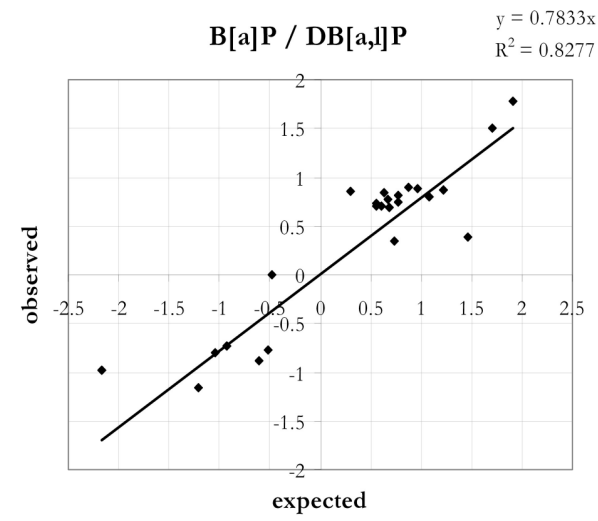

Figure 6.9d

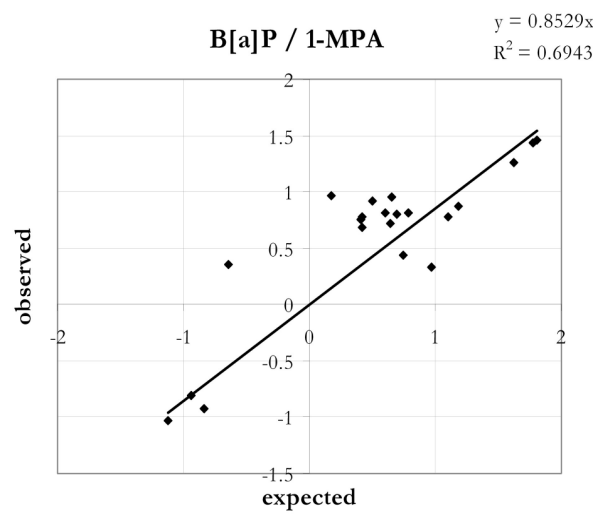

Figure 6.9e

FIGURE 6.9. Expected (based on additivity) (x-axis) versus observed (y-axis) gene expression of the equitoxic mixture of respectively B[a]P and B[b]F (6.9a), FA (6.9b), DB[a,h]A (6.9c), DB[a,l]P (6.9d) or 1MPA (6.9e). Correlation coefficients $\left(\mathrm{R}^{2}\right)$ and the line equation are indicated in the graph. 


\section{Assessing the additivity of effects induced by the mixture}

Expected gene expression profiles of the mixture were calculated based on the gene expression profiles of its individual compounds and plotted against the observed expression levels (Figure 6.9). All correlation coefficients were significant. Regression analysis showed that only mixtures with DB[a,l]P and 1-MPA deviate significantly from the line $y=x$, and the observed values were smaller than expected (slope $<1$ ), indicating an antagonistic effect. For mixtures of $\mathrm{B}[\mathrm{a}] \mathrm{P}$ with either $\mathrm{B}[\mathrm{b}] \mathrm{F}, \mathrm{DB}[\mathrm{a}, \mathrm{h}] \mathrm{A}$ or FA this deviation was not observed, suggesting an additive effect for these mixtures.

Comparing the observed and expected gene expression level for single genes, showed that for 14 genes the observed and expected values did not differ of the gene expression of the mixture. Also, we found a synergistic or antagonistic effect on gene expression for 12 out of the 55 modulated genes (observed consistently higher or lower than expected). Table 6.2 shows the interactive effects of each gene for all mixtures.

TABLE 6.2. Interactive effect of gene expression upon exposure to equitoxic PAH mixtures. Additivity is shown by "=”, synergism by "+” and antagonism by “-“.

\begin{tabular}{|c|c|c|c|c|c|c|c|}
\hline GeneSymbol & GeneName & $\begin{array}{c}\text { Genbank } \\
\text { Accession }\end{array}$ & 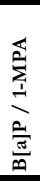 & $\begin{array}{l}\frac{1}{a} \\
\frac{a}{n} \\
\frac{a}{n}\end{array}$ & 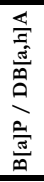 & 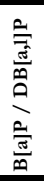 & $\frac{\sqrt{a}}{\frac{\pi}{\pi}}$ \\
\hline \multicolumn{8}{|c|}{ Additivity } \\
\hline ATF3 & activating transcription factor 3 & L19871 & & $=$ & $=$ & & \\
\hline$C A 3$ & carbonic anhydrase III, muscle specific & XM_005207 & & $=$ & $=$ & $=$ & \\
\hline CDH1 & cadherin 1, type 1, E-cadherin (epithelial) & L08599 & & $=$ & & & $=$ \\
\hline CEACAMG & $\begin{array}{l}\text { carcinoembryonic antigen-related cell } \\
\text { adhesion molecule } 6 \text { (non-specific cross } \\
\text { reacting antigen) }\end{array}$ & M18728 & $=$ & & & $=$ & \\
\hline CYP1A1 & $\begin{array}{l}\text { cytochrome P450, family } 1 \text {, subfamily A, } \\
\text { polypeptide } 1\end{array}$ & K03191 & $=$ & $=$ & $=$ & & \\
\hline$F A S N$ & fatty acid synthase & NM_004104 & & $=$ & $=$ & & \\
\hline$F G G$ & fibrinogen, gamma polypeptide & $\mathrm{X} 51473$ & & $=$ & $=$ & & \\
\hline FMO5 & flavin containing monooxygenase 5 & L37080 & & $=$ & $=$ & & \\
\hline$I G F 1$ & $\begin{array}{l}\text { insulin-like growth factor } 1 \text { (somatomedin } \\
\text { C) }\end{array}$ & M37484 & $=$ & $=$ & $=$ & $=$ & $=$ \\
\hline$I G F B P 1$ & insulin-like growth factor binding protein 1 & M31145 & $=$ & $=$ & $=$ & $=$ & \\
\hline MCL1 & $\begin{array}{l}\text { myeloid cell leukemia sequence } 1 \text { (BCL2- } \\
\text { related) }\end{array}$ & L08246 & $=$ & $=$ & $=$ & & \\
\hline$S A T$ & spermidine/spermine N1-acetyltransferase & M55580 & $=$ & $=$ & $=$ & $=$ & $=$ \\
\hline$S C D$ & stearoyl-CoA desaturase (delta-9-desaturase) & $\mathrm{AB} 032261$ & & $=$ & $=$ & & \\
\hline \multirow[t]{2}{*}{ TYROBP } & $\begin{array}{l}\text { TYRO protein tyrosine kinase binding } \\
\text { protein }\end{array}$ & NM_003332 & & & $=$ & $=$ & $=$ \\
\hline & & XM_005563 & $=$ & $=$ & $=$ & $=$ & $=$ \\
\hline
\end{tabular}




\begin{tabular}{|c|c|c|c|c|c|c|c|}
\hline GeneSymbol & GeneName & $\begin{array}{l}\text { Genbank } \\
\text { Accession }\end{array}$ & 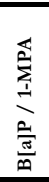 & $\begin{array}{l}\frac{\omega}{2} \\
\frac{1}{2} \\
\frac{a}{\pi} \\
\frac{\omega}{\infty}\end{array}$ & 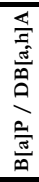 & 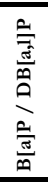 & $\frac{\sqrt{a}}{\frac{\pi}{a}}$ \\
\hline \multicolumn{8}{|c|}{ Mostly synergism } \\
\hline$A K R 1 B 1$ & $\begin{array}{l}\text { aldo-keto reductase family } 1, \text { member B1 } \\
\text { (aldose reductase) }\end{array}$ & J05474 & & $=$ & + & & + \\
\hline$A M A C R$ & alpha-methylacyl-CoA racemase & XM_003872 & + & & $=$ & + & \\
\hline CYP1A2 & $\begin{array}{l}\text { cytochrome P450, family } 1 \text {, subfamily A, } \\
\text { polypeptide } 2\end{array}$ & NM_000761 & & $=$ & + & + & \\
\hline$F A B P 1$ & fatty acid binding protein 1 , liver & M10617 & & + & $=$ & $=$ & + \\
\hline$G A D D 45 A$ & $\begin{array}{l}\text { growth arrest and DNA-damage-inducible, } \\
\text { alpha }\end{array}$ & M60974 & + & + & & $=$ & \\
\hline MT1E & metallothionein $1^{\mathrm{E}}$ (functional) & X97260 & + & $=$ & $=$ & + & \\
\hline$X R C C 1$ & $\begin{array}{l}\mathrm{X} \text {-ray repair complementing defective repair } \\
\text { in Chinese hamster cells } 1\end{array}$ & M36089 & + & & & & + \\
\hline \multicolumn{8}{|c|}{ Mostly antagonism } \\
\hline APOCZ & apolipoprotein C-III & X03120 & $=$ & - & - & $=$ & - \\
\hline ECE1 & endothelin converting enzyme 1 & D49471 & $=$ & - & - & - & $=$ \\
\hline$G C K$ & $\begin{array}{l}\text { glucokinase (hexokinase } 4 \text {, maturity onset } \\
\text { diabetes of the young } 2 \text { ) }\end{array}$ & XM_004994 & $=$ & - & - & - & - \\
\hline HIF1A & $\begin{array}{l}\text { hypoxia-inducible factor 1, alpha subunit } \\
\text { (basic helix-loop-helix transcription factor) }\end{array}$ & U22431 & - & $=$ & - & - & $=$ \\
\hline SERPINA3 & $\begin{array}{l}\text { serine (or cysteine) proteinase inhibitor, } \\
\text { clade A (alpha-1 antiproteinase, antitrypsin), } \\
\text { member } 3\end{array}$ & K01500 & - & - & $=$ & $=$ & - \\
\hline SPP1 & $\begin{array}{l}\text { secreted phosphoprotein } 1 \text { (osteopontin, } \\
\text { bone sialoprotein I, early T-lymphocyte } \\
\text { activation 1) }\end{array}$ & J04765 & - & - & - & & - \\
\hline \multicolumn{8}{|c|}{ Other interatcions } \\
\hline$A 2 M$ & alpha-2-macroglobulin & M11313 & - & & $=$ & $=$ & $=$ \\
\hline$A K R 1 B 1$ & $\begin{array}{l}\text { aldo-keto reductase family } 1, \text { member B1 } \\
\text { (aldose reductase) }\end{array}$ & J05474 & & $=$ & & & \\
\hline $\boldsymbol{B A} \boldsymbol{X}$ & BCL2-associated X protein & L22473 & & & & & + \\
\hline$C D K N 1 A$ & $\begin{array}{l}\text { cyclin-dependent kinase inhibitor } 1 \mathrm{~A}(\mathrm{p} 21 \text {, } \\
\text { Cip1) }\end{array}$ & U03106 & + & & & $=$ & $=$ \\
\hline CEACAM5 & $\begin{array}{l}\text { carcinoembryonic antigen-related cell } \\
\text { adhesion molecule } 5\end{array}$ & M17303 & + & & & $=$ & \\
\hline COPEB & core promoter element binding protein & $\mathrm{AB} 017493$ & + & & & & \\
\hline$C P$ & ceruloplasmin (ferroxidase) & M13699 & & & & & $=$ \\
\hline CYP2B & $\begin{array}{l}\text { cytochrome P450, family 2, subfamily B, } \\
\text { polypeptide } 6\end{array}$ & M29874 & & & + & & \\
\hline$F G A$ & fibrinogen, A alpha polypeptide & M58569 & & $=$ & $=$ & & \\
\hline FMO1 & flavin containing monooxygenase 1 & M64082 & & & & & \\
\hline$G 6 P D$ & glucose-6-phosphate dehydrogenase & $\mathrm{X} 03674$ & $=$ & $=$ & $=$ & - & $=$ \\
\hline$H I S T 1 H 2 A L$ & histone $1, \mathrm{H} 2 \mathrm{al}$ & XM_004453 & & $=$ & & & \\
\hline
\end{tabular}




\begin{tabular}{|c|c|c|c|c|c|c|c|}
\hline GeneSymbol & GeneName & $\begin{array}{l}\text { Genbank } \\
\text { Accession }\end{array}$ & 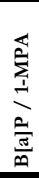 & $\frac{\frac{\omega}{a}}{\frac{a}{a}}$ & 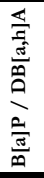 & 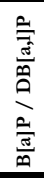 & $\frac{\sqrt{1}}{\frac{a}{\pi}}$ \\
\hline HIST1H3D & histone $1, \mathrm{H} 3 \mathrm{~d}$ & XM_004419 & & $=$ & & & \\
\hline$H M G C R$ & $\begin{array}{l}\text { 3-hydroxy-3-methylglutaryl-Coenzyme A } \\
\text { reductase }\end{array}$ & M11058 & & $=$ & $=$ & & \\
\hline HSPCA & heat shock $90 \mathrm{kDa}$ protein 1 , alpha & $\mathrm{X} 15183$ & & $=$ & & & \\
\hline$I G F 2$ & $\begin{array}{l}\text { insulin-like growth factor } 2 \text { (somatomedin } \\
\text { A) }\end{array}$ & M29645 & & $=$ & - & & \\
\hline$M B P$ & myelin basic protein & M13577 & & & & & \\
\hline MDM2 & $\begin{array}{l}\text { Mdm2, transformed 3T3 cell double minute } \\
\text { 2, p53 binding protein (mouse) }\end{array}$ & U33199 & & & & & $=$ \\
\hline PCK2 & $\begin{array}{l}\text { phosphoenolpyruvate carboxykinase } 2 \\
\text { (mitochondrial) }\end{array}$ & X92720 & & $=$ & & & \\
\hline$P C N A$ & proliferating cell nuclear antigen & J04718 & & & & + & \\
\hline PEPD & peptidase D & $\mathrm{J} 04605$ & & $=$ & & & \\
\hline$S L C 22 A 3$ & $\begin{array}{l}\text { solute carrier family } 22 \text { (extraneuronal } \\
\text { monoamine transporter), member } 3\end{array}$ & AJ001417 & & $=$ & & & \\
\hline$T F$ & transferrin & M12530 & & $=$ & & + & \\
\hline TNFSF4 & $\begin{array}{l}\text { tumor necrosis factor (ligand) superfamily, } \\
\text { member } 4 \text { (tax-transcriptionally activated } \\
\text { glycoprotein } 1,34 \mathrm{kDa})\end{array}$ & X79929 & & - & & & \\
\hline UBE2A & $\begin{array}{l}\text { ubiquitin-conjugating enzyme E2A (RAD6 } \\
\text { homolog) }\end{array}$ & M76125 & & & $=$ & + & \\
\hline$V M P 1$ & $\begin{array}{l}\text { likely ortholog of rat vacuole membrane } \\
\text { protein } 1\end{array}$ & NM_030938 & & $=$ & & & \\
\hline
\end{tabular}

An overview of all interactive effects in equitoxic mixtures is shown in Table 6.3.

TABLE 6.3. Summary of data comparison between observed and expected data for the equitoxic experiment. Additive effects have no difference between observed and expected data, for synergism the observed effect is higher than expected and for antagonism the observed effect is lower than expected.

\begin{tabular}{lccccc}
\hline & Apoptosis & $\begin{array}{c}\text { Cell } \\
\text { cycle }\end{array}$ & $\begin{array}{c}\text { DNA } \\
\text { adduct } \\
\text { formation }\end{array}$ & $\begin{array}{c}\text { Gene } \\
\text { expression }\end{array}$ & $\begin{array}{c}\text { CYP1A1 } \\
\text { expression }\end{array}$ \\
\hline $\mathbf{B}[\mathbf{a}] \mathbf{P} / \mathbf{B}[\mathbf{b}] \mathbf{F}$ & Additive & Unclear & Synergism & Additive & Additive \\
$\mathbf{B}[\mathbf{a}] \mathbf{P} / \mathbf{F A}$ & Additive / synergism & Unclear & Synergism & Additive & Unclear \\
$\mathbf{B}[\mathbf{a}] \mathbf{P} / \mathbf{D B}[\mathbf{a}, \mathbf{h}] \mathbf{A}$ & Additive & Unclear & Synergism & Additive & Additive \\
$\mathbf{B}[\mathbf{a}] \mathbf{P} / \mathbf{D B}[\mathbf{a}, \mathbf{l}] \mathbf{P}$ & Additive / synergism & Unclear & Synergism & Antagonism & Unclear \\
$\mathbf{B}[\mathbf{a}] \mathbf{P} / \mathbf{1 - M P A}$ & Additive & Unclear & Synergism & Antagonism & Additive \\
\hline
\end{tabular}




\section{DISCUSSION}

This study focuses on the effects of binary mixtures of PAHs on cell cycle, apoptosis, DNA adduct formation and gene expression modulation. We compared the observed gene expression effects of equimolar and equitoxic PAH mixtures with the expected data based on additivity of its individual compounds in HepG2 cells. We aim to gain insight into the effects of PAH mixtures and test possibility synergistic, antagonistic or additive effects of a mixture. Mixtures were assessed on their interactive effects based on an additive model. Deviation from this model indicated either synergism or antagonism.

\section{Cell cycle and apoptosis}

The effect on cell cycle and apoptosis in HepG2 cells treated with equimolar concentrations of $\mathrm{B}[\mathrm{a}] \mathrm{P}$ and $\mathrm{DB}[\mathrm{a}, 1] \mathrm{P}$ was found to resemble the effects of $\mathrm{DB}[\mathrm{a}, 1] \mathrm{P}$ alone. $\mathrm{B}[\mathrm{a}] \mathrm{P}$ had little effect on apoptosis and therefore did not contribute to the apoptosis of HepG2 cells exposed to the B[a]P / DB[a,l]P mixture. B[a]P did block cells in S-phase of cell cycle, although at higher concentrations than $\mathrm{DB}[\mathrm{a}, 1] \mathrm{P}$ and therefore the effect of $\mathrm{B}[\mathrm{a}] \mathrm{P}$ on cell cycle in the equimolar $\mathrm{B}[\mathrm{a}] \mathrm{P} / \mathrm{DB}[\mathrm{a}, 1] \mathrm{P}$ mixture mainly represented the effects of DB[a,l]P.

Of all 6 PAHs tested, we found that $\mathrm{DB}[\mathrm{a}, 1] \mathrm{P}$ and $\mathrm{B}[\mathrm{a}] \mathrm{P}$ are most toxic to HepG2 cells in the concentration range tested. Effects on cell cycle were shown by an increased number of cells in S-phase, which has been observed in other studies as well (16).

Equitoxic mixtures of each PAH with B[a]P showed slightly increased levels of apoptosis compared to the compounds individually. Only FA and DB[a,l]P showed some synergism. Interaction on S-phase arrest did not to occur. No comparable literature data was available.

\section{DNA adduct formation}

DNA adduct formation in HepG2 cells after exposure to equitoxic PAHconcentrations showed that equally toxic concentrations (based on apoptosis and cell cycle disturbances) did not induce the same level of DNA adducts in HepG2 cells. This indicates that the cytotoxic effects are not directly related to the total DNA adduct levels. Mixtures of two PAHs showed synergism on DNA adducts formation for all mixtures. Possibly PAH activation is enhanced in co-exposure of PAHs leading to a higher level of DNA reactive metabolites. This seems to be indicated by a synergistic effect on the expression of CYP1A2 which we found for B[a]P / DB[a,h]A and $\mathrm{B}[\mathrm{a}] \mathrm{P} / \mathrm{DB}[\mathrm{a}, 1] \mathrm{P}$. Or, as Uno et al (2) found increased levels of DNA adducts in CYP1A1 knockout mice, which results in a reduced metabolism of PAHs in mixtures, and may lead to higher DNA adduct levels. Also, phase II enzymes involved in detoxi- 
fying PAH metabolites might be saturated and thereby leading to increased levels of PAH metabolites.

Our findings were not supported by earlier studies, in which an antagonistic effect of PAH mixtures on DNA adduct formation was found in MCF7 cells (17), which may be due to the differences between breast tissue and actively metabolizing liver tissue or to the more complex mixtures studied. The synergistic effect found on DNA adduct formation seems to be strongest for FA and 1-MPA, which did not induce DNA adducts individually, but which are neither inducers of CYP450 activity. This might prove an important role of these low carcinogenic compounds in co-carcinogenesis, though the mechanism is currently not understood.

\section{Gene expression modulation}

For DB[a,1]P, FA and 1-MPA low numbers of genes were found to be affected in the equitoxic experiment. As we used the highest dose of $30 \mu \mathrm{M}$ for the latter two compounds, these compounds probably have little effect on gene expression in HepG2 cells, as was shown previously (7). For DB[a,l]P we used the $0.01 \mu \mathrm{M}$ concentration since at this dose it already showed increased apoptosis levels and marked cell cycle changes. However, DB[a,l]P had a small effect on gene expression at this concentration.

\section{Assessing the additivity of gene expression profiles for mixtures}

As the effects in equimolar mixtures were dominated by the effects of DB[a,1]P, we did not include those data in assessing the interactive effects of $\mathrm{PAH}$ mixtures. However, the effects at the highest concentration, at which both compounds contributed to the effects of the mixture, shows antagonism, which is also shown by this mixture in at equitoxic concentrations. Comparison of observed and expected gene expression levels (Figure 6.9), showed that the interactive effects on gene expression profiles differ between mixtures. Mixtures of B[a]P with $\mathrm{B}[\mathrm{b}] \mathrm{F}, \mathrm{FA}$ and $\mathrm{DB}[\mathrm{a}, \mathrm{h}] \mathrm{A}$ showed additive effects on gene expression, whereas the mixtures of $\mathrm{B}[\mathrm{a}] \mathrm{P}$ with $\mathrm{DB}[\mathrm{a}, 1] \mathrm{P}$ and with 1MPA showed antagonism.

\section{Assessing additivity of differential expression for single genes}

The expression of many genes showed additivity for many conditions in either of the experiments. Some of these genes are involved in PAH metabolism, like CYP1A1, and many others are related to tumorigenesis. Only one gene was found to show additivity at the equimolar as well as the equitoxic concentrations, which was ATF3. Since only one gene shows similar interaction in the equimolar and equitoxic mixtures, it shows that interactive effects are dependent on the concentrations selected.

Furthermore, 13 genes showed mostly synergism or antagonism in the various mixtures (Table 6.2). Many of these genes can be related to DNA damage induces by PAH 
and the early onset of carcinogenesis. These genes include XRCC1 and GADD45A, which are involved in DNA damage repair $(18,19)$, and $M T 2 A$ which is involved in protection against oxidative stress (20). The expression of many of these carcinogenesis related genes is higher expressed than expected, indicating a higher damaging effect of PAHs in mixtures than the individual compounds suggest. This is in agreement with the levels of DNA adducts we found after exposure to PAH mixtures. The expression of some other genes related to cell cycle or DNA damage (CDKN1A and $B A X)$ did not show interaction for more than one mixture.

\section{Synergism or antagonism?}

To our knowledge, no previous studies have been done on the interactive effects of mixtures on gene expression level. Therefore, we attempted to develop a method for assessing these effects. Although we realize this method may not be perfect, we have tried to design a method which allows studying effects of mixtures on gene expression level.

To assess the effects of PAH mixtures, an addition of concentrations is not always accurate (21), since a common mode of action is assumed. Alternatively, a model that assumes no common mode of action was found to predict the effects of the mixture more accurately. Our method adds effects on gene expression, and no common mode of action is required and therefore our method might be a good estimation of the effects of a mixture. However, further development is required, but our method could be useful for other researchers interested in interactive effects on gene expression level.

A comparison of interactive effects (Table 6.3) shows that no consistent effects are observed for each mixture. Most previous studies suggest an additive effect or an antagonistic effect of PAH mixtures (4,22). We found that interactions of $\mathrm{B}[\mathrm{b}] \mathrm{F}, \mathrm{FA}$ and $\mathrm{DB}[\mathrm{a}, \mathrm{h}] \mathrm{A}$ with $\mathrm{B}[\mathrm{a}] \mathrm{P}$ are mostly additive or show synergism, the latter for $\mathrm{DNA}$ adduct formation. The synergism we found for DNA adduct formation, was not found by Gray et al for mixtures of $\mathrm{B}[\mathrm{a}] \mathrm{P}$ and $7 \mathrm{H}$-dibenzo[c,g]carbazole on tumor formation in mice (23). This might be due to the different compounds tested or the difference of in vivo versus in vitro. However, James et al (24) did find a synergism in toxicity of PAHs and PCBs, which are also metabolized by the same enzymes of the Cytochrome P450 family.

Although 1-MPA and FA, did show some effect on the parameters tested individually, in mixtures both compounds showed to contribute to the effect of the mixture. This shows that compounds having little effect by itself, may contribute importantly to the effects of a mixture. 
Furthermore, whereas the effects of $\mathrm{B}[\mathrm{a}] \mathrm{P} / \mathrm{DB}[\mathrm{a}, 1] \mathrm{P}$ and $\mathrm{B}[\mathrm{a}] \mathrm{P} / \mathrm{1}-\mathrm{MPA}$ on gene expression can be antagonistic, the effects on other parameters can show synergism. Uno et al (2) found that levels of DNA adducts were higher in CYP1A1 knock-out mice. So, by its antagonistic effect on gene expression (including CYP1A1), of both mixtures, the levels of DNA adducts may be increasing, which is in accordance with what we found.

\section{CONCLUSION}

In our study we showed that many PAH mixtures show mostly additive or antagonistic effects on gene expression profiles, apoptosis and cell cycle. For individual genes, the expression of a few genes showed additivity, but many genes showed interactive effects. The only consistent interactive effect was on DNA adduct formation, which was always synergistic. Also, compounds like FA and 1-MPA, which do not induce adducts and are weak or not carcinogenic, have an impact on the effects of mixtures and thus affect the carcinogenic potency of PAH mixtures.

\section{Acknowledgements}

The research was carried out as part of the AMBIPAH project (mechanism-based approaches to improved cancer risk assessment of ambient air polycyclic aromatic hydrocarbons), funded by the European Union (No. QRLT-2001-024202). 


\section{REFERENCES}

1. Shimada, T., Sugie, A., Shindo, M., Nakajima, T., Azuma, E., Hashimoto, M. and Inoue, K. (2003) Tissue-specific induction of cytochromes P450 1A1 and 1B1 by polycyclic aromatic hydrocarbons and polychlorinated biphenyls in engineered C57BL/6J mice of arylhydrocarbon receptor gene. Toxicol Appl Pharmacol, 187, 1-10.

2. Uno, S., Dalton, T.P., Dragin, N., Curran, C.P., Derkenne, S., Miller, M.L., Shertzer, H.G., Gonzalez, F.J. and Nebert, D.W. (2006) Oral benzo[a]pyrene in Cyp1 knockout mouse lines: CYP1A1 important in detoxication, CYP1B1 metabolism required for immune damage independent of total-body burden and clearance rate. Mol Pharmacol, 69, 1103-14.

3. Shimada, T., Inoue, K., Suzuki, Y., Kawai, T., Azuma, E., Nakajima, T., Shindo, M., Kurose, K., Sugie, A., Yamagishi, Y., Fujii-Kuriyama, Y. and Hashimoto, M. (2002) Arylhydrocarbon receptor-dependent induction of liver and lung cytochromes P450 1A1, 1A2, and 1B1 by polycyclic aromatic hydrocarbons and polychlorinated biphenyls in genetically engineered C57BL/6J mice. Carcinogenesis, 23, 1199-207.

4. Nesnow, S., Mass, M.J., Ross, J.A., Galati, A.J., Lambert, G.R., Gennings, C., Carter, W.H., Jr. and Stoner, G.D. (1998) Lung tumorigenic interactions in strain A/J mice of five environmental polycyclic aromatic hydrocarbons. Environ Health Perspect, 106 Suppl 6, 1337-46.

5. Ross, J.A., Nelson, G.B., Wilson, K.H., Rabinowitz, J.R., Galati, A., Stoner, G.D., Nesnow, S. and Mass, M.J. (1995) Adenomas induced by polycyclic aromatic hydrocarbons in strain A/J mouse lung correlate with time-integrated DNA adduct levels. Cancer Res, 55, 1039-44.

6. Solhaug, A., Refsnes, M., Lag, M., Schwarze, P.E., Husoy, T. and Holme, J.A. (2004) Polycyclic aromatic hydrocarbons induce both apoptotic and anti-apoptotic signals in Hepa1c1c7 cells. Carcinogenesis, 25, 809-19.

7. Staal, Y.C.M., van Herwijnen, M.H.M., van Schooten, F.J. and van Delft, J.H.M. (2006) Modulation of gene expression and DNA adduct formation in HepG2 cells by polycyclic aromatic hydrocarbons with different carcinogenic potencies. Carcinogenesis, 27, 646-55.

8. Cassee, F.R., Groten, J.P., van Bladeren, P.J. and Feron, V.J. (1998) Toxicological evaluation and risk assessment of chemical mixtures. Crit Rev Toxicol, 28, 73-101.

9. Freedman, M.D. (1995) Drug Interactions: Classification and Systematic Approach. Am J Ther, 2, 433-443.

10. Liebler, D.C. (1993) The role of metabolism in the antioxidant function of vitamin E. Crit Rev Toxicol, 23, 147-69.

11. Cherng, S.H., Hsu, S.L., Yang, J.L., Yu, C.T. and Lee, H. (2006) Suppressive effect of 1-nitropyrene on benzo[a]pyrene-induced CYP1A1 protein expression in HepG2 cells. Toxicol Lett, 161, 236-43.

12. Willett, K.L., Wassenberg, D., Lienesch, L., Reichert, W. and Di Giulio, R.T. (2001) In vivo and in vitro inhibition of CYP1A-dependent activity in Fundulus heteroclitus by the polynuclear aromatic hydrocarbon fluoranthene. Toxicol Appl Pharmacol, 177, 264-71.

13. Reddy, M.V. and Randerath, K. (1986) Nuclease P1-mediated enhancement of sensitivity of 32Ppostlabeling test for structurally diverse DNA adducts. Carcinogenesis, 7, 1543-51.

14. Godschalk, R.W., Maas, L.M., Van Zandwijk, N., van 't Veer, L.J., Breedijk, A., Borm, P.J., Verhaert, J., Kleinjans, J.C. and van Schooten, F.J. (1998) Differences in aromatic-DNA adduct levels between alveolar macrophages and subpopulations of white blood cells from smokers. Carcinogenesis, 19, 81925.

15. Staal, Y.C.M., van Herwijnen, M.H.M., van Schooten, F.J. and van Delft, J.H.M. (2005) Application of four dyes in gene expression analyses by microarrays. BMC Genomics, 6, 101. 


\section{CHAPTER 6}

16. Binkova, B., Giguere, Y., Rossner, P., Jr., Dostal, M. and Sram, R.J. (2000) The effect of dibenzo[a,l]pyrene and benzo[a]pyrene on human diploid lung fibroblasts: the induction of DNA adducts, expression of $\mathrm{p} 53$ and p21(WAF1) proteins and cell cycle distribution. Mutat Res, 471, 57-70.

17. Mahadevan, B., Parsons, H., Musafia, T., Sharma, A.K., Amin, S., Pereira, C. and Baird, W.M. (2004) Effect of artificial mixtures of environmental polycyclic aromatic hydrocarbons present in coal tar, urban dust, and diesel exhaust particulates on MCF-7 cells in culture. Environ Mol Mutagen, 44, 99-107.

18. Caldecott, K.W., McKeown, C.K., Tucker, J.D., Ljungquist, S. and Thompson, L.H. (1994) An interaction between the mammalian DNA repair protein XRCC1 and DNA ligase III. Mol Cell Biol, 14, 68-76.

19. Vairapandi, M., Balliet, A.G., Hoffman, B. and Liebermann, D.A. (2002) GADD45b and GADD45g are cdc2/cyclinB1 kinase inhibitors with a role in S and G2/M cell cycle checkpoints induced by genotoxic stress. J Cell Physiol, 192, 327-38.

20. Reinecke, F., Levanets, O., Olivier, Y., Louw, R., Semete, B., Grobler, A., Hidalgo, J., Smeitink, J., Olckers, A. and Van der Westhuizen, F.H. (2006) Metallothionein isoform 2A expression is inducible and protects against ROS-mediated cell death in rotenone-treated HeLa cells. Biochem J, 395, 405-15.

21. Olmstead, A.W. and Leblanc, G.A. (2005) Joint action of polycyclic aromatic hydrocarbons: predictive modeling of sublethal toxicity. Aquat Toxicol, 75, 253-62.

22. Falahatpisheh, M.H., Donnelly, K.C. and Ramos, K.S. (2001) Antagonistic interactions among nephrotoxic polycyclic aromatic hydrocarbons. J Toxicol Environ Health A, 62, 543-60.

23. Gray, D.L., Warshawsky, D., Xue, W., Nines, R., Wang, Y., Yao, R. and Stoner, G.D. (2001) The effects of a binary mixture of benzo(a)pyrene and $7 \mathrm{H}$-dibenzo(c,g)carbazole on lung tumors and $\mathrm{K}$-ras oncogene mutations in strain A/J mice. Exp Lung Res, 27, 245-53.

24. James, M.O., Kleinow, K.M., Zhang, Y., Zheng, R., Wang, L. and Faux, L.R. (2004) Increased toxicity of benzo(a)pyrene-7,8-dihydrodiol in the presence of polychlorobiphenylols. Mar Environ Res, 58, 343-6. 


\section{7}

\section{Interactions between polycyclic aromatic hydrocarbons in binary mixtures: Effects on gene expression and DNA adduct formation in precision-cut rat liver slices}

In preparation

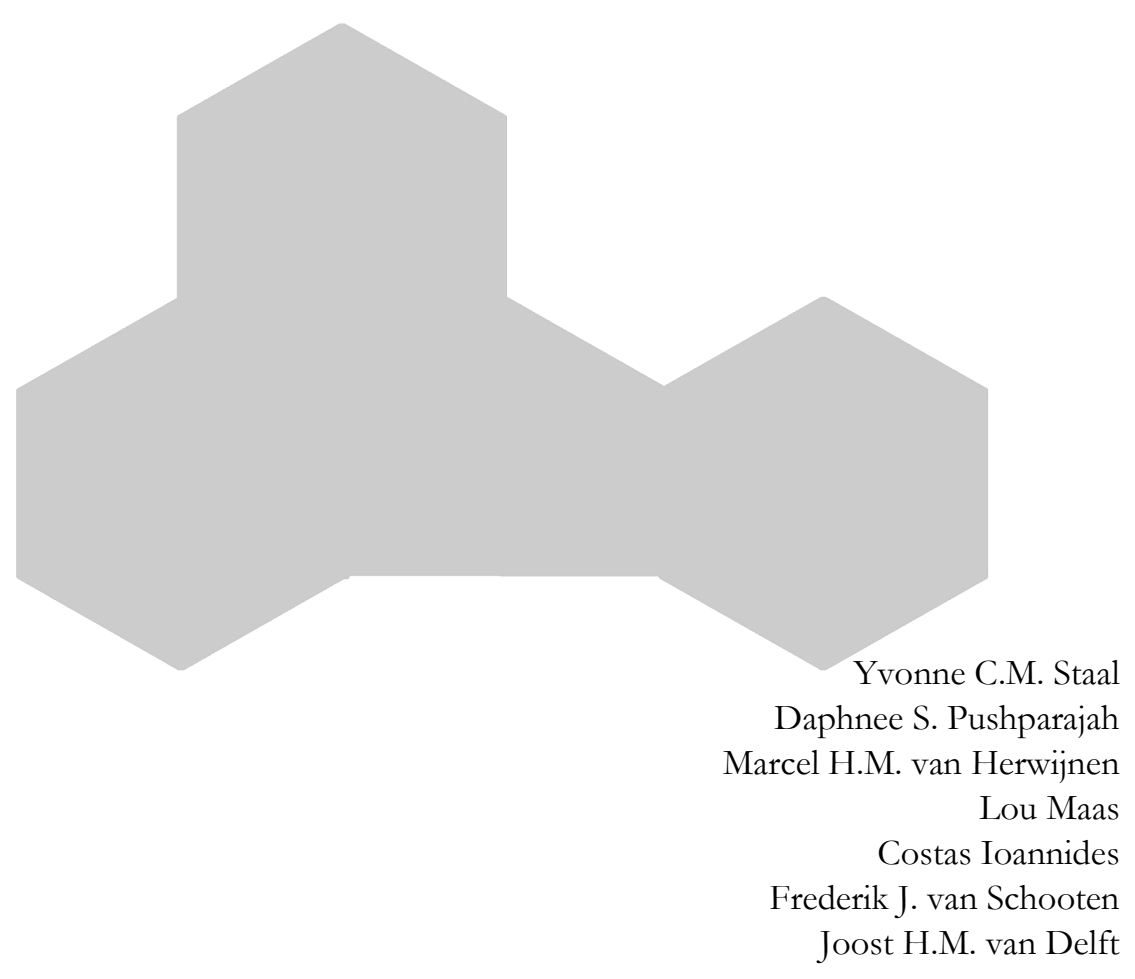




\begin{abstract}
Although exposure to polycyclic aromatic hydrocarbons (PAHs) occurs mostly through mixtures, research efforts have been directed towards the effects caused by individual compounds. In our previous study conducted in HepG2 cells, it was demonstrated that PAHs in binary mixtures interact, leading to additivity or antagonism on gene expression and synergism on DNA adduct formation. The objective of the current study is to gain more insight into the interactive effects of PAHs by extending these studies to precision-cut rat liver slices. The effects of benzo[a]pyrene $(\mathrm{B}[\mathrm{a}] \mathrm{P})$ or dibenzo[a,h]anthracene (DB[a,h]A) alone and in binary mixtures with another PAH $(\mathrm{DB}[\mathrm{a}, \mathrm{h}] \mathrm{A}$, benzo[b]fluoranthene $(\mathrm{B}[\mathrm{b}] \mathrm{F})$, fluoranthene $(\mathrm{FA})$ or dibenzo[a,l]pyrene) on gene expression and DNA adduct formation were investigated in liver slices. All compounds modulated the expression of several genes, although overlap between genes affected by the mixture and the individual compounds was relatively small. Furthermore, all mixtures show an antagonistic response on global gene expression. At the level of individual genes, mostly antagonism was evident, with additivity and synergism observed for only a few genes. These interactions are partly different to those previously observed in HepG2 cells. The effects in liver slices would suggest a lower carcinogenic potency of PAH mixtures than estimated based on additivity of individual compounds.
\end{abstract}




\section{INTRODUCTION}

Toxicological research is directed towards the adverse effects of single compounds on a cell system or an organism. However, human environmental exposure to chemicals mostly involves mixtures. Therefore it is of importance that studies are not confined to single compounds, but are extended to mixtures.

Through the environment, humans are daily exposed to chemical mixtures, including polycyclic aromatic hydrocarbons (PAHs). PAHs comprise a large class of structurally related compounds, many of which possess carcinogenic activity, which are formed during incomplete combustion of organic compounds. Not only the concentrations of PAHs in air vary, but also the mixture composition. Many studies have tried to estimate carcinogenic potency of PAHs in the air based on the concentration of a single compound, usually benzo[a]pyrene $(\mathrm{B}[\mathrm{a}] \mathrm{P})(1,2)$. Although $\mathrm{PAHs}$ are structurally similar, they vary greatly in their carcinogenic activity. Carcinogenic potency of PAHs is usually expressed relative to that of $\mathrm{B}[\mathrm{a}] \mathrm{P}$. Not only does this require extensive animal experiments to compare carcinogenic doses, but also interactive effects between compounds are not taken into account.

PAH exposure usually occurs through mixtures, and it is conceivable that constituents may interact with each other. Such interactions can lead to a higher effect than expected based on additivity (synergism), or one PAH may repress the effects of the other (antagonism). No interaction implies the addition of the effect of both PAHs (additivity) (3,4). Interactive effects may occur at all stages in PAH carcinogenicity, of which biotransformation might be one of the most important.

Biotransformation is important in the metabolic activation of PAHs into their ultimate carcinogenic metabolites. PAHs have shown to induce the expression of several Cytochrome P450 enzymes, among others CYP1A1 and CYP1A2, which metabolise PAHs to their reactive intermediates. These can bind to DNA and thereby induce the formation of mutations, which may lead to the initiation of carcinogenesis. Also, PAHs can induce epigenetic effects, which may lead to changes in biological processes, like cellular communication $(5,6)$, and ultimately may promote cancer development.

A useful applied tool in assessing global effects caused by toxic compounds is gene expression analysis by microarrays. By studying large numbers of genes, a transcriptomic fingerprint can be obtained, which can provide information on the toxicological properties of compounds. This approach can be applied in in vitro cell systems for both mixtures and single compounds. In our previous study, we have demonstrated that interactive effects on gene expression of binary PAH mixtures can be studied with an additive model based on the constituents of the mixture using a human hepatoma cell 
line, HepG2. In general, additive and antagonistic effects on global gene expression were observed, but synergistic effects on DNA adduct binding activities were also evident.

The aim of this study was to apply a toxicogenomics approach to assess whether interactions occur in rat precision-cut liver slices following exposure to binary PAH mixtures. Precision-cut liver slices are a frequently used in vitro model, which is increasingly applied in transcriptome profiling studies (7). In this model, primary cells are refrained in an environment with normal cell-cell and cell-matrix contacts, and express high levels of metabolic enzymes that are important in PAH-induced effects (8). We have already established that, in general, PAHs induce compound-specific gene expression profiles, both in HepG2 cells and in liver slices. For the current study we used 5 PAHs, namely benzo[a]pyrene $(\mathrm{B}[\mathrm{a}] \mathrm{P})$, dibenzo[a,h]anthracene (DB[a,h]A), dibenzo[a,l]pyrene $(\mathrm{DB}[\mathrm{a}, 1] \mathrm{P})$, benzo[b]fluoranthene $(\mathrm{B}[\mathrm{b}] \mathrm{F})$ and fluoranthene $(\mathrm{FA})$. The effects of PAHs on gene expression were examined for a total of 5700 genes by oligonucleotide arrays for individual PAHs as well as for binary mixtures of a $\mathrm{PAH}$ with $\mathrm{B}[\mathrm{a}] \mathrm{P}$ or $\mathrm{DB}[\mathrm{a}, \mathrm{h}] \mathrm{A}$. Effects on DNA adduct formation were determined with ${ }^{32} \mathrm{P}$ postlabelling. PAH concentrations were selected based on DNA adduct-forming potential as determined previously (9).

\section{MATERIALS AND METHODS}

\section{Chemicals}

Benzo[a]pyrene (B[a]P, purity 97\%, CAS no. 50-32-8), benzo[b]fluoranthene (B[b]F, purity 98\%, CAS no. 205-99-2), fluoranthene (FA, purity 99\%, CAS no. 206-44-0), dibenzo[a,h]anthracene (DB[a,h]A, purity 97\%, CAS no. 53-70-3) and dibenzo[a,1]pyrene (DB[a,1]P, purity 99.6\%, CAS no. 191-30-0) were obtained from Sigma-Aldich (Zwijndrecht, the Netherlands). All chemicals were dissolved in DMSO.

\section{Preparation and exposure of precision-cut liver slices to PAHs}

Rat livers were obtained from male Wistar albino rats (175-250g) killed by cervical dislocation. Livers were immediately excised and slices $(250 \mu \mathrm{m})$ were prepared using a Krumdieck tissue slicer (Alabama Research and Development Corp., Munsford, AL, USA) as previously described (10). Slices were pre-incubated for 30 minutes at $37^{\circ} \mathrm{C}$ in RPMI supplemented with $5 \%$ foetal calf serum, $0.5 \mathrm{mM} \mathrm{L}$-methionine, $1 \mu \mathrm{M}$ insulin, $0.1 \mathrm{mM}$ hydrocothsone-21-hemisuccinate and $50 \mu \mathrm{g} / \mathrm{ml}$ gentamycin in 12 well plates on a shaking gyratory in an incubator $\left(5 \% \mathrm{CO}_{2}\right.$ and $95 \%$ air). After pre-incubation, the slices were transferred to 12 well plates containing fresh media and $\mathrm{B}[\mathrm{a}] \mathrm{P}(3 \mu \mathrm{M})$, $\mathrm{DB}[\mathrm{a}, \mathrm{h}] \mathrm{A}(10 \mu \mathrm{M}), \mathrm{B}[\mathrm{b}] \mathrm{F}(10 \mu \mathrm{M})$, FA $(30 \mu \mathrm{M})$ or DB[a,l]P $(0.3 \mu \mathrm{M})$, or a mixture of one the PAHs with B[a]P or DB[a,h]A, or a solvent control (DMSO, $0.066 \% \mathrm{v} / \mathrm{v})$. 
Concentrations inducing a low, but significant level of DNA adducts in our previous study (9), were selected for each PAH. Only FA did not induce DNA adducts and therefore the highest concentration was selected. In each of two independent experiments, three slices were used for each treatment, except for the solvent control (18 slices), B[a]P (8 slices) and DB[a,h]A (5 slices). After $24 \mathrm{~h}$ exposure, the slices were removed from the medium and immediately frozen in liquid nitrogen. For the mixtures of $\mathrm{B}[\mathrm{a}] \mathrm{P}$ with $\mathrm{B}[\mathrm{b}] \mathrm{F}$, and $\mathrm{B}[\mathrm{a}] \mathrm{P}$ with $\mathrm{FA}$, only one experiment was conducted.

\section{RNA isolation, cDNA synthesis and dye labelling}

After crushing the frozen liver slices under liquid nitrogen, RNA was stabilized by dissolving the crushed powder in Trizol (Gibco/BRL, Breda, the Netherlands) and isolated according to the manufacturer's manual. RNA was purified using the RNeasy mini kit (Qiagen Westburg bv., Leusden, The Netherlands) with DNase treatment, RNA quantity was determined spectrophotometrically and quality was assessed using a BioAnalyzer (Agilent Technologies, Breda, The Netherlands). Only RNA samples which were not degraded (clear $18 \mathrm{~S}$ and $28 \mathrm{~S}$ peaks) were used for labelling and hybridization. RNA from all slices with the same treatment was pooled for each experiment.

TABLE 7.1. Labelling and hybridization design of RNA samples from liver slices exposed to the listed PAH (or PAH-mixture) for each experiment and all biological replicates.

\begin{tabular}{|c|c|c|c|c|c|}
\hline $\begin{array}{l}\text { Biological } \\
\text { experiment }\end{array}$ & $\begin{array}{c}\text { Biological } \\
\text { replicate }\end{array}$ & Array & Cyanine 3 & Cyanine 5 & Alexa 594 \\
\hline 1 & 1 & 1 & Control & $\mathrm{B}[\mathrm{a}] \mathrm{P}$ & $\mathrm{DB}[\mathrm{a}, \mathrm{h}] \mathrm{A} / \mathrm{DB}[\mathrm{a}, \mathrm{l}] \mathrm{P}$ \\
\hline 1 & 1 & 4 & Control & $\mathrm{DB}[\mathrm{a}, 1] \mathrm{P}$ & $\mathrm{B}[\mathrm{a}] \mathrm{P} / \mathrm{DB}[\mathrm{a}, \mathrm{l}] \mathrm{P}$ \\
\hline 1 & 1 & 5 & $\mathrm{~B}[\mathrm{a}] \mathrm{P} / \mathrm{DB}[\mathrm{a}, \mathrm{h}] \mathrm{A}$ & Control & $\mathrm{DB}[\mathrm{a}, \mathrm{h}] \mathrm{A}$ \\
\hline 1 & 1 & 7 & Control & $\mathrm{DB}[\mathrm{a}, \mathrm{h}] \mathrm{A} / \mathrm{FA}$ & $\mathrm{FA}$ \\
\hline 1 & 1 & 9 & $\mathrm{~B}[\mathrm{a}] \mathrm{P} / \mathrm{B}[\mathrm{b}] \mathrm{F}$ & $\mathrm{B}[\mathrm{b}] \mathrm{F}$ & Control \\
\hline 2 & 1 & 2 & $\mathrm{DB}[\mathrm{a}, \mathrm{h}] \mathrm{A} / \mathrm{DB}[\mathrm{a}, \mathrm{l}] \mathrm{P}$ & Control & $\mathrm{DB}[\mathrm{a}, \mathrm{l}] \mathrm{P}$ \\
\hline 2 & 1 & 3 & $\mathrm{~B}[\mathrm{a}] \mathrm{P}$ & $\mathrm{B}[\mathrm{a}] \mathrm{P} / \mathrm{DB}[\mathrm{a}, \mathrm{l}] \mathrm{P}$ & Control \\
\hline 2 & 1 & 6 & $\mathrm{DB}[\mathrm{a}, \mathrm{h}] \mathrm{A}$ & $\mathrm{B}[\mathrm{a}] \mathrm{P} / \mathrm{DB}[\mathrm{a}, \mathrm{h}] \mathrm{A}$ & Control \\
\hline 2 & 1 & 8 & FA & Control & $\mathrm{DB}[\mathrm{a}, \mathrm{h}] \mathrm{A} / \mathrm{FA}$ \\
\hline 2 & 1 & 10 & Control & $\mathrm{B}[\mathrm{a}] \mathrm{P} / \mathrm{B}[\mathrm{b}] \mathrm{F}$ & $\mathrm{B}[\mathrm{b}] \mathrm{F}$ \\
\hline 3 & 2 & 11 & Control & $\mathrm{B}[\mathrm{a}] \mathrm{P}$ & $\mathrm{DB}[\mathrm{a}, \mathrm{h}] \mathrm{A} / \mathrm{DB}[\mathrm{a}, \mathrm{l}] \mathrm{P}$ \\
\hline 3 & 2 & 14 & Control & $\mathrm{DB}[\mathrm{a}, \mathrm{l}] \mathrm{P}$ & $\mathrm{B}[\mathrm{a}] \mathrm{P} / \mathrm{DB}[\mathrm{a}, 1] \mathrm{P}$ \\
\hline 3 & 2 & 15 & $\mathrm{~B}[\mathrm{a}] \mathrm{P} / \mathrm{DB}[\mathrm{a}, \mathrm{h}] \mathrm{A}$ & Control & $\mathrm{DB}[\mathrm{a}, \mathrm{h}] \mathrm{A}$ \\
\hline 3 & 2 & 17 & Control & $\mathrm{DB}[\mathrm{a}, \mathrm{h}] \mathrm{A} / \mathrm{FA}$ & FA \\
\hline 3 & 2 & 19 & $\mathrm{DB}[\mathrm{a}, \mathrm{h}] \mathrm{A} / \mathrm{FA}$ & $\mathrm{B}[\mathrm{a}] \mathrm{P} / \mathrm{FA}$ & Control \\
\hline 4 & 2 & 12 & $\mathrm{DB}[\mathrm{a}, \mathrm{h}] \mathrm{A} / \mathrm{DB}[\mathrm{a}, \mathrm{l}] \mathrm{P}$ & Control & $\mathrm{DB}[\mathrm{a}, \mathrm{l}] \mathrm{P}$ \\
\hline 4 & 2 & 13 & $\mathrm{~B}[\mathrm{a}] \mathrm{P}$ & $\mathrm{B}[\mathrm{a}] \mathrm{P} / \mathrm{DB}[\mathrm{a}, \mathrm{l}] \mathrm{P}$ & Control \\
\hline 4 & 2 & 16 & $\mathrm{DB}[\mathrm{a}, \mathrm{h}] \mathrm{A}$ & $\mathrm{B}[\mathrm{a}] \mathrm{P} / \mathrm{DB}[\mathrm{a}, \mathrm{h}] \mathrm{A}$ & Control \\
\hline 4 & 2 & 18 & FA & Control & $\mathrm{B}[\mathrm{a}] \mathrm{P} / \mathrm{FA}$ \\
\hline
\end{tabular}


RNA samples were reverse transcribed into cDNA in triplicate with amino-allyl labelled dUTP (Sigma-Aldrich, St Louis, USA) and subsequently labelled with one of the three dyes, namely Cyanine 3 (Cy3), Cyanine 5 (Cy5) or Alexa 594 (A594), as was described previously (11). The labelling schedule is shown in Table 7.1.

\section{Microarray hybridization and data analysis}

Dye-labelled samples were hybridized on an Operon rat oligonucleotide array containing 5700 oligonucleotides (v1.2.1, Operon, Qiagen, Venlo, The Netherlands) printed in triplicate on Corning UltraGAPS Coated Slides (Corning Life Sciences, New York, USA) by the Genome Centre Maastricht (Maastricht University, Maastricht, The Netherlands). Hybridization and washing were performed according to Corning's protocol for oligonucleotide arrays as previously described (11).

The microarray slides were scanned on a ScanArrayExpress (Packard Biochip Technologies, Perkin Elmer life sciences, Boston, USA). All three channels were scanned at 100\% laser power and PMT Gain was adjusted, such that the signal of the highest fluorescent spots was just below the maximum measurable level. The images (10 micron resolution; 16 bit tiff) were processed with ImaGene 5.0 software (BioDiscovery Inc., Los Angeles, USA) to quantify spot signals. Irregular spots were manually or automatically flagged and excluded from the data analysis. If the averaged spot signal for the controls was higher than the corresponding SD , the gene was used for further analysis. Of all 5700 genes, 2156 genes met these criteria.

Data from ImaGene were transported into GeneSight software version 4.1.5 (BioDiscovery Inc. Los Angeles, USA) for further processing and analysis. For each spot, background was subtracted and flagged spots as well as spots with a net expression level below 20 were omitted. Data were log base 2 transformed and data normalization was carried out using LOWESS and centring expression differences by subtracting mean values. Expression differences between exposed and control were calculated and data of replicate spots were averaged while omitting outliers ( $>2$ standard deviations). Significantly modulated genes were found using the confidence analysis tool from GeneSight (up or down regulation of 0.1 and $99.9 \%$ confidence limit) using the averaged data per treatment. Unsupervised clustering was performed by hierarchical clustering analysis and principal component analysis using GeneSight tools.

\section{Assessing the additivity of gene expression data}

To calculate the expected gene expression levels of the PAH mixture based on the individual constituents, we used the method described in our previous study (12). This method assumes additivity of the effects on gene expression. Linear regression analysis and Pearson correlation coefficients were calculated using SPSS 12.0.1 for windows (SPSS Inc., Chicago, USA). Additivity was assumed when regression analysis for the observed and expected data did not show a deviation from $\mathrm{y}=\mathrm{x}$ (confidence interval of 
$2 \mathrm{SD})$. If it did deviate from $\mathrm{y}=\mathrm{x}$, synergism is shown by a slope $>1$ and antagonism by a slope $<1$.

\section{DNA adduct analysis}

After removal of the aqueous phase during RNA isolation using Trizol, the remaining phases were used for DNA isolation according to the manufacturer's protocol. DNA adduct levels were determined according to the procedure originally described by Reddy and Randerath (13) with the modifications introduced by Godschalk et al (14). DNA adduct levels were quantified by comparison with standard samples with known BPDE-DNA adduct levels (1 adduct per $10^{6}, 10^{7}$ or $10^{8} \mathrm{nts}$; detection limit 1 adduct per $10^{8} \mathrm{nt}$ ). Adduct spots on the chromatograms were located and quantified using a phosphor imager (FLA-3000, Fuji, Paris, France) and AIDA/2D densitometry software.

Expected DNA adduct levels were calculated by adding the total DNA adduct levels of both constituents, after correcting for background levels found in solvent control samples.

\section{RESULTS}

\section{Gene expression analysis}

Microarray analysis showed that in total 328 genes were significantly modulated after exposure to either of the mixtures or individual compounds. The highest number of affected genes was seen after exposure to the DB[a,h]A / FA mixture (80 genes).

The number of modulated genes decreased as follows; $\mathrm{B}[\mathrm{b}] \mathrm{F}(60), \mathrm{B}[\mathrm{a}] \mathrm{P} / \mathrm{B}[\mathrm{b}] \mathrm{F}(57)$, $\mathrm{B}[\mathrm{a}] \mathrm{P}(52), \mathrm{DB}[\mathrm{a}, \mathrm{h}] \mathrm{A}(49), \mathrm{B}[\mathrm{a}] \mathrm{P} / \mathrm{DB}[\mathrm{a}, \mathrm{h}] \mathrm{A}(45), \mathrm{DB}[\mathrm{a}, \mathrm{h}] \mathrm{A} / \mathrm{DB}[\mathrm{a}, 1] \mathrm{P}$ (42), FA (34), $\mathrm{B}[\mathrm{a}] \mathrm{P} / \mathrm{DB}[\mathrm{a}, 1] \mathrm{P}(34), \mathrm{B}[\mathrm{a}] \mathrm{P} / \mathrm{FA}(33)$ and DB[a,l]P (27). In Figure 7.1 it can be seen that the overlap between the modulated genes for each mixture with the individual compounds was relatively small. Most genes affected by either of the mixture constituents alone, were not similarly affected by the mixture. Gene names, abbreviations, GenBank accession numbers and gene expression differences of modulated genes can be found in the supplemented data file (http://fdgwgratsrv0401.unimaas.nl/data). 


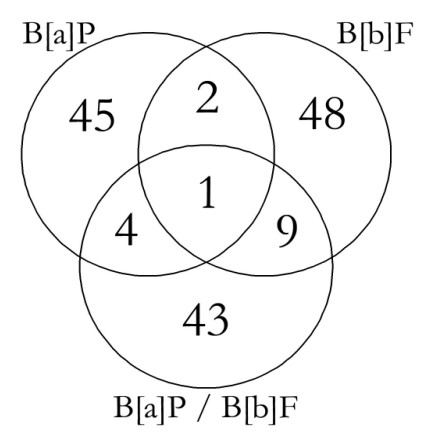

Figure 7.1a

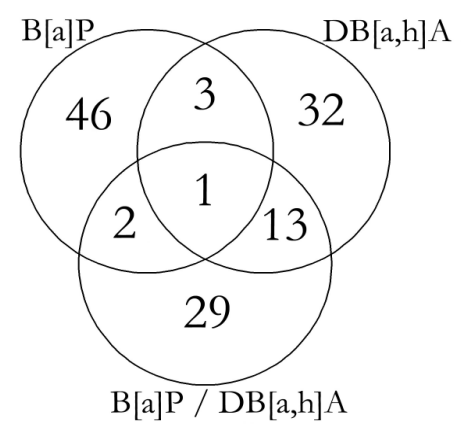

Figure 7.1c

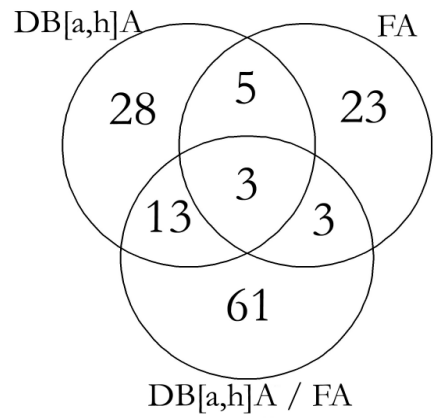

Figure 7.1e

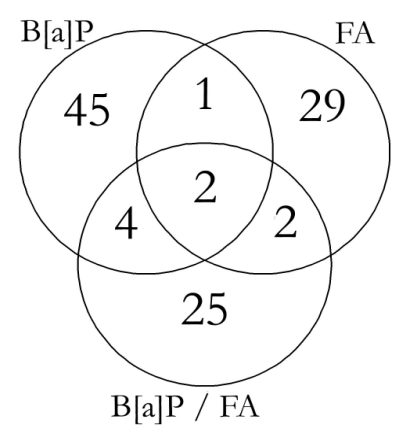

Figure 7.1b

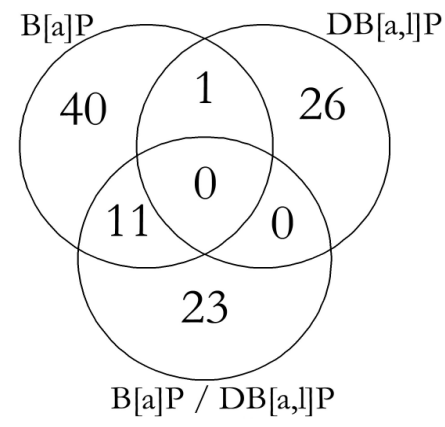

Figure 7.1d

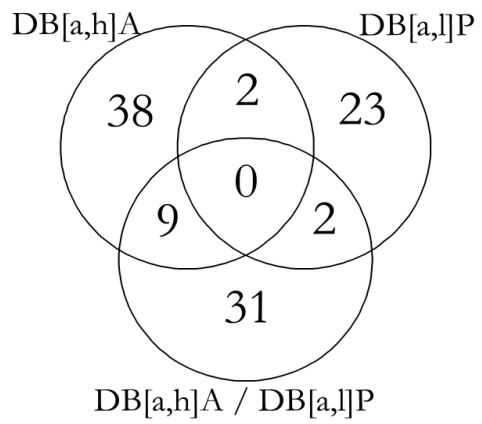

Figure 7.1e

FIGURE 7.1. Venn diagrams showing the numbers of modulated genes in rat liver slices to single PAHs, their mixtures and their overlap.

In Figure 7.2 the hierarchical clustering analysis (HCA) shows that gene expression profiles between mixtures and their individual constituents are similar. All treatments with $\mathrm{DB}[\mathrm{a}, \mathrm{h}] \mathrm{A}$, both individual as well as in mixtures, group together, indicating a distinct effect of DB[a,h]A on gene expression. Furthermore, the gene expression profile for the $\mathrm{B}[\mathrm{a}] \mathrm{P} / \mathrm{B}[\mathrm{b}] \mathrm{F}$ mixture differs most extensively from the gene expression profiles brought about by the other treatments. This HCA shows that all compounds have a contribution to the gene expression of the mixture and neither of the compounds has a dominating effect. 


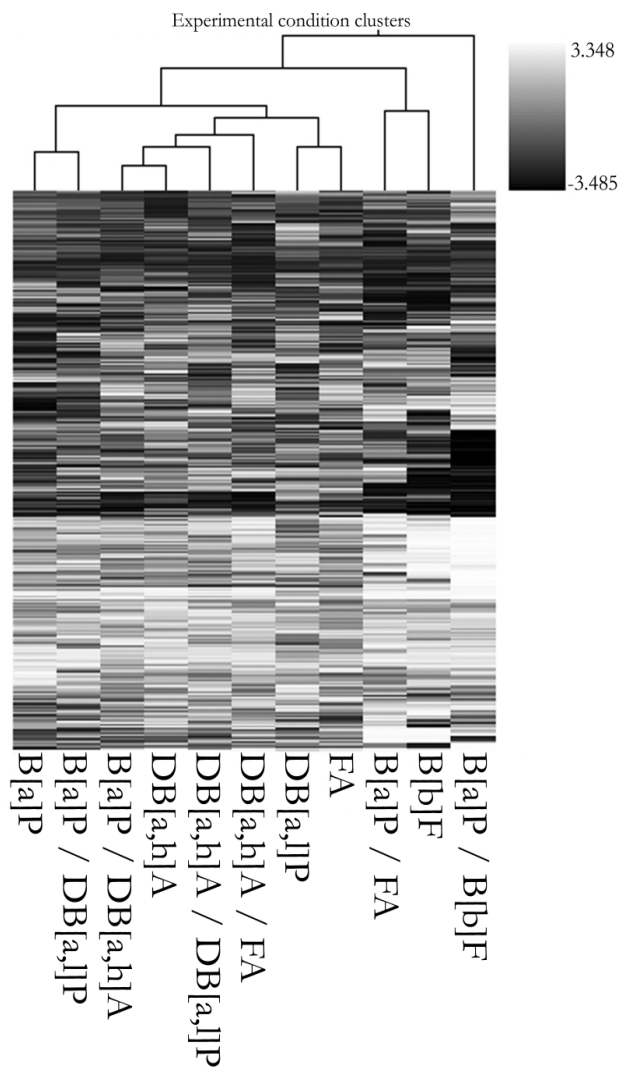

FIGURE 7.2. Hierarchical clustering analysis of gene expression differences in rat liver slices after $24 \mathrm{~h}$ exposure to PAHs and their mixtures in equitoxic concentrations with the 328 genes differentially expressed by either of the treatments. Euclidean clustering was used with average distance metric. 


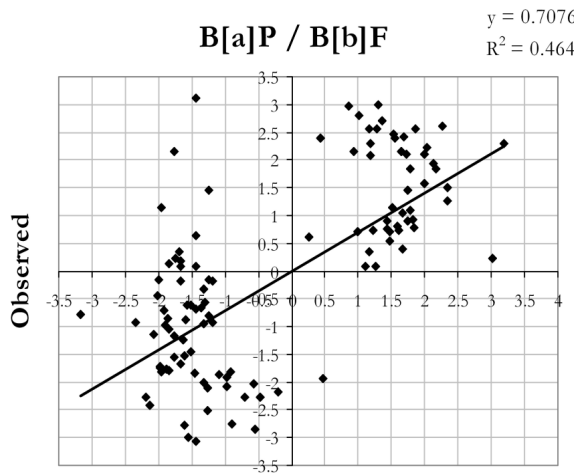

Figure $7.3 \mathrm{a}$

Expected

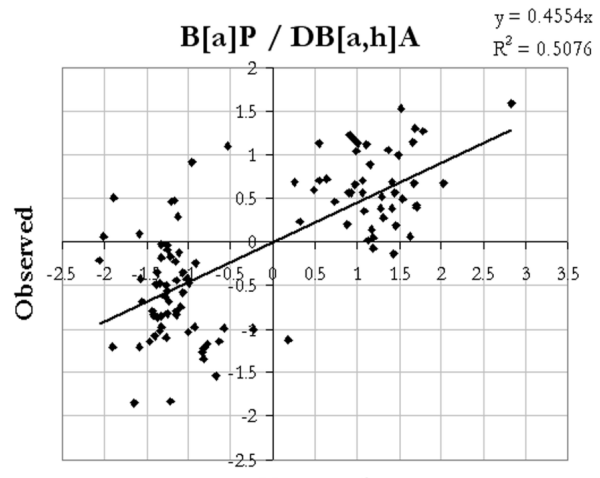

Figure $7.3 \mathrm{c}$

Expected

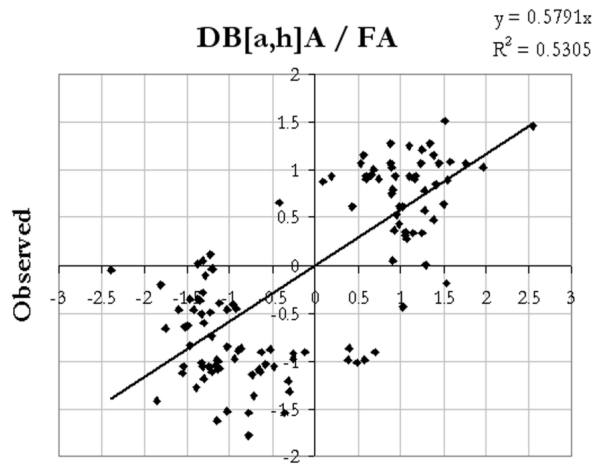

Figure 7.3e
Expected

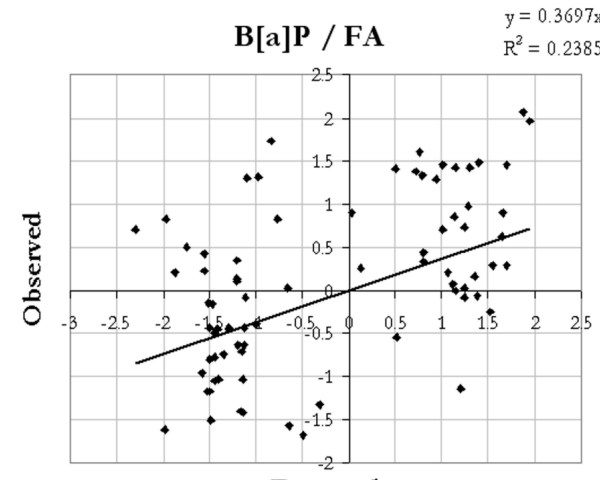

Figure $7.3 \mathrm{~b}$

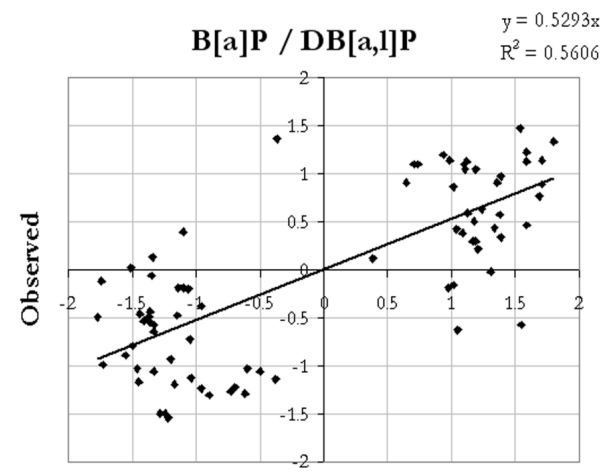

Figure $7.3 \mathrm{~d}$

Expected

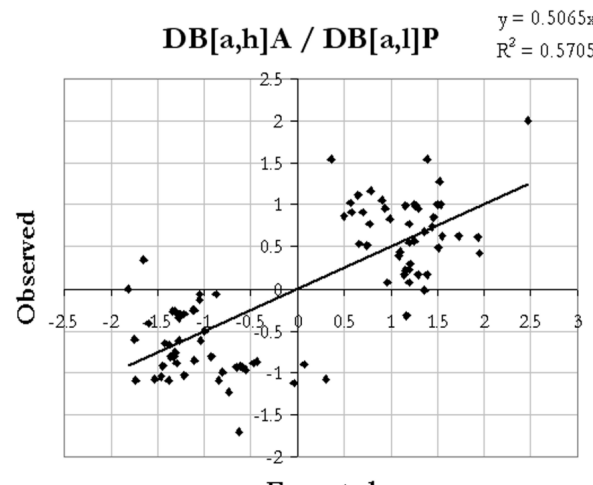

Figure $7.3 \mathrm{f}$

\section{Expected}

Figure 7.3. Expected (x-axis) versus observed (y-axis) gene expression in rat liver slices exposed to PAH mixtures. Figures 3a-f respectively show mixtures of B[a]P / B[b]F, B[a]P / FA, B[a]P / DB[a,h]A, B[a]P / $\mathrm{DB}[\mathrm{a}, \mathrm{l}] \mathrm{P}, \mathrm{DB}[\mathrm{a}, \mathrm{h}] \mathrm{A} / \mathrm{FA}$ and $\mathrm{DB}[\mathrm{a}, \mathrm{h}] \mathrm{A} / \mathrm{DB}[\mathrm{a}, \mathrm{l}] \mathrm{P}$. Correlation coefficients $\left(\mathrm{R}^{2}\right)$ and the live equation are indicated in the graph. 


\section{Assessing the additivity for gene expression profiles}

The expected gene expression modulation of the mixtures was calculated by adding the responses of the individual compounds. Figure 7.3 shows the expected gene expression differences versus the observed differences for each mixture. All linear regression equations significantly deviated from $y=x$ and their slopes were smaller than 1 . This indicates an antagonistic interaction of these PAHs in the mixtures.

A comparison of expected and observed gene expression differences was also made after a more strict selection of genes, namely only those genes modulated by at least 2 of the 3 treatments for each mixture (the intersections of Figure 7.1). This analysis again showed that all slopes are smaller than 1 , although the slopes for $\mathrm{B}[\mathrm{a}] \mathrm{P} / \mathrm{B}[\mathrm{b}] \mathrm{F}$ and $\mathrm{B}[\mathrm{a}] \mathrm{P} / \mathrm{FA}$ did not differ significantly from 1.

\section{Assessing the additivity for single genes}

Also at the level of individual genes, the expected expression was compared with the observed expression of the genes. Of all 328 differentially expressed genes, 21 showed lower gene expression levels in most mixtures than expected (at least 1SD), indicating antagonism. Ten genes showed consistently no deviation between observed and expected data (less than 1SD deviation), suggesting additivity, and two genes showed higher gene expression levels than expected, which points to synergism. These genes are shown in Table 7.2. Thus, most genes show antagonistic effects, which is in agreement with the antagonistic effect noted for all mixtures on global gene expression. The other genes show no dominating interactive effect; they are listed in the supplemented data file (http://fdgwgratsrv0401.unimaas.nl/data). 
TABLE 7.2. Interactive effect of gene expression upon exposure to PAH mixtures. Additivity is shown by “=”, synergism by “+” and antagonism by “-“.

\begin{tabular}{|c|c|c|c|c|c|c|c|c|}
\hline $\begin{array}{l}\text { Gene } \\
\text { Symbol }\end{array}$ & Gene Name & $\begin{array}{l}\text { Genbank } \\
\text { Accession }\end{array}$ & $\begin{array}{l}\frac{1}{0} \\
\frac{n}{n} \\
\frac{a}{n} \\
\frac{\pi}{n}\end{array}$ & 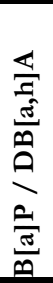 & 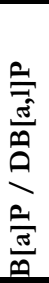 & 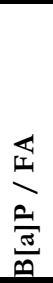 & 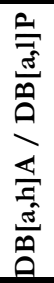 & 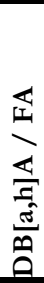 \\
\hline \multicolumn{9}{|c|}{ Additivity } \\
\hline$A B C D 3$ & $\begin{array}{l}\text { ATP-binding cassette, sub-family D } \\
\text { (ALD), member } 3\end{array}$ & NM_012804 & & & $=$ & & $=$ & $=$ \\
\hline$A L D R 1$ & $\begin{array}{l}\text { Aldehyde reductase } 1 \text { (low } \mathrm{Km} \text { aldose } \\
\text { reductase) ( } 5.8 \mathrm{~kb} \text { PstI fragment, } \\
\text { probably the functional gene) }\end{array}$ & NM_012498 & & $=$ & & & $=$ & $=$ \\
\hline$A R F G A P 1$ & $\begin{array}{l}\text { ADP-ribosylation factor } 1 \text { GTPase } \\
\text { activating protein }\end{array}$ & U35776 & $=$ & & $=$ & $=$ & & \\
\hline CCR2 & chemokine receptor CCR2 gene & NM_021866 & $=$ & $=$ & $=$ & & & \\
\hline $\mathrm{CDH17}$ & cadherin 17 & X78997 & & & $=$ & & $=$ & $=$ \\
\hline NQO1 & NAD(P)H dehydrogenase, quinone 1 & NM_017000 & $=$ & $=$ & & $=$ & $=$ & $=$ \\
\hline NUPR1 & nuclear protein 1 & AF014503 & $=$ & $=$ & & & $=$ & $=$ \\
\hline SPP1 & secreted phosphoprotein 1 & NM_012881 & $=$ & $=$ & $=$ & & & \\
\hline & $\begin{array}{l}\text { similar to hypothetical protein, clone 2- } \\
25\end{array}$ & AW530379 & & $=$ & & & $=$ & $=$ \\
\hline & similar to cDNA sequence AF155546 & BF548312 & $=$ & $=$ & & & & $=$ \\
\hline \multicolumn{9}{|c|}{ Mostly antagonism } \\
\hline$A C O X 2$ & $\begin{array}{l}\text { acyl-Coenzyme A oxidase 2, branched } \\
\text { chain }\end{array}$ & X95189 & & - & & & - & - \\
\hline CLDN7 & claudin 7 & AJ011811 & & - & & - & - & - \\
\hline CYP1A2 & cytochrome P45, 1a2 & NM_012541 & - & - & - & $=$ & - & - \\
\hline$D I G 1$ & dithiolethione-inducible gene-1 & U66322 & - & - & $=$ & $=$ & - & - \\
\hline $\begin{array}{l}E H- \\
H A D H\end{array}$ & $\begin{array}{l}\text { enoyl-Coenzyme A, hydratase/3- } \\
\text { hydroxyacyl Coenzyme A dehydro- } \\
\text { genase }\end{array}$ & K03249 & & - & & & - & - \\
\hline GILZ & glucocorticoid-induced leucine zipper & NM_031345 & & - & & & - & - \\
\hline HSD11B1 & hydroxysteroid 11-beta dehydrogenase 1 & NM_017080 & - & - & $=$ & & - & - \\
\hline ID1 & $\begin{array}{l}\text { Inhibitor of DNA binding 1, helix-loop- } \\
\text { helix protein (splice variation) }\end{array}$ & NM_012797 & $=$ & - & - & - & & - \\
\hline$L B P$ & lipopolysaccharide binding protein & NM_017208 & & - & - & & - & - \\
\hline$M A D H 3$ & MAD homolog 3 (Drosophila) & NM_013095 & $=$ & - & - & - & & \\
\hline$M E 1$ & malic enzyme 1 & NM_012600 & - & - & $=$ & - & & \\
\hline$P 58 / P 45$ & nucleoporin p58 & AF000899 & & - & & & - & - \\
\hline
\end{tabular}




\begin{tabular}{|c|c|c|c|c|c|c|c|c|}
\hline $\begin{array}{l}\text { Gene } \\
\text { Symbol }\end{array}$ & Gene Name & $\begin{array}{l}\text { Genbank } \\
\text { Accession }\end{array}$ & $\begin{array}{l}\frac{1}{\bar{n}} \\
\frac{0}{n} \\
\frac{a}{n} \\
\frac{0}{n}\end{array}$ & 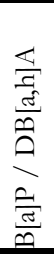 & 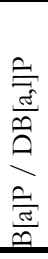 & $\begin{array}{l}\mathbb{I} \\
\overline{1} \\
\frac{\pi}{\pi} \\
\frac{\pi}{n}\end{array}$ & 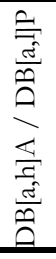 & 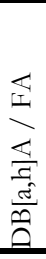 \\
\hline PTPN16 & $\begin{array}{l}\text { protein tyrosine phosphatase, non- } \\
\text { receptor type } 16\end{array}$ & X84004 & & - & & & - & - \\
\hline $\begin{array}{l}\text { SER- } \\
\text { PIND1 }\end{array}$ & leuserpin-2 & NM_024382 & & - & & & - & - \\
\hline$S L C 16 A 1$ & solute carrier family 16 , member 1 & NM_012716 & & - & & & - & - \\
\hline$S L C 16 A 1$ & solute carrier family 16, member 1 & $\mathrm{AB} 047324$ & - & & & - & & - \\
\hline$S P N B 3$ & beta-spectrin 3 & NM_019167 & - & - & - & - & & \\
\hline$T U B B 5$ & tubulin, beta 5 & $\mathrm{AB} 011679$ & - & - & $=$ & - & $=$ & $=$ \\
\hline$U G C G$ & $\begin{array}{l}\text { UDP-glucose:ceramide glycosyltransfe- } \\
\text { rase }\end{array}$ & AF047707 & & - & & & - & - \\
\hline & similar to HSPC288 & BG666041 & & - & & & - & - \\
\hline & $\begin{array}{l}\text { similar to Complement C5 precursor } \\
\text { (Hemolytic complement) }\end{array}$ & AW917065 & & - & $=$ & & - & - \\
\hline \multicolumn{9}{|c|}{ Mostly synergism } \\
\hline PFKFB1 & $\begin{array}{l}\text { 6-phosphofructo-2-kinase/fructose-2,6- } \\
\text { biphosphatase } 1\end{array}$ & NM_012621 & + & + & & + & & \\
\hline$R R A D$ & Ras-related associated with diabetes & U12187 & & + & + & + & $=$ & $=$ \\
\hline
\end{tabular}

\section{DNA adduct formation}

Figure 7.4 shows the DNA adduct formation in liver slices. Comparison of the DNA adduct level of each mixture with its expected level based on additivity of the individual compounds, generally showed antagonism for all mixtures. 


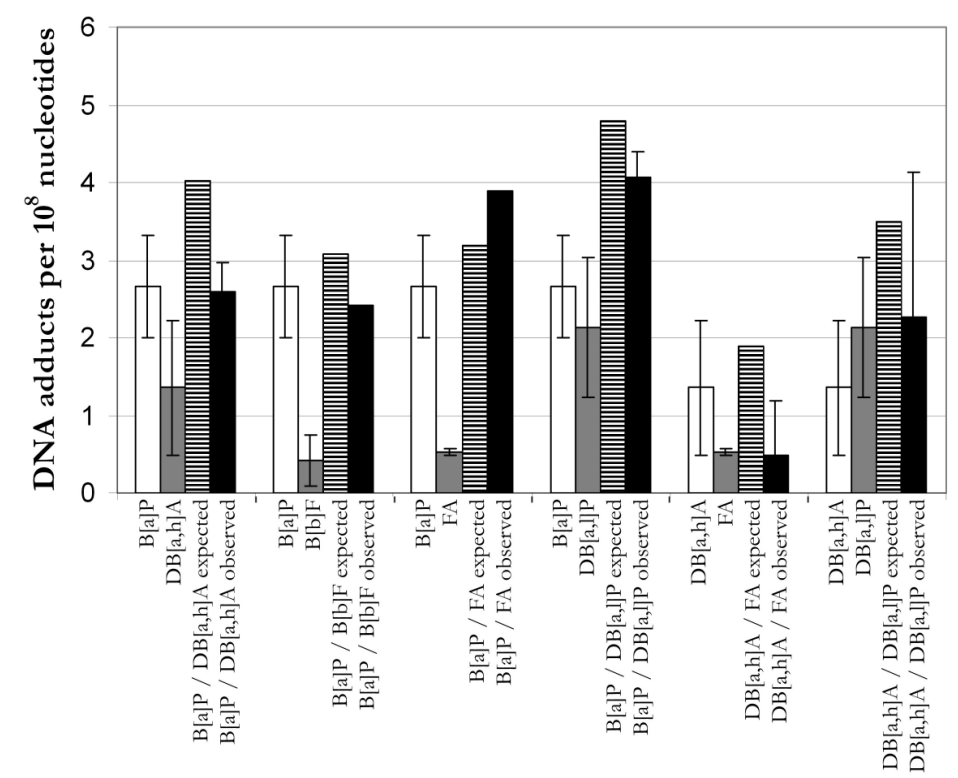

FIGURE 7.4. DNA adduct formation in liver slices exposed to individual PAHs or their binary mixtures as measured by ${ }^{32} \mathrm{P}$-postlabelling (detection limit 1 adduct per $10^{8}$ nucleotides). Mean adduct levels corrected for DMSO signals and their standard deviations are shown. $(\mathrm{n}=2$, except for mixtures of $\mathrm{B}[\mathrm{a}] \mathrm{P}-\mathrm{B}[\mathrm{b}] \mathrm{F}$ and $\mathrm{B}[\mathrm{a}] \mathrm{P}-\mathrm{FA})$.

\section{DISCUSSION}

This paper describes the results of a study on the effects of binary PAH mixtures on gene expression and DNA adduct formation in rat liver slices in comparison to the effects elicited by the individual compounds. We assessed whether effects of binary mixtures of PAHs on gene expression and DNA adduct formation compared to the individual compounds are additive or may show synergism or antagonism.

As both $\mathrm{B}[\mathrm{a}] \mathrm{P}$ and $\mathrm{DB}[\mathrm{a}, \mathrm{h}] \mathrm{A}$ induced the CYP1A1 expression in liver slices in our previous study, we used these compounds to assess the interactive effects of mixtures. CYP1A1 is important in PAH metabolism, and CYP1A1 induction may lead to effects on the metabolism of non-CYP1A1 inducers.

\section{Gene expression modulation}

Each treatment caused gene expression modulation in liver slices. However, the genes significantly affected by the mixtures were frequently different from those affected by either of the constituents. This is rather surprising and in contrast to what we observed 
in HepG2 cells, in which genes modulated by the individual compounds were generally also modulated by the mixtures. A possible explanation for this discrepancy is that in liver slices data on much more genes are available, and this may be more specific for each PAH exposure, whereas in the case of HepG2 cells a dedicated array was used with only toxicologically relevant genes.

\section{Assessing the additivity of gene expression of a mixture}

The differential gene expression was lower for all mixtures than expected as the slope of linear regression lines was less than 1 . This indicates that all mixtures show antagonism, similar to what we have previously observed in HepG2 cells. In agreement with our findings, Cherng et al (15) reported a decrease in the CYP1 $A 1$ gene expression and protein expression in $\mathrm{B}[\mathrm{a}] \mathrm{P} /$ 1-nitropyrene mixtures compared to the individual compounds.

\section{Assessing the additivity of differential expression of single genes}

In general, expression of most genes shows antagonism, which is in agreement with the observed global gene expression differences. For 21 genes expression differences were consistently lower than expected, and many of these are involved in carcinogenesis. For example ACOX2 and EHHADH play a role in carcinogenesis by affecting fatty acid metabolic pathways (16). This might be related to GILZ, which is involved in adipocyte differentiation (17) and ME1, which is involved in fatty acid biosynthesis. Furthermore, LPB and PTPN16 both play a role in inflammation and could be important in carcinogenesis $(18,19)$. CYP1 $A 2$ showed lower expression than expected and is involved in metabolism of PAHs. Furthermore, the expression of CLDN7 is elevated in neoplasias (20), DIG1 is involved in invasive growth (21) and, moreover, was also induced in our previous study (9). And finally, HSD11B1 plays a role in clearance of apoptotic cells (22), MADH3 plays a role in inhibition of cell cycle progression (23) and ID1 plays a role in the early stages of hepatocarcinogenesis (24). So, most genes showing antagonism are involved in carcinogenesis, and this lower expression would suggest a lower carcinogenic potency of PAH mixtures than expected on the basis of the individual compounds.

Ten of the affected genes showed consistent additive response after exposure to PAH mixtures. Their corresponding proteins are involved in several functions. The most relevant being $C D H 17$, which is up-regulated in gastric carcinomas (25), SPP1, which is deregulated in hepatocarcinogenesis (26) and NQO1 which is controlled by the Ahreceptor (27) and involved in xenobiotic metabolism.

Furthermore, for 2 genes the expression differences were higher than expected, indicating synergism. These two genes are PFKFB1, which is involved in neoplastic transformation (28) and $R R A D$, which is up-regulated in neoplasia (29). By a higher expres- 
sion than expected, both genes suggest a higher carcinogenic potency of the PAHs mixtures than expected.

\section{DNA adduct formation}

DNA adduct formation is relatively low in liver slices exposed to PAHs. The concentrations were selected based on DNA adduct formation in our previous study (9), and each compound shows similar DNA adduct levels. However, the DNA adduct levels are relatively low, and thereby approaching the limit of detection. Nevertheless, the data generally show an antagonistic effect on DNA adduct formation, which agrees with the effects on gene expression but contrasts our findings in HepG2 cells. The differences in cell type, species and PAH concentrations might explain this difference. Moreover, the difference in effects in HepG2 cells and liver slices might be due to different interaction on biotransformation enzymes and, thereby, altered metabolism of mixtures. This is shown by the antagonistic effect on the expression of CYP1A2 in liver slices, whereas the effects of mixtures on CYP1A2 in HepG2 cells are synergistic. Other studies also showed an antagonistic effect of PAH mixtures on DNA adduct formation in MCF7 cells (30).

\section{Synergism or antagonism?}

Table 7.3 shows an overview of the interactive effects on gene expression and DNA adduct formation for all mixtures, and data for the corresponding mixtures in HepG2 cells from our previous study. This shows that the effects of the PAH mixtures in liver slices on both gene expression and on DNA adduct formation are generally antagonistic. This similar response on both parameters agrees with the antagonistic effects on gene expression modulation in HepG2 cells and was also observed in previous studies $(31,32)$.

Comparison of DNA adduct formation in liver slices with data from HepG2 cells shows that both cell systems appear to respond very differently to PAH mixtures. Whereas HepG2 cells show an additive or synergistic response, liver slices show antagonism. The data we generated in the present study show more similarities with the antagonistic effects of PAH mixtures found in previous in vitro and in vivo studies $(31,32)$. Therefore, liver slices may be more comparable to other in vitro and in vivo systems than HepG2 cells. 
TABLE 7.3. Summary of data comparison between observed and expected data for liver slices and HepG2 cells exposed to PAH mixtures. Additive effects have no difference between observed and expected data, for synergism the observed effect is higher than expected and for antagonism the observed effect is lower than expected.

\begin{tabular}{lcc|cc}
\hline \multirow{2}{*}{ Mixture } & \multicolumn{2}{c|}{ Rat liver slices } & \multicolumn{2}{c}{ HepG2 cells } \\
\cline { 2 - 5 } & $\begin{array}{c}\text { Gene } \\
\text { expression }\end{array}$ & $\begin{array}{c}\text { DNA adduct } \\
\text { formation }\end{array}$ & $\begin{array}{c}\text { Gene } \\
\text { expression }\end{array}$ & $\begin{array}{c}\text { DNA adduct } \\
\text { formation }\end{array}$ \\
\hline B[a]P / B[b]F & Antagonism & Unclear & Additive & Additive / synergism \\
B[a]P / DB[a,h]A & Antagonism & Additive/ Antagonism & Additive & Additive / synergism \\
B[a]P / DB[a,l]P & Antagonism & Additive/ Antagonism & Antagonism & Additive / synergism \\
B[a]P / FA & Antagonism & Unclear & Additive & Additive / synergism \\
DB[a,h]A / DB[a,l]P & Antagonism & Additive/ Antagonism & N/A & N/A \\
DB[a,h]A / FA & Antagonism & Additive/ Antagonism & N/A & N/A \\
\hline
\end{tabular}

\section{CONCLUSION}

This study addressed the effects of binary PAH mixtures on gene expression profiles and DNA adduct formation in rat liver slices, and showed that in most cases the PAHs interact antagonistically. Similarly, at the level of individual genes, mostly antagonism was observed, swith some genes showing additivity and only few genes showing synergism. These interactions are partly different to those we observed in HepG2 cells. Effects on genes involved in metabolism show mainly antagonism or additivity, and in relation to DNA adduct formation, these findings suggest diminished metabolic activation by mixtures comprising a CYP-inducer with a non-CYP-inducer than additivity would suggest. Our observations would suggest a lower carcinogenic potency of PAH mixtures than would have been estimated based on the additivity of the individual constituents.

\section{Acknowledgements}

The research was carried out as part of the AMBIPAH project (Mechanism-based approaches to improved cancer risk assessment of ambient air polycyclic aromatic hydrocarbons), funded by the European Union (No. QRLT-2001-024202) 


\section{REFERENCES}

1. Collins, J.F., Brown, J.P., Alexeeff, G.V. and Salmon, A.G. (1998) Potency equivalency factors for some polycyclic aromatic hydrocarbons and polycyclic aromatic hydrocarbon derivatives. Regul Toxicol Pharmacol, 28, 45-54.

2. Nisbet, I.C. and LaGoy, P.K. (1992) Toxic equivalency factors (TEFs) for polycyclic aromatic hydrocarbons (PAHs). Regul Toxicol Pharmacol, 16, 290-300.

3. Cassee, F.R., Groten, J.P., van Bladeren, P.J. and Feron, V.J. (1998) Toxicological evaluation and risk assessment of chemical mixtures. Crit Rev Toxicol, 28, 73-101.

4. Freedman, M.D. (1995) Drug Interactions: Classification and Systematic Approach. Am J Ther, 2, 433-443.

5. Blaha, L., Kapplova, P., Vondracek, J., Upham, B. and Machala, M. (2002) Inhibition of gap-junctional intercellular communication by environmentally occurring polycyclic aromatic hydrocarbons. Toxicol Sci, 65, 43-51.

6. Rosenkranz, H.S., Pollack, N. and Cunningham, A.R. (2000) Exploring the relationship between the inhibition of gap junctional intercellular communication and other biological phenomena. Carcinogenesis, 21, 1007-11.

7. Parrish, A.R., Fisher, R., Bral, C.M., Burghardt, R.C., Gandolfi, A.J., Brendel, K. and Ramos, K.S. (1998) Benzo(a)pyrene-induced alterations in growth-related gene expression and signaling in precision-cut adult rat liver and kidney slices. Toxicol Appl Pharmacol, 152, 302-8.

8. Boess, F., Kamber, M., Romer, S., Gasser, R., Muller, D., Albertini, S. and Suter, L. (2003) Gene expression in two hepatic cell lines, cultured primary hepatocytes, and liver slices compared to the in vivo liver gene expression in rats: possible implications for toxicogenomics use of in vitro systems. Toxicol Sci, 73, 386-402.

9. Staal, Y.C.M., van Herwijnen, M.H.M., Pushparajah, D.S., Umachandran, M., Ioannides, C., van Schooten, F.J. and van Delft, J.H.M. (2007) Modulation of gene expression and DNA-adduct formation in precision-cut liver slices exposed to polycyclic aromatic hydrocarbons of different carcinogenic potency. Mutagenesis, 22, 55-62.

10. Hashemi, E., Dobrota, M., Till, C. and Ioannides, C. (1999) Structural and functional integrity of precision-cut liver slices in xenobiotic metabolism: a comparison of the dynamic organ and multiwell plate culture procedures. Xenobiotica, 29, 11-25.

11. Staal, Y.C.M., van Herwijnen, M.H.M., van Schooten, F.J. and van Delft, J.H.M. (2005) Application of four dyes in gene expression analyses by microarrays. BMC Genomics, 6, 101.

12. Staal, Y.C.M., Hebels DGAJ, van Herwijnen, M.H.M., van Schooten, F.J. and van Delft, J.H.M. (submitted) Binary PAH-mixtures cause additive or antagonistic effects on gene expression but synergistic effects on DNA adduct formation.

13. Reddy, M.V. and Randerath, K. (1986) Nuclease P1-mediated enhancement of sensitivity of 32Ppostlabeling test for structurally diverse DNA adducts. Carcinogenesis, 7, 1543-51.

14. Godschalk, R.W., Maas, L.M., Van Zandwijk, N., van 't Veer, L.J., Breedijk, A., Borm, P.J., Verhaert, J., Kleinjans, J.C. and van Schooten, F.J. (1998) Differences in aromatic-DNA adduct levels between alveolar macrophages and subpopulations of white blood cells from smokers. Carcinogenesis, 19, 81925.

15. Cherng, S.H., Hsu, S.L., Yang, J.L., Yu, C.T. and Lee, H. (2006) Suppressive effect of 1-nitropyrene on benzo[a]pyrene-induced CYP1A1 protein expression in HepG2 cells. Toxicol Lett, 161, 236-43.

16. Yeh, C.S., Wang, J.Y., Cheng, T.L., Juan, C.H., Wu, C.H. and Lin, S.R. (2006) Fatty acid metabolism pathway play an important role in carcinogenesis of human colorectal cancers by MicroarrayBioinformatics analysis. Cancer Lett, 233, 297-308. 
17. Shi, X., Shi, W., Li, Q., Song, B., Wan, M., Bai, S. and Cao, X. (2003) A glucocorticoid-induced leucine-zipper protein, GILZ, inhibits adipogenesis of mesenchymal cells. EMBO Rep, 4, 374-80.

18. Grube, B.J., Cochane, C.G., Ye, R.D., Green, C.E., McPhail, M.E., Ulevitch, R.J. and Tobias, P.S. (1994) Lipopolysaccharide binding protein expression in primary human hepatocytes and HepG2 hepatoma cells. J Biol Chem, 269, 8477-82.

19. Rauhala, H.E., Porkka, K.P., Tolonen, T.T., Martikainen, P.M., Tammela, T.L. and Visakorpi, T. (2005) Dual-specificity phosphatase 1 and serum/glucocorticoid-regulated kinase are downregulated in prostate cancer. Int J Cancer, 117, 738-45.

20. Hewitt, K.J., Agarwal, R. and Morin, P.J. (2006) The claudin gene family: expression in normal and neoplastic tissues. BMC Cancer, 6, 186.

21. Bardwell, L., Cook, J.G., Zhu-Shimoni, J.X., Voora, D. and Thorner, J. (1998) Differential regulation of transcription: repression by unactivated mitogen-activated protein kinase Kss1 requires the Dig1 and Dig2 proteins. Proc Natl Acad Sci U S A, 95, 15400-5.

22. Gilmour, J.S., Coutinho, A.E., Cailhier, J.F., Man, T.Y., Clay, M., Thomas, G., Harris, H.J., Mullins, J.J., Seckl, J.R., Savill, J.S. and Chapman, K.E. (2006) Local amplification of glucocorticoids by 11 beta-hydroxysteroid dehydrogenase type 1 promotes macrophage phagocytosis of apoptotic leukocytes. J Immunol, 176, 7605-11.

23. Pardali, K., Kurisaki, A., Moren, A., ten Dijke, P., Kardassis, D. and Moustakas, A. (2000) Role of Smad proteins and transcription factor Sp1 in p21(Waf1/Cip1) regulation by transforming growth factor-beta. J Biol Chem, 275, 29244-56.

24. Damdinsuren, B., Nagano, H., Kondo, M., Yamamoto, H., Hiraoka, N., Yamamoto, T., Marubashi, S., Miyamoto, A., Umeshita, K., Dono, K., Nakamori, S., Wakasa, K., Sakon, M. and Monden, M. (2005) Expression of Id proteins in human hepatocellular carcinoma: relevance to tumor dedifferentiation. Int J Oncol, 26, 319-27.

25. Ito, R., Oue, N., Yoshida, K., Kunimitsu, K., Nakayama, H., Nakachi, K. and Yasui, W. (2005) Clinicopathological significant and prognostic influence of cadherin-17 expression in gastric cancer. Virchows Arch, 447, 717-22.

26. Huang, J., Sheng, H.H., Shen, T., Hu, Y.J., Xiao, H.S., Zhang, Q., Zhang, Q.H. and Han, Z.G. (2006) Correlation between genomic DNA copy number alterations and transcriptional expression in hepatitis B virus-associated hepatocellular carcinoma. FEBS Lett, 580, 3571-81.

27. Tijet, N., Boutros, P.C., Moffat, I.D., Okey, A.B., Tuomisto, J. and Pohjanvirta, R. (2006) Aryl hydrocarbon receptor regulates distinct dioxin-dependent and dioxin-independent gene batteries. Mol Pharmacol, 69, 140-53.

28. Chesney, J. (2006) 6-Phosphofructo-2-kinase/fructose-2,6-bisphosphatase and tumor cell glycolysis. Curr Opin Clin Nutr Metab Care, 9, 535-9.

29. Suzuki, M., Toyooka, S., Shivapurkar, N., Shigematsu, H., Miyajima, K., Takahashi, T., Stastny, V., Zern, A.L., Fujisawa, T., Pass, H.I., Carbone, M. and Gazdar, A.F. (2005) Aberrant methylation profile of human malignant mesotheliomas and its relationship to SV40 infection. Oncogene, 24, 1302-8.

30. Mahadevan, B., Parsons, H., Musafia, T., Sharma, A.K., Amin, S., Pereira, C. and Baird, W.M. (2004) Effect of artificial mixtures of environmental polycyclic aromatic hydrocarbons present in coal tar, urban dust, and diesel exhaust particulates on MCF-7 cells in culture. Environ Mol Mutagen, 44, 99-107.

31. Falahatpisheh, M.H., Donnelly, K.C. and Ramos, K.S. (2001) Antagonistic interactions among nephrotoxic polycyclic aromatic hydrocarbons. J Toxicol Environ Health A, 62, 543-60.

32. Gray, D.L., Warshawsky, D., Xue, W., Nines, R., Wang, Y., Yao, R. and Stoner, G.D. (2001) The effects of a binary mixture of benzo(a)pyrene and $7 \mathrm{H}$-dibenzo(c,g)carbazole on lung tumors and K-ras oncogene mutations in strain A/J mice. Exp Lung Res, 27, 245-53. 



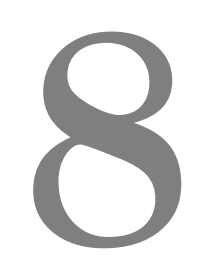

Summary and general discussion 
This thesis describes the research on the gene expression modulation by polycyclic aromatic hydrocarbons (PAHs) in relation to the varying carcinogenic potencies of PAHs. As human exposure to PAHs occurs daily, it is important to be able to estimate the human cancer risks due to $\mathrm{PAH}$ exposure. It can be hypothesized that PAHs with different carcinogenic potency will also differ in the gene expression profiles they induce in cells and organs. Therefore, this thesis aims to apply gene expression profiling to gain knowledge on PAH induced effects, with the ultimate goal to find a rationale for improvement of current risk assessment procedures for ambient air PAHs.

\section{New method for sample labelling for microarray studies}

First, we developed a new method for microarray hybridizations which allows analysis of three or four instead of two samples simultaneously (chapter 2). It was concluded that labelling with four dyes was applicable on the cDNA arrays, but on a different platform with in-house spotted oligonucleotide arrays, only three dyes could be used. This improved method was applied in chapters 3, 4, 6 and 7, and does not only reduce costs and time required, but it also reduces the technical variation between microarrays.

\section{In vitro studies}

The aim of chapters 3 and 4 is to explore the possibilities to use gene expression profiling for cancer risk assessment, and to gain insight into the mechanisms of carcinogenicity and the biological processes of PAH-exposure, which are of importance for carcinogenesis. Therefore, gene expression modulation and DNA adduct formation in a human hepatoma cell line, HepG2, and in rat liver slices was assessed in chapters 3 and 4 respectively. Gene expression modulation was related to DNA adduct formation, Ah-receptor binding capacity and carcinogenic potency. Although we could classify the six PAHs (benzo[a]pyrene $(\mathrm{B}[\mathrm{a}] \mathrm{P})$, benzo[b]fluoranthene $(\mathrm{B}[\mathrm{b}] \mathrm{F})$, fluoranthene (FA), dibenzo[a,h]anthracene (DB[a,h]A), dibenzo[a,l]pyrene (DB[a,l]P) and 1methylphenanthrene (1-MPA)) by gene expression profiling in HepG2 cells according to their carcinogenic potency, a perfect classification could not be achieved in liver slices for all compounds. $\mathrm{DB}[\mathrm{a}, 1] \mathrm{P}$, as being the most potent carcinogenic compound, was classified as having low carcinogenic potency in that model. This might be due to the relatively low induction of CYP1A1 compared to the other carcinogenic PAHs in liver slices, which seems to be important for correct classification. DB[a,l]P did induce the expression of CYP1A1 in HepG2 cells.

In order to obtain more insight in the biological consequences and the involved mechanisms, overrepresentation of pathways among the sets of modulated genes was investigated by the use of GenMAPP. Pathway analysis based on the genes significantly modulated by any of the six PAHs, showed some overlap between HepG2 cells and liver slices. Apoptosis, cholesterol biosynthesis and fatty acid synthesis were 
affected in both models, although not always similarly or by the same compounds. Apoptosis is important for removing damaged cells, before they can develop into cancerous cells. Both inhibition of fatty acid synthesis and induction of cholesterol biosynthesis have been related to carcinogenesis (1-6). Induction of cholesterol biosynthesis and increased mitochondrial fatty acid beta oxidation was found for liver slices. For HepG2 cells both fatty acid synthesis and cholesterol biosynthesis were inhibited. Increasing cholesterol synthesis by PAHs implies increased energy availability upon PAH exposure. Increased cholesterol synthesis has been shown for proliferating normal tissue and tumours (1), and neoplastic cells have a growth advantage by their ability to synthesize cholesterol (2). Effects on fatty acid synthesis by PAH exposure might be associated with increased carcinogenic risk through the involvement of peroxisome proliferator-acitvated receptors (PPARs). PPARs are nuclear hormone receptors and which are activated by fatty acids and are involved in cell proliferation and differentiation pathways (reviewed in (7)). Fatty acids might be required to meet the increased energy requirement of pre-tumour cells. Furthermore, only the carcinogenic PAHs induced the oxidative stress pathway in liver slices. This was not observed for HepG2 cells, indicating a different response of PAH exposure to both cell systems.

The order of the compounds in their ability to form DNA adducts was generally comparable between HepG2 cells and liver slices, only DB[a,l]P induced relatively much higher levels of DNA adducts in liver slices. These higher DNA adduct levels of $\mathrm{DB}[\mathrm{a}, 1] \mathrm{P}$ may be explained by the relatively low induction of CYP1 $A 1$ in liver slices. It has been shown that DNA adduct levels are higher in CYP1A1 knockout mice after PAH treatment than in wild types (8-10). So by the inability to induce the expression of CYP1A1, DB[a,1]P may be less metabolized and subsequently detoxified in liver slices, resulting in higher levels of DNA adducts than when $\mathrm{DB}[\mathrm{a}, 1] \mathrm{P}$ would be metabolized.

As expected, the PAHs with relatively low carcinogenic potency did not induce DNA adduct formation, and also showed minor effects on gene expression modulation in either model. DNA adduct formation has been shown to correlate with carcinogenic potency (11), which agrees with our findings.

In summary, we found that HepG2 cells are a better in vitro model to classify PAHs according to their carcinogenic potency by gene expression profiling. Although relatively low carcinogenic PAHs are classified correctly in both models, the most potent carcinogen, $\mathrm{DB}[\mathrm{a}, 1] \mathrm{P}$, was not correctly classified in liver slices. Using more PAHs for classification studies, and thereby inclusion of PAHs with a more diverse range in carcinogenic properties, might lead to better classification. Although both in vitro models are considered relevant models for in vivo liver, clearly differences exist between these models. These differences might be due to the differences in cell proliferation properties, with dividing HepG2 cells versus quiescent cells in liver slices, or to interspecies differences in metabolism (human versus rat), where different members of the Cytochrome P450 family may be involved in PAH metabolism. Another explanation 
might be that in liver slices the in vivo liver architecture is remained, including hepatocytes and Kupffer cells, whereas HepG2 cell cultures consist only of hepatocytes.

\section{In vivo study}

In chapter 5 the aim is to find similarities in gene expression changes between PAHs dosed at equally mutagenic doses in lung and liver of mice, which can help to gain insight into the mechanisms involved in PAH carcinogenicity. This study was conducted with CD2F1 mice, treated with either of four PAHs, followed by gene expression analysis in lung and liver. Doses of PAHs were selected based on mutagenic potency, in order to determine the similarities or differences on gene expression at equally mutagenic doses. The effects in liver appeared to be much more pronounced than in lung, and both organs showed a compound specific response. Genes similarly regulated by all PAHs were mainly involved in xenobiotic metabolism. Genes similarly regulated by at least one of the doses of each $\mathrm{PAH}$ were also involved in oxidative stress and cell cycle, which might be related to the DNA damaging effect of PAHs. This suggests a relation between mutagenic potency and these gene expression changes.

Similar to the liver slices, a relatively small induction of Cytochrome P450 enzymes by $\mathrm{DB}[\mathrm{a}, 1] \mathrm{P}$ was found in mice, whereas the other compounds $(\mathrm{B}[\mathrm{a}] \mathrm{P}, \mathrm{B}[\mathrm{b}] \mathrm{F}$ and $\mathrm{DB}[\mathrm{a}, \mathrm{h}] \mathrm{A}$ ) showed marked induction of CYP1A1, CYP1A2 (only in liver) and CYP1B1. This shows the similarities between mouse and rat or indicates that rat liver slices are a good model for in vivo PAH effects on gene expression.

Pathway analysis also showed effects on the oxidative stress pathway in both lung and liver, similar to the effects found in liver slices. However, oxidative stress was only affected after $\mathrm{B}[\mathrm{a}] \mathrm{P}$ and $\mathrm{B}[\mathrm{b}] \mathrm{F}$ dosing, indicating that both compounds induce more oxidative stress than DB[a,h]A and DB[a,l]P at equally mutagenic doses. Also fatty acid beta oxidation was affected, which was also found in liver slices. Thus the in vitro liver slices model is to some extend good models for the in vivo situation.

\section{Interactive effects by PAH-mixtures}

In the final chapters (chapters 6 and 7) the aim is to gain insight into the interactive effects of PAHs on gene expression and DNA adduct formation. As human exposure to PAHs occurs through mixtures, the structural similarities between PAHs may lead to interactive effects in mixtures. The effect of binary PAH-mixtures was compared to the effects by the individual compounds in HepG2 cells and rat liver slices, in chapters 6 and 7 respectively. Equally toxic concentrations of all compounds were used, which were selected based on cell cycle disturbances and apoptosis levels for HepG2 cells and on DNA adduct formation for liver slices. In HepG2 cells, the PAH-mixtures had mostly additive or antagonistic effects on gene expression profiles. For individual 
genes, the expression of a few genes showed additivity, but some genes showed predominantly antagonistic or synergistic effects on gene expression. In liver slices the effects on gene expression profiles were generally antagonistic. Further, mostly antagonistic responses on individual gene expression were observed, whereas only two genes showed synergism and ten genes showed additivity. Our studies were the first that assessed the effects of PAH-mixtures on gene expression profiles by microarray technologies. In the literature, generally additive or antagonistic effects of PAHmixtures on other parameters (Cytochrome P450 induction, tumorigenesis) were described (12-14). The effects on gene expression we found, would suggest a lower carcinogenic potency of PAH-mixtures than estimated based on additivity of individual compounds, which has also been observed on tumour formation previously $(12,13)$.

The effects on DNA adduct formation differed between HepG2 cells and liver slices. Whereas always synergism was observed in HepG2 cells, generally antagonistic effects were found in liver slices. Possibly, in HepG2 cells, PAH activation is enhanced in coexposure of PAHs leading to a higher level of DNA reactive metabolites. This agrees with the synergistic effect on the expression of CYP1A2 in HepG2 cells and the antagonistic effects on CYP1A2 in rat liver slices. Also, phase II enzymes involved in detoxifying PAH metabolites might become saturated and thereby lead to increased levels of PAH metabolites. Previous research showed an antagonistic effect of PAHmixtures on DNA adduct formation in MCF7 cells (15). Thus, with respect to interactive effects on DNA adduct formation, there is a clear difference between various in vitro models, which might be caused by differences in in vitro models (see also In vitro studies) or gene expression of metabolic enzymes.

Noteworthy, in HepG2 cells, compounds like FA and 1-MPA, which do not induce adducts and are weak or not carcinogenic, were found to have an impact on the effects of other PAHs in mixtures. Both compounds showed synergistic effects on DNA adduct formation and may thereby have an important contribution to increasing the carcinogenic potency of mixtures. However, so far these compounds have not been tested in interaction studies on carcinogenesis.

\section{Final remarks}

With these studies we aimed to gain knowledge on modulation of gene expression by single PAHs and on interactive effects that may occur in mixtures, which could help us to improve current risk assessment of ambient air PAHs. We have shown that classification of PAHs by gene expression profiling, according to carcinogenic potency is feasible in HepG2 cells, but in liver slices this was less. By pathway analysis, we have gained insight into the mechanisms involved in PAH exposure. These results show that although PAHs are structurally alike, they can differ greatly in their effects on gene expression. Furthermore, by assessing the effects of mixtures, we have shown that PAHs can have interactive effects on gene expression modulation, DNA adduct 
formation and other parameters, although interaction may differ between parameters, between compounds and between in vitro models. Most interactions on gene expression suggest that mixtures of PAHs pose a smaller carcinogenic risk then what would be expected based on the individual compounds, however, some of the interactive effects on DNA adduct formation would suggest an increase of carcinogenic potential. By assessing the effects of PAH mixtures on several parameters we have gained insight into the interactive effects of PAHs on different parameters and this may be of relevance to the cancer risk assessment of PAH-mixtures.

\section{LIMITATIONS AND FUTURE PERSPECTIVES}

Our studies focussed on a selection of six PAHs, representing a diverse range in abundance in the air and in mutagenic and carcinogenic potency. Although we showed that classification of these PAHs for carcinogenic risk is feasible, extending the number PAHs tested would allow improve classification and allow validating the applicability of gene expression as a classification tool for PAH carcinogenicity. This seems especially important if precision-cut rat liver slices are used as the in vitro cell system.

In these studies 3 types of microarrays were used, firstly PHASE-I arrays, containing cDNA clones for 600 toxicologically relevant genes in quadruplicate, secondly oligonucleotide arrays, containing 5700 oligonucleotides from Operon spotted in triplicate on Corning GAPS slides, and finally Agilent arrays, containing $22 \mathrm{~K}$ oligonuleotides spotted singly. Although the first two types of arrays contain only limited number of genes, we have shown that these arrays enabled investigating our aims. However, using microarrays with more genes might improve classification and gain more insight into the molecular pathways involved in PAH-carcinogenesis.

Furthermore, we were the first to study the effects of binary PAH-mixtures on gene expression profiles, and to relate this to effects on DNA adduct formation, cell cycle disturbances and apoptosis rates. Since no method for estimating an expected gene expression profile for mixtures based on the profiles for the individual constituents was available, we developed an approach for this. Although we realise this method has its limitations, for example, as genes up-regulated by one constituent and downregulated by the other constituent were left out. We believe that this method results in a good global estimation of the gene expression response based on additivity. However, improving our method, by for example including all genes, and not just genes which were regulated in the same direction for both constituents of the mixture, would be beneficial for studying the complete mixture effects.

As mentioned before, microarray technology is still rapidly evolving, which leads to reduced technical variation by the improved quality of microarrays. Also, the number of genes spotted on the arrays has increased up to the full genome. Furthermore, new 
or improved methods for data analysis and interpretation are also continuously substantiated. Increment of the number of genes on an array leads to enlargement of the obtained dataset, and herewith pathway analysis tools become more useful for biologically interpretation of the data. Many pathway analysis tools are available (16-20), of which some not only contain information on biological processes, but also on genes showing related control of modulation (21). Furthermore, gene expression analysis is more often combined with that for protein expression and metabolism $(22,23)$. Since effects of compounds on different stages of biological processes can be studied, combining these tools can be useful in assessing biological effects of exposure.

As part of the AMBIPAH project, research has been done on several other biological effects induced by PAHs, like on DNA adduct formation, metabolism and mutagenic potency. To allow a full risk assessment for PAHs, it is important to combine our data with those other data generated in the project and with literature data. By assessing effects on gene expression, more insight has gained into the mechanisms of PAH carcinogenicity, and thereby our research may lead to improved cancer risk assessment of ambient air PAHs. 


\section{REFERENCES}

1. Rao, K.N. (1995) The significance of the cholesterol biosynthetic pathway in cell growth and carcinogenesis (review). Anticancer Res, 15, 309-14.

2. Rao, K.N., Elm, M.S., Kelly, R.H., Chandar, N., Brady, E.P., Rao, B., Shinozuka, H. and Eagon, P.K. (1997) Hepatic hyperplasia and cancer in rats: metabolic alterations associated with cell growth. Gastroenterology, 113, 238-48.

3. Zhou, W., Simpson, P.J., McFadden, J.M., Townsend, C.A., Medghalchi, S.M., Vadlamudi, A., Pinn, M.L., Ronnett, G.V. and Kuhajda, F.P. (2003) Fatty acid synthase inhibition triggers apoptosis during $S$ phase in human cancer cells. Cancer Res, 63, 7330-7.

4. Pizer, E.S., Jackisch, C., Wood, F.D., Pasternack, G.R., Davidson, N.E. and Kuhajda, F.P. (1996) Inhibition of fatty acid synthesis induces programmed cell death in human breast cancer cells. Cancer Res, 56, 2745-7.

5. Kuhajda, F.P. (2000) Fatty-acid synthase and human cancer: new perspectives on its role in tumor biology. Nutrition, 16, 202-8.

6. Iwano, S., Nukaya, M., Saito, T., Asanuma, F. and Kamataki, T. (2005) A possible mechanism for atherosclerosis induced by polycyclic aromatic hydrocarbons. Biochem Biophys Res Commun, 335, 220-6.

7. Fajas, L., Debril, M.B. and Auwerx, J. (2001) Peroxisome proliferator-activated receptor-gamma: from adipogenesis to carcinogenesis. J Mol Endocrinol, 27, 1-9.

8. Uno, S., Dalton, T.P., Derkenne, S., Curran, C.P., Miller, M.L., Shertzer, H.G. and Nebert, D.W. (2004) Oral exposure to benzo[a]pyrene in the mouse: detoxication by inducible cytochrome P450 is more important than metabolic activation. Mol Pharmacol, 65, 1225-37.

9. Uno, S., Dalton, T.P., Dragin, N., Curran, C.P., Derkenne, S., Miller, M.L., Shertzer, H.G., Gonzalez, F.J. and Nebert, D.W. (2006) Oral benzo[a]pyrene in Cyp1 knockout mouse lines: CYP1A1 important in detoxication, CYP1B1 metabolism required for immune damage independent of total-body burden and clearance rate. Mol Pharmacol, 69, 1103-14.

10. Kondraganti, S.R., Fernandez-Salguero, P., Gonzalez, F.J., Ramos, K.S., Jiang, W. and Moorthy, B. (2003) Polycyclic aromatic hydrocarbon-inducible DNA adducts: evidence by 32P-postlabeling and use of knockout mice for Ah receptor-independent mechanisms of metabolic activation in vivo. Int $\mathrm{J}$ Cancer, 103, 5-11.

11. Brookes, P. and Lawley, P.D. (1964) Evidence for the Binding of Polynuclear Aromatic Hydrocarbons to the Nucleic Acids of Mouse Skin: Relation between Carcinogenic Power of Hydrocarbons and Their Binding to Deoxyribonucleic Acid. Nature, 202, 781-4.

12. Nesnow, S., Mass, M.J., Ross, J.A., Galati, A.J., Lambert, G.R., Gennings, C., Carter, W.H., Jr. and Stoner, G.D. (1998) Lung tumorigenic interactions in strain A/J mice of five environmental polycyclic aromatic hydrocarbons. Environ Health Perspect, 106 Suppl 6, 1337-46.

13. Gray, D.L., Warshawsky, D., Xue, W., Nines, R., Wang, Y., Yao, R. and Stoner, G.D. (2001) The effects of a binary mixture of benzo(a)pyrene and $7 \mathrm{H}$-dibenzo $(\mathrm{c}, \mathrm{g})$ carbazole on lung tumors and $\mathrm{K}$-ras oncogene mutations in strain A/J mice. Exp Lung Res, 27, 245-53.

14. Falahatpisheh, M.H., Donnelly, K.C. and Ramos, K.S. (2001) Antagonistic interactions among nephrotoxic polycyclic aromatic hydrocarbons. J Toxicol Environ Health A, 62, 543-60.

15. Mahadevan, B., Parsons, H., Musafia, T., Sharma, A.K., Amin, S., Pereira, C. and Baird, W.M. (2004) Effect of artificial mixtures of environmental polycyclic aromatic hydrocarbons present in coal tar, urban dust, and diesel exhaust particulates on MCF-7 cells in culture. Environ Mol Mutagen, 44, 99-107.

16. Dahlquist, K.D., Salomonis, N., Vranizan, K., Lawlor, S.C. and Conklin, B.R. (2002) GenMAPP, a new tool for viewing and analyzing microarray data on biological pathways. Nat Genet, 31, 19-20. 
17. Currie, R.A., Orphanides, G. and Moggs, J.G. (2005) Mapping molecular responses to xenoestrogens through Gene Ontology and pathway analysis of toxicogenomic data. Reprod Toxicol, 20, 433-40.

18. Curtis, R.K., Oresic, M. and Vidal-Puig, A. (2005) Pathways to the analysis of microarray data. Trends Biotechnol, 23, 429-35.

19. Boorsma, A., Foat, B.C., Vis, D., Klis, F. and Bussemaker, H.J. (2005) T-profiler: scoring the activity of predefined groups of genes using gene expression data. Nucleic Acids Res, 33, W592-5.

20. Subramanian, A., Tamayo, P., Mootha, V.K., Mukherjee, S., Ebert, B.L., Gillette, M.A., Paulovich, A., Pomeroy, S.L., Golub, T.R., Lander, E.S. and Mesirov, J.P. (2005) Gene set enrichment analysis: a knowledge-based approach for interpreting genome-wide expression profiles. Proc Natl Acad Sci U S A, 102, 15545-50.

21. Nikolsky, Y., Ekins, S., Nikolskaya, T. and Bugrim, A. (2005) A novel method for generation of signature networks as biomarkers from complex high throughput data. Toxicol Lett, 158, 20-9.

22. Ibrahim, S.M. and Gold, R. (2005) Genomics, proteomics, metabolomics: what is in a word for multiple sclerosis? Curr Opin Neurol, 18, 231-5.

23. Rochfort, S. (2005) Metabolomics reviewed: a new "omics" platform technology for systems biology and implications for natural products research. J Nat Prod, 68, 1813-20. 



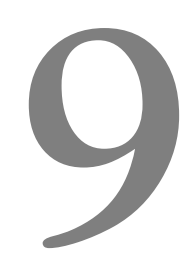

Samenvatting en algemene discussie 
Dit proefschrift beschrijft het onderzoek naar de veranderingen in genexpressie door polycyclische aromatische koolwaterstoffen (PAKs) in relatie tot hun verschillen in kankerverwekkend vermogen. Omdat de mens dagelijks blootgesteld wordt aan PAKs, is het van belang om de risico's van blootstelling aan PAKs te kunnen inschatten. Van PAKs met verschillende kankerverwekkend vermogen kan verwacht worden dat ze ook zullen verschillen in de genexpressie profielen die ze induceren in cellen en organen. Daarom heeft dit onderzoek als doel om door middel van genexpressie profilering inzicht te verkrijgen in PAK-geïnduceerde effecten, wat uiteindelijk een basis zou kunnen leggen voor verbetering van de huidige risicoschatting procedures voor PAKs die in de buitenlucht veel voorkomen.

\section{Een nieuwe methode voor het labelen van monsters voor de microarray}

Allereerst hebben we een methode ontwikkeld die het mogelijk maakt om drie of vier in plaats van twee RNA-monsters tegelijk te hybridiseren op microarrays. Het labellen van RNA-monsters met vier fluorforen was ontwikkeld voor de cDNA arrays, maar voor een ander platform met zelfgemaakte oligonucleotide arrays konden slechts drie fluorforen gebruikt worden. Deze nieuwe methode is toegepast in het onderzoek beschreven in de hoofdstukken 3, 4, 6 en 7. De methode vermindert niet alleen de kosten en benodigde tijd, maar reduceert ook de technische variatie voor microarray data.

\section{In vitro studies}

Het onderzoek beschreven in de hoofdstukken 3 en 4 heeft als doel om de mogelijkheden van genexpressie profilering voor gebruik in kankerrisicoanalyse verkennen. Daarnaast wordt inzicht verkregen in de mechanismen van kankerverwekkend vermogen en de biologische processen van PAK-blootstelling die van belang zijn bij de ontwikkeling van kanker. Hiervoor zijn genexpressie verandering en DNAadductvorming in de humane hepatoma cellijn HepG2 en in ratten lever coupes bestudeerd; dit wordt beschreven in respectievelijk de hoofdstukken 3 en 4 . Genexpressie veranderingen bleken gerelateerd aan DNA-adductvorming, capaciteit tot binding aan de Ah-receptor en kankerverwekkend vermogen. Alhoewel op basis van genexpressie profielen in HepG2 cellen de zes PAKs (benzo[a]pyrene $(\mathrm{B}[\mathrm{a}] \mathrm{P})$, benzo[b]fluoranthene $(\mathrm{B}[\mathrm{b}] \mathrm{F})$, fluoranthene $(\mathrm{FA})$, dibenzo[a,h]anthracene $(\mathrm{DB}[\mathrm{a}, \mathrm{h}] \mathrm{A})$, dibenzo[a,1]pyrene $(\mathrm{DB}[\mathrm{a}, 1] \mathrm{P})$ en 1-methylphenanthrene (1-MPA)) konden worden geclassificeerd naar kankerverwekkend vermogen, kon een perfecte classificatie voor deze PAKs niet worden bereikt voor de lever coupes. In dit model werd DB[a,1]P, die het meest kankerverwekkend is, geclassificeerd als een laag kankerverwekkende PAK. Dit kan mogelijk verklaard worden door de relatief lage inductie van CYP1A1 in vergelijking met de andere kankerverwekkende PAKs in lever coupes, welke een belangrijk aspect lijkt te zijn voor correcte classificatie. DB[a,1]P induceerde de expressie van CYP1A1 in HepG2 cellen wel. 
Om meer inzicht te verkrijgen in de mogelijke biologische gevolgen en de betrokken mechanismen, is met behulp van GenMAPP inzicht verkregen in de oververtegenwoordiging van biologische processen in de sets van veranderde genen. Analyse van de significant veranderde genen met GenMAPP liet zien dat verschillende processen overlappen in HepG2 cellen en in lever coupes. Apoptose, cholesterol biosynthese en vetzuursynthese werden beïnvloed in beide modellen, hoewel dit niet altijd in dezelfde richting was of door dezelfde PAKs. Apoptose speelt een belangrijke rol bij het verwijderen van beschadigde cellen voordat deze zich kunnen ontwikkelen tot kankercellen. Zowel de remming van vetzuursynthese als de stimulatie van cholesterol biosynthese zijn gerelateerd aan het proces van kankerontwikkeling (1-6). In lever coupes werd zowel een stimulatie van cholesterol biosynthese als van vetzuur oxidatie gevonden. In HepG2 cellen werden zowel de vetzuursynthese als de cholesterol biosynthese geremd. Een stimulatie van de cholesterol synthese door PAKs veroorzaakt een verhoogde beschikbaarheid van energie. In prolifererend normaal weefsel en tumoren wordt dan ook een stimulering van cholesterol synthese gevonden (1), en hebben neoplastische cellen een groeivoordeel door hun capaciteit om cholesterol te synthetiseren (2). Effecten op vetzuursynthese na blootstelling aan PAKs wordt geassocieerd met een verhoogd risico op kanker door de betrokkenheid van peroxisome proliferator-activated receptors (PPARs). Dit zijn nucleaire hormoon receptoren die betrokken zijn bij celproliferatie en differentiatie en die worden geactiveerd door vetzuren (7). Vetzuren zijn mogelijk nodig om in de toenemende energiebehoefte van pre-tumor cellen te voorzien. Verder bleken alleen de kankerverwekkende PAKs het proces van oxidatieve stress in de lever coupes te induceren. Dit werd niet gevonden voor HepG2 cellen, en duidt daarom op een verschil in respons van beide celsystemen op blootstelling aan PAKs.

De relatieve mate waarin PAKs in staat bleken te binden aan DNA was over het algemeen vergelijkbaar tussen HepG2 cellen en lever coupes, alleen DB[a,l]P induceerde relatief meer DNA-adducten in de lever coupes. Deze hogere DNA-adductvorming van $\mathrm{DB}[\mathrm{a}, 1] \mathrm{P}$ zou verklaard kunnen worden door de relatief lage inductie van CYP1A1 door $\mathrm{DB}[\mathrm{a}, 1] \mathrm{P}$ in lever coupes. In eerder onderzoek is gevonden dat DNAadductvorming hoger is in muizen met een defect CYP1A1 gen na blootstelling aan PAKs dan in wild type muizen (8-10). Dus doordat de expressie van CYP1A1 niet geïnduceerd wordt, zou $\mathrm{DB}[\mathrm{a}, 1] \mathrm{P}$ minder gemetaboliseerd kunnen worden door CYP1A1 en hierdoor minder gedetoxificeerd in lever coupes, wat leidt tot hogere DNA-adduct niveaus dan wanneer DB[a,1]P meer gemetaboliseerd zou worden.

Zoals verwacht veroorzaken de PAKs die relatief weinig kankerverwekkend zijn geen DNA-adduct vorming en veroorzaken weinig effect op genexpressie in beide modellen. DNA-adductniveaus correleren met kankerverwekkend vermogen van de desbetreffende PAK (11), hetgeen in onze studies ook gevonden wordt. 
Samenvattend vonden we dat HepG2 cellen een beter in vitro model zijn dan lever coupes van de rat voor de classificatie van PAKs op hun kankerverwekkend vermogen met behulp van genexpressie profilering. Hoewel de relatief minst kankerverwekkende PAKs correct geclassificeerd worden in beide modellen, wordt de meest kankerverwekkende PAK, DB[a,l]P, verkeerd geclassificeerd bij het gebruik van lever coupes als model. Het vergroten van het aantal PAKs voor classificatie, waarbij PAKs met een meer diverse range in kankerverwekkende eigenschappen meegenomen worden, kan dit probleem mogelijk ondervangen. Hoewel beide in vitro modellen beschouwd worden als een relevant model voor de lever in vivo, bestaan er duidelijke verschillen tussen de twee modellen. De verschillen worden mogelijk veroorzaakt door verschillen in celproliferatie, zoals delende HepG2 cellen en rustende cellen in de lever coupes, of door verschillen in metabolisme (humaan versus rat). Verschillen tussen humane of ratten cellen kunnen ook bestaan in enzymen van de Cytochrome P450 familie die betrokken zijn bij metabolisme van PAKs. Een andere mogelijke verklaring is dat in lever coupes de normale lever architectuur behouden is gebleven, waarin hepatocyten en Kupffer cellen aanwezig zijn, terwijl HepG2 cellen slechts hepatocyten zijn.

\section{In vivo studie}

In hoofdstuk 5 wordt getracht overeenkomsten te vinden in genexpressie veranderingen door PAKs welke in gelijke mutagene doseringen zijn toegediend, om inzicht te verschaffen in de mechanismen die betrokken zijn bij kankerontwikkeling door PAKs. Deze studie is uitgevoerd met CD2F1 muizen die blootgesteld zijn aan een van de vier kankerverwekkende PAKs, waarna genexpressie analyse van de long en de lever is uitgevoerd. PAKs-doseringen zijn geselecteerd op basis van een gelijke mutagene potentie in muizen om overeenkomsten en verschillen in genexpressie te kunnen bestuderen bij iso-mutagene doseringen. De effecten op genexpressie in de lever bleken veel groter dan de effecten in de long, en in beide organen waren deze effecten PAK-specifiek. Genen waarvan de expressie in dezelfde richting veranderd werd door alle doseringen van alle PAKs, waren vooral betrokken bij metabolisme van xenobiotica. Genen waarvan de expressie in dezelfde richting veranderd werd door een van de doseringen voor elke PAK, waren betrokken bij oxidatieve stress en cel cyclus. Dit kan mogelijk gerelateerd kan zijn aan de DNA beschadigende effecten van PAKs. Dit suggereert een relatie tussen mutagene potentie en deze genexpressie veranderingen.

Net als in de lever coupes, werd ook een relatief lage inductie waargenomen van Cytochrome $\mathrm{P} 450$ enzymen door $\mathrm{DB}[\mathrm{a}, 1] \mathrm{P}$ in muizen, terwijl de andere stoffen $(\mathrm{B}[\mathrm{a}] \mathrm{P}$, $\mathrm{B}[\mathrm{b}] \mathrm{F}$ en $\mathrm{DB}[\mathrm{a}, \mathrm{h}] \mathrm{A}$ ) een duidelijke inductie van $C Y P 1 A 1, C Y P 1 A 2$ (alleen in de lever) en CYP1B1 vertoonden. Dit laat de overeenkomsten tussen muis en rat zien, en duidt erop dat ratten lever coupes een goed model zijn voor de in vivo effecten van PAKs op genexpressie. 
Analyse van de biologische processen die oververtegenwoordigd zijn in de lijst van genen met veranderde expressie, liet zien dat oxidatieve stress beïnvloed wordt in zowel long als lever, vergelijkbaar met de effecten op de lever coupes. Oxidatieve stress werd echter alleen beïnvloed na B[a]P en $\mathrm{B}[\mathrm{b}] \mathrm{F}$ dosering, wat erop wijst dat deze twee stoffen meer oxidatieve stress veroorzaken dan DB[a,h]A en DB[a,l]P bij gelijk mutagene doseringen. Ook werd vetzuur beta-oxidatie beïnvloed, wat ook in de lever coupes gevonden werd. Hieruit kan worden geconcludeerd dat het in vitro lever coupes model tot een bepaalde hoogte een goed model is voor de in vivo situatie.

\section{Interactieve effecten van PAK-mengsels}

De laatste hoofdstukken (hoofdstukken 6 en 7) hebben als doel om inzicht te krijgen in de interactieve effecten van PAKs op genexpressie en op DNA-adductvorming. De structurele overeenkomsten tussen PAKs kunnen bij blootstelling aan PAK-mengsels leiden tot interactieve effecten. Hierom zijn de effecten van binaire PAK-mengsels vergeleken met de effecten van de individuele stoffen in HepG2 cellen en ratten lever coupes in respectievelijk hoofdstuk 6 en 7. Voor alle stoffen zijn gelijk toxische concentraties gebruikt, die voor HepG2 cellen bepaald zijn aan de hand van celcyclus veranderingen en apoptose niveaus en voor lever coupes zijn de concentraties bepaald aan de hand van DNA-adductvorming. In HepG2 cellen hadden de PAK-mengsels voornamelijk additieve of antagonistische effecten op genexpressie profielen. De expressie van vele individuele genen vertoonde ook additiviteit, terwijl andere genen voornamelijk antagonistische of synergistische effecten vertoonden. In de lever coupes was het effect op de genexpressie profielen voornamelijk antagonistisch. Ook voor individuele genen werd voornamelijk een antagonistisch effect gevonden, terwijl slechts twee genen synergisme vertoonden en tien genen additiviteit. Onze studies zijn de eerste geweest die het effect van PAK-mengsels op genexpressie profielen met behulp van microarray technologie bestudeerd hebben. In de literatuur wordt over het algemeen een additief of antagonistisch effect van PAK-mengsels op andere parameters gevonden, zoals Cytochrome P450 inductie en tumorigenese (12-14). De effecten die wij op genexpressie gevonden hebben, suggereren een lager kankerverwekkend vermogen van PAK-mengsels dan geschat wordt op basis van additiviteit van de individuele stoffen. Dit is in overeenstemming met wat eerder gevonden is op tumorvorming $(13,14)$.

De effecten op DNA-adductvorming verschilden tussen HepG2 cellen en lever coupes. Terwijl in HepG2 cellen de effecten synergistisch waren, waren de effecten in lever coupes over het algemeen antagonistisch. Mogelijk is in HepG2 cellen de bioactivatie van PAKs versterkt bij blootstelling aan meerdere PAKs, wat kan leiden tot hogere concentraties van DNA-reactieve metabolieten. Dit komt overeen met het synergistische effect op de CYP1A2 expressie in HepG2 cellen en de antagonistische effecten op de CYP1A2 expressie in lever coupes. Ook is het mogelijk dat phase II enzymen die betrokken zijn bij de detoxicificering van PAKs verzadigd raken en 
daarbij leiden tot verhoogde niveaus van PAK-metabolieten. Eerder onderzoek heeft aangetoond dat PAK-mengsels antagonistische effecten hebben op DNAadductvorming in MCF7 cellen (15). Dus wat betreft interactieve effecten op DNAadductvorming bestaat er een duidelijk verschil tussen verschillende in vitro modellen, welke mogelijk verklaart kan worden door de genexpressie verschillen op enzymen betrokken bij metabolisme.

Opmerkelijk is dat in HepG2 cellen stoffen als FA en 1-MPA, die geen DNAadducten vormen en zwak tot niet kankerverwekkend zijn, invloed hebben op de effecten van andere PAKs in mengsels. Beide stoffen veroorzaakten synergistische effecten op DNA-adductvorming en kunnen hierdoor een belangrijke bijdrage leveren aan een verhoogde kankerverwekkend vermogen van mengsels. Er is echter nog geen onderzoek gedaan naar de interactie van deze stoffen op de ontwikkeling van kanker.

\section{Tot slot}

Met deze studies wilden we inzicht verkrijgen in de verandering van genexpressie na blootstelling aan PAKs en de interactieve effecten die plaats kunnen vinden in mengsels, wat kan helpen om de risicoanalyse van PAKs uit de buitenlucht te verbeteren. We hebben laten zien dat classificatie van PAKs naar kankerverwekkend vermogen door middel van genexpressie profilering haalbaar is in HepG2 cellen, maar minder in lever coupes. Door middel van analyse van de biologische processen hebben we inzicht gekregen in de werkingsmechanismen die betrokken zijn bij PAK-blootstelling. Deze resultaten laten zien dat hoewel PAKs structureel gelijkend zijn, dat ze toch erg kunnen verschillen in hun effecten op genexpressie. Ook hebben we door de effecten van mengsels te bestuderen laten zien dat PAKs interactieve effecten kunnen hebben op genexpressie, DNA-adductvorming en andere parameters; hoewel het type interactie kan verschillen tussen parameters, tussen de stoffen en tussen in vitro modellen. De meeste interacties op genexpressie suggereren dat mengsels van PAKs een lager risico vormen dan op basis van de individuele stoffen verwacht wordt, hoewel sommige interactieve effecten op DNA-adductvorming juist een verhoogd kankerverwekkend vermogen suggereren. Door het bestuderen van de effecten van PAK-mengsels op verschillende parameters hebben we inzicht gekregen in de interactieve effecten van PAKs op verschillende parameters wat van belang kan zijn voor kankerrisicoanalyse van PAK-mengsels. 


\section{REFERENCES}

1. Rao, K.N. (1995) The significance of the cholesterol biosynthetic pathway in cell growth and carcinogenesis (review). Anticancer Res, 15, 309-14.

2. Rao, K.N., Elm, M.S., Kelly, R.H., Chandar, N., Brady, E.P., Rao, B., Shinozuka, H. and Eagon, P.K. (1997) Hepatic hyperplasia and cancer in rats: metabolic alterations associated with cell growth. Gastroenterology, 113, 238-48.

3. Zhou, W., Simpson, P.J., McFadden, J.M., Townsend, C.A., Medghalchi, S.M., Vadlamudi, A., Pinn, M.L., Ronnett, G.V. and Kuhajda, F.P. (2003) Fatty acid synthase inhibition triggers apoptosis during $\mathrm{S}$ phase in human cancer cells. Cancer Res, 63, 7330-7.

4. Pizer, E.S., Jackisch, C., Wood, F.D., Pasternack, G.R., Davidson, N.E. and Kuhajda, F.P. (1996) Inhibition of fatty acid synthesis induces programmed cell death in human breast cancer cells. Cancer Res, 56, 2745-7.

5. Kuhajda, F.P. (2000) Fatty-acid synthase and human cancer: new perspectives on its role in tumor biology. Nutrition, 16, 202-8.

6. Iwano, S., Nukaya, M., Saito, T., Asanuma, F. and Kamataki, T. (2005) A possible mechanism for atherosclerosis induced by polycyclic aromatic hydrocarbons. Biochem Biophys Res Commun, 335, 220-6.

7. Fajas, L., Debril, M.B. and Auwerx, J. (2001) Peroxisome proliferator-activated receptor-gamma: from adipogenesis to carcinogenesis. J Mol Endocrinol, 27, 1-9.

8. Kondraganti, S.R., Fernandez-Salguero, P., Gonzalez, F.J., Ramos, K.S., Jiang, W. and Moorthy, B. (2003) Polycyclic aromatic hydrocarbon-inducible DNA adducts: evidence by 32P-postlabeling and use of knockout mice for Ah receptor-independent mechanisms of metabolic activation in vivo. Int $\mathrm{J}$ Cancer, 103, 5-11.

9. Uno, S., Dalton, T.P., Derkenne, S., Curran, C.P., Miller, M.L., Shertzer, H.G. and Nebert, D.W. (2004) Oral exposure to benzo[a]pyrene in the mouse: detoxication by inducible cytochrome P450 is more important than metabolic activation. Mol Pharmacol, 65, 1225-37.

10. Uno, S., Dalton, T.P., Dragin, N., Curran, C.P., Derkenne, S., Miller, M.L., Shertzer, H.G., Gonzalez, F.J. and Nebert, D.W. (2006) Oral benzo[a]pyrene in Cyp1 knockout mouse lines: CYP1A1 important in detoxication, CYP1B1 metabolism required for immune damage independent of total-body burden and clearance rate. Mol Pharmacol, 69, 1103-14.

11. Brookes, P. and Lawley, P.D. (1964) Evidence for the Binding of Polynuclear Aromatic Hydrocarbons to the Nucleic Acids of Mouse Skin: Relation between Carcinogenic Power of Hydrocarbons and Their Binding to Deoxyribonucleic Acid. Nature, 202, 781-4.

12. Falahatpisheh, M.H., Donnelly, K.C. and Ramos, K.S. (2001) Antagonistic interactions among nephrotoxic polycyclic aromatic hydrocarbons. J Toxicol Environ Health A, 62, 543-60.

13. Gray, D.L., Warshawsky, D., Xue, W., Nines, R., Wang, Y., Yao, R. and Stoner, G.D. (2001) The effects of a binary mixture of benzo(a)pyrene and 7H-dibenzo(c,g)carbazole on lung tumors and K-ras oncogene mutations in strain A/J mice. Exp Lung Res, 27, 245-53.

14. Nesnow, S., Mass, M.J., Ross, J.A., Galati, A.J., Lambert, G.R., Gennings, C., Carter, W.H., Jr. and Stoner, G.D. (1998) Lung tumorigenic interactions in strain A/J mice of five environmental polycyclic aromatic hydrocarbons. Environ Health Perspect, 106 Suppl 6, 1337-46.

15. Mahadevan, B., Parsons, H., Musafia, T., Sharma, A.K., Amin, S., Pereira, C. and Baird, W.M. (2004) Effect of artificial mixtures of environmental polycyclic aromatic hydrocarbons present in coal tar, urban dust, and diesel exhaust particulates on MCF-7 cells in culture. Environ Mol Mutagen, 44, 99-107. 

Dankwoord 


\section{Bedankt!}

En dan is het tijd voor het allerlaatste stukje van dit proefschrift. Vier jaar onderzoek lijkt een hele tijd, maar die is voorbij gevolgen. Time flies when you are having fun... Zoals vele andere proefschriften was ook deze niet zo ver gekomen zonder hulp en ideeën van velen. Daarom wil ik iedereen hiervoor van harte bedanken!

Allereerst mijn promotor, prof. dr. F.J. van Schooten. Beste Frederik-Jan, bij het vorderen van het onderzoek raakte er je steeds meer bij betrokken. De wereld van de microarrays was niet direct jou vakgebied, maar het was een belangrijk onderdeel van mijn promotie-onderzoek. Door de complexiteit konden de discussies wel eens erg technisch worden, maar gelukkig kon je hierin de vertaalslag maken naar de relevantie voor het onderzoek. Bedankt hiervoor en bedankt voor je begeleiding.

En ook mijn co-promotor, dr. J.H.M. van Delft. Beste Joost, bedankt voor je begeleiding en de leuke discussies die we gehad hebben. Ze gaven me soms een hele andere kijk op de zaken, maar ik heb er ook veel aan gehad. Bedankt dat ik altijd bij je binnen kon lopen als ik wat wilde vragen, ook toen je enkele maanden niet in Nederland was, was je misschien zelfs beter te bereiken!

I would like to thank everyone who contributed to the AMBIPAH project. Thanks for our collaboration. Especially prof dr Soterios Kyrtopoulos, for the organisation of our meetings in Greece, I always enjoyed them. I would like to thank George Koukouves for the mouse experiments described in Chapter 5 of this thesis and for his quick and complete answers to my questions. Prof. dr. Costas Ioannides, thanks for making it possible to visit your lab and the excellent organization. Also thanks for your quick and useful feedback on the papers you co-authored. A special thanks goes to Daphnee and Meera. We first met when I was staying in Guildford for a month, and you made me feel right at home. It was good to see you regularly at our project-meetings. I hope we will stay in touch. Luckily the UK is not far and Daphnee, you are even closer by living in Amsterdam. Wish you both all the best for the future.

Verder wil ik alle collega's van GRAT hartelijk bedanken voor hun interesse, ideeën en gezelligheid! Marcel, als analist was je betrokken bij het AMBIPAH project en je hebt aan elk hoofdstuk in dit boekje een bijdrage geleverd. Mijn verse kennis van de microarrays heb ik aan je overgedragen, maar ik denk dat je er inmiddels een stuk dieper in zit. Andersom heb ik ook veel van jou geleerd. Bedankt voor de leuke samenwerking! En hartstikke leuk dat je mijn paranimf wilt zijn!

Pascal, bedankt voor het beschikbaar stellen van alle microarray data via de server. Simone en Danitsja, bedankt voor het wegwijs maken in de wereld van de microarrays. En ook de andere microarray-aio's, Anne, Pim en Karen voor het uitwisselen van ervaringen. Anne en Pim, succes met het afronden van jullie onderzoek en Anne, veel succes in Leiden. Danitsja, bedankt voor je adviezen over het maken van een proefschrift. Ook andere collega-aio's, bedankt voor de gezelligheid en het uitwisselen van aio-perikelen. 
Kirsten, nadat we heel even kamergenootjes waren, zagen we elkaar nog regelmatig bij POT cursussen, of 's ochtends vroeg op het station in Eindhoven. Veel succes met je post-doc baan en het afronden van je proefschrift. Nadat ik even met Jonathan op de kamer heb gezeten ben ik verhuisd naar de kamer van Daniëlle en Simone en inmiddels met Sabine, Nejla en Nicole op de "rustige" aio-kamer. Gelukkig mag ik nog even bij jullie op de kamer blijven! Bedankt voor het meedenken bij het zoeken naar een feestlocatie! Bedankt voor jullie gezelligheid!

Thijs, als mijn eerste stagiair kwam je voor een stage van 6 weken, dat is iets langer geworden, maar daardoor heb je de basis gelegd voor hoofdstuk 6 van dit proefschrift. Dennie, jij bent met de mengselstudies verder gegaan en een belangrijke bijdrage geleverd aan hoofdstuk 6 . Bedankt voor jullie bijdragen.

Jacqueline, we kennen elkaar al vanaf ons eerste jaar in Wageningen, zelfde studie en samen ingeschreven bij SSR-W en later in dezelfde jaarclub. Ook al wonen we nu wat verder uit elkaar en zijn we een andere richting op gegaan, ik ben blij dat we nog steeds vriendinnen zijn, en dat je mijn paranimf wil zijn!

Liesbeth, mijn andere jaarclubgenootje, Bedankt voor je vriendschap en voor je interesse. Ik hoop dat we nog eens dichterbij elkaar komen wonen zodat we elkaar vaker kunnen opzoeken. Annelie, leuk dat je mijn huisgenootje was in Engeland en dat we nog steeds vriendinnen zijn. De sauna-dagjes waren (zijn) erg ontspannend in drukke tijden! Suzanne, Nienke, Wouter, Arjan, Janneke, Diantha, Carolien bedankt voor jullie interesse!

Familie en schoonfamilie, bedankt voor jullie interesse. In het bijzonder Annie en Johan, bedankt voor het mogen logeren in hun huis in Maastricht als het laat was geworden.

Peter en Wilhelmien, bedankt voor jullie interesse en behulpzaamheid. Wim en Henriëtte, papa en mama, bedankt voor jullie steun en om mij de kans te geven om dit te bereiken. Het was niet altijd makkelijk om uit te leggen waar ik nu precies mee bezig was, maar hier dus het resultaat... Dit geldt waarschijnlijk ook voor jullie, Eric en Pauline. Bedankt voor jullie interesse. Eric, succes met je nieuwe baan in een nieuwe stad (jammer dat je net naar Eindhoven komt als ik misschien bijna weg ga), en veel geluk samen met Anna. Pauline, succes met je eindexamens en straks met studeren! Lieve Ralf, bedankt voor je steun, begrip en interesse. Mijn frustraties kon ik altijd met jou delen en je dacht met me mee. Bedankt ook voor het doorsturen van artikelen waarvan je dacht dat ze interessant konden zijn voor mij. Bedankt voor het lezen van (delen van) mijn proefschrift. Bedankt voor alles.

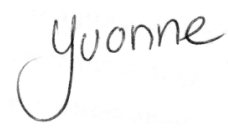


Curriculum Vitae 
Yvonne Catharina Maria Staal was born on April 9th 1979 in Espel, Noordoostpolder. After finishing secondary school at Zuyderzee College in Emmeloord in 1997, she started her education "Nutrition and Health" at Wageningen University (former Wageningen Agricultural University). She specialized in food toxicology, for which she did research at the department of Toxicology. She also did research at the department of Food Chemistry and an internship at the Natural Resources Institute in Chatham, UK. She won the competition on application of ICT in food safety organised by the ICT-company Vertis. In September 2002 she graduated. From July 2002 till December 2002 she worked as a technician at the department of Veterinary drugs of RIKILT - Institute of Food Safety in Wageningen. In January 2003 she started to work as a PhD-student at the department of Health Risk Analysis and Toxicology (GRAT) of Maastricht University, at which the research described in this thesis is conducted. Besides doing research, she participated in several courses, including the course Laboratory Animal Scientists (art. 9 of the Dutch Law on Animal Experiments) and several courses as part of the Postgraduate Education in Toxicology. The latter could lead to certification as a Toxicologist at graduation and than she will also obtain the VLAG-certificate. Furthermore, she had the opportunity to present her research at several symposia and conferences. In 2005 she won a poster prize on the GRC toxicogenomics conference in the USA. Currently, she is a postdoctoral researcher at the department of GRAT, Maastricht University.

Yvonne Catharina Maria Staal werd op 9 april 1979 geboren in Espel, Noordoostpolder. Na het behalen van het atheneum diploma aan het Zuyderzee College in Emmeloord in 1997, is ze begonnen aan de studie "Voeding en Gezondheid aan de Wageningen Universiteit (toenmalige Landbouwuniversiteit Wageningen). Binnen deze studie heeft ze zich gespecialiseerd in de voedingstoxicologie, waarvoor zij onderzoek heeft gedaan bij de leerstoelgroep Toxicologie. Ook heeft ze onderzoek gedaan bij de leerstoelgroep Levensmiddelenchemie en een stage bij het Natural Resources Institute in Chatham, UK. Verder won ze de door ICT-bedrijf Vertis uitgeschreven prijsvraag naar een toepassing van ICT in de voedselveiligheid. In september 2002 behaalde ze haar doctoraal diploma. Van juli 2002 tot december 2002 is ze werkzaam geweest als analist op de afdeling Dierbehandelingsmiddelen van het RIKILT - Instituut voor Voedselveiligheid in Wageningen. In januari 2003 is ze begonnen als promovenda bij de capaciteitsgroep GezondheidsRisico Analyse en Toxicologie (GRAT) van de Universiteit Maastricht, waar het onderzoek dat beschreven is in dit proefschrift is uitgevoerd. Naast het uitvoeren van het onderzoek heeft ze verschillende cursussen gevolgd, waaronder de cursus Proefdierkunde op grond van art. 9 van de Wet op de Dierproeven en verschillende modules van de Postdoctorale Opleiding Toxicologie. Dit laatste kan bij promotie leiden tot erkenning tot toxicoloog en ze zal ook het VLAG certificaat krijgen. Verder heeft ze haar onderzoek kunnen presenteren op verschillende symposia en congressen. In $2005 \mathrm{kreeg}$ zij een posterprijs op het GRC toxicogenomics congres in de VS. Momenteel werkt ze als post-doc bij de capaciteitsgroep GRAT, Universiteit Maastricht 
List of publications 


\section{Full papers}

YCM Staal, G Koukouves, MHM van Herwijnen, VL Souliotis, SA Kyrtopoulos, FJ van Schooten, JHM van Delft. Similarities on gene expression in lung and liver of CD2F1 mice by polycyclic aromatic bydrocarbons at equally mutagenic doses. in preparation.

YCM Staal, DS Pushparajah, MHM van Herwijnen, C Ioannides, FJ van Schooten, JHM van Delft. Combination toxicology of binary PAH-mixtures: Effects on gene expression and $D N A$ adduct formation in precision-cut rat liver slices. in preparation.

SL Hockley, K Mathijs, YCM Staal, D Brewer, I Giddings, JHM van Delft, DH Phillips. Inter-laboratory and inter-platform comparison of microarray gene expression analysis of HepG2 cells exposed to benzo[a]pyrene. Submitted.

YCM Staal, DGAJ Hebels, MHM van Herwijnen, FJ van Schooten, JHM van Delft. Binary PAH mixtures cause additive or antagonistic effects on gene expression but synergistic effects on DNA adduct formation. Submitted.

YCM Staal, MHM van Herwijnen, DS Pushparajah, M Umachandran, C Ioannides, FJ van Schooten, JHM van Delft. Modulation of gene expression and DNA adduct formation in precision-cut liver slices exposed to polycyclic aromatic hydrocarbons of different carcinogenic potency. Mutagenesis. 2007 Jan;22(1):55-62. Epub 2006 Dec 6.

DM van Leeuwen, MHM van Herwijnen, M Pedersen, LE Knudsen, M KirschVolders, RJ Sram, YCM Staal, E Bajak, JHM van Delft, JC Kleinjans. Genome-wide differential gene expression in children exposed to air pollution in the Czech Republic. Mutat Res. 2006 Aug 30;600(1-2):12-22. Epub 2006 Jul 11.

YCM Staal, MHM van Herwijnen, FJ van Schooten, JHM van Delft. Modulation of gene expression and DNA adduct formation in HepG2 cells by polycyclic aromatic bydrocarbons with different carcinogenic potencies. Carcinogenesis. 2006 Mar;27(3):646-55. Epub 2005 Nov 3.

YCM Staal, MHM van Herwijnen, FJ van Schooten, JHM van Delft. Application of four dyes in gene expression analyses by microarrays. BMC Genomics. 2005 Jul 25;6:101.

JHM van Delft, E van Agen, SGJ van Breda, MHM van Herwijnen, YCM Staal, JC Kleinjans. Comparison of supervised clustering methods to discriminate genotoxic from non-genotoxic carcinogens by gene expression profiling. Mutat Res. 2005 Aug 4;575(1-2):17-33. Epub 2005 Apr 19.

MJ van Erk, E Teuling, YCM Staal, S Huybers, PJ van Bladeren, JMMG Aarts, B van Ommen. Time- and dose-dependent effects of curcumin on gene expression in buman colon cancer cells. J Carcinog. 2004 May 12;3(1):8.

JHM van Delft, E van Agen, SGJ van Breda, MHM van Herwijnen, YCM Staal, JC Kleinjans. Discrimination of genotoxic from non-genotoxic carcinogens by gene expression profiling. Carcinogenesis. 2004 Jul;25(7):1265-76. Epub 2004 Feb 12. 


\section{Abstracts}

YCM Staal, DGAJ Hebels, DS Pushparajah, MHM van Herwijnen, C Ioannides, FJ van Schooten and JHM van Delft. Combination toxicology of binary PAH mixtures; Effects on gene expression and DNA adduct formation in vitro. Oral presentation at the Beltox/BEMS symposium, December 2006, Leuven, Belgium

YCM Staal, DGAJ Hebels, DS Pushparajah, MHM van Herwijnen, C Ioannides, FJ van Schooten and JHM van Delft. Combination toxicology of binary PAH mixtures; Effects on gene expression and $D N A$ adduct formation in vitro. Oral presentation at the forth symposium of the Netherlands Toxicogenomics centre, November 2006, Leiden, The Netherlands

YCM Staal, DGAJ Hebels, MHM van Herwijnen, FJ van Schooten and JHM van Delft. Combination toxicology of PAH-mixtures; Effects on apoptosis, cell cycle and gene expression in relation to the individual compounds in HepG2 cells. Poster presentation at the 3rd NuGO week, September 2006, Oxford, United Kingdom

YCM Staal, DGAJ Hebels, MHM van Herwijnen, FJ van Schooten and JHM van Delft. Combination toxicology of P AH-mixtures; Effects on apoptosis, cell cycle and gene expression in relation to the individual compounds in HepG2 cells. Poster presentation at the 19th symposium of the European Association for Cancer Research, July 2006, Budapest, Hungary

YCM Staal, DGAJ Hebels, MHM van Herwijnen, FJ van Schooten and JHM van Delft. Combination toxicology of PAH-mixtures; Effects on apoptosis, cell cycle and gene expression in relation to the individual compounds in HepG2 cells. Oral presentation at the symposium of the Dutch Society for Toxicology, June 2006, Wageningen, The Netherlands

YCM Staal, MHM van Herwijnen, FJ van Schooten and JHM van Delft. Predicting gene expression modulation of a mixture of benzo[a]pyrene and dibenzo[a,l]pyrene from individual compound data. Oral presentation at the second symposium of the Netherlands Toxicogenomics centre, December 2005, Wageningen, The Netherlands

YCM Staal, MHM van Herwijnen, FJ van Schooten and JHM van Delft. Gene expression changes of $\mathrm{P} A H \mathrm{~s}$ in vitro in relation to $\mathrm{DN} A$ adduct formation and carcinogenicity. Poster presentation at EEMS 2005, July 2005, Kos, Greece

YCM Staal, MHM van Herwijnen, FJ van Schooten and JHM van Delft. Gene expression changes of $P A H s$ in vitro in relation to $D N A$ adduct formation and carcinogenicity. Poster presentation at the GRC Toxicogenomics conference, June 2005, New Hampshire, USA

YCM Staal, MHM van Herwijnen, FJ van Schooten and JHM van Delft. Influence of six $P A H$ s on gene-expression in vitro. Oral presentation at the first symposium of the Netherlands Toxicogenomics centre, April 2005, Maastricht, The Netherlands 


\section{LIST OF PUBLICATIONS}

YCM Staal, MHM van Herwijnen, FJ van Schooten and JHM van Delft. The influence of six PAHs on gene expression in HepG2 cells; relation to DNA adduct formation and carcinogenicity. Poster presentation at EEMS 2004, September 2004, Maastricht, The Netherlands

$\underline{\text { YCM Staal, }}$ MHM van Herwijnen, FJ van Schooten and JHM van Delft. The influence of six $P A H$ s on gene expression in HepG2 cells; relation to DNA adduct formation and carcinogenicity. Poster presentation at the symposium of the Dutch Society for Toxicology, June 2004, Utrecht, The Netherlands

YCM Staal, Mechanism-based approaches to improved risk assessment of ambient air PAHs $(A M B I P A H)$. Poster presentation at the symposium of the European Graduate School, October 2003, Maastricht, The Netherlands 